\title{
ABOVE BONNEVILLE PASSAGE AND PROPAGATION COST EFFECTIVENESS ANALYSIS
}

\author{
Prepared by: \\ Charles M. Paulsen \\ Jeffrey B. Hyman \\ Kris Wernstedt \\ Resources for the Future \\ Washington, DC 20036
}

\author{
Prepared for: \\ U.S. Department of Energy \\ Bonneville Power Administration \\ Division of Fish and Wildlife \\ P.O. Box 3621 \\ Portland, OR 97283-3621 \\ Project Number 85-087-01 \\ Contract Number DE-AC79-89BP98852
}

MAY 1993 


\title{
ABOVE-BONNEVILLE PASSAGE AND PROPAGATION COST-EFFECTIVENESS ANALYSIS
}

\author{
by Charles M. Paulsen, Jeffrey B. Hyman, and Kris Wernstedt
}

\section{EXECUTIVE SUMMARY}

Resources for the Future has been working with the Bonneville Power Administration since 1984 to integrate biological and economic information to assist in the Pacific Northwest's Fish and Wildlife Program planning efforts. Our charge is to develop analytical tools that can contribute to the goal of a justifiable and accountable decision-making process. Over the last two years, we have developed several models to evaluate the cost-effectiveness of alternative strategies to mitigate hydrosystem impacts on salmon and steelhead, and applied these models to areas of the Columbia River Basin. Our latest application evaluates the cost-effectiveness of proposed strategies that target mainstem survival (e.g., predator control, increases in water velocity) and subbasin propagation (e.g., habitat improvements, screening, hatchery production increases) for chinook salmon and steelhead stocks, in the portion of the Columbia Basin bounded by Bonneville, Chief Joseph, Dworshak, and Hells Canyon dams. At its core the analysis primarily considers financial cost and biological effectiveness, but we have included other attributes which may be of concern to the region.

Planning documents written under the auspices of the Columbia Basin Fish and Wildlife Authority supplied the biological and utilization objectives for the 79 chinook and steelhead stocks that we included in our cost-effectiveness analysis. From the regional planning documents, we also identified approximately 120 propagation actions with sufficient biological and cost data for evaluation. We combined these actions with eight different passage strategies and five possible terminal harvest rates to yield a set of alternatives that includes all possible combinations of passage and propagation actions and harvest rates. We then used an optimization model that simulates the life cycle of chinook salmon and steelhead to identify cost-effective passage/propagation/harvest alternatives for meeting the desired objectives. 
Although the conclusions from our analysis are only suggestive, due to the great deal of uncertainty about the efficacy of recovery actions and the life history parameters of salmonids, our results offer a number of interesting points. First, it appears that no strategy can meet all of the goals of the subbasin planners as presented in the subbasin plans. Over fifteen percent of the stocks considered never met the harvest and spawning goals simultaneously. This suggests that the planners set unrealistically high govals in some of the subbasins, given the universe of propagation actions for each stock.

Second, the system-wide, least-cost strategies identified at various levels of spawning escapement and terminal harvest consistently include passage scenarios which maintain current flows. Even with pessimistic assumptions about transportation survival and bypass efficiency, flow augmentation does not appear to be a cost-effective passage option. This result prevails because: (1) any passage option generally is the most expensive single item in most system-wide strategies; (2) flows above current (1989-91) conditions are a very expensive passage option; and (3) the estimated effectiveness of flow for increasing adult returns is low in comparison with the estimated effectiveness of other available options, including propagation actions and other downstream passage measures. Many in the region claim that flow augmentation or drawdowns are necessary measures. Our results suggest that such efforts may not be cost-cffective. This, in turn, leads us to argue forcefully for a comprehensive biological research program on the relationship between flows and downstream survival.

Third, lowering the acceptable level of genetic risk introduced by hatchery plantings in wild stocks makes the subbasin escapement and terminal harvest objectives unattainable for several stocks, even with reduced objectives. If we ignore the genetic risk constraint for just these stocks and impose it on all other stocks, the overall, system-wide, least-cost alternative is the same as the alternative identified in the scenario without the genetic risk constraint. This result may change, however, if genetic risk is defined more stringently than in our analysis, as may happen when the NPPC produces final guidelines on genetic risk. 
Finally, the set of preferred subbasin propagation actions identified in the subbasin plans differs from the set of preferred actions ide «ufied in our cost-effectiveness analysis. Although a considerable overlap exists between the two sets of actions, the planner-identified set contains more propagation actions and costs more money. The subbasin plans did not include passage enhancements, so the difference in the two sets of preferred propagation actions rests on the improved passage survival that we include in our simulations. This suggests that any analysis which does not adopt a systems framework, and fails to include potential survival increases at every stage in the salmonid life cycle, risks missing fish enhancement and/or cost-saving opportunities. 
TABLE OF CONTENTS

Chapter

Page

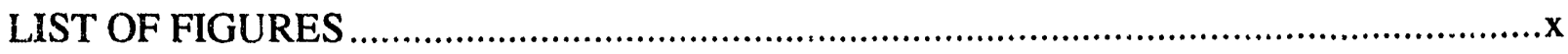

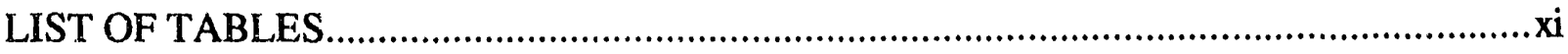

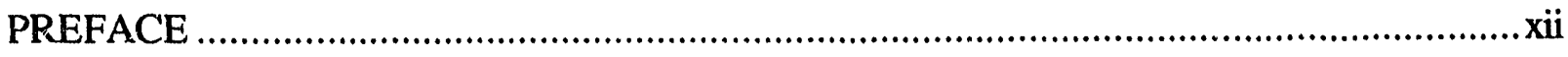

1 OVERVIEW OF SALMON AND STEELHEAD MITIGATION IN THE COLUMBIA BASIN

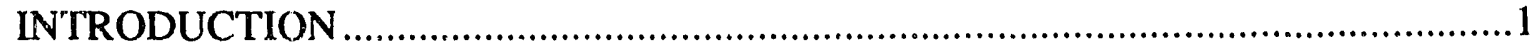

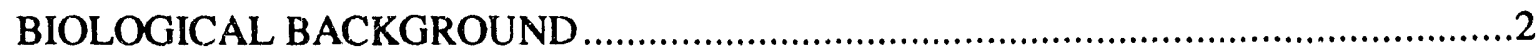

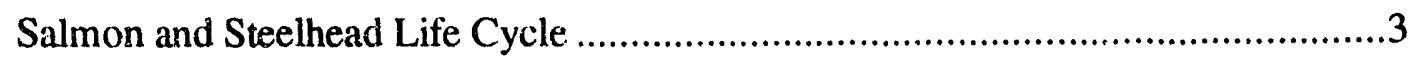

Recent Population Trends....................................................................................

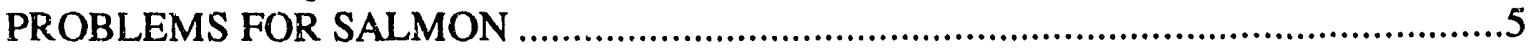

Dam Construction and Operation...................................................................6

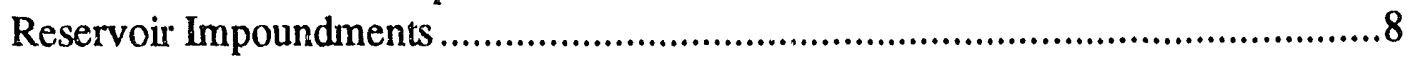

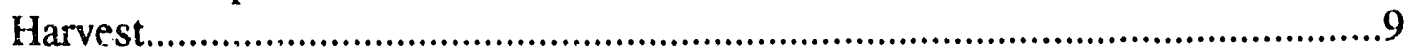

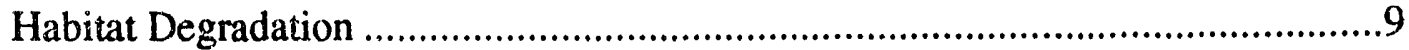

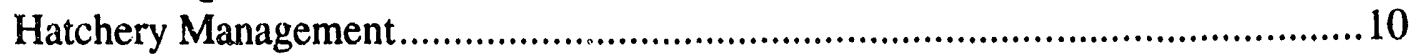

MITIGATION PLANNING IN THE COLUMBIA BASIN ......................................11

NPPC Goals and Objectives....................................................................11

Management Actions to Benefit Fish..............................................................12

RE'SOURCES FOR THE FUTURE'S RESEARCH PROGRAM …............................16

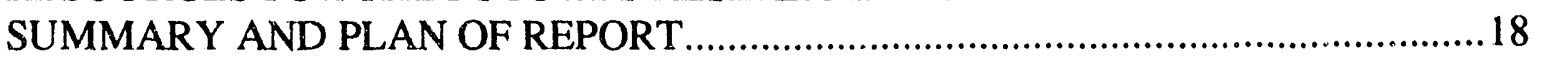

2 COST-EFFECTIVENESS AND SYSTEM COMPLEXITY

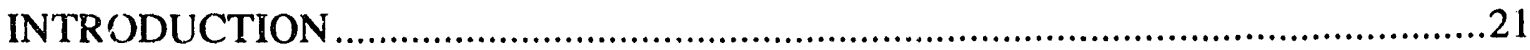

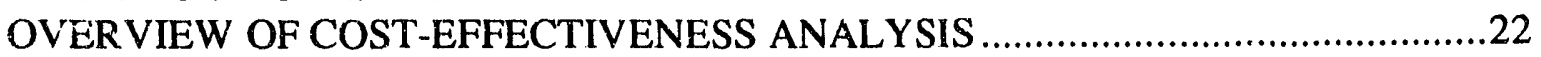

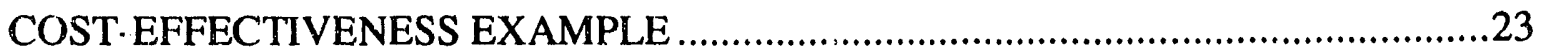

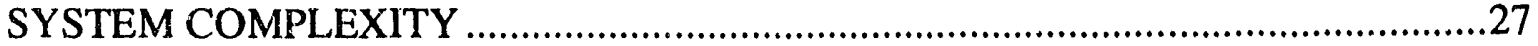

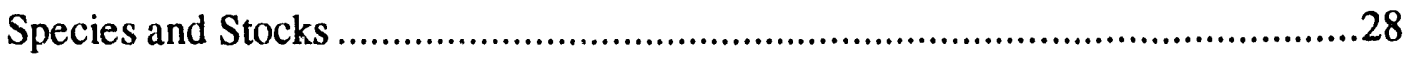

Mitigation Actions and Strategies .................................................................28

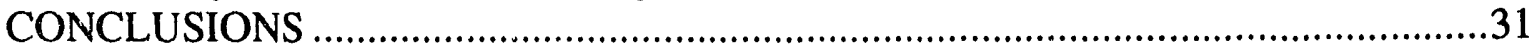

3 MODELING OVERVIEW

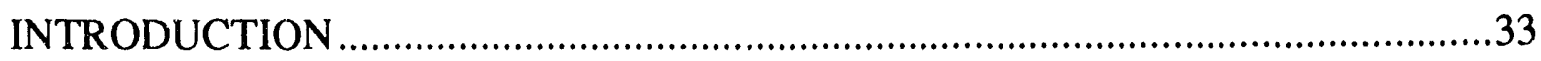

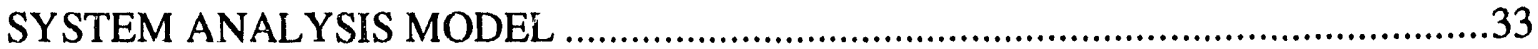

COLUMBIA RIVER SALMON PASSAGE MODEL .............................................36

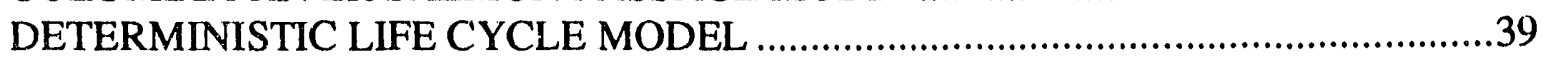

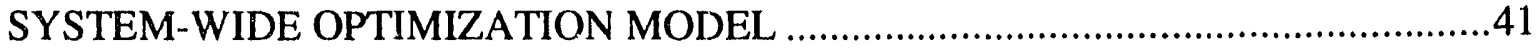

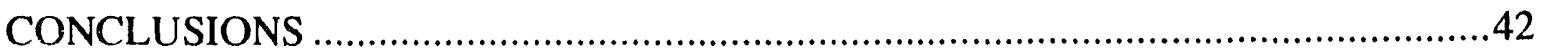


4 DATA INPUTS, ASSUMPTIONS, AND OBJECTIVES

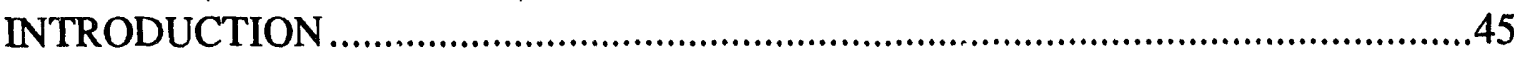

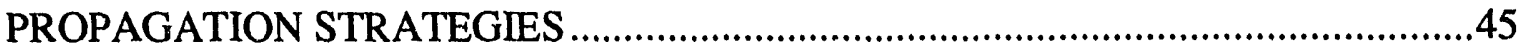

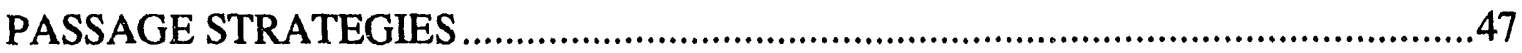

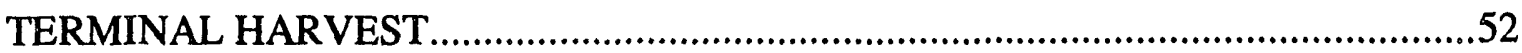

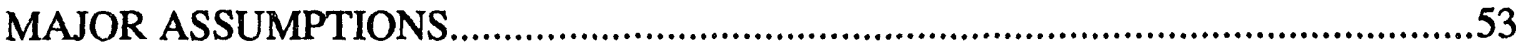

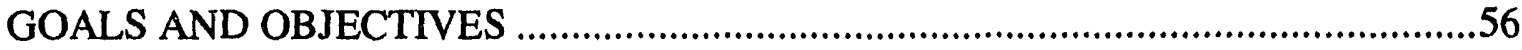

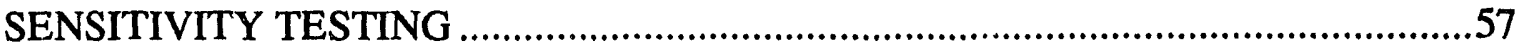

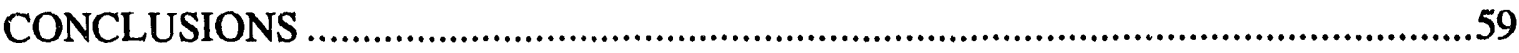

5 OPTIMIZATION MODEL GOALS AND RESULTS

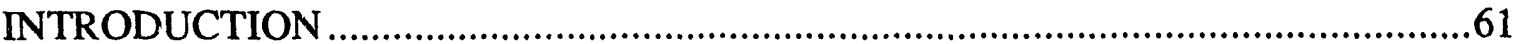

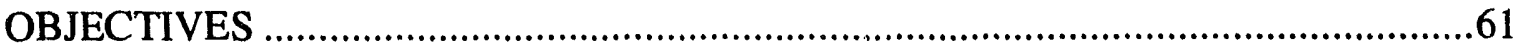

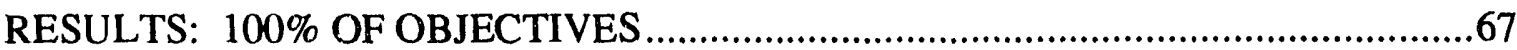

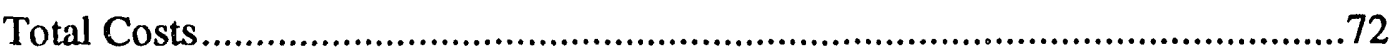

Distribution of Propagation Expenditures ..........................................................74

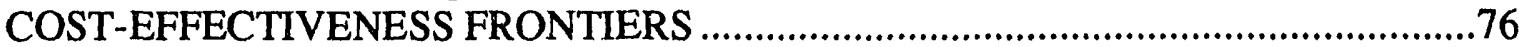

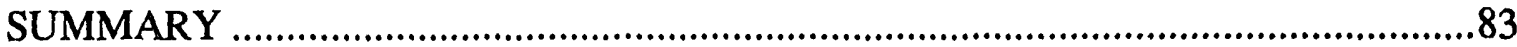

APPENDIX A DETERMINISTIC SIMULATION MODEL

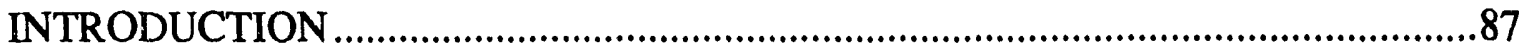

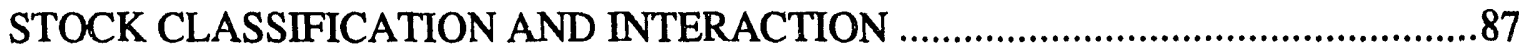

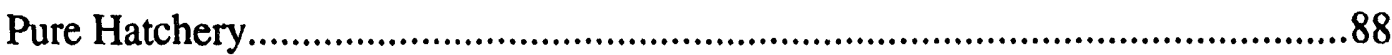

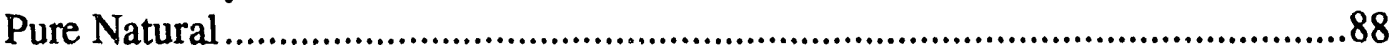

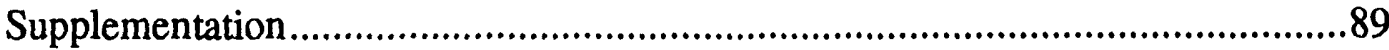

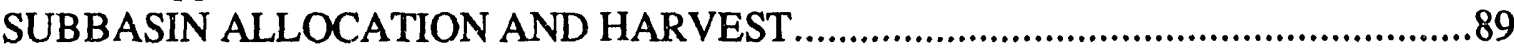

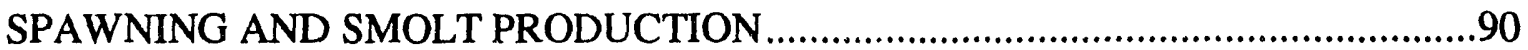

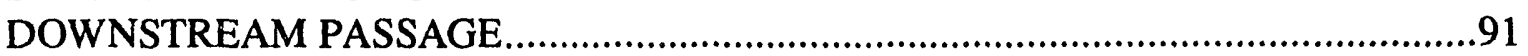

OCEAN SUR VIVAL AND NON-TERMINAL HARVEST …….................................91

DETERMINISTIC SIMULATION EQUATIONS....................................................92

Subbasin Allocation and Harvest....................................................................93

Spawning and Smolt Production ...................................................................99

Downstream Passage ......................................................................................97

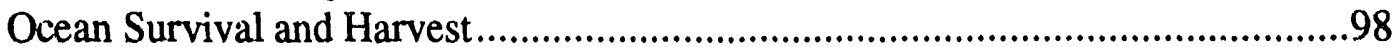

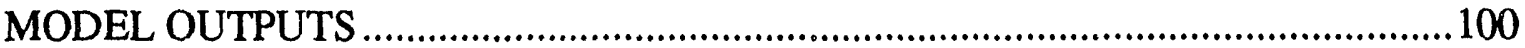


APPENDIX B OPTIMIZATION MODEL DESCRIPTION

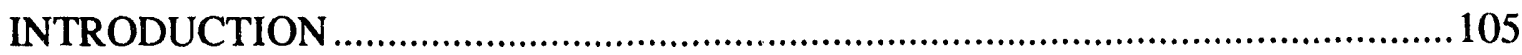

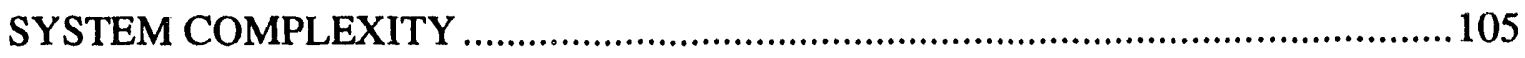

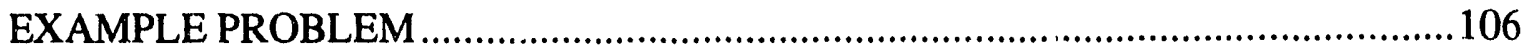

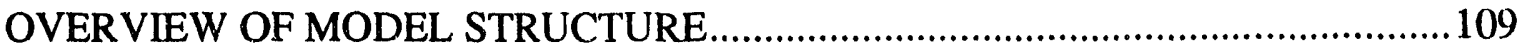

HEURISTIC OPTIMIZATION EXAMPLE …....................................................115

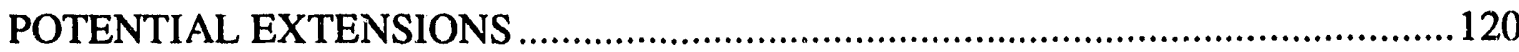

Other Objectives.......................................................................................120

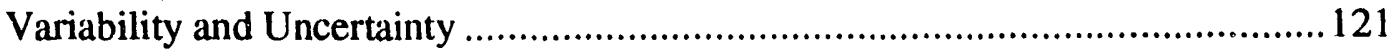

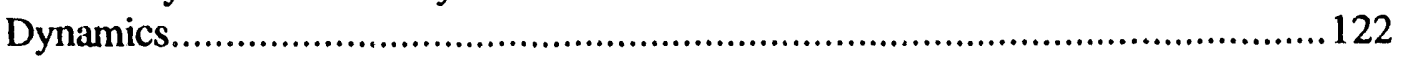

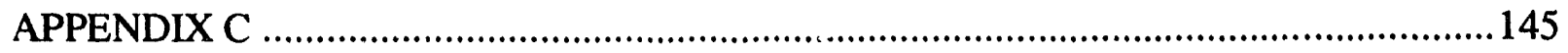

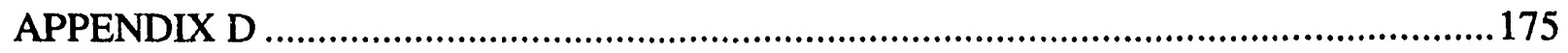

APPENDIX E

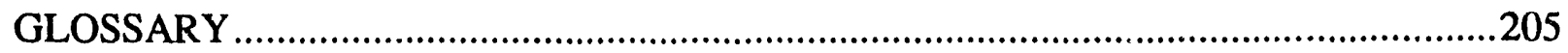

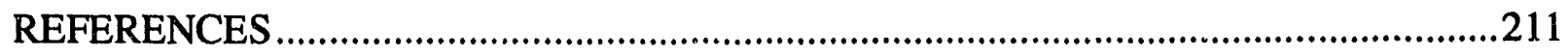




\section{LIST OF FIGURES}

Figure

Page

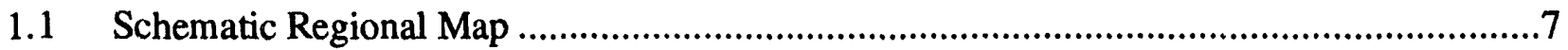

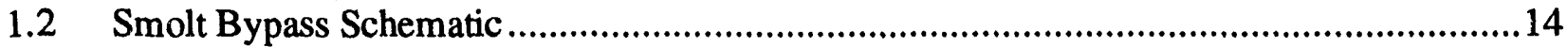

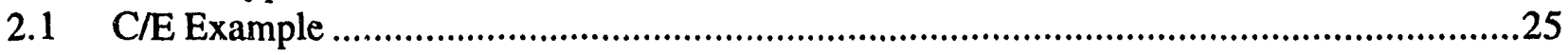

$2.2 \mathrm{C} /$ E Example without New Habitat .....................................................................26

3.1 Relationships Among Models Used in Cost-Effectiveness Analysis ..............................34

3.2 Salmon Life Cycle .....................................................................................40

5.1 Terminal Harvest/Spawning C/E Frontier............................................................79

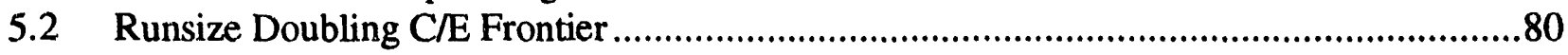

5.3 Combined Runsize Doubling - Spawning/Terminal Harvest Frontiers ............................81

A.1 Salmon Life Cycle .............................................................................................101

A.2 Illustrated Definition of Pure Hatchery, Supplementation, and Natural Stocks................102 


\section{LIST OF TABLES}

Table

Page

1.1 A General Comparison of Timing of the Life Cycle Stages................................................4

2.1 Cost and Effectiveness of Hypothetical Strategies to Increase Run Size .............................24

2.2 Definitions of Terms Used to Specify Mitigation Options...................................................30

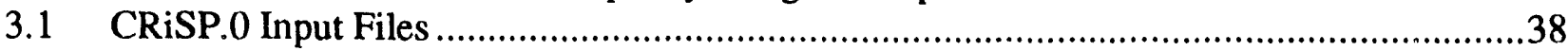

4.1 Passage Strategies Modeled in Cost-Effectiveness Analysis................................................48

4.2 Range in Transport Benefit Ratios at Each Transportation Project ..................................51

5.1 Subbasin Planners' Terminal Harvest and Spawning Escapement Numerical Objectives ....63

5.2 Percentage of Planners' Harvest and Spawning Objectives Met by Optimization Model ....64

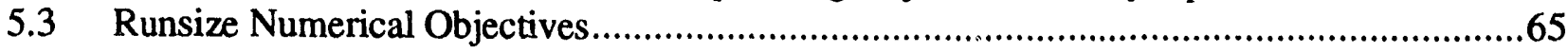

5.4 Percentage of Runsize Numerical Objectives Met by Optimization Model .........................66

5.5 Optimization Results for Different Passage Sensitivities, Objectives, and Genetic Risk .....68

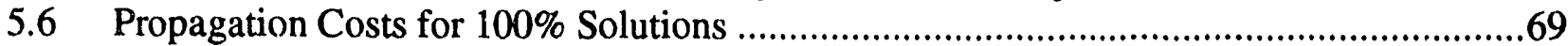

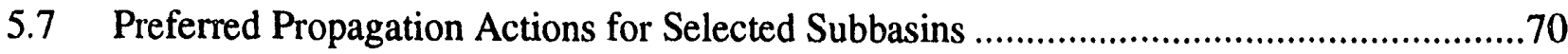

5.8 Cost of Attaining Harvest/Spawning Objectives, by Percent of Objective ..........................71

5.9 Cost of Attaining Runsize Doubling Objectives, by Percent of Objective ............................77

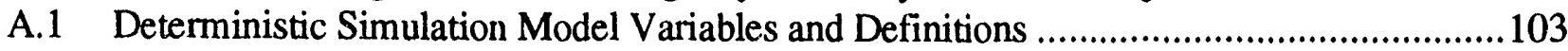

B.1 Definitions of Terms Used to Specify Mitigation Options............................................126

B.2 Example Propagation Strategies, Passage Strategies, and Terminal Harvest Alternatives 127

B.3 Results from the Deterministic Life Cycle Model ...................................................128

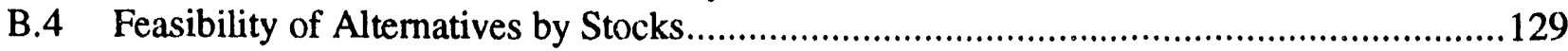

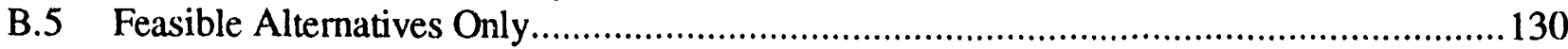

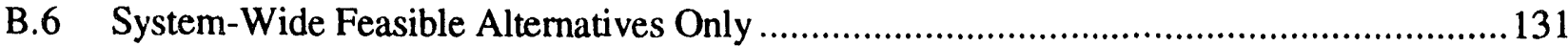

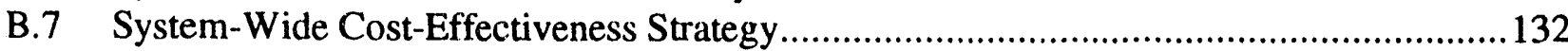

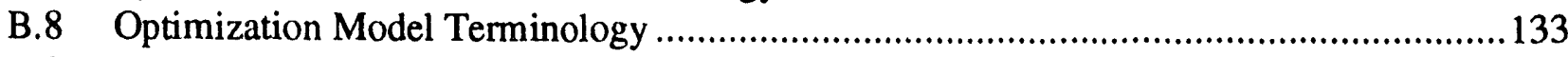

B.9 Optimization Model Variable and Subscript Definitions ...............................................134

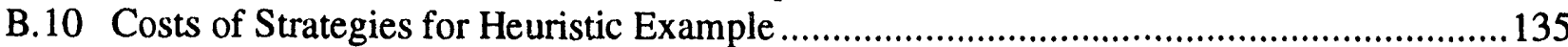

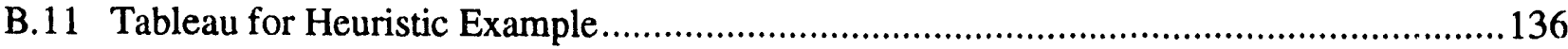

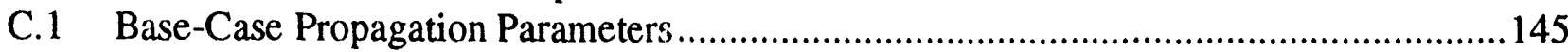

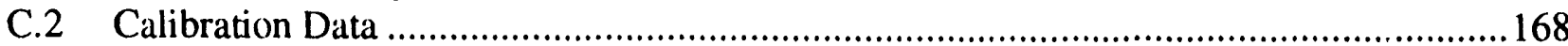

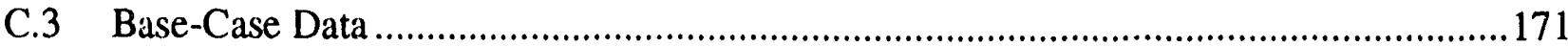

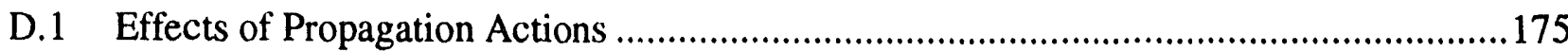

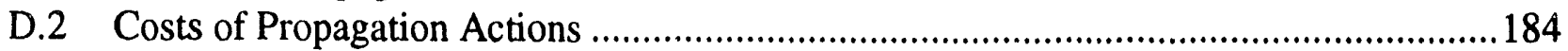

E.1 Selected Passage Model (CRiSP.0) Parameters.........................................................189

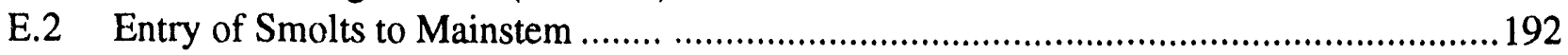




\section{PREFACE}

Congressional passage of the Pacific Northwest Electric Power Planning and Conservation Act $^{1}$ in 1980 ushered in a new era in natural resource conservation in the Pacific Northwest. The Act established the Northwest Power Planning Council, composed of two members from each of the four northwestern states (Idaho, Montana, Oregon, and Washington), and gave the Council the responsibility to develop programs for regional power planning, electricity conservation, and mitigating the effects of hydropower development and operation on fish and wildlife in the Columbia River Basin. The responsibility for implementing many of the power, conservation, and mitigation programs lies with the Bonneville Power Administration (BPA) and other federal agencies with hydro or power responsibilities in the region.

As the planning and implementation of alternative mitigation and protection measures has proceeded, questions about the costs, effectiveness, and justification of these measures have become increasingly complex. Since 1984, Resources for the Future (RFF) has been working with BPA and other regional entities to address this complexity and develop methodological tools and data that can be used to evaluate the biological and financial implication of the alternative measures. This document reports on our system-wide cost-effectiveness analysis of the mitigation and protection efforts for nearly eighty steelhead and chinook salmon stocks throughout the Columbia Basin. Although the analysis is the culmination of a multi-year research effort, it is but one step in the biological and financial evaluation. Ongoing and planned additional analyses include work on endangered salmon stocks, the dynamics of salmon populations and mitigation planning, and monitoring issues.

Our debts to others, both in the region and at RFF, for their assistance in the aboveBonneville, system-wide cost-effectiveness analysis are many. Many of these debts will go unrecognized here, although this in no way indicates a lack of appreciation for the help that we

${ }_{116}$ U.S.C. $\$ 8839-839 \mathrm{~h}$ (1982 and Supp. Il 1984) 
have received. Our most immediate thanks go to Katherine Beale, our contract officer at Bonneville, for her comments on all aspects of our work. We also wish to thank her BPA colleagues, Mark Schneider, Mark Shaw, Jim Geiselman, and Tim Fisher for their help. Chip McConnaha at the Northwest Power Planning Council, Darryll Olsen of Northwest Irrigation Utilities, and Rich Hinrichsen and Jim Anderson from the University of Washington have aiso given generously of their time and talents. Danny Lee of the U.S. Forest Service Intermountain Research Station has been an integral part of our work, both while he was at RFF and in his current position. Finally, Allen Kneese and Walter Spofford of Resources for the Future provided much of the intellectual foundation of the work reported here, by articulating the most important issues involved in the financial and biological aspects of mitigation and protection and by developing the cost-effectiveness framework. Our work owes its existence to their early efforts on the project and benefits from their continued involvement. Obviously, errors and shortcomings in this report are the responsibility of the authors.

The work was supported by BPA under contract 89-AC-98852. The views expressed in the report are those of the authors, and do not necessarily represent those of BPA or RFF. 


\section{CHAPTER 1 \\ AN OVERVIEW OF SALMON AND STEELHEAD MITIGATION IN THE COLUMBIA BASIN}

\section{INTRODUCTION}

In the last one-hundred years, annual returns of adult salmon and steelhead to the Columbia River and its tributaries have declined by as much as eighty percent. Some salmon stocks ${ }^{1}$ already are extinct. In the last several years alone, one stock of sockeye salmon has been declared endangered and two stocks of chinook salmon have been declared threatened under the federal Endangered Species Act. The American Fisheries Society has identified more than seventy additional Columbia Basin stocks as being of concern (Nehlsen, Williams, and Lichatowich, 1991).

A number of activities such as logging, mining, and agriculture have contributed to the decline of the Columbia salmon runs, by degrading salmon habitat or water quality or by removing water critical for salmon survival. Additionally, the construction of dams and development of reservoirs for power production, recreation, irrigation, and flood control have blocked off or flooded spawning and rearing habitat, and made upstream and downstream migrations more difficult on the lower-Snake and mid-and lower-Columbia rivers. Commercial and recreational fishing also have significantly reduced salmon populations.

Efforts to rebuild the salmon stocks have been underway for more than a half-century. These efforts currently include habitat improvement, flow augmentation, transportation of juvenile salmon, predator control, hatchery production, installation of bypass facilities at dam sites, and irrigation diversion screening. Individuals and organizations throughout the region have proposed extensions of these efforts as well as additional actions, and regional entities charged with designing, funding, and implementing protection programs, such as the Northwest Power

\footnotetext{
ISalmon that spawn in a particular location in the river system in a particular season that generally do not interbreed with 1) salmon that breed in other locations, or 2) salmon from the same location that breed in other seasons, constitute separate stocks. Each species of salmon can have multiple stocks.
} 
Planning Council (NPPC) and the Bonneville Power Administration (BPA), are continually in the pro $=$ of reviewing these proposals and deciding what package of actions to implement.

Resources for the Future (RFF) is currently assisting BPA and the region in an evaluation of the biological and economic tradeoffs among alternative mitigation and recovery actions. ${ }^{2}$ Our aim is to support fish and wildlife planning in the Columbia Basin. This document reports on our system-wide cost-effectiveness analysis of proposed mitigation and recovery strategies designed to increase the abundances of Columbia Basin salmon and steelhead populations.

In this chapter, we first provide a brief biological background to salmon and steelhead populations in the Columbia Basin. We continue with a discussion of the problems that Columbia Basin salmon and steelhead populations face. We then briefly examine recovery planning efforts for salmonids in the basin. We next present an overview of our research effort to assist the recovery planning efforts. The final section of this chapter lays out the chapter by chapter plan of this report.

\section{BIOLOGICAL BACKGROUND}

The recovery efforts in the Columbia Basin are concerned with a number of anadromous salmonids species such as sockeye salmon, coho salmon, chinook salmon, and steelhead trout, as well as resident fish such as kokanee salmon, white sturgeon (biologically anadromous), bull trout, and westslope cutthroat trout. We address two of the anadromous species in our analysis: chinook salmon and steelhead. In this section, we provide background on the life cycle and population trends of these two species.

\footnotetext{
2In this document, we use tive words mitigation and recovery loosely. In a formal sense, recovery refers to actions or planning related to stocks listed under the Endangered Species Act, for which a criterion for recovery has been established (i.e., a criterion which signifies that the stock can be taken off of the endangered species 'ist). Mitigation refers to a general class of actions or planning efforts related to the region's obligation to alleviate or compensate for the effects of hydropower development and operation on fish and wildlife in the Columbia River basin (Kneese, et al., 1988). Although their formal definitions differ, we generally use recovery and mitigation interchangeably. Other terms used in the region to signify efforts to protect fish include rebuilding and restoration.
} 


\section{Salmon and Steelhead Life Cycle}

One of the main features that broadly distinguishes salmonids stocks is the timing of their life-cycle stages. Table 1.1 summarizes the general differences in the timing of various life stages for summer steelhead and spring, summer, and fall chinook salmon. Hatching of fry takes place during late winter or early spring for all populations. Fall chinook and mid-Columbia summer chinook migrate downriver during their first year of life, after a brief period of rearing. Spring chinook and Snake River summer chinook migrate downriver during their second year after jverwintering in the subbasin. Summer steelhead generally remain in the subbasin for two or three winters before leaving for the ocean. All stocks spend one to four years in the ocean, some migrating as far as Alaska (e.g., fall chinook), before returning to the Columbia River. They then return upriver, most often to the subbasin and even to the river of their birth, although some straying occurs. After a holding period, the adults spawn and usually die (a small percentage of steelhead have more than one spawning migration).

\section{Recent Population Trends}

In a recent study, Pratt and Chapman (1989) estimated trends in salmon and steelhead returns to the Columbia River over the period from the late 1970's to the late 1980's. We cite here their estimated run size trends based on 3-year running medians, for the major runs above Bonneville dam. The run size of upriver summer steelhead (Oncorhynchus mykiss) more than doubled from about 120,000 fish in 1979 to 300,000 fish in 1988. Chinook salmon (Oncorhynchus tshawytscha) mostly decreased in tributaries above Bonneville dam, except for mid-Columbia bright fall chinook. Upriver spring and summer chinook decreased from about 125,000 and 60,000 in 1979 to about 100,000 and 40,000 in 1987, respectively. Moreover, the Snake River runs of spring, summer, and fall chinook were recently declared threatened under the federal Endangered Species Act (the Snake river sockeye have been declared endangered under the fecieral Endang sred Species Act). Current runs of upriver bright falls, most of which come 
4

TABLE 1.1

A General Comparison of Timing of the Life-Cycle Stages of Natural Upriver* Chinook Salmon and Summer Steelhead

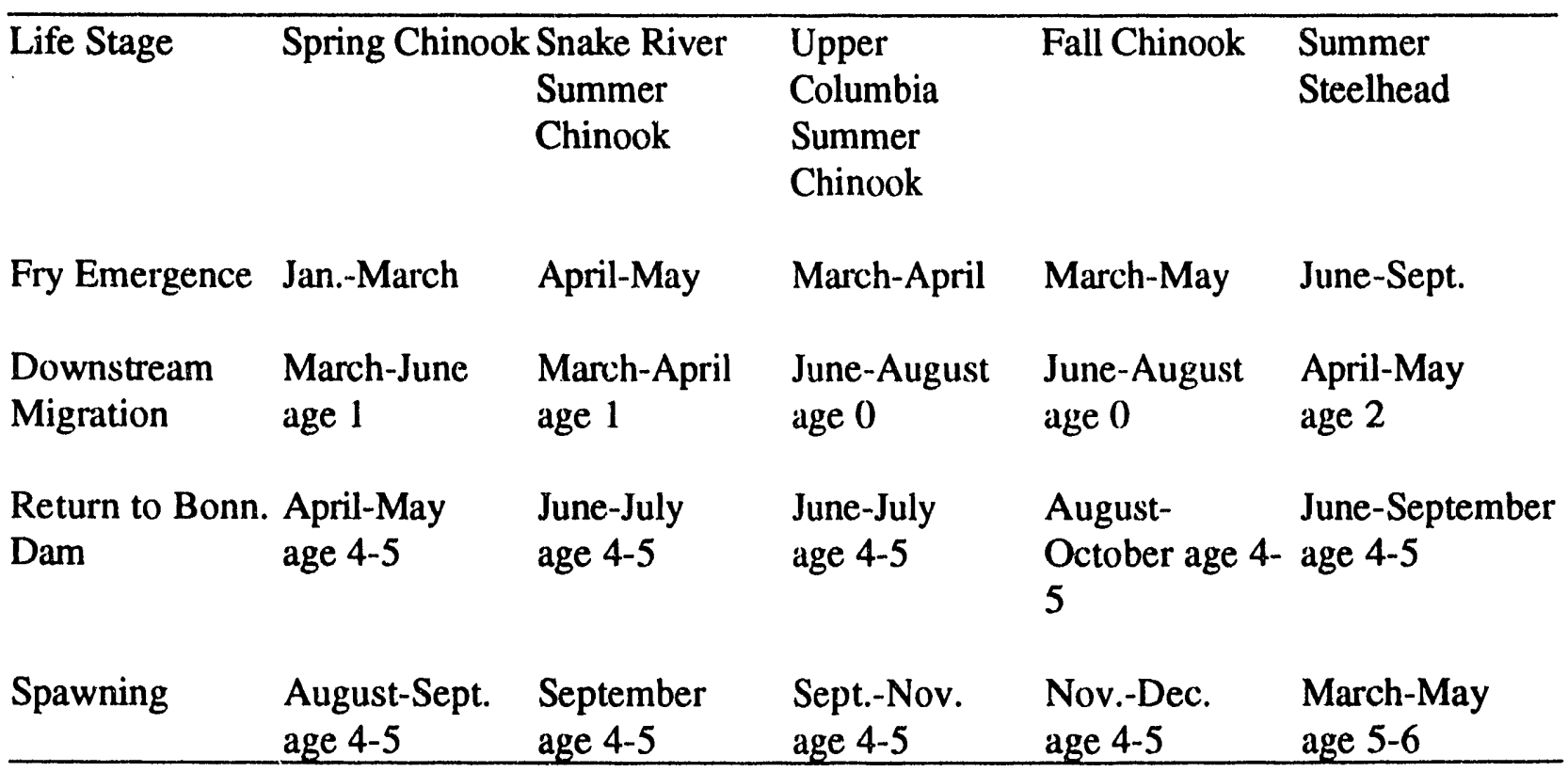

*above Bonneville Dam 
from the Hanford Reach area, are on the order of 400,000 fish, up from about 200,000 in the early 1980 's.

One should interpret these trends cautiously, for two reasons. First, trend estimates include both natural and hatchery-bred fish. Therefore, an infusion of hatchery fish may mask a precipitous decline in the natural component of the run. For example, natural fish made up virtually the entire annual run of upriver spring chinook during the 1950's (about 200,000 fish), whereas only about $35 \%$ of recent production (about 100,000 returns) is composed of natural fish. Indeed, many people express concern about these shifts in run composition. Second, there is no unique way to estimate a trend in run size. The data and statistic used to define a trend depend on the data at hand and the questions of interest.

\section{PROBLEMS FOR SALMON}

The downward trends for upriver salmon have not started only recently; salmon runs in the Columbia Basin have suffered a marked decline over the past one hundred and fifty years. Estimates from the available data suggest that even before the construction of Bonneville and Rock Island dams in the 1930s, the runs had already declined by fifty percent or more from their pre-European levels, and the total run size has since continued to edge downward to a level of perhaps 1.5-2.5 million fish today. Hatchery fish constitute eighty percent of the total. (Pratt and Chapman, 1989; NPPC, 1987; NPPC, 1991b).

Due to the scale of the Columbia River system and uncertainties associated with important components of the salmon life cycle, it is difficult to make definitive statements about the precise quantitative effects of the various causes of the decline. ${ }^{3}$ Nonetheless, it is likely that five major factors have contributed to the decline of salmonids popuiations. These factors are dam construction and operation, reservoir impoundments, harvest, habitat degradation, and hatchery programs.

${ }^{3}$ Kacyzynski and Palmisano (1992) provide a recent overview of management and environmental factors which contributed to the decline of anadromous stocks in Oregon waters. 


\section{Dam Construction and Operation}

In the middle and late 1930s several large dams and powerhouses were created on the mainstem of the Columbia River partly for the purpose of providing employment and other economic stimuli during the Great Depression. (Rock Island Dam, a Public Utilities District dam, was completed in 1933, and the much larger federal Bonneville and Grand Coulee Dams in 1938 and 1941, respectively.) During and after World War II, demand for electricity in the Pacific Northwest grew steadily and rapidly until the middle 1970's and federal hydropower development occurred simultaneously on a very large scale. The system of federal dams in the region came to be known as the Federal Columbia River Power System. At present it consists of 31 projects on the Columbia and Snake rivers with total installed capacity of 19,350 megawatts and over 20 million acre-feet of storage capacity. ${ }^{4}$ In addition, the region has built a number of large public and private utility hydroelectric dams and federal and state flood control dams. (See Figure 1.1 for a schematic map of the region.)

The impacts of the dams proper, as distinct from the impoundments behind them, take two forms. First, the storage dams, ${ }^{5}$ in particular Chief Joseph and Hells Canyon, present absolute barriers to upstream fish migration currently, since spawners migrating upstream cannot get over or around them. Their construction eliminated access for spawners to over 30 percent of the predam anadromous habitat (stream miles); absent construction of immensely costly fish ladders, those areas will remain inaccessible for the foreseeable future (NPPC, 1986).

Second, the run-of-river dams (from Bonneville to Wells on the Columbia, and Ice Harbor to Lower Granite on the Snake) present other problems. The most obvious is that juvenile salmon migrating downstream to the ocean (smolts) must pass either through the turbines or over the

\footnotetext{
${ }^{4} \mathrm{~A}$ city the size of Seattle requires about 1,000 megawatts. ${ }^{5}$ A storage dam allows dam operators to adjust the natural flow regime of the river to conform to river use needs, because such a dam permits the storage of large volumes of water. A run-of-river dam, in contrast, possesses oniy a limited ability to adjust flows, since it creates only a small storage pool and thus must allow water to flow past the dam at the same rate (more or less) that water is entering the upper end of the pool.
} 


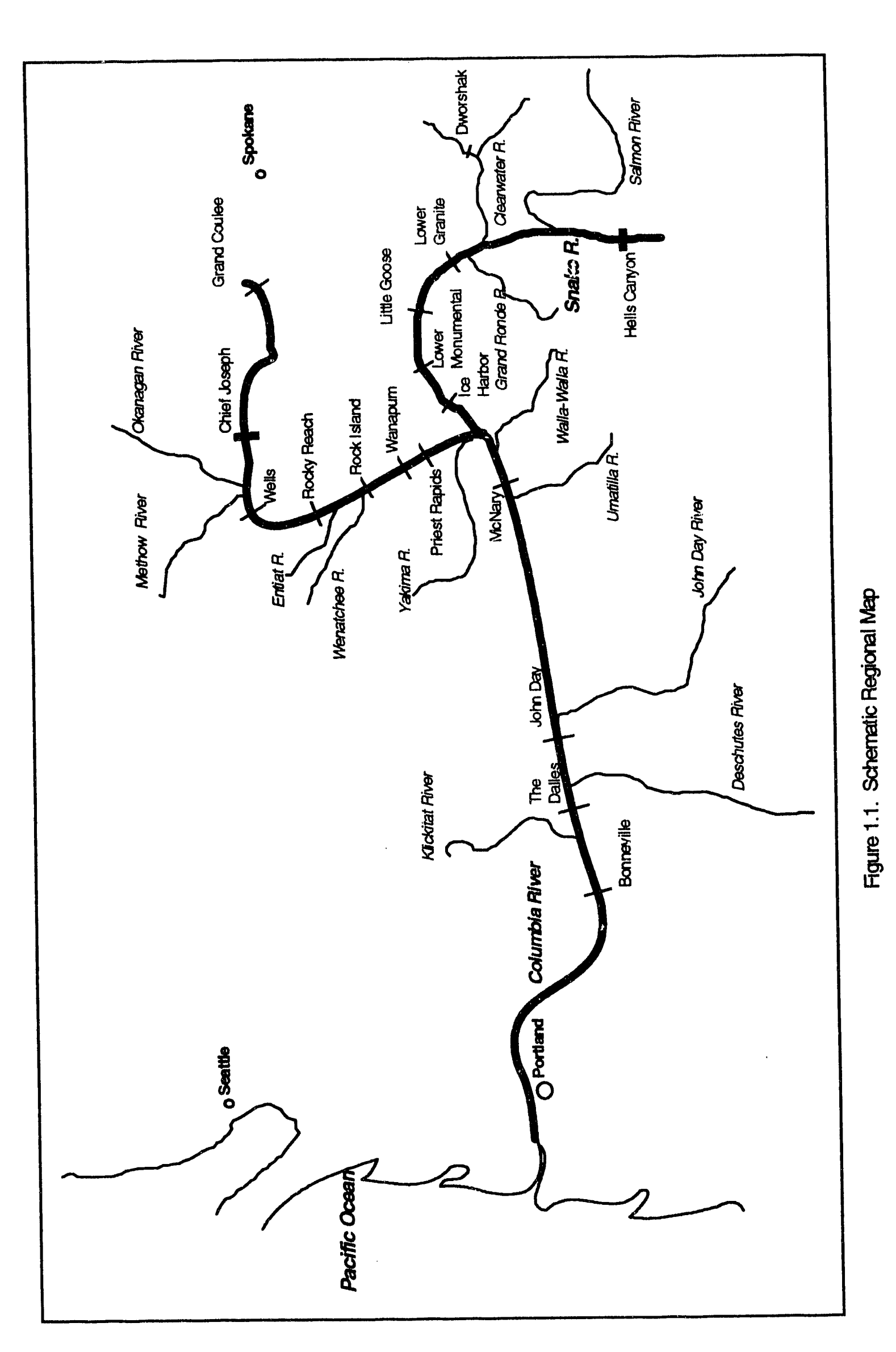


spillways of the dams. In the care of turbine passage, mortality rates can be quite high, approaching thirty percent per dam under adverse conditions (NPPC, 1987: p. 12). Smolts passing over the spillways have much lower mortality rates, on the order of one to two percent per dam (Kaczynski and Palmisano, 1992: p. 62). However, the fish only move over the spillway in proportion to the flow of water. In order to induce more of the smolts to travel past each dam via its spillway, rather than the turbines, water must be routed away from the turbines and to the spillway, thereby foregoing substantial power generation. Finally, although the majority of the adults successfully traverse the fish ladders provided for them, estimates of the upstream adult passage mortality (direct and indirect) at each project approach ten percent (Kaczynski and Palmisano, 1992: 58).

\section{Reservoir Impoundments}

The impoundments created by the dams pose hazards as well. Anadromous salmonids evolved to migrate both upstream as adults and downstream as smolts in fast-moving water. Although the adults swim vigorously, the smolts are thought to spend much of their time passively floating in the current. Prior to the construction of dams, smolts migrating downstream from Idaho took approximately half the time it currently takes smolts to reach the estuary from Idaho; travel time now averages thirty to forty days, and even more in low-flow years (Giorgi, 1991). During this time, the smolts are subject to predation, and some may miss the critical window during which they can make the physiological transition from freshwater to saltwater.

The degree of mortality that results from longer travel times is a topic of much debate in the region. Some argue that except for very low flow levels, data to support the assumption that improved smolt survival will result from decreased travel times are limited (Giorgi, 1991). Others argue that travel time is significant for smolt survival over a much wider range of flows (Columbia Basin Fish and Wildlife Authority (CBFWA), 1991a). 


\section{Harvest}

In addition to being killed by the hydropower system, the fish are also harvested heavily in the ocean as they mature, and in the rivers when they return to spawn. For many stocks, our analysis of coded wire tag (CWT) data suggests that commercial and sport fisheries may harvest more than 80 percent of the fish surviving to adulthood. The proportion of the adults harvested varies widely among species and stocks; for example, naturally spawned steelhead have very low harvest rates, while almost 90 percent of hatchery-spawned fall chinook may be harvested before they can return to the hatchery to spawn.

The net economic value of the commercial harvest is modest (Kneese et al., 1988, Volume III), but many communities depend upon it and commercial fishermen are well-organized and vocal in defending their rights to a substantial share of the fish runs. In addition, Indian treaty rights entitle various tribes to fish "in their usual and accustomed places" and to take significant portions of the fish runs. These factors, combined with a considerable sport harvest, suggest that harvest will continue to be an important influence on both the size of the run (since harvested fish obviously cannot spawn) and on its composition. The latter is a problem since naturally spawning stocks (particularly those originating upriver) generally cannot withstand the same harvest rates as hatchery stocks. It is often impossible to separate hatchery and natural fish during harvest activities, so mixed-stock harvest likely has contributed to the precipitous decline in many natural stocks.

\section{Habitat Degradation}

Habitat degradation also contributes to the decline of many stocks. Erosion due to mining, timber extraction, and grazing has changed both the topography and substrate in many spawning and rearing areas. Topographically, stream beds have become more uniform, with fewer deep pools and fast-moving rapids, and more shallow, flat-water reaches. Pre-development gravel substrates have been buried in sand and silt, which smother salmon eggs and despoil habitat used by pre-smolt juveniles. In addition, stream banks have been altered by clear-cutting and 
grazing, thus reducing riparian vegetation, raising water temperatures, and reducing dissolved oxygen content. Irrigation diversion dams have blocked access to spawning and rearing areas, while intake pipes draw in fish along with irrigation water and leave them stranded in fields. Finally, a process euphemistically known as dewatering results when most or all of the flows in a subbasin are withdrawn for irrigation; while many uncertainties surround salmonid management, most would agree that water is an important part of salmonid habitat.

\section{Hatchery Management}

Many researchers in the field of salmonid behavior and management believe that hatcheries may have a number of pernicious effucts on natural stocks (Kacyzynski and Palmisano, 1992; Meffe, 1992 and references therein). The least coniroversial negative effect arises from the fact that hatchery stocks are usually more productive than natural stocks; that is, they produce more adults in generation $(n+1)$ per adult in generation $(n)$ than do natural stocks. Thus, they can withstand higher harvest rates than naturally spawned stocks, other things being equal. The higher productivity, combined with mixed stock harvest and a tendency by fisheries management agencies to allow high harvest rates on many hai hery stocks, likely has contributed to the decline of some natural stocks.

The second possible negative effect of hatchery programs results from the potential genetic mixing between hatchery-bred and wild fish. Such mixing may be detrimental to the wild population, especially if the introduced hatchery stock is developed from fish adapted to a different portion of the basin (NPPC, 1992; CBFWA, 1991b). Extensive mixing may dilute the genotype of the natural stock to the point where it has trouble surviving in its original subbasin. Additionally, the risk of extinction for both the hatchery and natural stock may increase in the event that environmental changes require the "lost" genetic diversity for the stocks' survival.

Two other possible negative effect derive from short-term interactions between hatchery and wild stocks. Hatchery stocks, when released into the wild as pre-smolt juveniles, generally feed inefficiently and aggressively. When competing for food in areas with natural populations, 
their behavior may be detrimental to the natural populations. Furthermore, many biologists express a concern that hatchery stocks may introduce diseases such as bacterial kidney disease (BKD) and infectious hepitatic necrosis (IHN) into naturally spawning populations.

\section{MITIGATION PLANNING IN THE COLUMBIA BASIN}

The federal Pacific Northwest Electric Power Planning and Conservation Act of $1980^{6}$ created the Northwest Power Planning Council (NPPC) and gave it the responsibility for developing a program to mitigate the effects on fish and wildlife of hydropower development in the Columbia Basin. The Northwest Power Act specifies that the NPPC shall include in the program measures which are based on the "best available scientific knowledge" and which utilize, "where equally effective means of achieving the same sound biological objective exists, the alternative with the minimum economic cost." Federal agencies charged with implementing the NPPC's Fish and Wildlife Programs include BPA, the U.S. Army Corps of Engineers, the U.S. Bureau of Reclamation, and the Federal Energy Regulatory Commission.

The Fish and Wildlife Program developed by the NPPC stresses a system-wide approach to rebuilding salmon and steelhead runs. It provides plans for the Columbia Basin as a whole as well as for the individual subbasins, and attempts to integrate improvements in fish production, mainstem fish passage, and harvest management. The following two subsections discuss the goals and objectives of the NPPC Fish and Wildlife Program and the types of management actions available to help meet these goals and objectives.

\section{NPPC Goals and Objectives}

The NPPC has established a number of general goals for salmon and steelhead (NPPC, 1987). The first of these is the goal of doubling the size of the basin-wide run. As part of that

\footnotetext{
616 USC 839. The 1980 Act, generally referred to as the Northwest Power Act, gives the NPPC the responsibility to develop programs for power planning and electricity conservation. The NPPC consists of two representatives appointed by the governor from each of the Pacific Northwest states (Washington, Oregon, Idaho, and Montana).
} 
goal, the NPPC has accorded priority to the runs above Bonneville. Since the inception of the National Marine Fisheries Service listing process for Snake River salmon in April of 199(), the NPPC has accorded additional priority to Snake River sockeye and chinook stocks, which have suffered a more marked decline than other upriver runs. A related goal is to try to restore the runs by emphasizing natural production more than has been done in the past. This reflects a desire to minimize genetic risk in the restoration process, by protecting weaker stocks and decreasing the genetic mixing of hatchery and wild fish.

While these goals are certainly reasonable, they do not provide sufficient detail to be analyzed quantitatively. The thirty subbasin plans developed by the Columbia Basin Fish and Wildlife Authority (1990) are important in this regard, since they establish specific, stock-by-stock numeric objectives, expressed in terms of subbasin harvest and spawning escapement for each stock above Bonneville Dam. As the results in Chapter 5 show, the objectives are sometimes unattainable, given the menu of management actions under consideration, but they provide a useful starting point for the quantitative analysis.

\section{Management Actions to Benefit Fish}

The Pacific Northwest can take a wide variety of actions to increase fish numbers. We discuss these possible actions in the same order that we presented the problems earlier, starting with passage past dams and ending with hatchery production. Although the various actions described below can be implemented independently, their effects on the salmon depend directly on conditions elsewhere in the system, including other management actions. For example, the region can implement a downstream passage action independently of any action that influences conditions in spawning and rearing areas. However, in order to predict the number of additional fish produced by a passage action, one must know what conditions are faced by the fish in the ocean and in spawning and rearing areas.

Dam Passage: Actions to improve downstream passage past dams focus on helping juveniles migrating downstream to avoid the turbines. One can route smolts around the turbines 
either by routing water (and fish) over the spillways, rather than through the turbines, or by screening the turbine intakes, to induce the smolts into a bypass system (see Figure 1.2). Most of the Federal dams have already been screened, and some of the currently unscreened Federal dams are scheduled for bypass installation within the next few years.

Reservoir Passage: A number of methods have been attempted or proposed to move the smolts downstream more quickly in order to increase their survival. The first method entails an increase in the volume of flows in the river during the migration season. The water budget, a special, reserved volume of water that fish and wildlife agencies and the tribes can allocate between April 15th and June 15th, augments Columbia and Snake river mainstem flows, in order to aid the passage of smolts downstream. The region has utilized the water budget since 1982 , and the NPPC plans to increase spring flows even further. Another method proposed to hasten the downstream journey of juveniles involves the drawdown of particular reservoirs to pool elevations below current pool elevations. Such drawdowns will increase the velocity of the river water and thus, theoretically, the velocity of the juvenile fish. Much of the current debate over passage actions focuses on the efficacy and desirability of these reservoir drawdowns, particularly for the endangered chinook and sockeye stocks in the Snake River subbasins. A third method, used extensively since the early $1980 \mathrm{~s}$, is to place smolts collected in the bypass systems into barges, transport them downstream past all dams, and release them below Bonneville Dam so that they can continue their migration under their own power. A fourth, proposed method is to build a fish canal parallel to the Snake and/or Columbia River, and route collected fish into the canal, essentially transporting them in a canal instead of barges.

To reduce the mortality of smolts as they travel through the reservoirs, BPA has begun a predator control program. The program pays a reward to anglers who catch squawfish, a major predator of smolts, in order to reduce the size of the squawfish population. In 1991, it removed more than 200,000 squawfish from the Columbia Basin (BPA, 1992).

Harvest Management: If the salmonids smolts survive their migration to the ocean, commercial, sport, and tribal harvesting together remove a large percentage of the fish surviving 


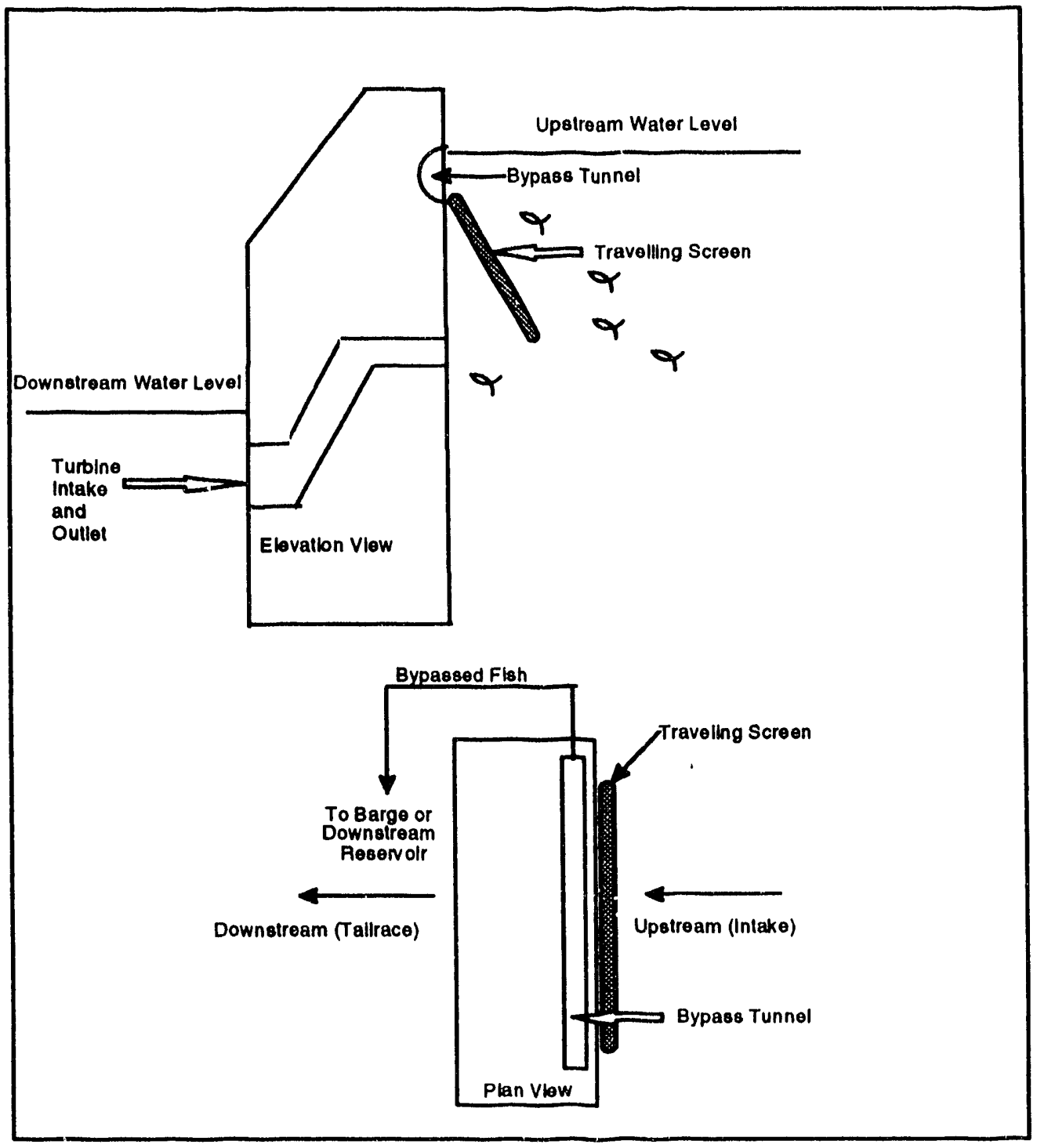

Flgure 1.2 Smolt Bypass Schematlc (nol to scale) 
to adulthood, as mentioned earlier. Several opportunities exist to regulate harvest by adjusting the timing, location, duration, and quotas of fisheries, and by controlling which stocks may be harvested and which are designated as catch and release. Many subbasin sport fisheries on salmon have been sharply curtailed or put on hold to allow for recovery of the stocks. Regulators also have increasingly restricted ocean and in-river harvests over the past decade. In 1992, salmon harvests in the Pacific Ocean were reduced dramatically, because of the low run sizes of salmon predicted for 1992.

Unfortunately, options for regulating harvest often are poorly integrated with passage, habitat, and hatchery options. Many argue that the poor integration results in large part from the highly fragmented administration of harvest management across the Basin.

Habitat Improvement: Mitigation for habitat problems in the subbasins includes barrier removal, stream habitat improvement, and screening of irrigation intakes. In some subbasins, a substantial amount of potential spawning ground remains unused because man-made or natural barriers block the path of returning spawners. Actions to allow upstream passage may involve either removal of the physical barrier (e.g., removal of a small dam) or construction of a bypass or ladder over the barrier (e.g., a fish ladder up a natural falls).

A large variety of actions fall in the category of stream habitat improvement, such as replenishing stream beds with spawning gravel, placing logs in streams to create pools, and replanting and protecting riparian vegetation. Recent legislative attempts to set minimum instream flows for fish during spawning and migration periods also could be categorized as habitat improvement.

The screening of irrigation water intakes attempts to prevent migrating juveniles from being routed into irrigation channels and stranded in irrigated fields. Because of the large toll that unscreened intakes may take on juveniles and the relatively straightforward nature of screening, agencies in the region currently are pushing to screen the worst intakes.

Hatchery Management: Although hatchery programs were originally conceived to be part of the solution to dwindling fish runs, there is concern that they may be part of the problem as 
well, as we pointed out earlier. Recently-proposed hatchery programs take much greater account of the problems that potentially arise when hatchery fish are mixed with natural or wild fish. The Integrated System Plan (Columbia Basin Fish and Wildlife Authority, 1991b) discusses at length the issues, technology, and risks associated with hatchery supplementation programs (see also Meffe, 1992). In general, if hatchery input is used to supplement a natural population, implying that hatchery and natural fish will inierbreed, then the hatchery fish should be as close to the natural fish as possible in their tehaviur, physiology, and genetics. This involves taking great care in broodstock selection and in rearing, acclimation, and release conditions. For most hatchery programs, a major efforts ceniers on tickling the problem of disease in hatchery populations to protect both the hatchery fish and the natural fish they may come in contact with. Moreover, since the goal of many hatchery programs is to provide harvest, it is important to develop fish marking schemes that allow stock-selective fisheries.

\section{RESOURCES FOR THE FUTURE'S RESEARCH PROGRAM}

In view of the complexity of the planning problem in regard to the fish mitigation problem, and BPA's responsibility for funding a major part of the effort, ${ }^{7}$ BPA officials apnroached RFF in early 1984 requesting that RFF assist BPA in developing a research program in support of the mitigation effort. Of special relevance to the proposed research efforts are the requirements of the Northwest Power Act that damage to fish be mitigated while assuring a "safe, reliable, economic supply. .." of electricity, that the region follow a system-wide approach, and that the measures undertaken be cost-effective.

Subsequently RFF proposed the outline of a research program to BPA. The program proposed by RFF was intended to be completed in three phases. Phase I, jointly sponsored by the BPA and RFF. was designed to identify econonic and related research issues to be pursued in

\footnotetext{
${ }^{7}$ In the 1980s, the region spent about $\$ 1$ billion to rebuild Columbia River salmon runs and wildlife affected by federal hydroelectric facilities. Estimates of the costs of mitigation and recovery efforts for fish and wildlife in the next decade range from $\$ 1.5$ billion to $\$ 3$ billion. (BPA, 1991; Foster, 1992)
} 
later stages of the research program. Allen Kneese delivered a document reporting on Phase I to BPA in mid-1984. The Phase II research was aimed at providing a comprehensive design of the research program -- including development of needed analytical methods, identification of data needs and potential sources, and a plan for the program's execution. We provided this to BPA in 1988 (Kneese, et al., 1988). We are conducting the bulk of the actual research in Phase III, although the Phase Il planning effort involved considerable research in its own right.

The primary objective in the Phase IIl analysis is to provide a basis for examining the tradeoffs among alternative management strategies with regard to cost, numerical objectives for subbasin harvest, spawning escapement, and runsize, and non-numerical objectives such as genetic integrity. We have adopted a cost-effectiveness framework for this purpose (see Chapter 2).

Although we discuss the scope of the analysis, methods, and data sources in subsequent chapters and appendices, it is useful to understand at the outset what our analysis addresses and what it omits. Important points to note are:

1) We have restricted our analysis to chinook salmon and steelhead in subbasins above Bonneville dam. We include only those stocks with identifiable and documented proposed mitigation and recovery proposals and terminal harvest and spawning escapement objectives. In total, we evaluate actions for 79 hatchery and natural stocks. Table 5.1 provides a complete list of the included stocks and the spawning escapement and terminal harvest objectives for each stock.

2) We draw nearly all cost and biological information for subbasin propagation and passage actions from existing sources; that is, we did not conduct any new empirical field work. The only exception to our reliance on existing published data is that we updated some mid-Columbia hatchery cost information based on interviews with hatchery managers. We include only those subbasin propagation actions proposed in the CBFWA subbasin plans. Furthermore, we analyze only those proposed actions that have quantified costs and 
associated biological effects.

3) We do not assess management actions that change ocean or in-river harvest rates, although we do evaluate different terminal harvest rates.

4) We evaluate only direct financial costs and opportunity costs of lost hydropower generation to Bonneville, and do not consider the possible economic costs and benefits to navigation, recreation, flood control, irrigated agriculture, dryland agriculture, or commercial and sport harvest.

5) Our analysis adopts a deterministic framework, except for the variability introduced by different water years.

6) Our analysis takes a comparative statics approach. We try to identify the lowest-cost means of meeting the specified objectives by some indeterminate future date. Thus, we do not investigate alternative rebuilding schedules or the implications of alternative sequences of actions.

7) We adopt a system-wide perspective; that is, we investigate management options for downstream passage, subbasin propagation, and terminal harvest across all stocks simultaneously. For example, we do not fix conditions in the subbasin and look for the most cost-effective passage action. Our approach thus attempts to find the system-wide least-cost set of passage, propagation, and terminal harvest actions that will meet the specified objectives for each stock.

\section{SUMMARY AND PLAN OF REPORT}

Many populations of Columbia Basin salmon are at very low levels. Direct and indirect mortality and habitat losses resulting from damming the river, harvest, habitat degradation due to a variety of human activities, and hatchery practices have all contributed to the declines of the fish 
runs. Although many mitigation actions have been implemented during the 1980 )'s, the situation remains critical for a number of stocks, especially the chinook and sockeye, runs in the Snake River basin. Many more actions to benefit the fish have been proposed for the entire Columbia Basin, mostly involving mainstem passage enhancement, subbasin habitat enhancement, and hatchery programs. Examining the trade-offs among expenditures, objectives, and constraints of alternative recovery strategies, to provide decision-makers with information on how these aspects of the problem affect one another, is the overall goal of our work described in this document.

In the remaining chapters, we describe the data, models, analyses, and results associated with our system-wide cost-effectiveness analysis of mitigation and recovery alternatives in the Columbia Basin. In the next chapter, we provide the conceptual underpinnings of the costeffectiveness approach that we have adopted. Chapter 3 presents an overview of the models that we use in our analysis and describes their interconnections. Chapter 4 discusses the data that we use, as well as the objectives that we include in our cost-effectiveness analysis. We furnish results in Chapter 5. The appendices at the end of this report are for those readers who are interested in the details of the models and the data. We also provide a glossary at the end of the report to clarify some of the important concepts of our discussion. 


\section{CHAPTER 2 \\ COST-EFFECTIVENESS AND SYSTEM COMPLEXITY}

\section{INTRODUCTION}

The main questions we address in the work presented in this report are (1) what actions should the region implement to achieve a set of goals for the fish at least cost, and (2) how do changing goals or constraints affect the least-cost choice of actions? These questions are easy to pose yet extremely difficult to answer. For a complex system like the Columbia Basin, the design and exercise of a basin-wide, multiple-stock analysis that can provide information to address these questions present a daunting task. It is difficult to evaluate each possible management option for each stock while keeping track of the tradeoffs with other possible management options and stocks. On the other hand, if we focus on individual stocks and subbasins and proceed with an analysis on a stock-by-stock basis in order to make our analysis more tractable, we may fail to see the possible positive and negative interactions among stocks. In this situation, we may unknowingly choose a set of actions that benefit some stocks but have deleterious economic and/or biological effects in the aggregate.

We have chosen a basin-wide approach for our analysis, since we believe that decision makers in the Pacific Northwest ultimately must make decisions about management options for stocks throughout the basin. However, to work at the basin-wide level and to provide a reproducible and justifiable account of the tradeoffs among options, we need a sound conceptual and analytical framework. The framework on which we base our work is cost-effectiveness analysis. We use the method to examine the tradeoffs between different courses of action with respect to cost, biological effectiveness, and other variables of interest, in a system context. While this approach handles the large, interconnected system well, it also can be used fruitfully at much smaller spatial scales and for less-complex systems.

In this chapter, we briefly discuss the concept of cost-effectiveness analysis and the complexity of such an analysis in the Columbia basin. We start with a brief overview of the technique. We next provide a simple didactic example of a cost-effectiveness analysis. We then 
discuss the complexity of the Columbia River system and its management and present a classification of management actions and strategies which we use to find basin-wide, least-cost solutions to the problem of mitigation and recovery planning for Columbia basin salmon and steelhead.

\section{OVERVIEW OF COST-EFFECTIVENESS ANALYSIS}

Cost-effectiveness analysis is a useful tool for exploring tradeoffs among any number of alternative strategies with respect to costs and measures of effectiveness (e.g., number of arlult fish that escape to a subbasin). In brief, with the approach we attempt to find the least-cost way to achieve some desired, pre-set level of effectiveness. Moreover, we can vary the desired level of effectiveness over a range of values, and for each level find the least-cost alternative. ${ }^{1}$

If we plot the costs and effects of alternative management options on a graph and identify the least-cost strategies for a number of desired levels of effectiveness, we can trace the "frontier" of cost-effective strategies. This frontier grapnically highlights the potential cost-savings associated with choosing cost-effective strategies, because points on the frontier provide equal or higher levels of effectiveness at lower cost than points not on the frontier. The frontier also shows that higher levels of effectiveness mean not only higher costs, but also generally smaller increments in effectiveness for a given increase in cost (i.e., increasing marginal costs). ${ }^{2}$

It is important to note that cost-effectiveness analysis differs significantly from cost-benefit analysis. While cost-benefit analysis attempts to evaluate whether the benefits of a particular alternative exceed the costs, cost-effectiveness analysis attempts to identify the least-cost alternative for a given objective. Cost-effectiveness thus says nothing directly about the desirability of attaining a given objective. Although this may limit the usefulness of costeffectiveness analysis in some venues, we believe that in mitigation and recovery planning for

\footnotetext{
1See Spofford (1989) for more details on applications of cost-effectiveness analysis. 2.In theory, the marginal costs of alternatives on the cost-effective frontier will increase as the level of effectiveness increases. However, this does not necessarily hold true in real-world applications, as our results in Chapter 5 display.
} 
salmon populations in the Columbia basin it does not. The clear separation of biological objectives and economic costs furnished by the cost-effectiveness framework provides both a simpler and a more relevant approach than does a cost-benefit framework, which would require estimating the monetary value of the benefits derived from preservation or enhancement of the salmon populations. Furthermore, the language of the Northwest Power Act clearly promotes the use of cost-effectiveness analysis.

\section{COST-EFFECTIVENESS EXAMPLE}

Table 2.1 and Figure 2.1 help illustrate a simple example of a cost-effectiveness analysis. Table 2.1 presents fifteen hypothetical strategies which increase adult run sizes, with accompanying costs and biological effects (for purposes of the example, assume that each strategy contributes a certain number of adult fish). We plot these points in Figure 2.1, with costs in the $y$ dimension and number of adult fish in the $\mathrm{x}$ dimension. We then trace the cost-effective frontier. Each point on the frontier represents the lowest cost strategy which provides the corresponding number of adult fish. Strategies not on the frontier are economically and/or biologically inferior, because one can attain at least as many adults with another, lower-cost strategy (compare strategies 2 and 7), or a higher number of adults with another strategy, at the same cost (compare strategies 9 and 4$)$.

The results of the hypothetical analysis depicted in Figure 2.1 portray costs and effects for the entire set of fifteen strategies. But other attributes besides cost and effectiveness may merit consideration in the evaluation of different strategies (e.g., public support for a strategy and the numerical strength of the targeted stock). We incorporate these additional attributes by allowing them to constrain the types of strategies that we consider or the objectives we seek.

To illustrate how this works, consider the example displayed in Figure 2.2. This figure shows two cost-effectiveness frontiers: the original frontier from Figure 2.1 (Frontier I) and a new frontier (Frontier II, indicated by arrows, using only the bold-face numbers) beside it. We produce the new frontier by omitting from the cost-effectiveness analysis those strategies that rely 
TABLE 2.1

Cost and Effectiveness of Hypothetical Strategies to Increase Run Size

\begin{tabular}{clrc}
\hline $\begin{array}{l}\text { Management } \\
\text { Action Code }\end{array}$ & $\begin{array}{l}\text { Management } \\
\text { Action Description }\end{array}$ & $\begin{array}{c}\text { Additional } \\
\text { Adults }\end{array}$ & $\begin{array}{c}\text { Annualized Cost } \\
\text { (thousand \$) }\end{array}$ \\
A & Improve Existing Habitat I & 1,700 & \\
B & Add New Habitat I & 5,000 & $\$ 50$ \\
C & Improve Existing Habitat II & 6,250 & $\$ 400$ \\
D & Add Hatchery & 3,000 & $\$ 1,1(0)$ \\
\hline & & & \\
Management & Action(s) Included & Additional & Annualized Cost \\
Strategy & & Adults & (thousand \$) \\
& & & \\
1 & A only & 1,700 & $\$ 50$ \\
2 & B only & 5,000 & $\$ 400$ \\
3 & C only & 6,250 & $\$ 1,100$ \\
4 & D only & 3,000 & $\$ 1,500$ \\
5 & A \& B & 6,700 & $\$ 450$ \\
6 & A \& C & 7,950 & $\$ 1,150$ \\
7 & A \& D & 4,700 & $\$ 1,550$ \\
8 & B \& D & 8,000 & $\$ 1,900$ \\
9 & B \& C & 11,250 & $\$ 1,500$ \\
10 & C \& D & 9,250 & $\$ 2,600$ \\
11 & A \& B \& C & 12,950 & $\$ 1,550$ \\
12 & B \& C \& D & 14,250 & $\$ 3,0(0)$ \\
13 & A \& B \& D & 9,700 & $\$ 1,950$ \\
14 & A \& C \& D & 10,950 & $\$ 2,650$ \\
15 & A \& B \& C \& D & 15,950 & $\$ 3,050$ \\
\hline
\end{tabular}




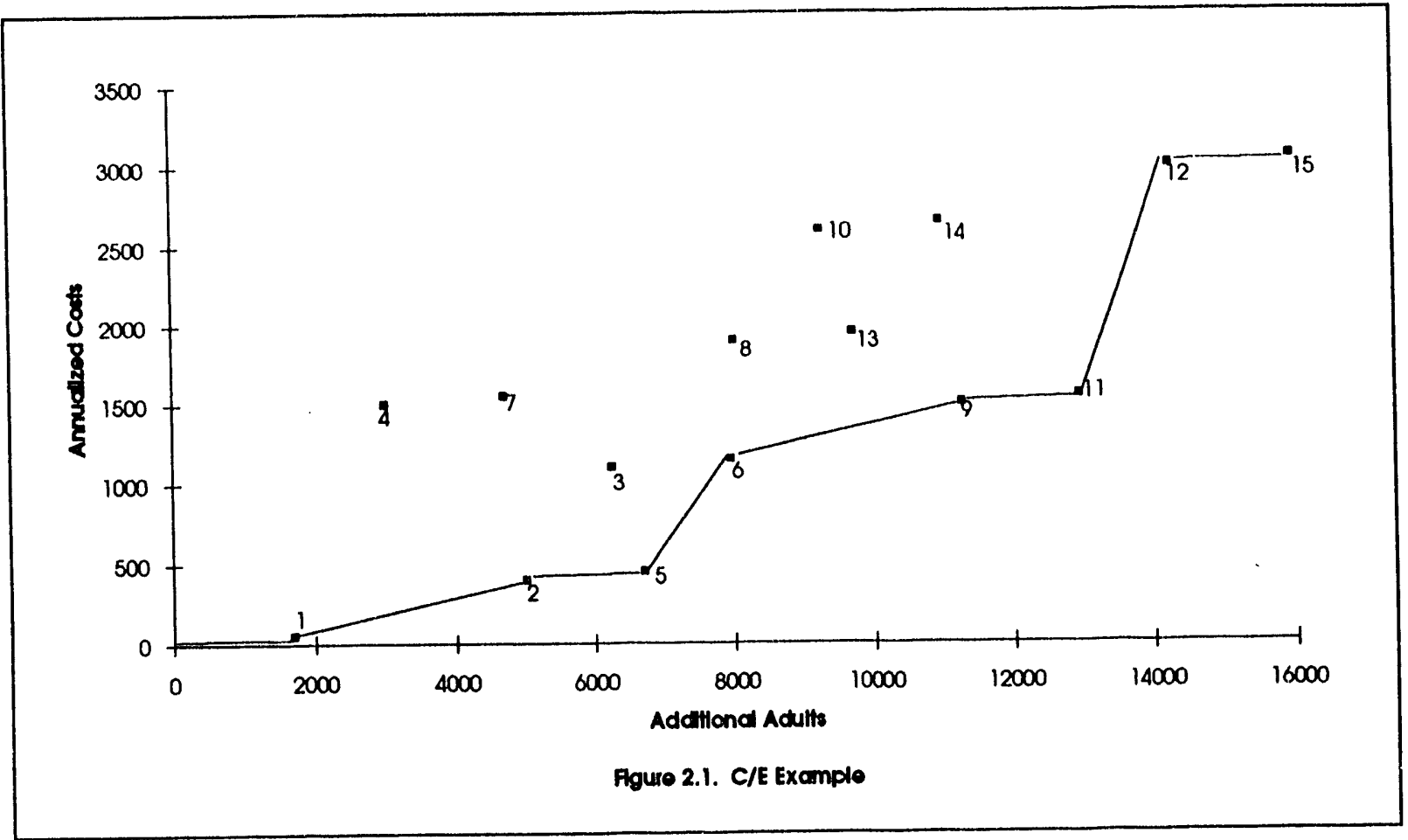




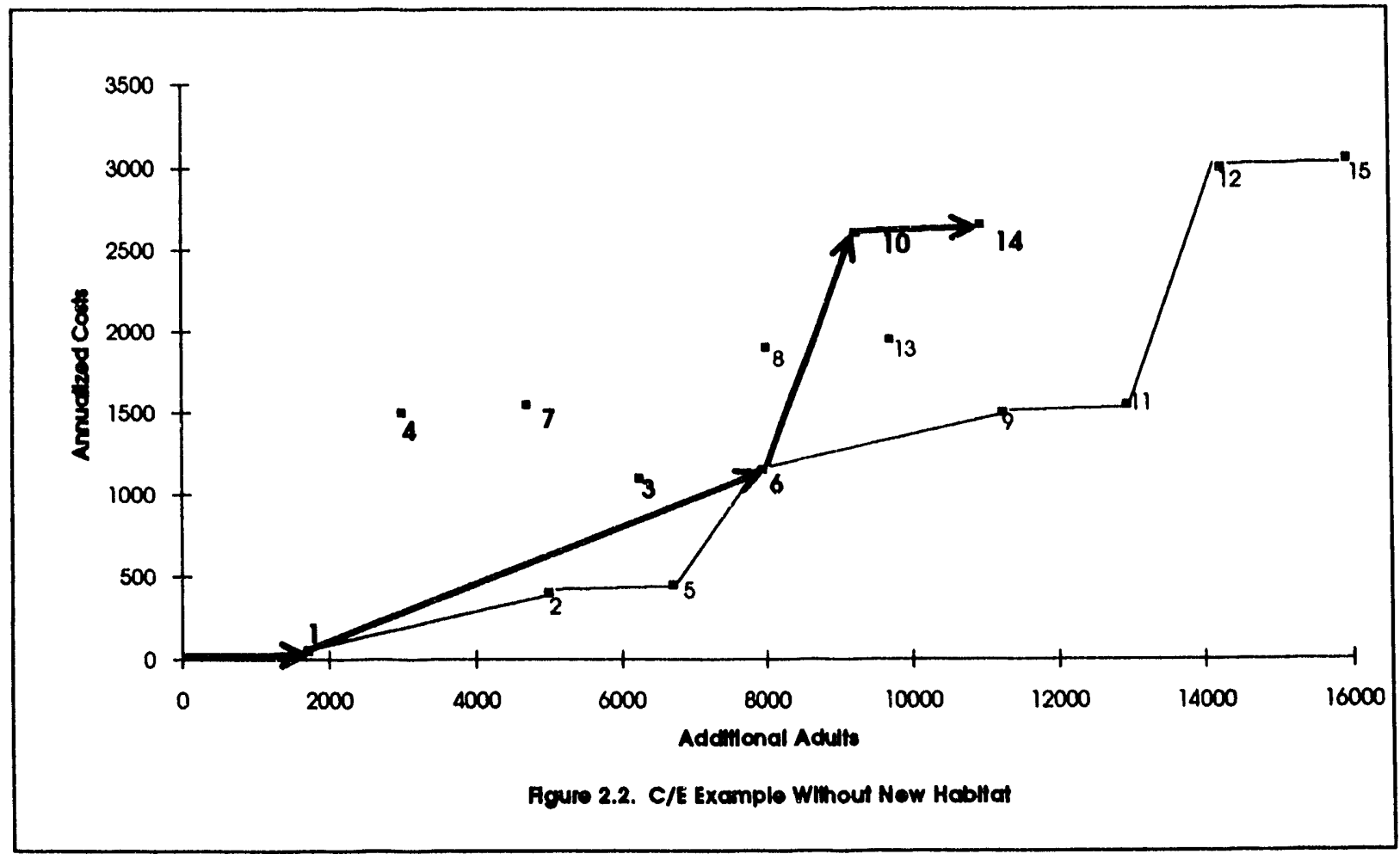


on new habitat (perhaps due to concern about resident fish); 7 strategies remain. We then compare the new cost-effectiveness frontier for the 7 strategies to the frontier for the entire set of 15 strategies. Such a comparison can tell us the effect that rely on existing habitat has on the composition and choice of cost-effective strategies. This simple extension of the basic analysis thus allows us to explore the implications of emphasizing attributes other than cost and effectiveness.

The immediate objective of the cost-effectiveness analysis is to define the least-cost strategy that will meet a set of stock-specific objectives for subbasin harvest and spawning escapement. The strategy will use a combination of passage actions (which affect all stocks simultaneously), subbasin-specific propagation actions, (which affect all stocks spawning in the subbasin), and harvest rates (which affect each stock individually). The larger goal of the analysis is to explore tradeoffs among expenditures, biological effectiveness, and other attributes to provide decision-makers with information on how the multiple dimensions of recovery planning affect one another.

\section{SYSTEM COMPLEXITY}

In the work discussed in this and subsequent chapters, we extend the methods demonstrated in the above example to the portion of the Columbia basin bounded by Bonneville Dam, Hells Canyon Dam, Chief Joseph Dam, and Dworshak Dam. (See Figure 1.1) Although our system-wide analysis follows the simple logic of Figures 2.1 and 2.2, the large number of stocks, propagation strategies, and passage strategies complicates the picture. This section addresses the complexity of the decision problem which results from our efforts to take a basinwide perspective on the enormous number of combinations of recovery actions that the region must evaluate. 


\section{Species and Stocks}

The area above Bonneville Dam currently boasts a number of species of anadromous fish: steelhead, sockeye salmon, coho salmon, and several runs (spring, summer and fall) of chinook salmon. Of these we have excluded sockeye and coho from our analysis, due to the lack of both biological data and stock-specific objectives for most sockeye and coho populations. We also have excluded Hanford Reach chinook, mid-Columbia steelhead, and several other stocks because of data limitations and/or an absence of proposed mitigation actions. Finally, we have excluded all stocks in the Yakima subbasin, since this basin already has major mitigation projects underway.

The subbasin plans developed by the Columbia Basin Fish and Wildife Authority (CBFWA, 1990) that provide the foundation of our work divide the species into stocks, based upon the subbasin where they spawn and whether they are of hatchery or natural origin. We make an additional division of hatchery-origin fish into "pure" hatchery and supplementation stocks (Chapter 4 offers more information on stock definitions). In total, we analyze management objectives and management actions for 79 stocks.

\section{Mitigation Actions and Strategies}

In addition to the large number of stocks, three other factors complicate the analysis. First, as noted earlier, passage actions can affect more than one stock at a time. Actions specific to a particular dam can affect every stock above that dam, and flow actions can influence the survival of all smolts migrating during the period when the flow action is in operation. Even within subbasins, propagation actions often affect every stock which spawns in the subbasin (e.g., removal of a barrier on a tributary stream). Thus, one cannot hope to find a basin-wide combination of passage and propagation actions to meet the stock-specific objectives at least cost without taking account of the possible multiple effects of passage and propagation actions.

Second, the effects of some actions are not entirely independent of each other when viewed in a life cycle context. For example, an action which increases the downstream survival of a stock's smolts by 100 percent may lead to a less than 100 percent increase in that stock's 
abundance if the population already lies near the subbasin's carrying capacity. This possibility necessitates a life-cycle approach which combines passage, propagation, and harvest.

Third, the sheer number of possible combinations of the proposed recovery actions is very large. A simple example may illuminate this problem. Consider first a single subbasin, "A", having a single stock, with 3 propagation management actions, denoted $\mathrm{A} 1, \mathrm{~A} 2$, and $\mathrm{A} 3$. (We define underlined terms from this section in Table 2.2). We can define these propagation actions into eight propagation strategies: A0, or no action, A1 only, A2 only, A3 only, A1A2, A1A3, A2A3, and A1A2A3. Next, analogous to the methods used in subbasin planning, let us assume that managers can vary the terminal harvest rates for the stock, and that they can employ any of three terminal harvest rates, AT1, AT2, or AT3. Even if the whole system consists of only this one subbasin, we still need to consider 24 propagation/terminal harvest combinations to be considered ( 8 propagation strategies * 3 terminal harvest rates). If one then adds 4 passage strategies (P0, or no action, P1 only, P2 only, and P1P2, derived from 2 passage actions, P1 and $\mathrm{P} 2$ ), the number of propagation/terminal harvest/passage alternatives for the subbasin increases to 96 (24 propagation strategy/terminal harvest rate combinations * 4 passage strategies). While this number seems high, considering the small number of propagation strategies, terminal harvest rates, and passage strategies, it is still manageable. In our cost-effectiveness modeling, we can easily evaluate this number of alternatives with the deterministic simulation model, described in more detail in Appendix A.

What happens when we add another subbasin, "B", to the example? Assume that subbasin $\mathrm{B}$ also has three propagation actions, B1, B2, and B3, resulting in 8 propagation strategies, and three possible terminal harvest rates, BT1, BT2, and BT3. Obviously, subbasin B also will have 24 propagation strategy/terminal harvest rate combinations. If we add the four possible passage strategies, subbasin B also will have 96 propagation strategy/terminal harvest rate/passage strategy alternatives. An analysis that investigates the two subbasins in isolation from each other would require 192 runs of a simulation model, since both subbasin A and subbasin B have has 96 alternatives. The deterministic simulation model can accommodate this number of simulations. 
TABLE 2.2

Definitions of Terms Used to Specify Mitigation Options

\section{Term}

Management Action

Passage Strategy

Propagation Strategy

Propagation/Passage/Terminal Harvest/Alternative

System-Wide Strategy

System-Wide Least-Cost Strategy

\section{Definition}

Smallest single management option that will have a unique effect on a biological parameter; e.g., add screens at a run-of river dam, or add rearing capacity at a hatchery.

Combination of passage actions; will affect all stocks in the system simultaneously; can only use one passage strategy for the entire system.

Combination of propagation actions; will affect all stocks in a given subbasin simultaneously. Exactly one propagation strategy per subbasin.

Combination of a system-wide passage strategy, subbasin-specific propagation strategy, and stockspecific terminal harvest rate, for a single stock. The alternative defines all the information necessary to calculate the adults produced for a given stock. Generated by the deterministic simulation model.

Combination of propagation/terminal harvest/passage alternatives for all stocks in the model. All stocks use the same passage strategy and all stocks within a given subbasin use the same propagation strategy, although different stocks in the same subbasin may have different terminal harvest rates.

The system-wide strategy which meets a set of biological objectives at the lowest possible cost of subbasin-specific propagation strategies and one passage strategy. Generated by the linear programming model, using alternatives generated by the deterministic simulation model. 
However, if decision makers want a basin-wide analysis of subbasin A, subbasin B, and passage options, the difficulty of te evaluation increases dramatically. The number of possible system-wide strategies, defined here as all possible propagation strategy/terminal harvest rate/passage strategy alternatives for subbasin $\mathrm{A}$ and all possible propagation strategy/terminal harvest rate/passage strategy alternatives for subbasin B, increases to 2,304 system-wide strategies -- (24 propagation/terminal harvest combinations for subbasin A) * (24 propagation/terminal harvest combinations for subbasin B)*(4 passage strategies). Although the deterministic simulation model $;$ an easily simulate this number of system-wide strategies, identification of the least-cost system-wide strategy that meets the objectives would require analyzing 2,304 sets of results. One cannot say what the system-wide costs and biological results would be simply from an examination of the two sets of 96 alternatives in isolation from each other. In the Columbia basin, the number of possible sets of results to sort through becomes astronorinically large. ${ }^{3}$

The analysis of the results and identification of the least-cost system-wide strategy for recovery planning in the Columbia basin thus requires some sort of screening mechanism to sort through the billions of different strategies. We discuss the linear programming model which we developed to perform this screening function in the next chapter and Appendix B.

\section{CONCLUSIONS}

In order to provide useful information to inform decisions about which actions the Pacific Northwest should implement to achieve a set of goals for the fish at least-cost, we have adopted a cost-effectiveness framework. The framework allows us to uncover the least-cost set of actions, as well as investigate how changing goals and constraints affect the least-cost choice. The need to integrate passage, propagation, and harvest options to provide a basin-wide least-cost strategy complicates the cost-effectiveness analysis, because it forces us to analyze an astronomical

${ }^{3}$ We estimate that we need to assess $7 * 10^{47}$ possible combinations of passage, propagation, and harvest. Although we can take shortcuts to eliminate many of these combinations, we still face billions of system-wide strategies to analyze. 
number of possible combinations of management options. However, while the large number of combinations makes the analysis difficult, it does not make the problem intractable.

We have developed a linear programming model to screen the combinations of management actions. The model uses output from a deterministic simulation model, ${ }^{4}$ and systematically searches for the combination of alternatives which produces a system-wide leastcost strategy to meet a set of terminal harvest, spawning escapement, run size, or other biological objectives at least cost, without violating any constraints we impose, such as maintenance of genetic integrity. We discuss our modeling approach in the next chapter.

\footnotetext{
${ }^{4}$ The simulation model estimates the number of adults produced by each propagation strategy/terminal harvest rate/passage strategy alternative for each subbasin and stock.
} 


\section{CHAPTER 3 \\ MODELING OVERVIEW}

\section{INTRODUCTION}

The basin-wide cost-effectiveness analysis discussed in Chapter 2 relies on the application of a suite of computer models, which analysts in the Pacific Northwest and at Resources for the Future have developed over the last ten years. Each of the models that we use contributes a piece of information to our analysis. Since none of the models individually can provide the full range of information necessary for the cost-effectiveness analysis, we link them together. The linked models collectively constitute the cost-effectiveness modeling process.

This chapter describes each model's history of development, general logic, necessary inputs, outputs, and role in the cost-effectiveness analysis. We start with the model which simulates physical characteristics and economic costs of the operation of the Columbia Basin hydropower system (System Analysis Model). We then move to the simulation of the downstream passage of smolts from upriver sites to the estuary below Bonneville dam (Columbia River Salmon Passage Model). We next focus on the model which simulates the entire life cycle of salmonids in the Basin (Deterministic Life Cycle Model). We finish the model overview with the System-Wide Optimization Model, which uses inputs from the other models to identify system-wide cost-effective strategies for Columbia Basin fisheries management. We conclude the chapter with a brief recounting of the links between the models. The reader may find it useful throughout this chapter to refer to Figure 3.1, which depicts the relationships among the models that we discuss.

\section{SYSTEM ANALYSIS MODEL}

The System Analysis Model (SAM) performs a simulation of the region's power system to meet the demand for capacity and energy within the region. The Northwest Power Planning Act that was passed in 1980 highlighted the need for a tool which could model the operation of the region's power system, both for shorter-term operational guidance and for longer-term planning 
MANAGEMENT ACTIONS

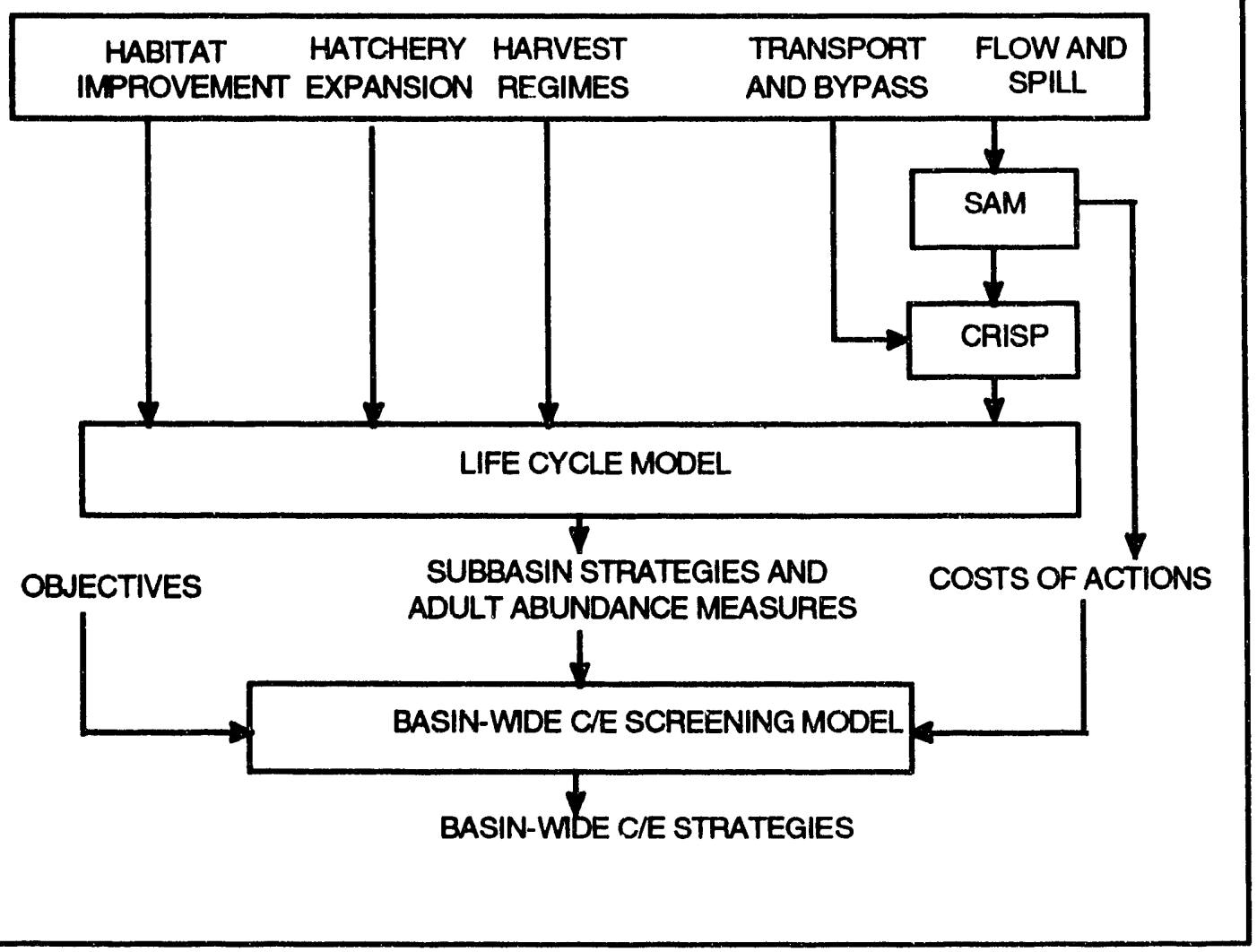

Figure 3.1. Relationships Among Models Used In Cost-Effectiveness Analysis 
for the acquisition of power generating resources. Begun in 1981, SAM has evolved into a complex collection of sub model components, with the capability to model the operation of the hydro and thermal power resources needed to meet demand season-by-season, month-by-month, or hour-by-hour. For a complete description see the SAM documentation (Pacific Northwest Utilities Conference Committee, 1983).

The model works in a Monte Carlo framework and depicts variability in both energy supply (due primarily to changing water condition) and demand. Although SAM assumes a single-owner system, the model does not optimize the operation of the power system. Rather, it simulates the short-term, least-cost operation for a given mix of available generating resources. Given a set of natural water conditions, a mix of available generating resources, and load forecasts, SAM can provide estimates of the revenue requirements necessary to cover the costs of operating resources to meet the load. Generally, a run of the simulation model covers a twentyyear planning horizon and forty or fifty games. ${ }^{1}$

The most salient outputs of SAM for the cost-effectiveness analysis are the monthly regulated flows (from companion hydro-regulator models) and associated revenue requirements. Load constraints and the capability of resources to meet these loads, natural water conditions, and non-power constraints such as minimum flows and spill for fish determine the regulated flows. The revenue requirements depend in large part on these regulated flows, because generally as hydrosystem operators alter their flow regulation for reasons other than producing power (e.g., to provide flows for fish), the costs of operating the power system increase. The cost increases occur both because the region may need to operate higher-cost generating resources and because the value and/or quantity of hydropower sold may decrease. SAM can report revenue requirements for each Monte Carlo game or the average revenue requirement over all games, for

\footnotetext{
1The planning horizon refers to the span of system operation which a simulation exercise covers (e.g., twenty operating or power years from 1992 to 2011). A game refers to each simulation of the planning horizon in the Monte Carlo process (e.g., forty games means forty simulations of the twenty year planning horizon). The sequence of natural water conditions (water years) provides the major source of variability in SAM's simulation of hydropower generation.
} 
each year in the planning horizon.

As Figure 3.1 displays, the revenue requirement and regulated flows outputs from SAM serve as inputs to other parts of the cost-effectiveness analysis. More specifically, the difference in revenue requirements between operating the power system under a particular flow scenario (e.g., the Council's Phase II Amendment) and a base case (e.g., current operations) becomes the hydropower-related cost of that scenario. We express this difference as the average difference over a 50-game, 1 power year simulation. Thus, the hydropower-related costs that we report from a flow scenario do not represent the average overall revenue requirements for operating under that scenario, but rather the marginal increase (or decrease) in average revenue requirements. The regulated flows passed from SAM to the downstream passage model described next are monthly regulated flows for each water year (game) at each run-of-river project.

\section{COLUMBIA RIVER SALMON PASSAGE MODEL}

The Columbia River Salmon Passage Model (CRiSP) simulates the downstream migration of salmon and steelhead smolts from their initial entry into the mainstem Columbia and Snake rivers to a point just below Bonneville dam, the lowest mainstem dam on the Columbia River. The version of CRiSP (CRiSP.0) that we use in our cost-effectiveness analysis accounts for smolt mortality due to turbine, bypass, spillway, and sluiceway passage at each of 13 mainstem dams, and mortality associated with passage through the reservoirs behind each dam (the user can supply several different flow/travel time/mortality relationships for reservoir passage). CRiSP also models the collection and transportation of smolts. The CRiSP.0 documentation by Hinrichsen et al. (1991) provides extensive details on the model.

The Center for Quantitative Science at the University of Washington developed CRiSP.0 for the Bonneville Power Administration in 1990-1991, but the origins of the model lie in the FISHPASS salmon passage model developed by the U.S. Army Corps of Engineers in the mid1980s (Swartzman et al., 1990; Tanovan, 1985). CRiSP.0 is a user-friendly, graphical version of 
FISHPASS, with a few minor coding modifications, and a different platform (CRiSP.0 currently operates on a SUN workstation in a UNIX environment, whereas FISHPASS operates on a mainframe or mini computer). CRiSP.0 introduces smolts (spring, summer, and fall chinook, sockeye, and steelhead) into the mainstem at user-specified points on a daily basis, and tracks the survival of smolts through each downstream reservoir and project. Mortality in reservoirs depends on daily average flows (computed from the SAM inputs), reservoir length, and (indirectly) level of transportation, while mortality at dams accrues hourly, and depends primarily on the efficacy of bypass structures and spill levels. CRiSP.0 tracks fish migration from April through September for each operating year in the planning horizon and for each game (water year).

In order to simulate the effects of the management actions in our cost-effectiveness analysis, we altered one or more of the six CRiSP.0 input files that contain parameters which represent the effects of the actions. For example, to model the effects on survival of reducing predator populations by twenty percent, as called for in the NPPC's Phase II Amendment (NPPC, 1991a: 27), we reduced the predator multiplier parameter for all species at all projects in the species input file. We also modified the input files to test different assumptions about the efficacy of passage actions and the biological processes at work. For example, we do not know with certainty the flow-mortality relationship for each stock, so we tried two different forms of survival relationships (constant mortality per day and a broken stick model). We ran CRiSP.0 under the two relationships and analyzed the difference in survival. (Table 3.1 displays the relevant input file for each passage action that we modeled, while Chapter 4 discusses the passage management actions in more detail.)

The output of each CRiSP.0 run can provide estimates of survival proportions for fish, separated into groups by stock, species, pool of origin, and/or hatchery verses natural. The model can supply overall system survival for each grouping, as well as pool and dam survivals. We generated only system survivals for each stock of interest, since our primary concern lies with the contribution that each passage strategy makes to fish survival below Bonneville. In each CRiSP 
TABLE 3.1

CRiSP.(1) Input Files

\begin{tabular}{|c|c|c|}
\hline Input File & Description & $\begin{array}{l}\text { Modeled Passage Actions } \\
\text { Affected by Input File }\end{array}$ \\
\hline SAM & $\begin{array}{l}\text { flow volumes at each of } 13 \text { projects by } \\
\text { month, for each water year }\end{array}$ & flow scenarios \\
\hline spill & hours, day, amount, and location of fish spill & none \\
\hline modulate & $\begin{array}{l}\text { ratio of daily average flow to monthly } \\
\text { average flow for each month, at each of } \\
\text { three control points }\end{array}$ & none \\
\hline dam & $\begin{array}{l}\text { powerhouse, sluiceway, and transportation } \\
\text { operation schedules at each project }\end{array}$ & level of transportation \\
\hline species & $\begin{array}{l}\text { control parameters for each species at each } \\
\text { project and pool, flow-travel time survival } \\
\text { relationship (including effects of lower } \\
\text { reservoir elevation, degree of predator } \\
\text { control }\end{array}$ & $\begin{array}{l}\text { predator control, transportation } \\
\text { survival, fish guidance efficiencies }\end{array}$ \\
\hline stock & $\begin{array}{l}\text { timing, location, and number of fish entering } \\
\text { mainstem Snake and Columbia, by stock }\end{array}$ & timing of fish entering mainstem \\
\hline
\end{tabular}


run, we obtained fifty survival values for each stock, corresponding to the 50 games or water years. We use the mean survival over the fifty games for each stock as input to the deterministic life cycle simulation model.

\section{DETERMINISTIC LIFE CYCLE MODEL}

The Deterministic Life Cycle Model (DLCM) developed at RFF simulates the life cycle of anadromous salmon and steelhead. We designed the DLCM so that it not only would mimic the basic factors regulating populations of Pacific salmonids, but also so that it would run relatively fast and require relatively simple set-up procedures. Speed and simplicity are important because the DLCM must simulate the biological effects of nearly 100,000 passage/propagation/terminal harvest alternatives.

We can conceptualize the DLCM as a series of linked compartments corresponding to stages within the life cycle. For any one simulated stock, each life stage requires at least one input from the previous stage and provides at least one output to the subsequent stage; some stages

also may have other outputs (e.g., harvest and hatchery broodstock take). The number of fish alive at each stage during any given year are the state variables of the model. Figure 3.2 provides a schematic representation of how the different life stages connect with one another. We furnish a more detailed description of the DLCM in Appendix A.

The DLCM resembles the System Planning Model (SPM) and other deterministic lifecycle models in basic structure, but it contains less detail in that it does not consider separate age classes. Data inputs to the model include parameters describing the number of eggs spawned per female each year, the proportion of fish surviving from one stage to the next, harvest and broodstock removals, and the proportion of fish surviving from the migrant smolt stage to below Bonneville dam (calculated in CRiSP). The values of all of these parameters depend on the management strategy being simulated. After supplying the input parameter values, we run the DLCM over a planning horizon that will allow the state variables to equilibrate. Model outputs include the number of adults that return to each subbasin, fish caught in the subbasin (terminal) 


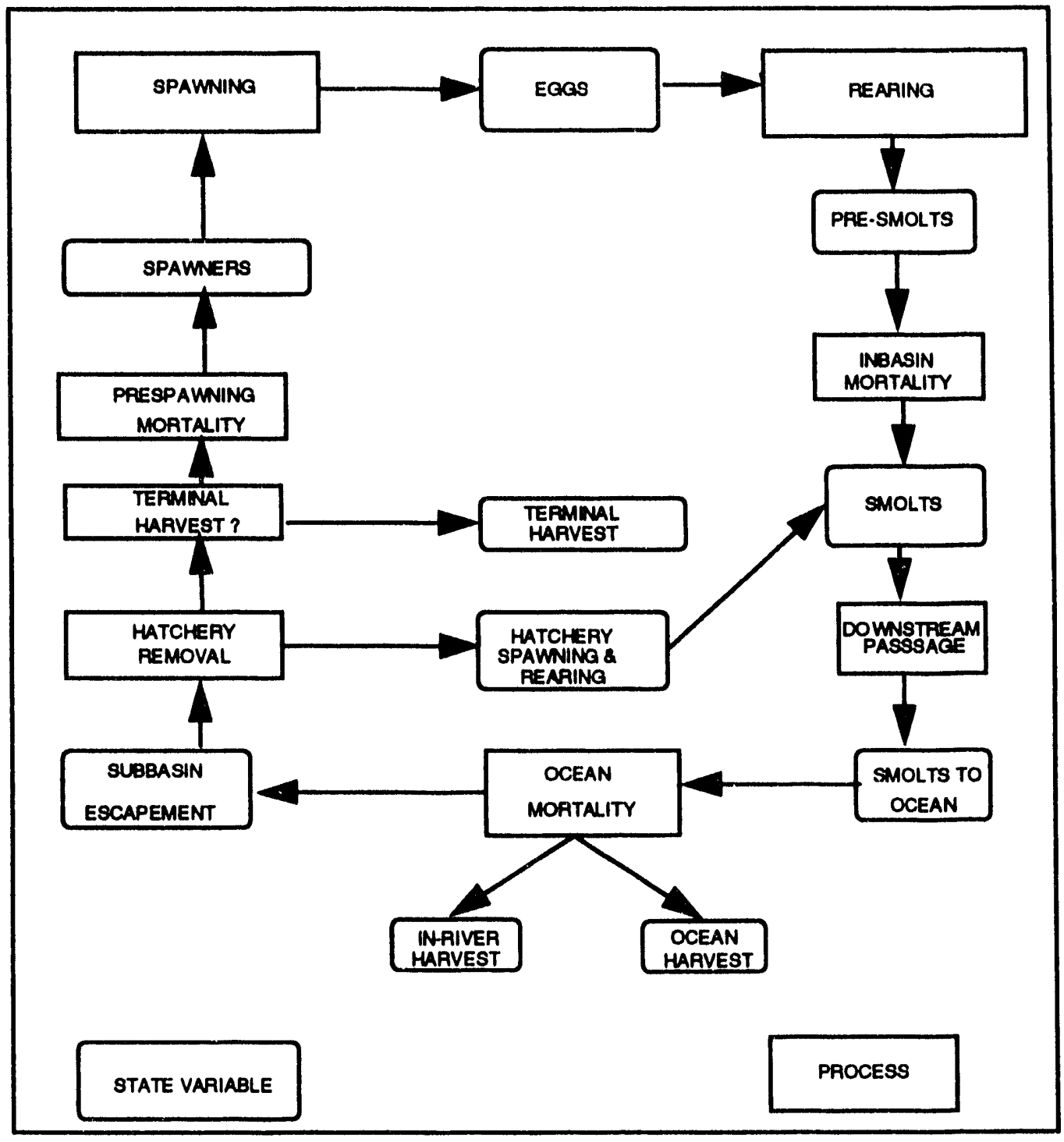

FIGUFE 3.2 : SALMON LIFE CYCLE 
harvest, and spawners, at equilibrium, for each stock. These outputs constitute the measures of effectiveness for each propagation/passage/terminal harvest alternative modeled, and furnish the biological inputs to the System-Wide Optimization Model.

\section{SYSTEM-WIDE OPTIMIZATION MODEL}

The system-wide optimization model processes cost data for propagation and passage actions, and biological outputs from the DLCM, in order to select the system-wide strategy which meets various objectives for each stock at lowest cost. As Chapter 2 points out, a very large number of possible propagation/passage/terminal harvest alternatives that meet the objectives may exist. Since we can not practically sort through the entire set of combinations of alternatives to find the least-cost system-wide strategy in a reasonable amount of time, we have developed a model that relies on linear programming techniques to find the least-cost solution in an efficient manner.

Appendix B describes the system-wide optimization in detail, but a few points merit mention here. First, although a single run of the optimization model identifies only a single leastcost, system-wide strategy (composed of propagation, passage, and terminal harvest alternatives

for all stocks), the model can identify a set of least-cost, system-wide strategies for different levels of fish (a cost-effectiveness frontier) with multiple runs. Each run would entail a different set of objectives. For example, we can perform a series of model runs with the level of the numerical objective in each run set to some proportion of the numerical levels specified in the subbasin plans. In the first run, we may set the objective at 100 percent of the numbers specified in the subbasin plans, in the second run we may set the objective at 80 percent of the numbers specified in the subbasin plans, in the third run 110 percent of the subbasin plans levels, and so forth. Similarly, we can obtain the least-cost strategy for different kinds of objectives with multiple runs. For example, if we wish to identify the least-cost system-wide strategy which will furnish a particular number of fish and will not rely on hatchery production, we can eliminate alternatives which contain hatchery actions and use the optimization model to find the least-cost system-wide 
strategy that remains. This provides an important feature, since it gives the optimization model the capability to look beyond simple tradeoffs between dollars spent and fish numbers.

Second, the system-wide optimization relies integrally on two other models described in this chapter. The System Analysis Model furnishes estimates of the marginal costs of each alternative flow or spill scenario. The Deterministic Life Cycle Model provides the biological effects for the entire set of propagation/terminal harvest/passage alternatives that the optimization model searches through. The set of feasible system-wide strategies (i.e., those system-wide strategies which meet the objectives for all stocks) will come from these alternatives.

Third, the optimization model relies on a database of cost estimates for each propagation, passage, and harvest action. We have not discussed the cost estimates in this chapter, since the estimates are not models themselves, but the reader should note that the optimization model requires an extensive cost data base. Chapter 4 describes the sources and assumptions behind the cost estimates.

Finally, we designed the system-wide optimization model for the explicit purpose of identifying least-cost, system-wide strategies from the set of alternatives supplied by the deterministic life cycle simulation model. As such, the optimization model currently does not present a user-friendly interface with easy-to-follow, click-and-run instructions (in contrast to CRiSP). The concepts and approach in the model reflect straightforward and well-established norms, but we would be doing a disservice to the reader if we gave the impression that the present version of the optimization model is simple to operate.

\section{CONCLUSIONS}

The models outlined in this chapter -- SAM, CRiSP.0, Deterministic Life-Cycle Model, and the System-Wide Cost-Effectiveness Optimization Model -- collectively form the base of our assessment of system-wide strategies for salmon and steelhead recovery planning in the Columbia basin. These models, together with databases containing information on the costs and survival benefits of alternative strategies, provide useful tools for exploring the cost-effectiveness of 
alternative actions and tradeoff's in trying to reach different levels or kinds of objectives.

The models play important roles in their own right, but their real utility in costeffectiveness analysis comes from linking them together. The System Analysis Model provides a means by which we can model the hydrological and economic aspects of alternative flow and spill scenarios. The hydrological outputs from SAM serve as inputs to the flow component of CRiSP.0, which generates the downstream passage survivals for each stock. We use these passage survivals in Deterministic Life Cycle Model, which simulates the life-cycle of salmonids from egg to spawning adult. The results from the deterministic model, together with cost data from SAM and other sources, constitute the inputs for the optimization model, which ultimately allows us to evaluate the cost-effectiveness of alternative strategies.

In Chapter 4, we provide more information on the costs and biological effects of proposed propagation and passage actions, data sources, and our classification of salmon and steelhead stocks. We also discuss the goals, objectives, and constraints that we place in the models. Readers interested in more details on the Deterministic Life Cycle Model and the optimization model should refer to Appendices A and B, respectively. 


\section{CHAPTER 4 \\ DATA INPUTS, ASSUMPTIONS, AND OBJECTIVES}

\section{INTRODUCTION}

The preceding three chapters have laid the groundwork for our system-wide costeffectiveness analysis of passage and propagation actions to enhance salmon and steelhead populations in the Columbia basin. This chapter discusses data inputs, assumptions made to facilitate the analysis, and objectives included in the evaluation. We start with a discussion of the propagation strategies proposed in each subbasin. The section following this discussion describes the passage strategies evaluated in the analysis. We then briefly explain how we incorporated different terminal harvest rates. We follow these discussions of data inputs with a section that addresses some of the major assumptions used in the analysis. We then outline the goals and objectives included in the analysis. The final section presents a brief discussion of sensitivity testing. 1

\section{PROPAGATION STRATEGIES}

Propagation actions can be categorized into four types: hatchery program initiation or expansion, habitat improvement, diversion screening, and barrier removal. The subbasin propagation actions that we analyzed largely come from the subbasin plans developed under the auspices of the Northwest Power Planning Council and the Columbia Basin Fish and Wildlife Authority (Columbia Basin Fish and Wildlife Authority, 1990). The plans delineate the subbasins and stocks of interest, and furnish most of the quantitative information on the costs and biological effects of propagation actions that we include in our analysis. However, we modified the information and analysis presented in the subbasin plans in several ways.

First, we modeled a stock only if it had both numerical objectives associated with it and at least one specific, quantifiable propagation action (with identifiable costs and biological effects) targeted at it. A notable exception to our rule of evaluating only those actions with identifiable

${ }^{1}$ The interested reader can find more extensive documentation on input data in appendices C, D, and $\mathrm{E}$. 
effects and costs involve actions that necessitate the development and use of new water sources (e.g., hatcheries), where we assigned zero cost to the appropriation of the water itself. This assumption may significantly understate the cost of obtaining new water for hatchery programs.

A second modification of the subbasin plans concerns our attempt to evaluate as many realistic combinations of individual propagation actions as possible (each possible combination constitutes a propagation strategy). This differs from the approach of the subbasin planners, who evaluated only a subset of the possible propagation strategie:.

Third, we supplemented the information in some of the subbasin plans with more recent daca. On the biological side, the more-recent data consists of adjusted hatchery plantings to reflect 1989-1990 hatchery releases, provided by the Fish Passage Center (Fish Passage Center, 1991). On the cost side, we made two adjustments. First, we annualized all capital and operation and maintenance costs at a three percent real discount rate. Second, we updated cost estimates of hatchery-production in the mid-Columbia. Hatchery-related costs in all subbasin plans are based on per-pound capital and annual operation/maintenance costs of $\$ 23$ and $\$ 2.50$, respectively. We retained the $\$ 2.50$ per-pound annual operation and maintenance cost assumption, but assigned higher capital costs of $\$ 40$ per-pound (for mid-Columbia stocks only), which lies at the low end of estimates provided by hatchery program funders in the mid-Columbia (Klinge, 1991; Nason, 1991).

Finally, we did not evaluate the cost-effectiveness of a number of actions proposed in the subbasin plans that the region has implemented or decided to implement since publication of the plans. We consider any action that has been completed, initiated, or has gone out for final bid and been budgeted for as a sunk cost and therefore an action that forms part of every propagation strategy. For example, we included actions agreed upon in the mid-Columbia PUD Settlement Agreements in all propagation strategies, and thus did not evaluate whether those actions are cost-effective.

Table D.1 and Table D.2 in the appendices present the costs and biological effects of the propagation actions for each stock. Combinations of actions have costs that are the sum of the 
costs of individual actions, and biological effects that are the product or the sum of the effects of each individual action. For example, the combination of habitat enhancement and groundwater channels for Methow spring chinook, which contribute a 0.1 increase and a 0.2 increase in eggsmolt survival and cost $\$ 1,266$ and $\$ 21,660$, respectively, produces a strategy that costs $\$ 22,926$ and contributes a $0.32([1.1 \times 1.2]-1.0)$ increase in egg-smolt survival.

\section{PASSAGE STRATEGIES}

The passage strategies that we analyzed consist of combinations of flow modification, smolt transportation, and predator control. For each set of assumptions that we made regarding the efficacy of passage actions, ${ }^{2}$ we modeled at least nine passage strategies. (For one set of assumptions, we included ten passage strategies.) Table 4.1 presents general information on the passage actions included in each of the passage strategies.

The reader should keep several points in mind when viewing Table 4.1. First, the passage strategy labeled CASE00 represents a special passage condition that we used solely for the purpose of calibrating the Deterministic Life Cycle Model (DLCM). It does not represent a separate alternative for evaluation in the cost-effectiveness analysis. Rather, it depicts passage conditions in the mid-1970s to the early-1980s, which corresponds to the time span for which we have actual runsize data. We modeled CASE00 in CRiSP.0 under one set of assumptions (see note 2), input the resulting downstream passage survivals for each stock into the DLCM, and compared the DLCM-generated run size figures with actual run size data, in order to estimate the value of a DLCM parameter that captures natural mortality attributable to the adult phase of the life cycle. ${ }^{3}$ Once calibrated with CASEO0, the adult natural mortality parameter in question

\footnotetext{
${ }^{2}$ We modeled each passage strategy under a number of different scenarios. Each scenario involves a different set of assumptions regarding transportation survival, predator control effectiveness, and the efficiency of fish guidance systems. See the section on sensitivity testing in this chapter for further details.

${ }^{3}$ The calibration case differs from other cases in the CRiSP.0 files that contain: 1) SAMgenerated $: ;$ ws; 2 ) modulator values to shape monthly average flows from SAM to daily average flows; 3) spill levels and timing at each project; and 4) dam and transportation operation schedules. Most of the parameters that represent different survival characteristics by species (in
} 
TABLE 4.1

Passage Strategies Modeled in Cost-Effectiveness Analysis

\begin{tabular}{cccc}
\hline $\begin{array}{c}\text { STRATEGY } \\
\text { NUMBER }\end{array}$ & FLOWS & $\begin{array}{c}\text { PREDATOR } \\
\text { CONTROL }\end{array}$ & TRANSPORTATION \\
$\begin{array}{c}\text { CASE00 } \\
\text { (calibration) } \\
\text { CASE01 }\end{array}$ & historical & none & historical \\
CASE02 & current & none & partial \\
CASE03 & NPPC Phase II & none & partial \\
CASE04 & current & none & full \\
CASE05 & NPPC Phase II & high & full \\
CASE06 & current & high & partial \\
CASE07 & NPPC Phase II & high & partial \\
CASE08 & current & high & full \\
CASE09* & NPPC Phase II & none & full \\
\hline
\end{tabular}

*We modeled CASE09 for only the average fish guidance efficiency, average transportation survival sets of assumptions. See discussion in sensitivity analysis section.

the CRiSP.0 species file) remain identical for the calibration and other cases, although fish guidance efficiencies differ for some projects (see Table E.1 in Appendix E). 
remains constant for all passage strategies, as long as we do not vary our assumptions about the efficacy of passage actions and the life history parameters of salmonids. For each different set of assumptions, however, we re-calibrate and generate a new adult natural mortality parameter.

Second, the passage strategy CASE01 represents a base case strategy, which reflects passage conditions that exist in 1992 , or which we assume will be in place in the next five years absent any change in plans due to NPPC actions. The base case strategy thus includes existing flow conditions; current bypass facilities plus bypass installation at Lower Monumental, The Dalles, and all mid-Columbia projects; long screens at Lower Granite, Little Goose, and McNary; improvements in screening at the second powerhouse at Bonneville; and continued smolt transportation at Lower Granite, Little Goose, and McNary, plus transportation at Lower Monumental. Sherer and Fisher (1991) provide estimates for most of the CRiSP.0 parameter values to represent these base case conditions.

Third, the limited amount of data that depict different system operation characteristics necessarily restricted the range of passage scenarios that we could model. For example, different flow scenarios require SAM runs, and at the time of the analysis we possessed only two useful SAM files to use as input in CRiSP.0. These SAM files represent current flows (1991 power year with fifty years of water record) and flows proposed by the Northwest Power Planning Council (1991a) under the Phase II amendments to the Fish and Wildlife Program. To complicate matters, in order to maintain compatibility with these SAM files, we could not model spill that differed from the level and timing of spill specified in the current memorandum of agreement on spill. 4 Additionally, we could analyze only a very limited version of drawdowns (decreases in the elevation of reservoirs in order to decrease water particle travel times) and this only by modeling corresponding flow levels which would produce equivalent water particle travel times. We could not investigate the Idaho drawdown plan and our treatment of drawdowns (e.g., in the John Day

\footnotetext{
${ }^{4}$ If we had altered the CRiSP.0 input file responsible for controlling spill, the CRiSP.0 SAM input file would not have reflected the change in spill (i.e., the regulated flows and revenue requirements would not have included the effects of the altered spill).
} 
pool) that rests on the flow-equivalent approach may bias the results in an unknown direction. Furthermore, since we possess cost data only for two levels of predator control (no predator control and high predator control), we could analyze only these two levels. Finally, while we could have evaluated a wide range of transportation levels since we can easily control transportation levels in the relevant CRiSP.0 input files, we modeled only three levels -- full transportation of all smolts at all transportation projects at all times, partial transportation (only sub-yearlings are targeted), and no transportation -- due to time constraints. However, these three levels should bracket the realistic range of transportation efforts, at least in the short-run.

Fourth, our estimates of both the effects and the costs for the passage actions that we modeled rest on limited information. As we noted in Chapter 3, SAM provides an estimate of the marginal revenue requirement of the alternative flow scenario (the difference in revenue requirements between current flow conditions and the Phase II Amendment flows). Estimates of the costs and effects of predator control come from the Northwest Power Planning Council (NPPC, 1991b: 16, 3-3). We assume that the marginal transportation costs of full transportation equal zero, since the U.S. Army Corps of Engineers will need no new barges or facilities (beyond the base case) for full transportation. ${ }^{5}$ Estimates of the effects of transportation come from Sherer and Fisher (1991). Transport-benefit ratios (TBRs) calculated from CRiSP.0 runs vary by stock, project, and passage alternative, but averages for yearlings, sub-yearlings, and steelhead across all projects and all strategies are 1.14, 1.49, and 1.23, respectively (for the fish guidance efficiencies and transportation survivals assumed in Sherer and Fisher). Table 4.2 presents species-specific ranges of model-derived TBRs (across eight passage strategies) at each transportation project. These TBR estimates generally lie slightly below those estimates used in the System Planning Model (McConnaha, 1991a, McConnaha, 1991b), and thus reflect less optimism about the relative effectiveness of transportation.

${ }^{5}$ Collection and barging from Lower Monumental may slightly increase the operating costs of the six barges and five trucks currently used. We ignored this possible additional operating cost, since it is likely to be small. We included, however, an annual $\$ 500,000$ plus savings gained from eliminating transport in CASE09. (Woodruff, 1992) 
TABLE 4.2

Range in Transport-Benefit Ratios at Each Transportation Project, By Species

\begin{tabular}{lllll}
\hline SPECIES & GRANITE & GOOSE & MONUMENTAL & MCNARY \\
yearling & $1.11-1.32$ & $1.12-1.35$ & $1.02-1.33$ & $0.85-1.09$ \\
subyearling & $1.46-1.49$ & $1.79-1.81$ & $1.38-1.39$ & $1.28-1.35$ \\
steelhead & $1.11-1.28$ & $1.17-1.37$ & $1.11-1.34$ & $1.11-1.48$ \\
\hline
\end{tabular}

*We calculated the range of TBRs over eight passage strategies, assuming average fish guidance efficiency, average transportation survival, and optimistic predator control effectiveness. 


\section{TERMINAL HARVEST 6}

As discussed in Chapter 3, we theoretically could model up to twelve stocks in each subbasin: the three types of stocks possible in each subbasin and fish run (natural stock, supplementation stock, and pure hatchery stock) for each of the four fish runs that we investigated (spring chinook, summer chinook, fall chinook, and steelhead). We furnished a separate parameter for the terminal harvest rate for each of these stocks, although we forced many of the rates within each fish run to be the same. In the calibration case, for example, the values for the terminal harvest rate for the three types of stocks possible (natural, supplementation, and pure hatchery) for each species and fish run could be equivalent if we could not distinguish hatchery-bred fish from naturally-produced fish with the run size data. In cases where we could distinguish the natural stock (e.g., steelhead), the calibration-case rates usually differed for the natural stock relative to the other two stocks.

When we ran the Deterministic Life Cycle Model to produce the estimates of effectiveness for each passage/propagation strategy, we allowed all of the terminal harvest rates for the separate subbasins and fish runs to vary independently from 0 to 80 percent in 20 percent increments. However, we generally did not aliow the terminal harvest rates for the three types of stocks possible in each subbasin and fish run (natural stocks, supplementation stocks, and hatchery stocks of Grande Ronde spring chinook, for example) to differ. If we had varied the terminal harvest rates for each of the three types of stocks independently, we would have had to run up to 125 combinations of harvest rates when all three types of stocks existed in the subbasin.

We justify this approach by making three simplifying assumptions. First, in most cases where a pure hatchery stock and supplementation stock coexist in the same subbasin, we assumed that they are subject to the same terminal fishery and thus share the same terminal harvest rate.

\footnotetext{
${ }^{6}$ We treat terminal harvest differently than we do propagation and passage actions in that the range of possible terminal harvest rates that we model does not represent any proposed action. Obviously, terminal harvest rates theoretically can be as low a 0 percent and as high as 100 percent. We provide a range of harvest rates for the model to evaluate, and assume that the cost of "implementing" a terminal harvest rate is zero.
} 
Second, in some cases we assumed that the terminal harvest rate on natural fish is zero. This assumption seems safest if the region has accorded priority to the rebuilding of the natural stock and hatchery-bred fish exist in sufficient quantities for harvest. Third, if the run size data indicate equivalent terminal harvest rates among the two or more types of stocks in the calibration case, we assumed that the terminal harvest rates in the cases where we modeled passage strategies also varied together.

\section{MAJOR ASSUMPTIONS}

During the development of the database of passage and propagation actions and the subsequent modeling exercise, we made a number of important assumptions about the costs and effectiveness of actions and about the characteristics of the life-cycles of salmonids. We have remarked on some of the assumptions in the preceding sections, but it is useful to reiterate some of these and note other major assumptions here.

Our most obvious kind of assumption relates to the values of model parameters and the biological effects and financial costs of the propagation and passage actions. For the most part, we accepted the estimates of the values (e.g., effectiveness of habitat improvement, cost of predator control) and relationships (e.g., the form of the flow-survival relationship for downstream passage) reported in regional planning documents. Whether our estimates accurately reflect reality poses a question that we cannot answer at present, although we made a limited attempt to assess the importance of parameter uncertainty in our sensitivity analysis.

On the passage side, some of the most important assumptions to bring to the reader's attention include the form and parameterization of the travel time-flow-survival relationship for downstream passage (see Table E.1); the timing and distribution of the arrival of each stock's

smolts to the mainstem (see table E.2); and the shaping of monthly average flows from SAM into daily average flows by the CRiSP.0 modulator file (we use only a single modulator file from 1990). On the propagation side, important premises include our assumptions that (1) the Beverton-Holt spawner-recruit relationships we use depict the actual spawner-recruit 
relationship; ${ }^{7}$ (2) we can logically separate hatchery and supplementation stocks based on the criteria that out-planted hatchery smolts (i.e., smolts that hatchery managers plant in tributaries away from the hatchery) constitute supplementation stocks, while smolts released directly from the hatchery constitute hatchery stocks; and (3) no net straying occurs among hatchery, supplementation, and natural stocks.

We also assumed that the immediate effects of propagation actions do not depend directly on passage actions or on each other, and that the immediate effects of passage actions do not depend on each other. ${ }^{8}$ The ultimate biological effect of any action may be influenced by other actions and thus the desirability of an action may depend very integrally on what other actions the region implements, ${ }^{9}$ but the immediate, direct effect of any given action does not depend on whether the region undertakes other actions. ${ }^{10}$

Furthermore, we assumed that the effects of an action do not vary over the projected life of that action. We posited that the region will implement propagation actions once, at time zero, and that the actions' effects will remain constant throughout the planning horizon evaluated in the analysis. We also assumed that the region will take passage actions at time zero and passagerelated operating conditions for each strategy (e.g., power demand characteristics and nonenvironmental passage conditions such as the level of transportation and fish guidance

\footnotetext{
7Previous modeling exercises with the Northwest Power Planning Council's System Planning Model also used the Beverton-Holt relationship.

${ }^{8}$ We sometimes needed to adjust a strategy's effectiveness so that it did not double count the biological effects or costs of two component actions which overlapped in part. For example, in some cases the subbasin plans presented two separate habitat enhancement actions which differed in large part but entailed habitat improvements in some of the same tributary streams. In such cases, we adjusted downwards the effectiveness and costs of any strategy for the subbasin that included both actions.

${ }^{9}$ For example, the effects of a passage action taken in generation $t$ on the number of smolts in generation $\mathrm{t}+1$ may depend on whether the region takes some action to increase carrying capacity in the relevant subbasin.

${ }^{10} \mathrm{An}$ apparent exception to this rule is that predator control contributes relatively less survival improvement with Council flows than with current flows. However, this reflects the difference in travel times between Council and current flows, and not a direct effect of predator control per se.
} 
efficiencies) will remain constant over the planning horizon. ${ }^{11}$ We further assumed that the region must take an action either in its entirety or not at all (e.g., the region can choose to either improve a subbasin's habitat or not to improve it, but it can not choose to improve only some habitat, unless such an activity constitutes an entirely separate action proposed in the subbasin plans).

We also made some general assumptions about the feasibility of implementing actions and the desirability of the stated objectives. We assumed that staff, equipment, technology, and funds exist in sufficient quantity to implement actions at time zero, and that harvest managers can set harvest rates and control harvest accordingly. We took the utilization and biological objectives stated in the subbasin plans at face value, or in cases such as the Salmon River subbasins we calculated disaggregated objectives from information in the subbasin plans. This implies an equal weighting of the subbasin planners' objectives for each stock, which may not accurately reflect the concern with critical stocks.

Finally, we assumed that the value for the DLCM parameter that represents adult natural mortality (i.e., unknown mortality that we attribute to the adult phase of the life cycle), which we estimated when we calibrated the life-cycle model to run size data from the 1970s and 1980s, remains constant across all years and passage strategies. Thus, if we calculated an adult natural mortality value of 10 percent from the run size data, we assumed the same 10 percent value in all model runs. This stands out as a critical assumption. It means that our calibration run had to reflect assumptions that we made about the efficacy of current processes or management actions, if the processes or actions also existed during the 1970s and 1980s (e.g., bypass systems, barge transportation of smolts). Thus, for instance, if we wanted to model the robustness of our results to an assumption that fish guidance efficiencies (fge) of bypass systems lie 25 percent lower than

\footnotetext{
11 Our simulations with the downstream passage model reflect the assumption that passage actions are implemented immediately and that their efficacy remains constant over the planning horizon. We provide 50 years of water record in each run of the simulation model in order to generate a distribution of survival values, but we model only one power year (1991) for each of those fifty water years. We use the mean of the 50 passage survivals from the passage simulation for each year of the planning horizon that we model in the Deterministic Life Cycle Model.
} 
we normally assumed, we first had to recalibrate the model to reflect the lower fge assumption; that is, if we introduced more mortality in the calibration run, the parameter that represents the unknown adult natural mortality had to increase in order to yield the observed run size data. When we incorporated the new adult natural mortality parameter value in a current management scenario, this tended to dampen the negative effects associated with the lower fge assumption. In other words, the relative efficacy of management strategies from model runs does not change as readily in response to different assumptions about the efficacy of passage actions as one might initially expect. Of course, this result derives from the fact that we set the adult natural mortality parameter value equal to the adult natural parameter value calculated in calibration model runs that represents conditions 15 to 20 years ago.

\section{GOALS AND OBJECTIVES}

We developed the system-wide cost-effectiveness analysis in order to find the set of passage, propagation, and terminal harvest alternatives which will meet a set of defined objectives at lowest cost. The objectives represent stock-specific numerical targets, which reflect the biological and utilization objectives specified in each subbasin plan. ${ }^{12}$ For some stocks, we could not achieve the biological and/or utilization objectives with any strategy. In such cases, we reduced the objectives until it became feasible to meet them. We include details on numerical objectives for each stock in Chapter 5.

In addition to evaluating the trade-offs between costs and different levels of spawning escapement and terminal harvest, we also considered other possible goals and constraints of the fish and wildlife program. For example, program managers may be reluctant to rely on hatchery production to augment a weak stock, because of the potential genetic risk associated with hatchery-dominant programs. We attempted to address this concern by first assessing the genetic risk of propagation actions, ranking them on a simple zero to two scale, with a zero indicating no

\footnotetext{
${ }^{12}$ We express biological objectives as average annual spawning escapement levels for each stock, and utilization objectives as terminal harvest levels (sport and tribal) for each stock.
} 
modeled, for all strategies, both this fifty percent reduction and a less-optimistic twenty-five percent reduction.

Finally, we also explored assumptions about the fish guidance efficiencies of bypass systems. We used the anticipated fish guidance efficiencies reported in Sherer and Fisher (1991) as a base case, but also modeled a twenty-five percent drop in fish guidance efficiencies at all projects for all passage strategies.

\section{CONCLUSIONS}

The system-wide cost-effectiveness analysis of mitigation and recovery options in the Columbia basin requires a tremendous amount of data on the costs and biological effects of passage and propagation actions. We obtained most of these data from the subbasin plans developed in the region and the planning documents from the Phase II amendments to the region's fish and wildlife program. Parameter values for the downstream passage model come from CRiSP.0 documentation and analyses conducted by the researchers at the Bonneville Power Administration.

In addition, we have had to make a number of assumptions in order to make the analysis tractable. We have provided documentation on some of the major assumptions in this chapter. Finally, the subbasin planning documents provide the subbasin escapement and terminal harvest objectives that we modeled. However, because the subbasin planners' objectives are somewhat arbitrary, and because decision-makers may want to explore the tradeoffs of different objectives and the cost of attaining them, we varied the escapement and harvest objectives over a wide range in our analysis. We present our results in the next chapter. 


\section{CHAPTER 5 \\ OPTIMIZATION MODEL GOALS AND RESUL'TS}

\section{INTRODUCTION}

This chapter examines results from our application of the optimization model. Given the limits of the existing data and our incomplete understanding of the dynamics of salmonid populations, we believe strongly that the model provides reasonable and justifiable results. However, we recognize that our approach adopts some arguable assumptions about the efficacy of recovery actions and the behavior of salmonids. Thus, we portray our results as suggestive of general outcomes and illustrative of the possible applications of the optimization model rather than as certain conclusions. To re-iterate a point made in earlier chapters, we developed the model to help decision-makers examine trade-offs among passage and propagation costs, fish production measures, and attributes of fish stocks, and not to provide unambiguous answers as to how they should proceed.

We start with a general discussion of objectives and a quick purview of the results. We next move to a lengthy treatment of results from the model runs in which we tried to achieve 100 percent of the stock and subbasin harvest and subbasin escapement objectives which the subbasin plans specify. We then examine the cost-effectiveness frontiers developed from varying the harvest and escapement objectives over a range of values. We conclude with some brief comments on major points of the analysis.

\section{OBJECTIVES}

The subbasin planners established numerical objectives for terminal harvest and natural spawning escapement for each species and run. In many subbasins, we could not determine unambiguously how to establish the separate objectives for hatchery, natural, and supplementation stocks, so we compromised by using two objectives for each subbasin/species combination: one objective for combined terminal harvest (encompassing all of the three types of stocks of the same subbasin/species combination), and one objective for natural spawning escapement. We display our interpretation of the objectives in Table 5.1. We attempted to base the objectives as closely 
as possible on the planners' apparent intent, but our numerical objectives probably do not reflect their goals in all cases.

In many cases, the model results suggest that no strategy can meet the numerical objectives for harvest and escapement. ${ }^{1}$ Table 5.2 highlights this by showing the percentage of the planners' numerical objective achieved in the modeling exercise for each species in each subbasin. For example, for Clearwater spring chinook, we could attain the numerical objectives for both harvest and spawning escapement in the model, while for summer chinook on the South Fork of the Salmon River, we could reach only 50 percent of the numerical objective for terminal harvest $(18,000$, from Table 5.1) and 24 percent of the numerical objective for natural spawning $\left(5,760\right.$, from Table 5.1). ${ }^{2}$

We also considered different ways to double the base-case runsize for each stock. In a similar fashion to our efforts with the harvest and escapement objectives, we formulated objectives for each subbasin and run, for natural and hatchery fish combined, and for natural fish only. We define doubling as an increase from the base-case runsize for each subbasin/species combination of 100 percent, where runsize equals the total of all harvest (ocean, in-river, and terminal) plus spawning escapement. Table 5.3 exhibits our interpretation of the numerical objectives associated with doubling the runsize for each stock. As with the terminal harvest and escapement objectives, the results of our modeling indicate that many stocks could not meet their runsize objectives. Table 5.4 shows the percentage of the numerical objective associated with

\footnotetext{
${ }^{1}$ While the flow regime in the NPPC Phase II amendments produces slightly more fish than the current (89-90) flow regime for some stocks, the difference is very small, and does not affect the conclusion that the modeled terminal harvest and/or spawning escapement sometimes falls far short of the planners' objectives.

${ }^{2}$ It is important to emphasize that once we establish the terminal harvest and spawning escapment numerical objectives that at least one passage/propagation/terminal harvest alternative can meet for each stock, we define these numerical objective as the 100 percent level. Therefore, in the subsequent discussion, our definition of the 100 percent level will differ from the planners' 100 percent level for those stocks for which we had to reduce the numerical objective in order to find a feasible solution.
} 
TABLE 5.1

Subbasin Planners' Terminal Harvest and Spawning Escapement Numerical Objectives**

\begin{tabular}{lrlrrrrrr}
\hline Subbasin & FAC* & FAC* & SPC* & SPC* & SSH* & SSH* & SUC* & SUC* \\
& Harv & Spawn & Harv & Spawn & Harv & Spawn & Harv & Spawn \\
Clearwater & 0 & 0 & & & & & & \\
Deschutes & 0 & 0 & 45000 & 5000 & 74000 & 12000 & 0 & 0 \\
Entiat & 4500 & 6500 & 6750 & 1950 & 8000 & 10000 & 0 & 0 \\
Grande Ronde & 0 & 0 & 500 & 0 & 0 & 0 & 0 & 0 \\
Hood River & 0 & 0 & 4000 & 10140 & 9050 & 17400 & 0 & 0 \\
Imnaha & 190 & 125 & 1300 & 200 & 4600 & 2400 & 0 & 0 \\
John Day & 0 & 0 & 700 & 3800 & 0 & 0 & 0 & 0 \\
Klickitat & 0 & 0 & 1050 & 2975 & 11250 & 16875 & 0 & 0 \\
Little White & 0 & 0 & 3015 & 494 & 3920 & 2256 & 0 & 0 \\
Methow & 200 & 3700 & 2000 & 202 & 0 & 0 & 0 & 0 \\
Okanogan & 0 & 0 & 2000 & 3200 & 0 & 0 & 3000 & 1458 \\
Bear V. (Salmon) & 0 & 0 & 0 & 0 & 0 & 0 & 2000 & 5830 \\
Lemhi R. (Salmor) & 0 & 0 & 16000 & 4500 & 0 & 0 & 0 & 0 \\
Lower Salmon & 0 & 0 & 10000 & 1978 & 12000 & 686 & 0 & 0 \\
Mid-Salmon & 0 & 0 & 6000 & 330 & 10000 & 664 & 0 & 0 \\
Panther C. (Salmon) & 0 & 0 & 12000 & 350 & 2000 & 1306 & 0 & 0 \\
Phsimroi R. (Salmon & 0 & 0 & 0 & 0 & 8000 & 58 & 4000 & 118 \\
S. Fork Salmon & 0 & 0 & 0 & 0 & 33000 & 209 & 7000 & 175 \\
Little Salmon & 0 & 0 & 0 & 0 & 4000 & 1560 & 18000 & 5760 \\
Upper Salmon & 0 & 0 & 10000 & 805 & 22000 & 832 & 0 & 0 \\
Tucannon & 0 & 0 & 30000 & 3018 & 33000 & 4656 & 15000 & 670 \\
Umatilla & 0 & 0 & 1152 & 357 & 700 & 1500 & 0 & 0 \\
Wind River & 5400 & 12500 & 8800 & 1760 & 2730 & 3370 & 0 & 0 \\
Wenatchee & 0 & 0 & 5000 & 984 & 1000 & 1557 & 0 & 0 \\
White Saimon & 0 & 0 & 9150 & 5250 & 0 & 0 & 3000 & 5600 \\
Walla Walla & 0 & 0 & 500 & 96 & 2400 & 60 & 0 & 0 \\
\hline & 0 & 0 & 2441 & 2000 & 7680 & 3000 & 0 & 0 \\
\hline
\end{tabular}

*FAC, SPC, SSH, and SUC are fall chinook, spring chinook, summer steelhead, and summer chinook, respectively

**See text for explanation of termunal harvest and spawning escapment objectives 
TABLE 5.2

Percentage of Planners' Terminal Harvest and Spawning Escapement Numerical Objectives Met By the Optimization Model**

\begin{tabular}{|c|c|c|c|c|c|c|c|c|}
\hline Subbasin & $\begin{array}{l}\text { FAC* } \\
\text { Harv }\end{array}$ & $\begin{array}{l}\text { FAC* } \\
\text { Spawn }\end{array}$ & $\begin{array}{l}\text { SPC* } \\
\text { Harv }\end{array}$ & $\begin{array}{l}\text { SPC* } \\
\text { Spawn }\end{array}$ & $\begin{array}{l}\text { SSH* } \\
\text { Harv }\end{array}$ & $\begin{array}{l}\text { SSH* } \\
\text { Spawn }\end{array}$ & $\begin{array}{l}\text { SUC* } \\
\text { Harv }\end{array}$ & $\begin{array}{l}\text { SUC* } \\
\text { Spawn }\end{array}$ \\
\hline Clearwater & 0 & 0 & 100 & 100 & 100 & 100 & 0 & 0 \\
\hline Deschutes & 100 & 100 & 100 & 100 & 100 & 100 & 0 & 0 \\
\hline Entiat & 0 & 0 & 100 & 0 & 0 & 0 & 0 & 0 \\
\hline Grande Ronde & 0 & 0 & 100 & 49 & 100 & 100 & 0 & 0 \\
\hline Hood River & 50 & 100 & 100 & 100 & 100 & 100 & 0 & 0 \\
\hline Imnaha & 0 & 0 & 100 & 25 & 0 & 0 & 0 & 0 \\
\hline John Day & 0 & 0 & 100 & 100 & 100 & 100 & 0 & 0 \\
\hline Klickitat & 0 & 0 & 100 & 100 & 50 & 100 & 0 & 0 \\
\hline Little White & 100 & 50 & 100 & 100 & 0 & 0 & 0 & 0 \\
\hline Methow & 0 & 0 & 100 & 100 & 0 & 0 & 100 & 100 \\
\hline Okanogan & 0 & 0 & 0 & 0 & 0 & 0 & 100 & 100 \\
\hline Bear V. (Salmon) & 0 & 0 & 50 & 50 & 0 & 0 & 0 & 0 \\
\hline Lemhi R. (Salmon) & 0 & 0 & 50 & 50 & 50 & 50 & 0 & 0 \\
\hline Lower Salmon & 0 & 0 & 100 & 100 & 100 & 100 & 0 & 0 \\
\hline Mid-Salmon & 0 & 0 & 50 & 100 & 100 & 100 & 0 & 0 \\
\hline Panther C. (Salmon) & 0 & 0 & 0 & 0 & 100 & 100 & 100 & 100 \\
\hline Phsimroi R. (Salmon) & 0 & 0 & 0 & 0 & 100 & 100 & 100 & 100 \\
\hline S. Fork Salmon & 0 & 0 & 0 & 0 & 100 & 100 & 50 & 24 \\
\hline Little Salmon & 0 & 0 & 100 & 100 & 100 & 100 & 0 & 0 \\
\hline Upper Salmon & 0 & 0 & 100 & 100 & 100 & 100 & 50 & 50 \\
\hline Tucannon & 0 & 0 & 100 & 100 & 100 & 100 & 0 & 0 \\
\hline Umatilla & 100 & 100 & 100 & 100 & 100 & 100 & 0 & 0 \\
\hline Wind River & 0 & 0 & 100 & 100 & 100 & 51 & 0 & 0 \\
\hline Wenatchee & 0 & 0 & 100 & 100 & 0 & 0 & 100 & 100 \\
\hline White Salmon & 0 & 0 & 100 & 100 & 100 & 100 & 0 & 0 \\
\hline Walla Walla & 0 & 0 & 100 & 100 & 100 & 100 & 0 & 0 \\
\hline
\end{tabular}

*FAC, SPC, SSH, and SUC are fall chinook, spring chinook, summer steelhead, and summer chinook, respectively

**See text for explanation of terminal harvest and spawning escapment objectives 
TABLE 5.3

Runsize Numerical Objectives***

\begin{tabular}{|c|c|c|c|c|c|c|c|c|}
\hline Subbasin & $\begin{array}{l}\text { FAC** } \\
\text { runsize } \\
\text { (both*) }\end{array}$ & $\begin{array}{l}\text { FAC** } \\
\text { runsize } \\
\text { (natural) }\end{array}$ & $\begin{array}{l}\text { SPC** } \\
\text { runsize } \\
\text { (both*) }\end{array}$ & $\begin{array}{l}\text { SPC** } \\
\text { runsize } \\
\text { (natural) }\end{array}$ & $\begin{array}{l}\text { SSH** } \\
\text { runsize } \\
\text { (both*) }\end{array}$ & $\begin{array}{l}\mathrm{SSH}^{* *} \\
\text { runsize } \\
\text { (natural) }\end{array}$ & $\begin{array}{l}\text { SUC** } \\
\text { runsize } \\
\text { (both*) }\end{array}$ & $\begin{array}{l}\text { SUC** } \\
\text { runsize } \\
\text { (natural) }\end{array}$ \\
\hline Clearwater & 0 & 0 & 21853 & 6466 & 156549 & 18390 & 0 & 0 \\
\hline Deschutes & 108741 & 108741 & 28412 & 18051 & 89500 & 16883 & 0 & 0 \\
\hline Entiat & 0 & 0 & 8836 & 7152 & 0 & 0 & 0 & 0 \\
\hline Grande Ronde & 0 & 0 & 7999 & 4430 & 30158 & 17714 & 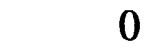 & 0 \\
\hline Hood River & 3043 & 3043 & 3196 & 930 & 16094 & 9215 & 0 & $\mathbf{0}$ \\
\hline Imnaha & 0 & 0 & 3615 & 2475 & 0 & 0 & 0 & 0 \\
\hline John Day & 0 & 0 & 14796 & 14796 & 71486 & 71486 & 0 & 0 \\
\hline Klickitat & 0 & 0 & 13543 & 4579 & 14335 & 12432 & 0 & 0 \\
\hline Little White & 37980 & 922 & 6001 & 142 & 0 & 0 & 0 & 0 \\
\hline Methow & 0 & 0 & 12282 & 9321 & 0 & 0 & 86253 & 70377 \\
\hline Okanagan & 0 & 0 & 0 & 0 & 0 & 0 & 98183 & 70804 \\
\hline (Salmon) & 0 & 0 & 3349 & 3349 & 0 & 0 & 0 & 0 \\
\hline Lemhi R. (Salmon) & $\mathbf{0}$ & 0 & 559 & 559 & 2371 & 2371 & . & 0 \\
\hline Lower Salmon & 0 & 0 & 125 & 125 & 11388 & 2296 & 0 & 0 \\
\hline Mid-Salmon & 0 & $\mathbf{0}$ & 425 & 425 & 4502 & 4502 & $\mathbf{0}$ & 0 \\
\hline Panther & 0 & 0 & 0 & 0 & 305 & 305 & 18 & 18 \\
\hline Phsimroi R. (Salmon) & $\mathbf{0}$ & 0 & 0 & 0 & 7967 & 726 & 15690 & 65 \\
\hline S. Fork Salmon & 0 & 0 & 0 & 0 & 2485 & 2485 & 16448 & 1207 \\
\hline Little Salmon & 0 & 0 & 39682 & 263 & 14301 & 4206 & 0 & 0 \\
\hline Upper Salmon & 0 & 0 & 36215 & 1911 & 62843 & 15052 & 482 & 482 \\
\hline Tucannon & 0 & $\mathbf{0}$ & 5677 & 2447 & 4233 & 1511 & 0 & 0 \\
\hline Umatilla & 329314 & 147777 & 16662 & 2090 & 6894 & 4491 & 0 & 0 \\
\hline Wind River & 0 & 0 & 11491 & 608 & 2688 & 742 & 0 & 0 \\
\hline Wenatchee & 0 & 0 & 45041 & 17780 & 0 & 0 & 172134 & 140776 \\
\hline White & 0 & 0 & 429 & 144 & 13839 & 228 & 0 & 0 \\
\hline Walla Walla & 0 & 0 & 5019 & 5019 & 18266 & 10467 & 0 & 0 \\
\hline
\end{tabular}

*Both refers to combined objectives for natural and hatchery stocks.

**FAC, SPC, SSH, and SUC are fall chinook, spring chinook, summer steelhead, and summer chinook, respectively

***See text for explanation of runsize doubling objectives 
TABLE 5.4

Percentage of Runsize Numerical Objectives Met by Optimization Model****

\begin{tabular}{|c|c|c|c|c|c|c|c|c|}
\hline Subbasin & $\begin{array}{l}\text { FAC** } \\
\text { runsize } \\
\text { (both*) }\end{array}$ & $\begin{array}{l}\text { FAC** } \\
\text { runsize } \\
\text { (natural) }\end{array}$ & $\begin{array}{l}\text { SPC** } \\
\text { runsize } \\
\text { (both*) }\end{array}$ & $\begin{array}{l}\text { SPC** } \\
\text { runsize } \\
\text { (natural) }\end{array}$ & $\begin{array}{l}\text { SSH** } \\
\text { runsize } \\
\text { (both*) }\end{array}$ & $\begin{array}{l}\text { SSH** } \\
\text { runsize } \\
\text { (natural) }\end{array}$ & $\begin{array}{l}\text { SUC** } \\
\text { runsize } \\
\text { (both*) }\end{array}$ & $\begin{array}{l}\text { SUC** } \\
\text { runsize } \\
\text { (natural) }\end{array}$ \\
\hline Clearwater & 0 & 0 & 100 & 100 & 64 & 76 & 0 & 0 \\
\hline Deschutes & 100 & 100 & 100 & 100 & 100 & 100 & 0 & 0 \\
\hline Entiat & 0 & 0 & 100 & 100 & 0 & 0 & 0 & 0 \\
\hline Grande Ronde & 0 & 0 & 100 & 100 & 100 & 96 & 0 & 0 \\
\hline Hood River & 59 & 59 & 100 & 48 & 100 & 54 & 0 & 0 \\
\hline Imnaha & 0 & 0 & 100 & 81 & 0 & 0 & 0 & 0 \\
\hline John Day & 0 & 0 & 81 & 81 & 100 & 100 & 0 & 0 \\
\hline Klickitat & 0 & 0 & 100 & 100 & 63 & 64 & 0 & 0 \\
\hline Little White & 100 & 100 & 100 & 100 & 0 & 0 & 0 & 0 \\
\hline Methow & 0 & 0 & 100 & 100 & 0 & 0 & 100 & 100 \\
\hline Okanogan & 0 & 0 & 0 & 0 & 0 & 0 & 100 & 100 \\
\hline Bear V. (Salmon) & 0 & 0 & 100 & 100 & 0 & 0 & 0 & 0 \\
\hline Lemhi R. (Salmon) & 0 & 0 & 100 & 100 & 100 & 76 & 0 & 0 \\
\hline Lower Salmon & 0 & 0 & 100 & 100 & 100 & 65 & 0 & 0 \\
\hline Mid-Salmon & 0 & 0 & 100 & 100 & 100 & 67 & 0 & 0 \\
\hline Panther C. (Salmon) & 0 & 0 & 0 & 0 & 100 & 100 & 100 & 100 \\
\hline Phsimroi R. (Salmon) & 0 & 0 & 0 & 0 & 100 & 62 & 100 & 100 \\
\hline S. Fork Salmon & 0 & 0 & 0 & 0 & 100 & 80 & 100 & 100 \\
\hline Little Salmon & 0 & 0 & 76 & 100 & 100 & 71 & 0 & 0 \\
\hline Upper Salmon & 0 & 0 & 100 & 100 & 100 & 66 & 100 & 100 \\
\hline Tucannon & 0 & 0 & 100 & 100 & 100 & 100 & 0 & 0 \\
\hline Umatilla & 76 & 81 & 100 & 100 & 100 & 100 & 0 & 0 \\
\hline Wind River & 0 & 0 & 100 & 100 & 100 & 81 & 0 & 0 \\
\hline Wenatchee & 0 & 0 & 56 & 56 & 0 & 0 & 100 & 100 \\
\hline White Salmon & 0 & 0 & 100 & 100 & 100 & 44 & 0 & 0 \\
\hline Walla Walla & 0 & 0 & 100 & 100 & 100 & 100 & 0 & 0 \\
\hline
\end{tabular}

*Both refers to combined objectives for natural and hatchery stocks.

**FAC, SPC, SSH, and SUC are fall chinook, spring chinook, summer steelhead, and summer chinook, respectively

***See text for explanation of runsize doubling objectives 
runsize doubling for each stock that the modeling exercise could achieve. ${ }^{3}$

In addition to these numerical objectives, we also investigated whether the imposition of objectives related to the genetic integrity of salmon populations influences the cost and composition of recovery strategies. More specifically, we modeled the possibility that a crude constraint on genetic risk would increase costs or alter the preferred actions, by curtailing new hatchery operations in reaches with wild stocks. As a final step in the analysis, as noted earlier we conducted a sensitivity analysis to determine whether changing our assumptions about the effectiveness of two passage-related actions affects the composition and cost of the preferred passage strategy. We modeled both average (designated as average passage sensitivity) and low (designated as low passage sensitivity) assumptions about fish guidance efficiencies (fge) in bypass systems, transportation survival, and predator control effectiveness. ${ }^{4}$ We discuss conclusions from our sensitivity analysis as well as more-detailed results from our modeling of the numerical objectives and the genetic constraint in the following sections.

\section{RESULTS: $100 \%$ OF OBJECTIVES}

Table 5.5 through Table 5.8 display the results from model runs. The tables display how the costs and composition of the recovery alternatives (i.e., the preferred actions) vary as we alter our assumptions about the efficacy of passage actions, introduce a genetic constraint, or change our emphasis between terminal harvest or natural spawning escapement. We first discuss how the costs of the recovery alternatives change as we introduce constraints and then examine how the composition of the recovery alternatives shift.

\footnotetext{
${ }^{3}$ Once we establish the runsize doubling numerical objective for each stock that at least one passage/propagation/terminal harvest alternative can attain, we define this numerical objective as the 100 percent level. See note 2 .

${ }^{4}$ As detailed in Chapter 4, the low passage sensitivity case represents fge 25 percent below average fge, transportation survivals 50 percent below average transportation survivals, and predator control effectiveness 50 percent below average predator control effectiveness. Table E.1 furnishes the average values for these parameters.
} 
TABLE 5.5

Optimization Results for Different Passage Sensitivities, Objectives, and Acceptable Levels of Genetic Risk*

\begin{tabular}{|c|c|c|c|c|c|c|c|}
\hline Scenario & Passage & Objectives & Genetic Risk & Passage & Passag & Prop. & Total \\
\hline Number & Sensitivity** & & & Strategy & Cost & Cost & Cost \\
\hline 1 & Average & Harvest Only & No Constraint & 8 & 9.0 & 3.7 & 12.7 \\
\hline 2 & $\begin{array}{l}\text { Average w/ } \\
\text { Council Flow }\end{array}$ & $\begin{array}{l}\text { Harvest \& Natural } \\
\text { Spawning Escapement }\end{array}$ & No Constraint & 7 & 79.0 & 10.0 & 89.0 \\
\hline 3 & Average & $\begin{array}{l}\text { Harvest \& Natural } \\
\text { Spawning Escapement }\end{array}$ & No Constraint & 8 & 9.0 & 10.0 & 19.0 \\
\hline 4 & Average & $\begin{array}{l}\text { Harvest \& Natural } \\
\text { Spawning Escapement }\end{array}$ & $\begin{array}{l}\text { Low Genetic } \\
\text { Risk }\end{array}$ & 8 & 9.0 & 10.0 & 19.0 \\
\hline 5 & $\begin{array}{l}\text { Low FGE, } \\
\text { etc. }\end{array}$ & $\begin{array}{l}\text { Harvest \& Natural } \\
\text { Spawning Escapement }\end{array}$ & No Constraint & 8 & 9.0 & 13.9 & 22.9 \\
\hline 6 & Average & Runsize Doubling & No Constraint & 8 & 9.0 & 14.9 & 23.9 \\
\hline 7 & $\begin{array}{l}\text { Average } \\
\text { (Planners } \\
\text { Preferred) }\end{array}$ & $\begin{array}{l}\text { Harvest \& Natural } \\
\text { Spawning Escapement }\end{array}$ & No Constraint & 8 & 9.0 & 18.0 & 27.0 \\
\hline
\end{tabular}

*Costs are in millions of dollars, annualized at a three percent real discount rate. **Sensitivity runs for passage included "average" assumptions regarding the efficacy of fish guidance efficiencies (fge), transportation survival, and predator control, and "low" assumptions, in which we reduced fish guidance efficiencies by 25 percent, transport survival by 50 percent, and predator control efficacy by 25 percent. 
TABLE 5.6

Propagation Costs for $\mathbf{1 0 0 \%}$ Solutions*

\begin{tabular}{|c|c|c|c|c|}
\hline Subbasin & $\begin{array}{l}\text { Average fge } \\
\text { Assumption** }\end{array}$ & $\begin{array}{l}\text { Runsize } \\
\text { Doubling }\end{array}$ & $\begin{array}{l}\text { Planners' } \\
\text { Strategy }\end{array}$ & $\begin{array}{l}\text { Low Fge } \\
\text { Assumption** }\end{array}$ \\
\hline Clearwater & 0.205 & 0.370 & 0.845 & 0.205 \\
\hline Deschutes & 0.279 & 0.474 & 0.661 & 0.301 \\
\hline Entiat & 0 & 0.081 & 0.027 & 0 \\
\hline Grande Ronde & 2.709 & 1.578 & 2.030 & 2.709 \\
\hline Hood River & 0.313 & 0.238 & 0.245 & 0.313 \\
\hline Imnaha & 0.330 & 0.234 & 0.563 & 0.563 \\
\hline John Day & 0.739 & 0.799 & 0.825 & 0.739 \\
\hline Klickitat & 0 & 0.039 & 1.254 & 0 \\
\hline Little White & 0.006 & 0.006 & 0.346 & 0.006 \\
\hline Methow & 0 & 0.052 & 0.708 & 0.173 \\
\hline Okanagan & 0.005 & 0 & 0.334 & 0.299 \\
\hline Bear V. (Salmon) & 0.188 & 0 & N/A & 0.189 \\
\hline Lemhi R. (Salmon) & 0.867 & 0.679 & 0.867 & 0.867 \\
\hline Lower Salmon & 0.188 & 0.882 & N/A & 0.189 \\
\hline Mid-Salmon & 0.867 & 0.679 & N/A & 0.867 \\
\hline Panther C. (Salmon) & 0.469 & 0.036 & 0.699 & 0.469 \\
\hline Pahsimeroi R. (Salmon) & 0 & 0.664 & 0.664 & 0 \\
\hline S. Fork Salmon & 0.380 & 0.380 & 0.229 & 0.569 \\
\hline Little Salmon & 0.189 & 0.807 & 0.807 & 0.189 \\
\hline Upper Salmon & 0.716 & 2.225 & 0.724 & 0.716 \\
\hline Tucannon & 0.017 & 0.022 & 0.069 & 0 \\
\hline Umatilla & 0.419 & 3.169 & 3.169 & 2.842 \\
\hline Wind River & 0.495 & 0.556 & 0.709 & 0.495 \\
\hline Wenatchee & 0 & 0 & 0.185 & 0.582 \\
\hline White Salmon & 0.017 & 0.035 & 0.469 & 0.017 \\
\hline Walla Walla & 0.633 & 0.856 & 1.600 & 0.633 \\
\hline Total Propagation Cost & 10.031 & 14.862 & 18.032 & 13.932 \\
\hline
\end{tabular}

* Costs are in millions of dollars, annualized at a three percent real discount rate. The passage strategies chosen by the optimization model for each entry were current conditions (1989-1991 flows with planned improvements to bypass and transport facilities) and predator control, with an annual cost of 9.0 million dollars.

**Sensitivity runs for passage included "average" assumptions regarding the efficacy of fish guidance efficiencies (fge), transportation survival, and predator control, and "low" assumptions, in which we reduced fish guidance efficiencies by 25 percent, transport survival by 50 percent, and predator control efficacy by 25 percent. 
TABLE 5.7

Preferred Propagation Actions For Selected Subbasins

\begin{tabular}{|c|c|c|c|c|c|}
\hline Subbasin & Action Description & $\begin{array}{l}\text { Average } \\
\text { fge }\end{array}$ & $\begin{array}{l}\text { Runsize } \\
\text { Doubling }\end{array}$ & $\begin{array}{l}\text { Planners' } \\
\text { Strategy }\end{array}$ & $\begin{array}{l}\text { Low } \\
\text { fge }\end{array}$ \\
\hline Grand Ronde & improve hatchery effectiveness & $\mathrm{X}$ & $\mathbf{X}$ & $\mathrm{X}$ & $\mathbf{x}$ \\
\hline Grand Ronde & improve habitat & $\mathbf{X}$ & $\mathbf{X}$ & $\mathbf{X}$ & $\mathbf{X}$ \\
\hline Grand Ronde & add 2 million hatch smolts & $X$ & & $\mathbf{X}$ & $\mathbf{X}$ \\
\hline Grand Ronde & supplement $w / 1$ million hatch smolts & $\mathrm{x}$ & & & $\mathbf{X}$ \\
\hline Grand Ronde & improve habitat & $\mathrm{X}$ & $\mathbf{X}$ & $\mathrm{X}$ & $\mathbf{X}$ \\
\hline Klickitat & remove barrier at Castile Falls & & $\mathbf{X}$ & $\mathrm{X}$ & \\
\hline Klickitat & redesign ladder at Klickitat Hatchery & & $\mathbf{X}$ & $\mathbf{X}$ & \\
\hline Klickitat & $\begin{array}{l}\text { reduce sediment from Big Muddy } \mathrm{Ck} \text {.; } \\
\text { enhance riparian habitat }\end{array}$ & & & $\mathbf{X}$ & \\
\hline Klickitat & remove barrier at $\mathrm{W}$. Fork Falls & & & $\mathbf{X}$ & \\
\hline Klickitat & remove barrier at L. Klickitat Falls & & & $\mathrm{X}$ & \\
\hline Klickitat & add 2.4 million smolts (action 2) & & & $\mathrm{x}$ & \\
\hline U. Salmon & enhance habitat & & & $\mathbf{X}$ & \\
\hline U. Salmon & add 2.8 million smolts & & $\mathbf{X}$ & $\mathbf{X}$ & $\mathbf{X}$ \\
\hline U. Salmon & add 1 million smolts & $\mathbf{X}$ & & $\mathbf{X}$ & $\mathbf{X}$ \\
\hline U. Salmon & add 2.5 million smolts & & $\mathrm{X}$ & & \\
\hline Umatilla & enhance flow & & $\mathbf{X}$ & $\mathbf{X}$ & $\mathbf{x}$ \\
\hline Umatilla & add 600,000 smolts & & $\mathrm{X}$ & $\mathbf{X}$ & \\
\hline Umatilla & provide headwater storage & & & & \\
\hline Umatilla & improve adult and juvenile passage & & & & \\
\hline Umatilla & enhance instream and riparian habitat & $\mathrm{X}$ & $\mathbf{X}$ & $\mathbf{x}$ & $\mathbf{X}$ \\
\hline Walla Walla & improve adult and juvenile passage & & $\mathbf{x}$ & $\mathbf{x}$ & \\
\hline Walla Walla & enhance instream and riparian habitat & & $\mathbf{X}$ & $\mathrm{X}$ & \\
\hline Walla Walla & initiate 100,000 smolt release $(3 b)$ & $\mathbf{X}$ & $\mathbf{X}$ & $\mathrm{X}$ & $\mathbf{X}$ \\
\hline Walla Walla & headwater storage to improve flow & & & & \\
\hline Walla Walla & produce 500,000 hatchery smolts & $\mathrm{X}$ & & $\mathbf{X}$ & $\mathbf{X}$ \\
\hline Walla Walla & produce 100,000 hatchery smolts & $\mathbf{X}$ & & $\mathrm{X}$ & $\mathrm{X}$ \\
\hline Walla Walla & improve adult and juvenile passage & & & $\mathrm{X}$ & \\
\hline Walla Walla & enhance instream and riparian habitat & $\mathrm{X}$ & $\mathbf{X}$ & $\mathrm{X}$ & $\mathrm{X}$ \\
\hline Walla Walla & $\begin{array}{l}\text { enhance flows using headwater } \\
\text { storage }\end{array}$ & & & & \\
\hline
\end{tabular}


TABLE 5.8

Cost of Attaining Terminal Harvest/Spawning Escapement Objectives, by Percent of Objective*

\begin{tabular}{cccc}
\hline Percent of Objective** & Passage Cost*** & Propagation Cost*** & Total Cost*** \\
100 & 9.0 & 10.0 & 19.0 \\
95 & 9.0 & 9.5 & 18.5 \\
90 & 9.0 & 9.1 & 18.1 \\
85 & 9.0 & 6.1 & 15.1 \\
80 & 9.0 & 6.0 & 15.0 \\
75 & 9.0 & 6.0 & 15.0 \\
70 & 9.0 & 5.4 & 14.4 \\
65 & 9.0 & 5.2 & 14.2 \\
60 & 0.0 & 6.0 & 6.0 \\
55 & 0.0 & 5.6 & 5.6 \\
50 & 0.0 & 5.3 & 5.3 \\
\hline
\end{tabular}

*For average assumptions regarding the efficacy of fish guidance efficiencies (fge), transportation survival, and predator control. See text for explanation.

$* *$ Percent of the terminal harvest and spawning escapment numerical objectives specified in the subbasin plans. See text for explanation.

$* * *$ Costs are in millions of dollars, annualized at a three percent real discount rate. 


\section{Total Costs}

Table 5.5 summarizes the results for seven scenarios or combinations of biological objectives, passage sensitivity, and genetic risk. Total annualized costs for the seven scenarios range from $\$ 12.7$ million to $\$ 89$ million per year, with these total costs disaggregated into passage and propagation expenditures as shown. Several features of the results deserve mention. First, the optimization model almost always selects passage strategy 8, which includes 89-91 flows, increased transportation levels, and increased predator control. Only in scenario 2, where we forced the model to select Council Phase II flows, do current flows not appear. In comparing scenarios 2 and 3, which are identical in their passage sensitivities, numerical objectives, level of acceptable genetic risk, and preferred propagation strategy, ${ }^{5}$ we can see that the requirement for Phase II flows appears to yield a system-wide strategy to meet the planners' objectives that costs $\$ 70$ million more annually than the system-wide strategy identified by the optimization model. This result may rest on the different assumptions inherent in the cost-effectiveness models (particularly the relationship between reservoir flows and smolt survival in CRiSP.0), but it nonetheless strongly suggests that additional empirical work on the relationship between flows and survival is warranted. Given the tension among the popularity of increased flows, the apparent large cost and limited effectiveness of these flows, and the biological importance of enhancing survival for many stocks above Bonneville Dam, the region clearly needs to continue and extend its investigation of downstream survival.

Second, the addition of a constraint on acceptable genetic risk appears to make little difference in the system-wide cost-effective strategy. In Table 5.5, scenarios 3 and 4 are identical, except for the addition of a constraint on genetic risk in scenario 4 (see Chapter 4 for details). After initially imposing the genetic constraint (i.e., no new hatchery releases to wild stocks) to model scenario 4, we saw that spring chinook in the Hood River, Bear Valley (in the Salmon River), and the Lemhi River, had no analyzable propagation alternatives (with costs and biological

\footnotetext{
5 The preferred propagation strategy identified by the optimization model in scenario 2 contains exactly the same propagation actions as the preferred propagation strategy for scenario 3 , although Table 5.5 does not show this directly.
} 
effects) with acceptable genetic risks, and that passage strategies alone could not meet the objectives for these stocks. When we relaxed the genetic risk constraint for these stocks, however, the optimization model selected the same passage and propagation strategies for scenarios 3 and 4 . In other words, except for the three stocks with no propagation alternatives that did not introduce some genetic risk, the constraint on genetic risk did not affect the composition or cost of the least-cost, system-wide strategy.

Third, in contrast to the minor effects of the genetic risk constraint, our alteration of assumptions regarding the efficacy of passage actions substantially affected the costs and choice of preferred propagation strategies. ${ }^{6}$ In Table 5.5, scenario 5 differs from scenario 3 only in the more pessimistic assumptions concerning fish guidance efficiencies (fge) and transportation survival (see Chapter 4 for details) included in scenario 5. However, the different assumptions result in considerably higher costs for propagation strategies $(\$ 13.9$ million per year versus $\$ 10.0$ million). In addition, although we do not show this in Table 5.5, we had to reduce the objectives for Tucannon steelhead, Bear Valley spring chinook, and Pahsimeroi summer chinook by 10 to 50 percent in order to model scenario 5, since under the low fge of scenario 5, no combinations of propagation and passage could meet their biological objectives.

Fourth, our analysis of the preferred propagation strategies identified in the subbasin plans indicated that the planners' strategies cost considerably more and sometimes do not yield harvest and spawning escapement levels that meet the objectives. In scenario 7, we evaluated the subbasin planners' preferred propagation strategies in combination with each of the 8 passage strategies and allowing the terminal harvest rates to vary in the same fashion as in the other model runs ( 0 to 80 percent in 20 percent increments). As Table 5.5 displays, the cost of the planners' preferred propagation strategies ( $\$ 18.0$ million annually) greatly exceeds the cost of the preferred propagation strategies identified by the optimization model $(\$ 10.0$ million annually in the comparable case, scenario 3). Additionally, the planners' preferred strategies did not meet the terminal harvest and spawning escapement objectives used in the other analyses (i.e., scenarios

\footnotetext{
6The preferred passage strategies remain robust, however.
} 


\section{$2,3,4$, and 5) for several stocks. ${ }^{7}$}

Finally, our evaluation of the goal of doubling the runsize of each stock indicattes that attainment of the goal will entail higher costs. Scenario 6 in Table 5.5 summarizes the results of modeling this goal. The model selects a substantially higher-cost group of propagation strategies in comparison to the terminal harvest/spawning escapement objectives in scenario 3 (\$14.9 million versus $\$ 10.0$ million per year), and again selects passage strategy 8 . The runsize doubling goal entails substantially lower terminal harvest rates for most stocks, since reducing harvest rates increases total runsize at no cost. The next section provides more details on how the propagation strategies differ among scenarios.

\section{Distribution of Propagation Expenditures}

As just indicated, the total cost of propagation strategies can vary widely among the different scenarios that we modeled, from $\$ 10.031$ million annually to $\$ 18.032$ million annually. However, the variation becomes even more pronounced when we look at the disaggregated propagation strategies for each individual subbasin. Table 5.6 clearly shows both that the cost of the preferred propagation strategy for any given subbasin can vary greatly among scenarios, and that the cost of the propagation strategies among different subbasins can vary greatly within any given scenario. As an example of the former variation, we can see in Table 5.6 that the Klickitat has a propagation cost of zero for two scenarios, and a maximum propagation cost of $\$ 1.254$ million for the planners' preferred strategy. As an example of the between-subbasin cost variation, in the average fge scenario five subbasins have a propagation cost of zero (and therefore evidently require no propagation actions to achieve their terminal harvest and escapement objectives), five subbasins require propagation strategies that cost between $\$ 500$ thousand and $\$ 1$ million annually,

\footnotetext{
7 The subbasin planners identified preferred strategies for each subbasin, but we could analyze only those actions in the preferred strategies that had usable economic and biological data. Therefore, for some subbasins, we had to exclude some actions which were components of the preferred strategies. For example, we could not analyze any of the actions in the planners' preferred strategies in three subbasins (Bear Valley, the Lower Salmon, and the mid-Salmon), due to the lack of biological and/or cost data.
} 
and one subbasin has a cost that exceeds $\$ 2.7$ million annually. When we make more pessimistic assumptions regarding the efficacy of passage actions (the rightmost column of Table 5.6), four subbasins still require no propagation actions, eight require expenditures between $\$ 500$ thousand and $\$ 1$ million annually, and two subbasins have costs that exceed $\$ 2.7$ million annually. 8

We show the actions associated with the propagation strategies for five subbasins with significant propagation expenditures in Table 5.7. (Appendix D provides details on the actions' costs and biological affects.). An $X$ in the row and column entry for each action and scenario indicates that the model solution for the scenario included the action identified in the row, while a blank indicates its exclusion. The table highlights several points. First, recall from our earlier discussion that the average fge scenario and the planners' strategies scenario share the same set of terminal harvest and spawning escapement numerical objectives for each stock, even though the planners' strategies did not meet the numerical objectives for several stocks, and the planners recommended propagation strategies that cost more in total than those suggested by the optimization model. For example, as Table 5.7 shows, the planners suggested six actions in the Klickitat, while the optimization model identified the need for no propagation actions. Similarly, the planners recommended three actions in the Upper Salmon, while the preferred propagation strategy identified by the optimization model included only one action. This pattern does not hold universally, since the optimization model identified a strategy with more propagation actions in the Grand Ronde than did the planners. However, the selection of additional actions in the Grand Ronde occurs because the additional action (adding hatchery smolts) is required to meet the planners' numerical objectives.

A second interesting feature displayed in Table 5.7 is that six of the twenty-nine actions shown in the table are included in all four scenarios. The six include an action to improve hatchery effectiveness in the Grand Ronde, two habitat enhancement actions in the Grand Ronde,

8In Table 5.6 the alert reader may note that the Tucannon requires a modest amount of propagation activity under the average FGE scenario, but none under the low-FGE scenario. This anomaly obtains because we had to reduce the objectives for Tucannon summer steelhead in order to find a feasible solution. We obviously reduced them a bit too far. 
a supplementation action in the Walla Walla, a habitat enhancement action in the Walla Walla, and a habitat enhancement action in the Umatilla. The robustness of these actions over the four scenarios suggests that the region should investigate these six actions very thoroughly, since both the planners and the optimization model selected them across a range of objectives and assumptions.

A final point raised by Table 5.7 is that the optimization model never selects three of the options (Walla Walla headwater storage, Umatilla headwater storage, and Umatilla passage improvements) in any of the scenarios. These actions cost a lot of money and seemingly can boast only limited biological effectiveness. While this does not mean of course that the region should abort all consideration of these projects, their apparent limited efficacy and high costs suggests that these actions require more extensive study and justification.

\section{COST-EFFECTIVENESS FRONTIERS}

Table 5.8 and Table 5.9 show the costs of meeting varying percentages of the terminal harvest/spawning escapement numerical objectives (using scenario 2) and the runsize doubling numerical objectives, respectively. We varied the percentages from 50 to 100 percent in five percent increments. Note that because of the way we defined the objectives, the table entries mean different things for terminal harvest/spawning escapement and run-size doubling. For example, the 50 percent level for terminal harvest/spawning escapement in Table 5.8 indicates that we have reduced the numerical objectives for each stock by 50 percent. For the runsize doubling objectives in Table 5.9, however, the 50 percent level indicates a numerical objective that equals the base case runsize for each stock. ${ }^{9}$ (The 75 percent level for the runsize doubling objectives

\footnotetext{
${ }^{9}$ The numerical objective associated with the 50 percent of the doubling goal level should agree with the calibration-case runsize for all stocks, since the calibration case serves as the reference point for the runsize doubling goal. Furthermore, the cost of attaining this level should equal zero, because the cost of the calibration and base cases is zero by definition. However, Wind River steelhead had slightly higher downstream passage survival under historical conditions (during the calibration period) than they do today. Therefore, in order to achieve the same runsize in the future as this stock enjoyed in the years represented by the calibration case, the model selects a propagation strategy for the Wind River which includes actions that cost about $\$ 400$ thousand per year; hence the cost of meeting the base case run size slightly exceeds zero.
} 
TABLE 5.9

Cost of Attaining Runsize Doubling Numerical Objectives, by Percent of Objective*

\begin{tabular}{|c|c|c|c|}
\hline Percent of Objective** & Passage Cost*** & Propagation Cost ${ }^{* * *} \mathrm{~T}$ & Total Cost*** \\
\hline 100 & 9.0 & 14.9 & 23.9 \\
\hline 95 & 9.0 & 11.6 & 20.6 \\
\hline 90 & 9.0 & 10.9 & 19.9 \\
\hline 85 & 9.0 & 9.6 & 18.6 \\
\hline 80 & 9.0 & 8.7 & 17.7 \\
\hline 75 & 9.0 & 7.4 & 16.4 \\
\hline 70 & 0.0 & 11.0 & 11.0 \\
\hline 65 & 0.0 & 8.7 & 8.7 \\
\hline 60 & 0.0 & 7.6 & 7.6 \\
\hline 55 & 0.0 & 3.0 & 3.0 \\
\hline 50 & 0.0 & 0.4 & 0.4 \\
\hline
\end{tabular}

*For average assumptions regarding the efficacy of fish guidance efficiencies (fge), transportation survival, and predator control. See text for explanaticn.

**Percent of the runsize doubling goal expressed by the Council. See text for explanation.

***Costs are in millions of doilars, annualized at a three percent real discount rate. 
indicates an objective that represents a 50 percent increase in runsize from the base case [ 0.75 $0.50) / 0.50]$, and the 100 percent level an objective that represents a 100 percent increase [i.e., doubling] in runsize from the base case $[(1.00-0.50) / 0.50])$.

We display the cost-effective frontiers for the terminal harvest/spawning escapment objectives and runsize doubling objectives in Figure 5.1, Figure 5.2, and Figure 5.3. From Figure 5.1 , we can see that the costs of attaining the terminal harvest/spawning escapement objectives rise sharply at two points. The sharpest increase -- $\$ 8$ million per year -- occurs when the number of fish for terminal harvest and spawning escapement for each stock increases from 60 percent to 65 percent of the number originally specified in the subbasin plans. This increase results from the introduction of an expensive predator control action. The other sharp increase -- $\$ 3$ miliion per year -- occurs when the number of fish for terminal harvest and spawning escapement for each stock increases from 85 percent to 90 percent of the number originally specified. This increase results from a large increment in propagation costs.

Figure 5.2 shows that the costs of attaining runsize increases above the base case also rise most sharply at two points. Again, the sharpest increase -- $\$ 5$ million per year -- occurs with the introduction of predator control, although this takes place when the number of fish increases from the 70 percent level to the 75 percent level. As indicated above, because of the way we defined the objectives this represents a change from a 40 percent increase from the base case runsize to a 50 percent increase from the base case runsize. The next sharpest increase -- $\$ 3$ million per year - occurs from the 95 percent level to the 100 percent level. This represents a change from a 90 percent increase from the base case runsize to a 100 percent increase (doubling) from the base case runsize.

Figure 5.3 provides an overlay of the cost-effectiveness ..untiers for terminal harvest/spawning escapement and runsize increases. From this, we see that the frontiers cross each other twice: once between 55 percent and 60 percent, and again between 70 percent and 75 percent. We also can see that the frontier depicting runsize increases above base case runsizes consistently lies above the harvestescapement frontier from the 75 percent level to the 100 


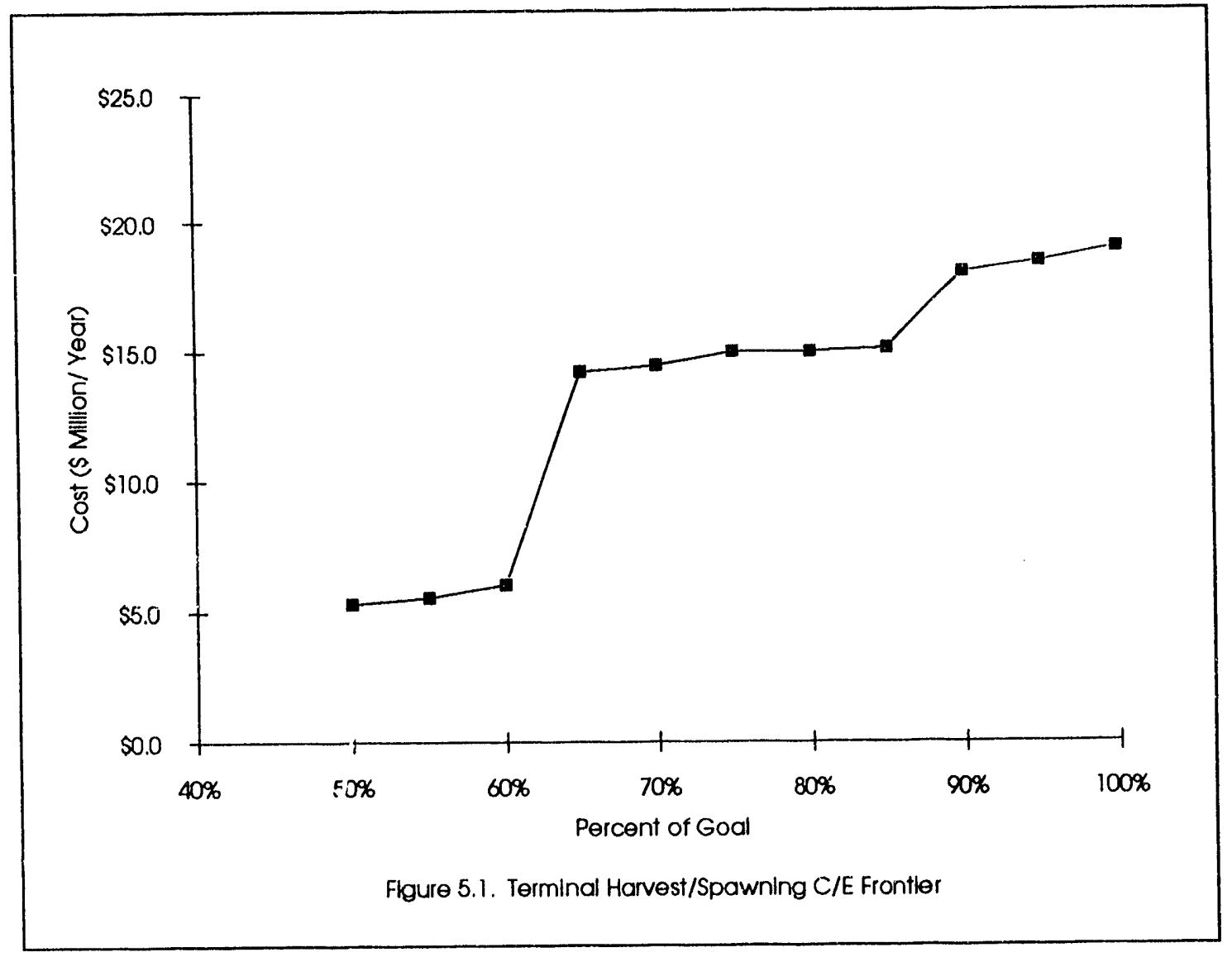




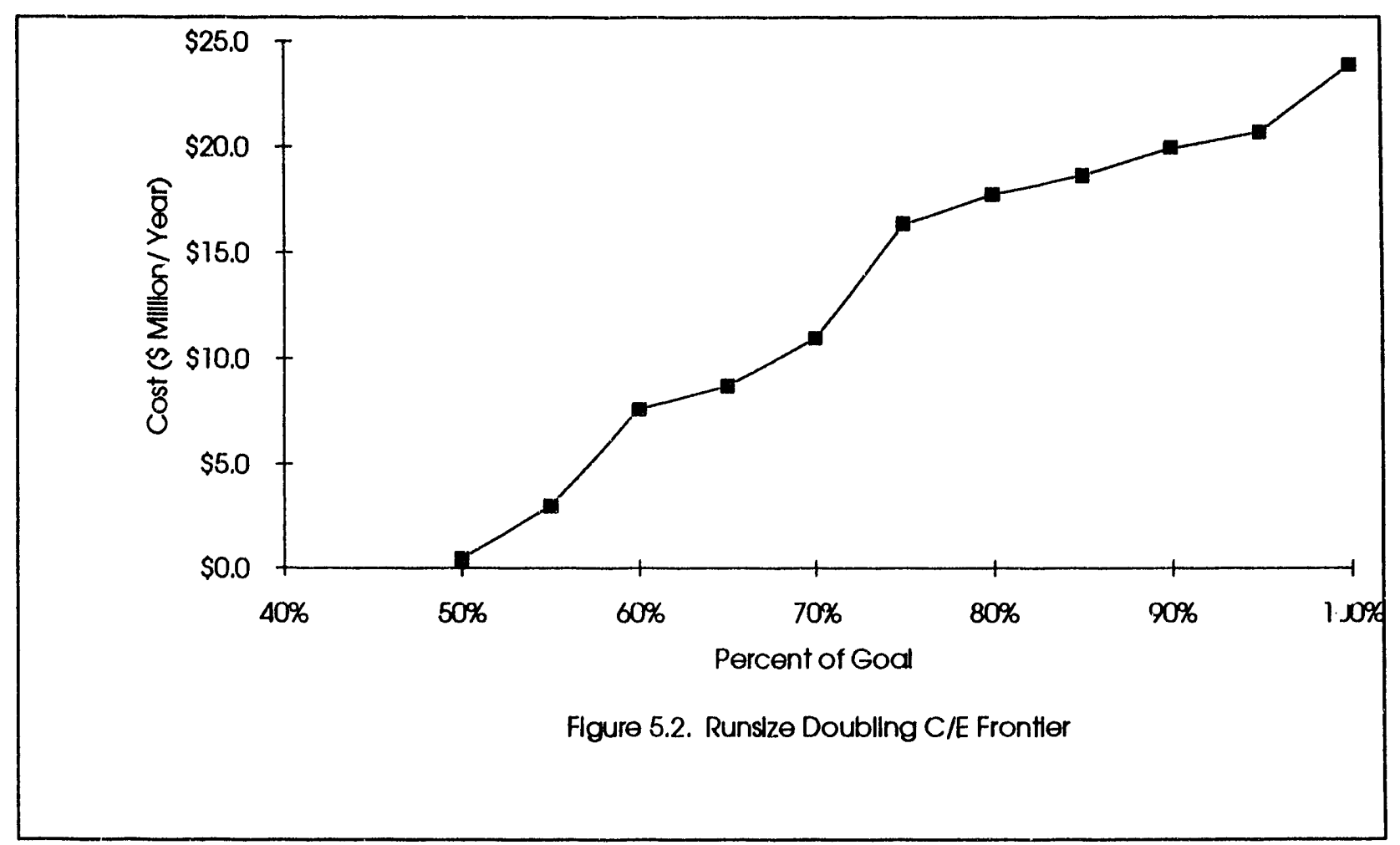




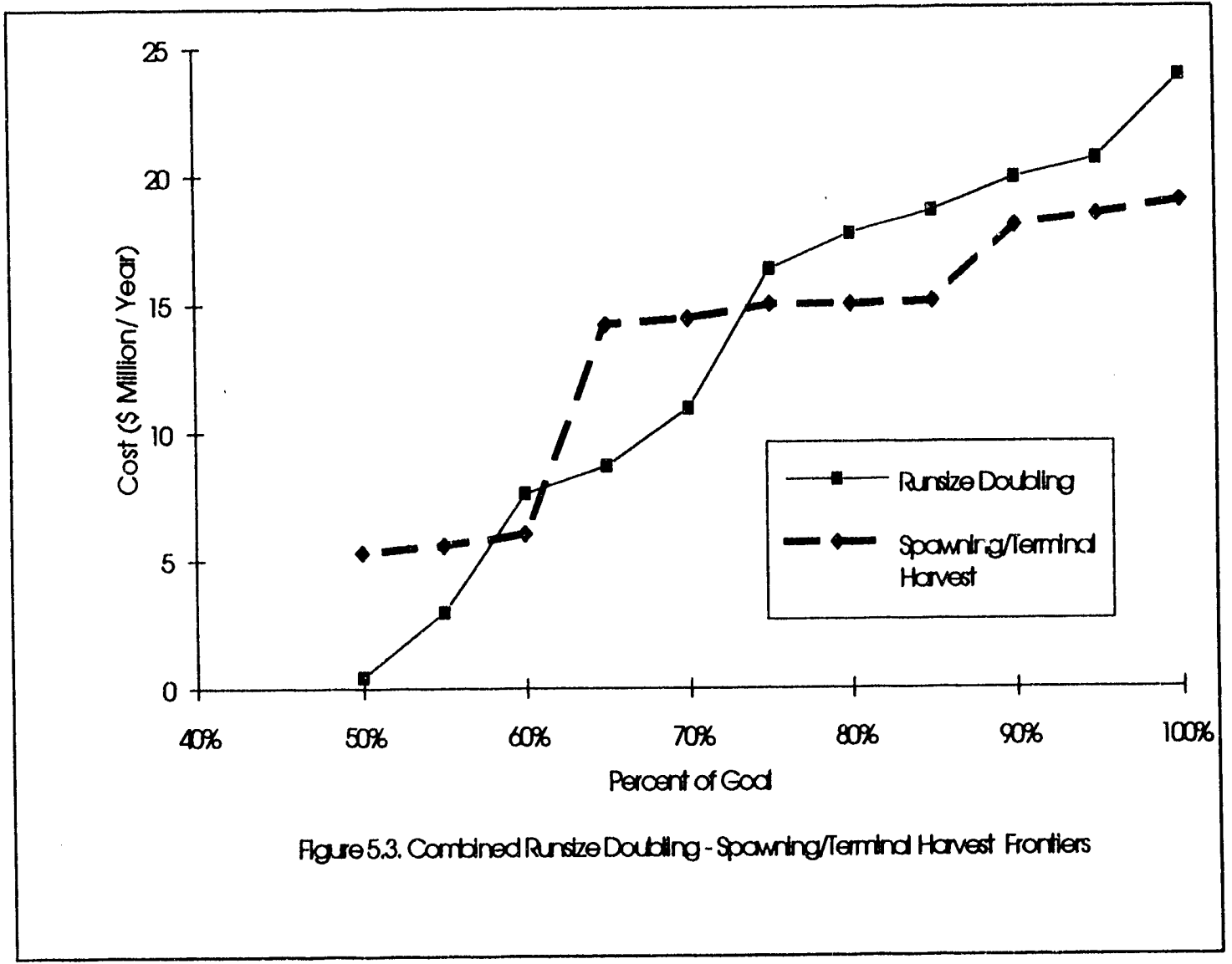


percent level. Taken together, this suggests that while increasing the size of the runs likely will cost more than increasing terminal harvest and spawning escapement as one approaches likely ranges for the two kinds of objectives, the attainment of the proportional runsize increases sometimes may cost less than attainment of the stock-specific numerical objectives for terminal harvest and spawning escapement. An approach for setting objectives that is based on equal proportional increases above one reference case (i.e., historical run sizes) thus may not be entirely consistent with an approach that is based on equal proportional increases above another reference case (i.e., terminal harvest and spawning escapement objectives set by subbasin planners). In other words, not only can the composition and cost of least-cost recovery alternatives depend very much on what reference case is chosen for setting objectives, but objectives defined on an apparently less-ambitious reference case may not always yield a recovery alternative that entails fewer recovery actions and lower costs. 10

As a final point, the shape of the cost-effectiveness frontiers differs somewhat from expectations, in that the marginal cost of each 5-percent increase in the number of fish does not always increase as the number of fish increases. 11 (Each of the three figures that depict costeffectiveness frontiers displays this clearly.) One would expect each 5 percent increment to cost no less than the previous 5 percent increment, because if it cost less (to go from 65 percent to 70 percent than from 60 percent to 65 percent, for example) it seems as if the optimization model would have chosen the less-costly 5 percent increment earlier. However, the actions evaluated in the analysis are lumpy; that is, one can either implement an action in whole or not at all. Passage actions exhibit this lumpiness most clearly. This appears most evident in moving from the 60 percent level to the 65 percent level of terminal harvest/subbasin escapement, where we need to add an expensive predator control action to reach the 65 percent level. Once we include this

${ }^{10}$ The counter-intuitive result of a less ambitious reference case requiring more actions and higher costs at certain levels of effectiveness prevails when the allowed tradeoffs among objectives for different stocks in the less ambitious reference case are more restrictive.

11 If marginal costs increased as the number of fish increased, the lines connecting the points on the cost-effectiveness frontier would become progressively steeper as we moved from left to right on the frontier. 
action, we need no additional passage actions beyond the base case passage actions. Instead, propagation actions, which generally cost less than passage actions, can drive further increases in the numbers of fish.

\section{SUMMARY}

The cost-effectiveness analysis presented in this report can provide useful information to decision makers about how to achieve a set of objectives related to recovery planning for salmonids at least cost. As this chapter clearly shows, the composition and financial cost of the least-cost recovery alternatives identified in the analysis depend on the number of fish specified in an objective, the type of objective (e.g., runsize doubling objectives verses subbasin planners' objectives), constraints (e.g., genetic risk), and assumptions regarding the behavior of salmonids and the efficacy of recovery actions (e.g., different estimates of transportation survival). Furthermore, the analysis demonstrates vividly that any analysis which excludes portions of the fish life-cycle, or which focuses exclusively on a few stocks, may miss both fish-production and cost-saving opportunities.

Several results discussed in this chapter and points made elsewhere in this document deserve reiteration and expansion here. First, the consistency with which the optimization model chooses passage strategies using current (1989-91) flows and rejects those calling for increased flows furnishes a strong argument for much more extensive research on the relationship between flow and survival. While we recognize that the flow-survival relationships that we included in our model have not gained acceptance in some quarters, the tremendous cost and potentially limited efficacy of measures to increase flows trumpets the need for further work to justify proposed flow measures. Arguments that enhanced flows will more nearly approximate historical (i.e. preEuropean settlement) conditions do not provide evidence in and of themselves that such flows will significantly improve survival. Fortunately, it appears that further work on the relationships betwen flow and survival, as well as other work in other critical areas related to passage and 
propagation measures, is proceeding. 12

Second, and related to this, while we recognize that other characteristics or objectives associated with flow enhancement or drawdown (i.e., those not directly related to biological effectiveness or costs) may make such measures appealing or necessary, it seems desirable to state these other characteristics or objectives up front in order to facilitate examination of the best way to achieve them. For example, the muted but persistent argument that flow enhancement provides a mechanism for distributing the costs of recovery actions around the region (by incorporating the costs into the electric power rate base) may represent a legitimate objective, but unless we clearly express the desire to spread the costs and construct a vision of what a desirable distribution is, we may miss more appealing opportunities to achieve the distribution of costs and fish levels that we seek. More generally, clear articulation of possible objectives by interests in the region will facilitate analysis and help promote the development of relevant information for policy makers who need to explore the trade-offs between different objectives.

Third, it appears that the objectives set by the subbasin planners lie close to the upper limits for many stocks, given the propagation and passage actions modeled. This suggests that if interests within the region desire fish production increases greater than the levels established in the subbasin plans or above the runsize doubling objectives, they will need to develop additional actions beyond those presented in the subbasin plans and in regional discussion of passage alternatives.

Fourth, the modeling exercise highlights the need for documentation of all types of passage and propagation actions. We omitted many passage and propagation actions from the cost-effectiveness analysis because we had no estimates of their effectiveness (or costs in a few cases). In some cases this reflects an understandable lack of information on the effects of experimental actions. It is precisely for such cases that the region should commit itself to rigorous monitoring of the effects of experimental actions. However, in situations in which proposed

\footnotetext{
12The Skalski and Giorgi (1992) proposal to estimate smolt travel time and mortality provides an obvious example of such efforts.
} 
passage or propagation actions follow directly from established practices, proponents of the artions should provide more documentation on the intended effects and consequences of the actions. Funders in particular should require clear justifications for proposed actions. Even in the unlikely occurrence that the region is willing to commit an infinite amount of money to recovery of salmonids, some actions will preclude or obviate others (e.g., removal of a barrier to adult migration may eliminate the need for an adult ladder), while other actions will take precedence (a subbasin may require removal of a barrier before enhancement of habitat). Without documentation of an actions anticipated effects, decision makers may lack useful guidance on what actions to implement.

Finally, the results suggest that regional policy makers may need to decide whether they want to adopt (or whether the Regional Power Act requires) least-cost, system-wide planning for fish and wildlife. Analysts and planners have concentrated a significant amount of separate effort on subbasins within the Columbia Basin and on passage alternatives, yet the combination of results from subbasin analyses and passage analyses conducted separately does not necessarily lead to system-wide least-cost planning. As we stated elsewhere in this paper, a focus on propagation actions in isolation from passage actions in all likelihood will not yield a system-wide, least-cost set of management actions. Given the limited financial resources, finite amount of political will, and the tremendous need to enhance survival of salmonids in the Columbia basin, it seems evident to us that the region can not afford to miss the opportunity for effective least-cost, system-wide planning. 


\section{APPENDIX A \\ TETERMINISTIC SIMULATION MODEL,}

\section{INTRODUCTION}

This appendix describes the deterministic simulation model in considerably more detail than did Chapter 3. In contrast to the optimization model, the simulation model is concerned with one subbasin, species, and propagation/passage option at a time; interactions among species and subbasins are not included here. In this chapter, we first show how individual stocks are classified, and describe the possible interactions among subdivisions of related stocks. Next, we conceptually relate how the deterministic simulation handles each stage of the life cycle, from spawning and rearing to subbasin harvest (Chapter 3 described input data sources). We then outline the model equations in detail. We conclude with a description of the model outputs used, in turn, as inputs to the optimization model described in Appendix B. The reader may wish to consult Figure A.1, which depicts the relationships among the various life stages, before proceeding to the remainder of this appendix.

\section{STOCK CLASSIFICATION AND INTERACTION}

Stocks are divided into three categories for purposes of the deterministic simulation model: pure hatchery stocks, pure natural stocks, and supplementation stocks. Essentially, the determination is based on two criteria: whether a fish is produced naturally or in a hatchery, and where the fish subsequently spawns as an adult (see Figure A.2). Any given species or run (the model includes steeinead, spring chinook, summer chinook, and fall chinook runs) can therefore have at most three stocks per subbasin, as defined above. Note that although the deterministic simulation overall considers multiple stocks of the each species or run, and the inter-stock interactions within each subbasin, it does not include inter-species, inter-run, or inter-subbasin interactions; these are handled in the optimization model.

Within this context, the simulation model looks at three basic types of stock interaction. First, broodstock take for supplementation is directed jointly at natural and supplementation 
stocks. Second, terminal harvest may be directed at either hatchery-spawned individuals, naturally-spawned individuals, or both types jointly. Finally, hatchery-produced juveniles (i.e., immature fish prior to or at the smolt stage) may be introduced into the naturally-produced juvenile population. Note that this classification scheme says nothing about how the stocks behave outside the subbasin. Their behavior, in both the model and in reality, may be identical or quite different with respect to downstream passage, ocean survival and harvest, et cetera.

\section{Pure Hatchery}

We define pure hatchery stocks as those produced in hatcheries and subsequently spawned in hatcheries. In essence, pure hatchery stocks are most nearly like traditional hatchery operations. We assume they have no subbasin-level interaction with natural or supplementation fish; that is, they are not allowed to spawn naturally, broodstock is taken from the pure hatchery stock only, they are harvested separately (at least within the subbasin), and they are not outplanted until they reach the smolt stage, so there is no interaction among juveniles of hatchery stocks and natural or supplemented stocks. Note that this does not preclude the possibility of interactions outside the subbasin, including mixed-stock harvest and similar or identical results for downstream passage.

As with any model, our representation of fish behavior is a simplification of reality. Obviously, even pure hatchery stocks must get their initial broodstock from another hatchery or from natural-origin fish, and natural or supplementation fish are sometimes used as broodstock for pure hatchery operations. We assume these interactions are small enough that they can be ignored. Moreover, some straying of pure hatchery fish into naturally-spawning populations must certainly occur for most or all hatchery stocks. We assume there is no net straying of hatchery fish (incoming strays are balanced by outgoing strays).

\section{Pure Natural}

We define pure natural fish as those which are produced naturally and which spawn 
naturally in the stream, regardless of where their parents were produced. A pure natural stock, as represented here, does not interact with pure hatchery fish, but may provide brot dstock for one or more supplementation stocks. Furthermore, we assume that terminal harvest on natural stocks is physically separated from terminal harvest on pure hatchery stocks, but that natural and supplementation stocks are at least potentially subject to the same terminal fishery (their harvest rates may differ where naturally-spawned fish can be distinguished from hatchery-bred fish).

\section{Supplementation}

A supplementation stock is produced in a hatchery but spawns naturally in the stream, interbreeding with pure natural fish. Thus, the offspring of a supplementation fish that escapes to spawn will be a pure natural fish. A supplementation stock can interact with a natural stock in several ways: supplementation and natural fish are jointly removed to provide broodstock for supplementation, they interbreed, supplementation fish can be outplanted as juveniles into a natural population of juveniles, and there may be a joint terminal harvest on both stocks. We assume that supplementation fish, unlike pure hatchery fish, do not return to any hatchery on their own volition.

\section{SUBBASIN ALLOCATION AND HARVEST}

As can be seen from Figure A.1, adults returning to the subbasin are subject to a "hatchery first" policy, in that hatchery broodstock requirements take priority over terminal harvest and spawning escapement. Next, the fish are subject to terminal harvest. For pure hatchery stocks, the terminal harvest rate is generally set to 100 percent in the model -- all pure hatchery subbasin escapenient not used for hatchery broodstock is assumed to be harvested in the subbasin. For natural and supplementation stocks, we vary terminal harvest rates from zero to eighty percent, except where the rates are known to be zero. Individuals escaping this terminal harvest are then subject to pre-spawning mortality, and those fish surviving pre-spawning losses are allowed to spawn naturally. This allocation scheme represents a compromise between the complexities of 
subbasin-level management and a desire for simplicity in the models, and is not intended to faithfully represent how any particular "real" subbasin is actually managed.

\section{SPAWNING AND SMOLT PRODUCTION}

Spawning and smolt production take place either in a hatchery or naturally. For pure hatchery stocks, the process is very straight-forward. Since the only pure hatchery spawners are those taken for broodstock, this broodstock is used to produce a fixed number of smolts (the hatchery smolt capacity), ready to migrate downstream. In order to account for the low survival rates of hatchery smolts relative to naturally produced fish, the smolts are subject to an initial mortality immediately after release, prior to downstream migration. While it may appear overly optimistic to assume that a hatchery will meet its broodstock needs every year, as this method does, currently all model pure hatchery stocks always meet their broodstock requirements. If this assumption proves problematic, we can easily relax it, as is already done for supplementation operations.

For pure natural and supplementation stocks, the situation is a bit more complex. After the spawners arrive on the spawning ground, they are divided into males and females, and we assume that the number of females is the limiting factor in producing viable eggs. Currently, supplementation (hatchery-origin) fish are assumed to have the same characteristics as fish of natural-origin with respect to spawning behavior.

Once naturally spawned eggs hatch out, the number of pre-smolts (now part of the pure natural stock) produced from these eggs is determined based upon one of three density-dependent relationships: the Beverton-Holt (Beverton and Holt, 1957), a logistic survival function (Neter, Wasserman, and Kutner, 1985), or an empirically-derived stock-recruit relationship (Lee and Hyman, 1992). ${ }^{1}$ Pre-smolts over-wintering in the subbasin are also subject to an in-basin mortality each winter they remain in the subbasin; the proportions of pre-smolts staying over for

\footnotetext{
${ }^{1}$ Although the model can incorporate all of the three density-dependent relationships, we used the Beverton-Holt relationship in all model runs.
} 
one, two, or three winters are usually taken from data in the subbasin plans. Once the fish mature to the smolt stage, they are ready to migrate downstream.

Smolt production for supplementation stocks is similar to that for pure hatchery stocks, except for three differences. First, the model allows for the possibility that a supplementation program may not meet its broodstock requirement; if it falls short the smolt output is reduced proportionately. Second, the model allows for the possibility that juveniles are released from the hatchery at a stage where they compete with natural juveniles for food or space, decreasing the survival of both types of juveniles, although this option is not used for any stocks presently included in the analysis. Third, supplementation fish, unlike pure hatchery fish, can be released as pre-smolts, and are thus subject to the same over-wintering mortality as natural pre-smolts.

\section{DOWNSTREAM PASSAGE}

Once smolts leave the subbasin, they are subject to downstream mortality. This is calculated in the downstream passage section. While computation of the actual survival proportions is complex (see Chapter 3 and Hinrichsen et al. [1991] for more details) the application of the proportions is straight-forward. Separate survival proportions are calculated for hatchery and natural fish, expressed as the proportion of fish surviving from the smolts' entry into the mainstem Columbia or Snake to below Bonneville Dam; these proportions are applied to the number of smolts leaving the subbasin to yield the number of smolts surviving to below Bonneville Dam. These downstream survivals may differ due to different release dates or other factors.

\section{OCEAN SURVIVAL AND NON-TERMINAL HARVEST}

Like the Stochastic Life Cycle Model, the deterministic model handles this stage of the life cycle rather ditferently than the NPPC's System Planning Model (Northwest Power Planning Council, 1989) and other life cycle models, in that it does not make any assumptions about when mortality occurs. The ocean survival and non-terminal harvest relationships are based upon 
coded-wire tag (CWT) data. As with any mark-recapture data, CWT data do not contain any direct information on when and where fish die; one can only say when (that is, at what age) and where the fish are recaptured. From the CWT data, one can estimate model parameters which allocate surviving adults to ocean harvest, river harvest, and subiasin escapement, for each age. These parameters are expressed as the proportions of recovered fish that ocean harvest, river harvest, and subbasin escapement separately account for. The set of three coefficients for each stock thus provides the likelihood of being recovered in the ocean fishery, the in-river fishery, or of escaping to the subbasin, given that a fish is recovered in any of these three locations.

The proportion of fish that survive to be recovered (i.e., the proportion of smolts reaching below Bonneville dam that survive the estuary and the ocean life stages so that they can be recovered) is then calculated. This single parameter (for each stock) is estimated by making an initial guess and then adjusting its value until the equilibrium subbasin escapement output from the DLCM matches the average observed subbasin escapement. ${ }^{2}$ The final, stock-specific estimates that yield modeled subbasin escapement that match the observed subbasin escapement become the calibration coefficients for the DLCM. These calibration coefficients are meant to represent the proportion of fish surviving from below Bonneville Dam to recovery in one of the possible locations for recovery (i.e., recovery as ocean harvest, in-river harvest, and subbasin escapement). The value of the estimated calibration coefficients in relation to generally accepted, ballpark values for survival and recovery provides insight into the soundness of the model as a whole.

\section{DETERMINISTIC SIMULATION EQUATIONS}

The equations used in the simulation are derived directly from the Stochastic Life Cycle Model. There are three differences between the two models. First, in the Stochastic Life Cycle Model, the transition from one life stage to another is treated as a stochastic process with a probability of transition, $P$. The deterministic model treats the transitions as fixed proportions,

\footnotetext{
${ }^{2}$ The average observed subbasin escapement for each stock is calculated from 5 to 20 years of observations on subbasin escapement, depending on data availability.
} 
where the proportions are equivalent to the expected P values within the SLCM. Second, the Stochastic Life Cycle Model utilizes an age-structured population of adult fish (for harvest and spawners); the deterministic model collapses this into an adult population with no age structure. Finally, the Stochastic Life Cycle Model does not produce a non-zero equilibrium population; instead populations vary continuously over time. In contrast, the deterministic model guarantees an equilibrium (of size zero or otherwise).

In the discussion that follows, we describe the model equations in detail. The order is the same as that of the preceding sections of this appendix; variables are defined in Table A.1. The emphasis in the discussion is on presenting the concepts and principles which serve as the foundation for the model, rather than as a users' guide to the programs. The programs themselves are available from the authors at RFF, and interested parties are urged to contact us for the programs and further information.

One final note before proceeding to the equations themselves. Although it is possible to solve these models analytically, we have opted for a simulation approach. Analytical approaches, involving Leslie matrices and similar techniques produce only modest savings in computer time, and more importantly, are both more complex, in terms of model equations and computer code, and far less flexible than simulation, which can readily incorporate special cases, such as supplementation with several stocks as broodstock sources and/or multiple outplanting locations. Therefore, when reviewing the equations in the sections which follow, keep in mind that these are, in effect, in a larger "DO loop" which runs until the population reaches an equilibrium.

\section{Subbasin Allocation and Harvest}

The pure hatchery stock is the most straight-forward case:

\section{HATTERHA $=$ HATSUBES - HATREM}

where

HATTERHA = Pure Hatchery stock terminal harvest 
HATSUBES $=$ Pure Hatchery stock subbasin escapement

HATREM = Pure hatchery stock hatchery brood take.

Thus, for the pure hatchery stock, all not used for broodstock are assumed to be harvested in the subbasin.

For pure natural and supplementation stocks, things are slightly more complex, since the terminal harvest rate is allowed to vary, and the fish are subject to pre-spawning mortality:

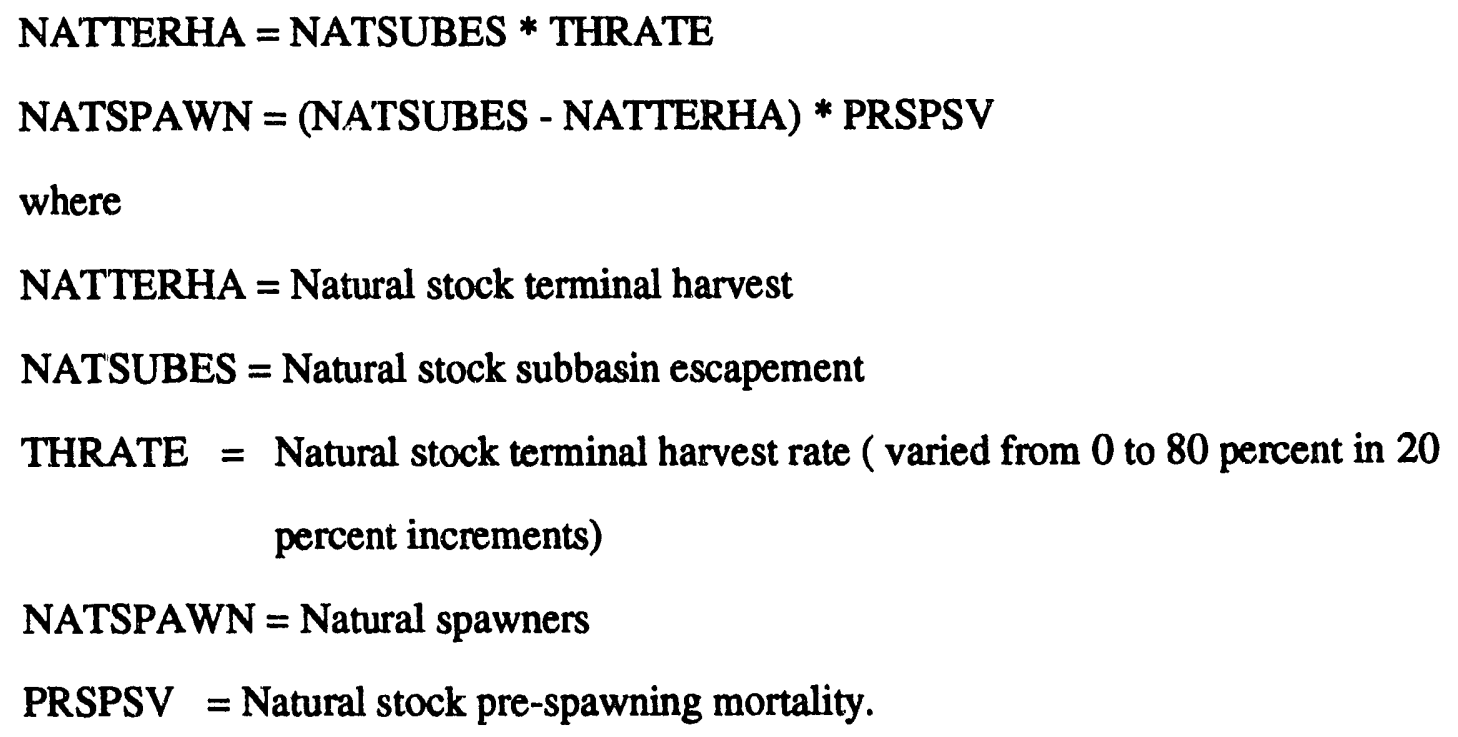

Supplementation is more complex than either of these, and there are several special cases (e.g., Lyons Ferry and Wells hatcheries) which involve multiple broodstock sources and/or outplanting locations.

\section{Spawning and Smolt Production}

As might be expected, pure hatchery smolt production is straight-forward. It essentially consists of "pumping out" smolts, as follows:

$$
\text { HSMOLTS }=\text { HATCAP } * \text { HINTSV }
$$


where

HSMOLTS $=$ hatchery smolts

HATCAP = hatchery smolt capacity

HINTSV = Hatchery smolt initial survival rate

As noted earlier, this relationship assumes that pure hatchery stocks always have sufficient broodstock to meet their smolt capacity. In effect, this implies that if a particular hatchery does not have enough fish returning in a given year, it will use broodstock or eggs from another hatchery. In any event, model runs to date suggest that this is not a problem for the hatcheries as modeled.

For natural spawners, there are three functional forms for the egg-to-smolt relationship. The first is the logistic, which works as follows:

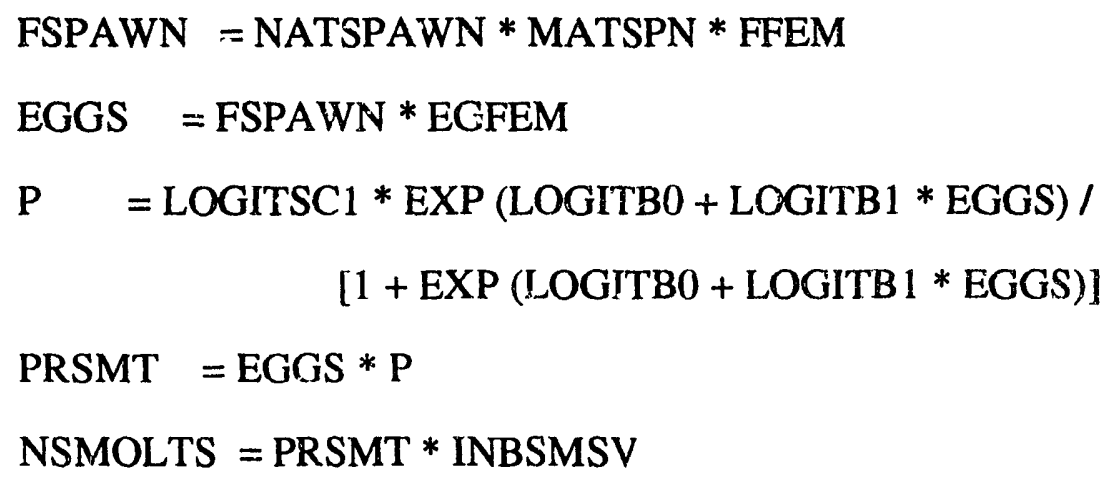

where

FSPAWN $=$ Female spawners

NATSPAWN = Total natural spawners, as defined in the preceding section

MATSPN = Sexually mature proportion of total spawning escapement

(To account for jacks among steelhead escapement)

FFEM = Fraction of spawning escapement that is female

EGFEM = Eggs per female spawner 
P = Proportion of eggs which survive to become pre-smolts

LOGITSCl $=$ Logistic equation scaling parameter

LOGITB0 = Logistic equation low-density survival parameter

LOGITB1 = Logistic equation high-density survival parameter

PRSMT = Number of natural pre-smolts produced

NSMOLTS $=$ Naturally spawned smolts leaving the subbasin

INBSMSV = Proportion of pre-smolts surviving to leave the subbasin

(Set to 1 for smolts leaving as sub-yearlings, $<1$ otherwise)

The foregoing equations require some explanation. The expressions for FSPAWN, EGGS, PRSMT and NSMOLTS are straight-forward representations of linear mortality processes. "P", on the other hand, is rather more complex. It is a representation of a survival process in which the likelihood of survival depends on the population density, measured here in terms of number of eggs. LOGITB1 has more influence on the "P" function's behavior at high densities, while LOGITB0 is more influential at lower densities. LOGITSC1 is a densityindependent scalar; its effect, like those of the other parameters in the spawning section, is strictly linear. In addition to these equations, we also make allowance for steelhead, which often remain in a subbasin for more than one year. This is done by breaking PRSMT into up to three segments, representing the proportions of smolts leaving as one, two, and three year-olds, and applying INBSMSV to each age class. The equations are omitted from this disclission for compactness.

For the Beverton-Holt option (which is actually used for all of the stocks in the systemwide cost-effectiveness analysis), the equations are the same as those shown above, except for the "P" function, which is:

$$
\text { P = BHINCP } /[1+(\text { BHINCP * EGGS }) / \text { BHCAP }]
$$


where

BHINCP $=$ Beverton-Holt low-density parameter

BHCAP $=$ Beverton-Holt smolt capacity

with other terms as previously defined. This functional form is widely used in fisheries modeling (Beverton and Hickt, 1957), and so we do not discuss it further.

The third option for the stock-recruitment relationship is the "empirical" stock-recruitment function. The method used in the Stochastic Life Cycle Model is documented in Lee and Hyman (1992). Because we did not use it in the above-Bonneville analysis, we do not discuss it further.

For supplemented stocks whose members sometimes spawn naturally, the stock-recruit functions are as described above. Note that for supplementation stocks spawning in hatcheries, we allow for the possibility that a supplementation hatchery may not meet its broodstock requirements.

\section{Downstream Passage}

The downstream passage portion of the simulation takes smolts produced in the subbasins and transports them to below Bonneville Dam, accounting for mortality incurred along the way. The equations are shown below.

HSMTOSEA $=$ HSMOLTS $*$ HMSURV

NSMTOSEA $=$ NSMOLTS * NMSURV

where

HSMTOSEA = Hatchery-origin smolts below Bonneville Dam

HMSURV = Hatchery-smolt downstream survival, from subbasin of origin to below Bonneville Dam

NSMTOSEA $=$ Natural-origin smolts below Bonneville Dam 
NMSURV = Natural-snolt downstream survival, from subbasin of origin to below Bonneville Dam

and HSMOLTS and NSMOLTS are as defined in the "Spawning and Smolt Production" section.

\section{Ocean Survival and Haryest}

As noted earlier, this section of the model is constructed somewhat differently from other life-cycle models. The focus is on smolts surviving to adulthood and where the adults are recovered, rather than on survival rates and harvest rates. To see how the recovery factors are calculated, consult the equations below.

OCNRECVRAT $=$ OCNREC $/$ TOTREC

RIVRECVRAT $=$ RIVREC/TOTREC

SUBESCVRAT $=$ SUBREC/TOTREC

where

OCNRECVRAT $=$ Proportion of total recoveries which occur in the ocean fishery

RIVRECVRAT $=$ Proportion of total recoveries which occur in the in-river fishery

SUBESCVRAT $=$ Proportion of total recoveries which occur in the subbasin (as subbasin harvest or returns to the hatchery or natural spawning area).

Recoveries are based upon analysis of coded-wire-tag (CWT) data. Because CWT data is rarely available for naturally spawned fish, we usually employ the same parameters for both hatchery, natural, and supplementation stocks. One exception to this rule is for naturally 
produced steelhead, which we assume are not subject to non-terminal harvest. Note that although this approach avoids assumptions about mortality rates, it also means that changes in non-terminal harvest rates (as management actions to benefit the fish) must be handled carefully to avoid other problems. Since we do not include changes in non-terminal harvest regimes in the current version of the model, this type of calculation is not shown here.

The next step is to calculate the actual numbers of fish, by stock, which are recovered. To do this, we employ a fitting parameter for each stock, which is designed so that average subbasin escapement for the calibration case (see Chapter 4) is the same as the historical record for each stock. The equations for hatchery and natural stocks are shown below.

\section{HOCNHARV $=$ HSMTOSEA $*$ OCNRECVRAT $*$ HADTRECV \\ HRIVHARV $=$ HSMTOSEA $*$ RIVRECVRAT $*$ HADTRECV \\ HATSUBES $=$ HSMTOSEA * SUBESCVRAT * HADTRECV}
NOCNHARV $=$ NSMTOSEA $*$ OCNRECVRAT $*$ NADTRECV
NRIVHARV $=$ NSMTOSEA $*$ RIVRECVRAT * NADTRECV
NATSUBES $=$ NSMTOSEA $*$ SUBESCVRAT $*$ NADTRECV

where

HOCNHARV = Hatchery-stock ocean harvest

HRIVHARV $=$ Hatchery-stock in-river harvest

HATSUBES = Hatchery-stock subbasin escapement

HADTRECV = Hatchery-stock fitting parameter, expressed as adults per smolt arriving below Bonneville Dam

NOCNHARV = Natural-stock ocean harvest

NRIVHARV = Natural-stock in-river harvest

NATSUBES = Natural-stock subbasin escapement 
NADTRECV $=$ Natural-stock fitting parameter, expressed as adults per smolt arriving below Bonneville Dam

\section{MODEL OUTPUTS}

The outputs from the deterministic simulation serve as inputs to the optimization model. Recall that the simulation model is run once per stock/propagation strategy/passage strategy combination. The simulation model population projections on runsize, terminal harvest and spawning escapement are then used by the optimization model, to calculate basin-wide costeffective strategies to meet goals for harvest and spawning escapement. At present, both models concentrate on subbasin harvest, but this could be expanded to include non-terminal harvest, if required. 
101

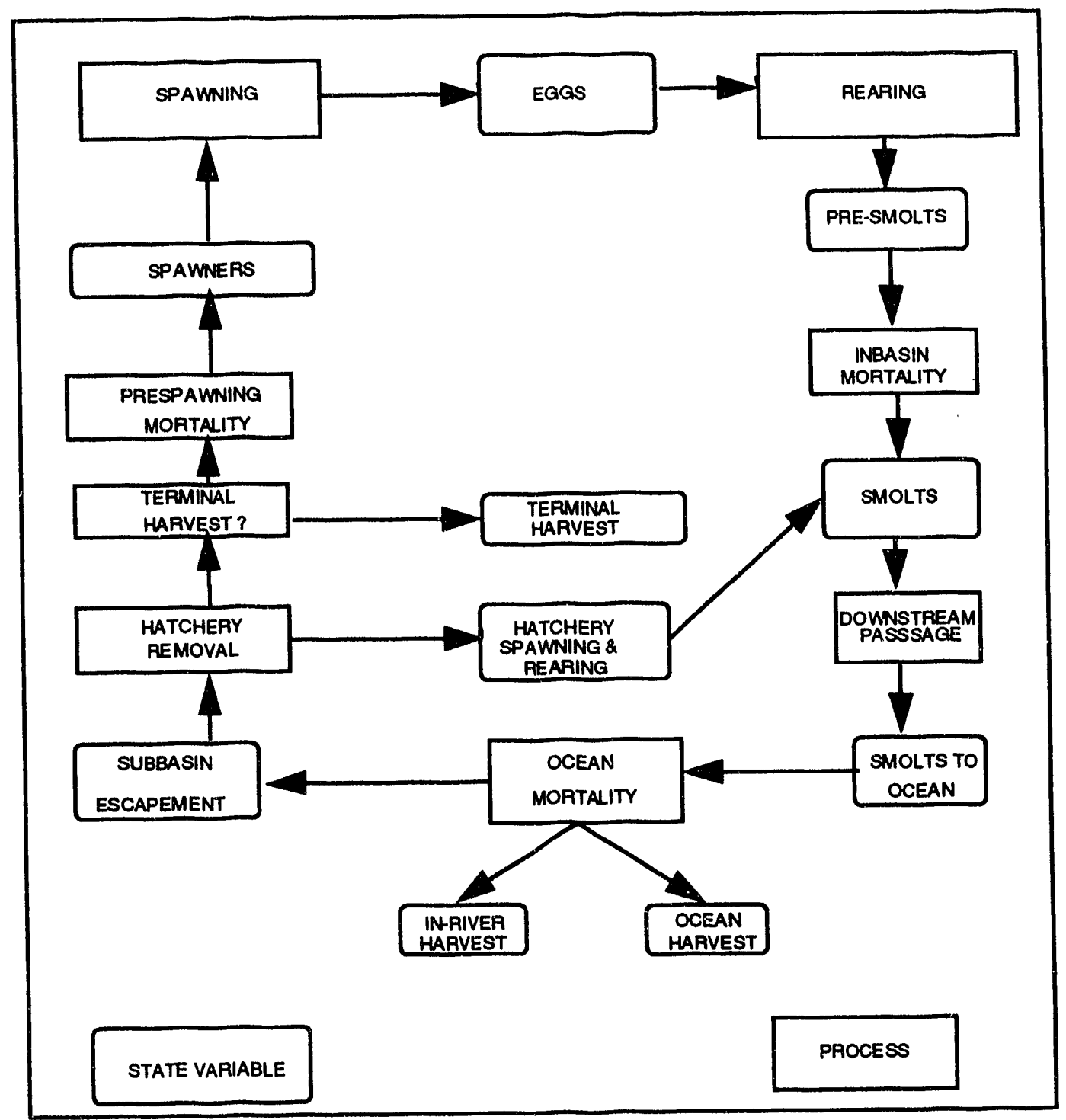

FIGURE A.1. SALMON LIFE CYCLE 


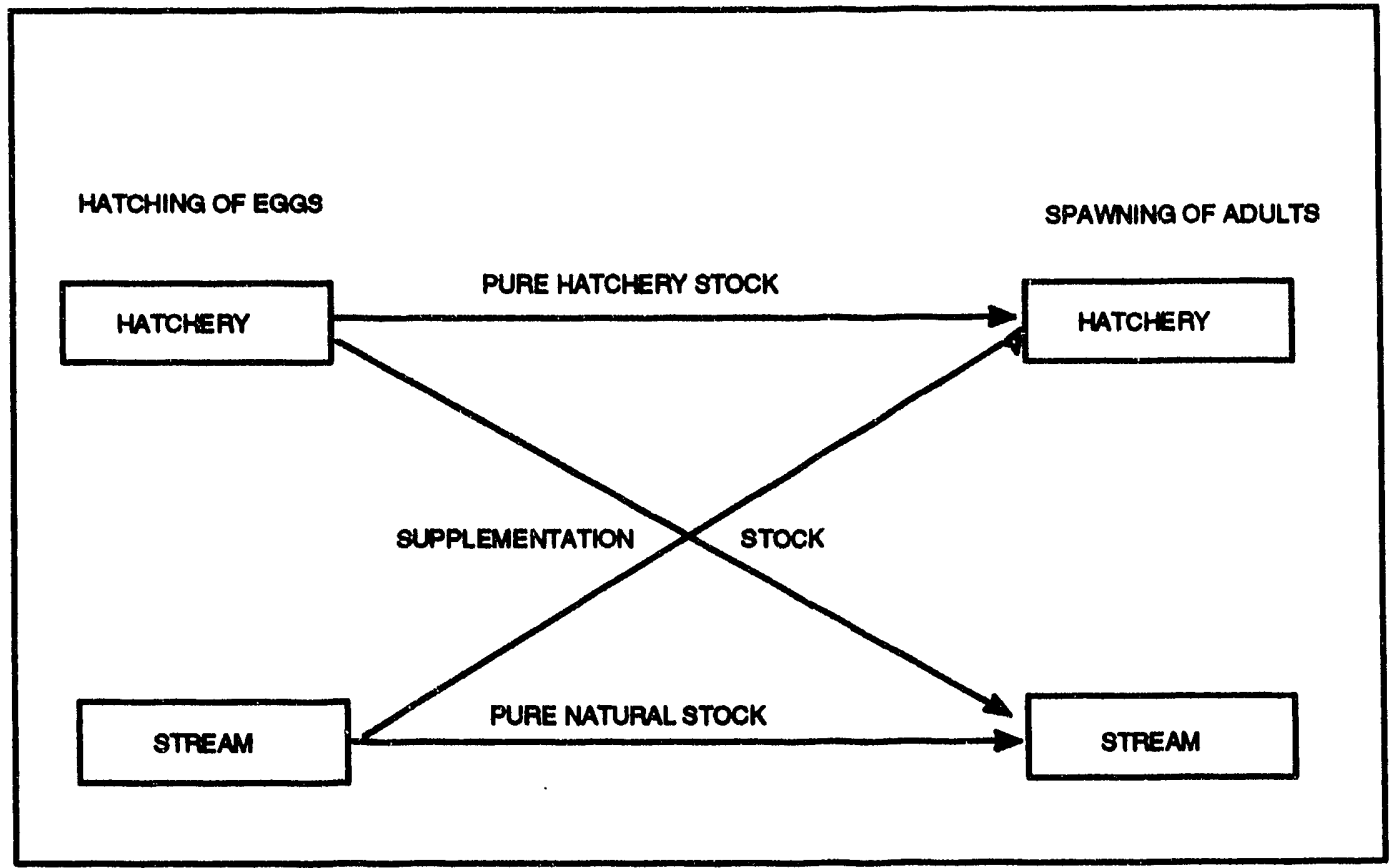

Figure A.2. Illuetreded Dellintion Or Pure Hatchory, 8upplomentation, and Natural Stocke 
TABLE A.1

Deterministic Simulation Model Variables and Definitions

\begin{tabular}{|c|c|}
\hline Variable $^{*}$ & Definition \\
\hline HATTERHA & Pure Hatchery stock terminal harvest \\
\hline HATSUBES & Pure Hatchery stock subbasin escapement \\
\hline HATREM & Pure hatchery stock hatchery brood take. \\
\hline NATTERHA & Natural stock terminal harvest \\
\hline NATSUBES & Natural stock subbasin escapement \\
\hline THRATE & Natural stock terminal harvest rate \\
\hline NATSPAWN & Natural spawners \\
\hline PRSPSV & Natural stock pre-spawning mortality. \\
\hline HSMOLTS & hatchery smolts \\
\hline HATCAP & hatchery smolt capacity \\
\hline HINTSV & Hatchery smolt initial survival rate \\
\hline FSPAWN & Female spawners \\
\hline NATSPAWN & Total natural spawners \\
\hline MATSPN & $\begin{array}{l}\text { Sexually mature proportion of total spawning escapement (to account for jacks among steelhead } \\
\text { escapement) }\end{array}$ \\
\hline FFEM & Fraction of spawning escapement that is female \\
\hline EGFEM & Eggs per female spawner \\
\hline $\mathbf{P}$ & Proportion of eggs which survive to become pre-smolts \\
\hline LOGITSC1 & Logistic equation scaling parameter \\
\hline LOGITBO & Logistic equation low-density survival parameter \\
\hline LOGITB1 & Logistic equation high-density survival parameter \\
\hline PRSMT & Number of natural pre-smolts produced \\
\hline NSMOLTS & Naturally spawned smolts leaving the subbasin \\
\hline INBSMSV & $\begin{array}{l}\text { Proportion of pre-smolts leaving the subbasin. Set to } 1 \text { for smolts leaving as sub-yearlings, } \\
0 \text { otherwise }\end{array}$ \\
\hline BHINCP & Beverton-Holt low-density parameter \\
\hline BHCAP & Beverton-Holt smolt capacily \\
\hline HSMTOSEA & Hatchery-origin smolts below Bonneville Dam \\
\hline HMSURV & Hatchery-smolt downstream survival, from subbasin of origin to below Bonneville Dam \\
\hline NSMTOSEA & Natural-origin smolts below Bonneville Dam \\
\hline NMSURV & Natural-smolt downstream survival, from subbasin of origin to below Bonneville Dam \\
\hline OCNRECVRAT & Proportion of total recoveries which occur in the ocean fishery \\
\hline RIVRECVRAT & Proportion of total recoveries which occur in the in-river fishery \\
\hline SUBESCVRAT & Proportion of total recoveries which occur in the subbasin \\
\hline HOCNHARV & Hatchery-stock ocean harvest \\
\hline HRIVHARV & Hatchery-stock in-river harvest \\
\hline HATSUBES & Hatchery-stock subbasin escapement \\
\hline NOCNHARV & Natural-stock ocean harvest \\
\hline NRIVHARV & Natural-stock in-river harvest \\
\hline NATSUBES & Natural-stock subbasin escapement \\
\hline NADTRECV & Natural-stock fitting parameter, expressed as adults per smolt arriving below Bonneville Dam \\
\hline HADTRECV & Hatchery-stock fitting parameter, expressed as adults per smolt arriving below Bonneville Dam \\
\hline
\end{tabular}

* $\quad$ Bolded variables are exogenous, fixed parameters, while variables without bolded text are variables whose values are calculated endogenously. 


\section{APPENDIX B OPTIMIZATION MODEL DESCRIPTION}

\section{INTRODUCTION}

The optimization model identifies the least-cost combination of passage, propagation, and harvest alternatives to meet a set of numerical goals for each stock. In this appendix, we begin with a brief review of concepts presented in Chapter 2, including system complexity and management strategies. We then proceed to a simplified example of the workings of the optimization model. We develop the example heuristically, to give an intuitive feel for how the optimization model solves the system-wide $\mathrm{C} / \mathrm{E}$ problem. Next, we lay out the equations which formally comprise the model structure as applied to the above-Bonneville subbasins in this report. In the next-to-last section, we combine the heuristic example with the formal optimization equations, and describe the example using the notation developed for the formal description. The appendix concludes with our thoughts on how the optimization model could be extended to handle more complex objectives, including dynamic analyses and explicit consideration of stochasticity.

\section{SYSTEM COMPL.EXITY}

The ared above Bonneville Dam contains steelhead, sockeye salmon, and several runs (spring, summer and fall) of chinook saimon, and other fish as well. We have excluded sockeye from our analysis, due to the lack of biological data and stock-specific objectives for most sockeye populations. The subbasin planners divide each species into stocks, based upon the subbasin where they spawn and whether they are of hatchery or natural origin. We make an additional division of hatchery-origin fish into "pure" hatchery and supplementation stocks. The result is that we analyze management objectives and management actions for 79 stocks.

In addition to the large number of stocks, two other factors complicate the analysis. First, as noted earlier, passage actions affect more than nne stock at a time. Actions specific to a particular dam affect every stock above that dam, while flow actions affect all stocks migrating 
during the period when the flow action is in operation. Second, even within subbasins, propagation actions often affect every stock which spawns in the subbasin. Finally, the number of adilts priduced is a function of both fropagation ard passage conditions. The result is that one cannot hope to find a system-wide combination of passage and propagation actions to meet the stock-specific objectives at least cost without taking account of these interactions. The reader may wish to refer to the simple example in Chapter 2; definitions of key terms are repeated in Table B.1.

\section{EXA MPLE PROBLEM}

To help provide a better understanding of the workings of the optimization, we have created a small empirical example using data from one of the scenarios reported in Chapter 5. For the example, we have chosen two subbasins -- the Clearwater and the Deschutes -- and two stoaks for each of the subbasins -- spring chinook and summer steelhead. Each subbasin has two propagation strategies: a base case and a strategy with improved habitat. Each stock in each subbasin has two terminal harvest rates: twenty and forty percent. In addition, the two-subbasin system has two passage strategies: a base case and strategy with improved downstream passage. We show these alternatives in Table B.2.

Following the logic in Chapter 2, there are 16 propagation/terminal harvest/passage alternatives for each subbasin ( 2 propagation strategies * 2 passage strategies * 2 stocks * 2 terminal harvest rates per stock). This, in turn, leads to 128 possible system-wide strategies, looking across all of the cornbinations of system-wide passage strategies, subbasin-specific propagation strat:gies, and stock-specific terminai harvest rates (i.e., 2 passage strategies * [2 Clearwater propagation strategies * 2 Clearwater stocks * 2 terminal harvest rates per stock] * [2 Deschutes propagation strategies * 2 Deschutes stocks * 2 terminal harvest rates per stock] ).

Having determined which alternatives are of interest, the next step in the process is to use the deterministic life cycle model to calculate terminal harvest and spawning escapement levels for each alternative for each stock. Table B.3 shows the numerical results from the deterministic 
simulation model for each of the propagation-terminal harvest-passage alternatives ( 16 for each of the two subbasins). Table B.4 shows which alternatives meet the goals for each stock ${ }^{1}$.

We will now try to demonstrate how the basin-wide model identifies the least-cost systemwide strategy $s 0$ meet the objectives for each stock. ${ }^{2}$ The first step is to select the propagationterminal harvest-passage alternatives that meet the goals for both stocks, since alternatives which do not meet the objectives can be excluded from further consideration. Starting with the results shown in Table B.4, one can see that within each subbasin, only a small subset of the alternatives meet the terminal harvest and spawning goals for hoth stocks simultaneously. Looking only at these feasible alternatives limits the number of possibilities considerably; we show the feasible alternatives in Table B.5. This reduces the number of alternatives under consideration from 32 to 15. Furthermore, because base case passage and base-case propagation do not meet the objectives for Clearwater spring chinook, we can eliminate all alternatives in Table B.5 that contain either the base-case passage strategy, the Clearwater base case propagation strategy, or both. Eliminating base-case passage and Clearwater base case propagation is possible since both subbasins must use the same passage strategy (i.e., improved passage), and within the Clearwater, both steelhead and chinook must use the same propagation strategy (i.e., improved habitat). This leaves 8 propagation-terminal harvest-passage alternatives still under consideration; they are shown in Table B.6.

At this point, we are left with only one combination of passage and propagation for the Clearwater: improved passage conditions and improved habitat. In addition, we can see from Table B.6 that no choices remain on harvest rates for the Clearwater -- only the forty percent terminal harvest rates are still under consideration, since the iwenty percent rate does not meet the

\footnotetext{
${ }^{1}$ The choice of goals (i.e., terminal harvest and spawning escapement) are similar to those chosen by the subbasin planners. We have modified the planners' specific numerical objectives for this example to provide a better illustration of how the optimization model works.

2 The intention behind this example is to show how the model solves the optimization problem based on ordinary intuition. Technically, the model uses a modified simplex method, which gives the same result using different computational methods than those presented here.
} 
terminal harvest objectives. For the Deschutes, things are slightly more complicated. (Recall that Deschutes alternatives using base case passage were eliminated above.) At this point (and not before) costs enter into the picture. First of all, it is obvious that doing nothing costs less than habitat improvements, and since base-case propagation conditions still allow the Deschutes harvest and spawning escapement goals to be met, we can eliminate habitat improvement strategies from further consideration in the Deschutes. This leaves only the twenty percent harvest rate alternatives for spring chinook and steelhead in the Deschutes, since the alternatives using forty percent terminal harvest do not meet spawning escapement objectives for either stock. Table B.7, then, shows the system-wide cost-effective strategy. The strategy consists of passage improvements, habitat improvements in the Clearwater, and base case propagation conditions in the Deschutes.

To summarize the screening process, the procedure for finding the system-wide least-cost strategy which meets the objectives for all stocks consists of the following steps:

1. Run the deterministic simulation mode' (described in appendix A) for each passage/propagation/terminal harvest alternative, for each stock.

2. For each stock, find and eliminate all passage/propagation/terminal harvest alternatives that are infeasible (i.e., alternatives that do not meet the stock's terminal harvest and/or spawning goals).

3. Determine which passage strategy is common among all alternatives remaining under consideration, and eliminate any alternatives chosen in (2) which use a different passage strategy.

4. For each subbasin, select the lowest-cost propagation strategy from those remaining after step (3)

5. For each passage/propagation/terminal harvest alternative remaining after step (4), select a terminal harvest rate. The result will be the system-wide cost-effective strategy.

Obviously, as the system under consideration becomes more complex, this simple solution procedure would need to be expanded. For example, more than one passage strategy may meet 
the goals for all stocks (in combination with propagation strategies in each subbasin). In addition, it is possible that no passage/propagation/terminal harvest alternative will meet the objectives for some stocks. Finally, some stocks may be able to meet their goals using more than one terminal harvest rate. The next section shows how the simple methods explained above can be extended to the more complex above-Bonneville analysis.

\section{OVERVIEW OF MODEL STRUCTURE}

This section explains the structure of the optimization model in detail. In contrast to the heuristic description, in this section we present and explain the equations in the actual optimization. We demonstrate how the model is constructed and the logic behind each of the equations, but we do not explain how the model actually solves the linear programming problem. In the section following this one, we have an example of how to construct the matrix of equations used by the model, using the same data as the heuristic example.

In reading the subsections which follow, several points should be kept in mind. First, the model structure is explained sequentially, as though the optimization looked at costs first, passage strategies second, and so forth. We do this solely for ease in explication. In fact, the algorithm which is employed (a modified simplex ${ }^{3}$ ) looks at the biological objectives, passage and propagation strategies, costs, and other information simultaneously to identify a system-wide least-cost strategy. Second, the model structure is complicated because it contains so many subibasin: and stocks. However, the iux of the proulem is really fairly simple. The objective of the exercise is to select the combination of passage, propagation, and terminal harvest options which will meet a set of stock-specific goals, and do so at least cost. Third, with the exception of the objective function (which has cost information for each passage and propagation strategy), and constraints on fish production (to ensure that the model "produces" at least as many fish of

\footnotetext{
${ }^{3}$ The model is solved using SAS PROC LP (SAS is a registered trademark of the SAS Institute, Cary, NC). PROC LP uses a modified version of the simplex algorithm, and for this model, requires approximately one to three hours of CPU time to solve the basin-wide linear programming (LP) parts of the model.
} 
each stock as the user specifies) the model structure is made up of what are known in optimization as mass-balance constraints. These serve to ensure that the solution is internally consistent, such that the Deschutes subbasin, for example, uses the same downstream passage strategy as the Clearwater, and that Clearwater chinook and steelhead both use the same propagation strategy.

In the context of the system-wide model, the essential concepts can be explained without reference to the technical details, which are described in subsequent sections of this appendix. ${ }^{4}$ The task of the optimization model is to meet stock-specific goals for terminal harvest and spawning escapement at the lowest possible system-wide cost, given the available passage strategies, propagation strategies, and terminal harvest rates. Using the terms defined in Chapter 2 , the linear program (LP) must choose a single system-wide least-cost strategy, using a combination of one passage strategy (for the entire basin) and one propagation strategy per subbasin, and one terminal harvest rate per stock.

In the remainder of this section, we first define the variables used in the optimization model, then define the equations used for the passage, propagation, fish production, and constraint portions of the optimization. Readers unfamiliar with optimization models in general and linear programming terms in particular may wish to consult Table B.8 for some informal definitions of the technical terms used in the discussion. Table B.9 shows the definitions of the variables and subscripts used in the discussion below.

Recall from the earlier discussion that only passage and propagation strategies have costs. Therefore, they are the only LP activities which have objective function entries:

${ }^{4}$ In traditional matrix notation, the formal structure of the linear programming model is Minimize $\quad$ CX Subject to $\mathbf{A X}=\mathbf{B}$ where " $\mathbf{X}$ " is an array of decision variables, "C" is an array of costs, " $\mathbf{A}$ " is a matrix of technical coefficients, and "B" an array of constraints. 
Minimize $\sum_{\mathrm{m}}\left(\right.$ PASS $\left._{\mathrm{m}} * \mathrm{CPASS}_{\mathrm{m}}\right)+\sum_{1} \sum_{\mathrm{r}}\left(\mathrm{PROP}_{\mathrm{i}, \mathrm{n}} * \mathrm{CPROP}_{\mathrm{i}, \mathrm{n}}\right)$

where:

$$
\begin{aligned}
& \text { PASS }_{\mathrm{m}}=\quad \text { Passage strategy } \\
& \text { PROP }_{i, n}=\quad \text { Propagation strategy } \\
& \text { CPASS }_{m}=\text { Cost of passage strategy } \\
& \text { CPROP }_{i, n}=\text { Cost of propagation strategy (cost of strategy is } \\
& \text { sum of costs of actions included in strategy). }
\end{aligned}
$$

As the LP chooses among corrbinations passage and propagation strategies, the values for PASS $_{m}$ and PROP $_{i, n}$ take on non-zero values. ${ }^{5}$ The $L P$ will minimize the total cost of passage and propagation, while at the same time it meets constraints on fish production and the internal mass-balance constraints described below. Note that the set of system-wide passage strategies, and each set of subbasin-specific propagation strategies, will include one base-case strategy with cost of 0 .

Next, since the LP can use only one system-wide downstream passage strategy,

$$
\sum_{m} \text { PASS }_{m}=1
$$

Equation (2) requires the LP to choose exactly one system-wide passage strategy, since the $\mathrm{PASS}_{\mathrm{m}}$ variables can only take on $0 / 1$ values.

The next set of equations are mass-balance constraints used to ensure that the subbasin

5In practice, all model activities (passage, propagation, etc.) take on only two values -- zero or one -- in the system-wide cost-effective strategy. 
and stock-level passage capacities can operate only if the required system-wide passage strategy activity has taken on a value of one ${ }^{6}$.

$$
\begin{aligned}
& \forall_{i} \text { SUBPASS }_{\mathrm{i}, \mathrm{m}}=\text { PASS }_{\mathrm{m}} \\
& \forall \text { STOCKPASS }_{\mathrm{i}, \mathrm{j}, \mathrm{m}}=\text { SUEPASS }_{\mathrm{i}, \mathrm{m}}
\end{aligned}
$$

where:

SUBPASS $_{\mathrm{i}, \mathrm{m}}=$

STOCKPASS $_{\mathrm{i}, \mathrm{j}, \mathrm{m}}=$
Subbasin -specific passage activities

Stock-specific passage activities.

Equations (3) and (4) connect the PASS $m$ activities to subbasins and stocks in the following fashion. Suppose that the LP operates PASS 2 which then takes a value of 1 . Then SUBPASS $_{i, 2}$ will need to take on a value of 1 (to meet the constraint in equation (3)), as will STOCKPASS $\mathrm{i}_{\mathrm{i}, \mathrm{j}, 2}$, in order to fulfill the requirements of equation (4). This will hold for all subbasins (i.e., for every " $\mathrm{i}$ ") and for all stocks in each subbasin (i.e., for every " $\mathrm{j}$ "). In other words, one PASS $_{m}$ must be equal to one in order to operate the corresponding SUBPASS $S_{i, m}$ variable. A SUBPASS ${ }_{i, m}$ variable must equal one in order to operate STOCKPASS $_{i, j, m}$, and, in turn, one STOCKPASS $\mathrm{i}_{\mathrm{i}, \mathrm{j}} \mathrm{m}$ variable must be greater than zero to "operate" the corresponding stock-specific alternative, in the adult production section. This ensures that a given system-wide passage strategy will be iinked correctly to the subbasin and stock-level passage activities. The STOCKPASS capacities are used to "create" fish, as described below.

The propagation capacities are constructed in much the same fashion as the passage capacities. The first are the subbasin-level propagation strategies.

6The symbol $\forall i$ denotes "for every $\mathrm{i}$ ". 
$\forall_{i} \sum_{\mathrm{n}}$ PROP $_{\mathrm{i}, \mathrm{n}}=1$

where the PROP $i, n$ are as previously defined in equation (1). There are "I" constraints on propagation strategies or activities, one per subbasin. This set of constraints ensures that exactly one propagation strategy will be chosen for each subbasin, in the same way that equation (2) ensures that exactly one passage strategy will be chosen system-wide. It also ensures that when a propagation strategy is chosen, the corresponding PROP $_{\mathrm{i}, \mathrm{n}}$ variable will then take a value of exactly one.

As with the passage strategies, the propagation strategies are split into stock-specific capacities.

$\forall{ }_{j}$ STOCKPROP $\quad i, j, n=$ PROP $i, n$

where:

STOCKPROP $_{i, j, n}=$ Stock-level propagation activities.

This set of constraints ensures that the stock-level STOCKPROP activities can take on a value of one if and only if the corresponding subbasin-level PROP activities are non-zero. For example, STOCKPROP $1,2,3$ can be equal to one if and only if $\operatorname{PROP}_{1,3}=1$. The STOCKPROP variables are used in the adult production section, below.

The adult production activities use the stock-specific capacities created in the previous two sections. The result, is that any given adult production activity, MAKEFISH $_{i, j, m, n, h}$, can only operate, (i.e., take on a value of one) if its corresponding passage and propagation strategies also are equal to one. ${ }^{7}$

${ }^{7}$ Note that the model will contain a MAKEFISH $\mathrm{i}, \mathrm{j}, \mathrm{m}, \mathrm{n,h}$ for every passage/propagation/terminal harvest alternative, for every stock. These are the activities or decision variables which actually "produce" fish. 


$$
\forall_{\mathrm{i}, \mathrm{j}, \mathrm{n}} \sum_{\mathrm{b}} \text { MAKEFISH }_{\mathrm{i}, \mathrm{j}, \mathrm{m}, \mathrm{a}, \mathrm{h}}=\text { STOCKPASS }_{\mathrm{i}, \mathrm{j}, \mathrm{a}}
$$

and

$$
\forall_{\mathrm{i}, \mathrm{j}, \mathrm{m}} \sum_{\mathrm{b}} \text { MAKEFISH }_{\mathrm{i}, \mathrm{j}, \mathrm{m}, \mathrm{n}, \mathrm{h}}=\text { STOCKPROP }_{\mathrm{i}, \mathrm{j}, \mathrm{m}}
$$

where MAKEFISH $\mathrm{i}_{\mathrm{j}, \mathrm{m}, \mathrm{n}, \mathrm{h}}=$ fish production activity, harvest rate $\mathrm{h}$.

In effect, equations (7) and (8), in combination with equations (3), (4), and (6), ensure that any given propagation/terminal harvest/passage alternative, MAKEFISH $i, j, m, n, h$, can take a value of one in the model solution only if the corresponding system-wide passage strategy and subbasin-level propagation strategy are operated by the LP. The summations are needed so that all harvest rates will sum to one, and exactly one terminal harvest rate will be operated for each stock.

The final portion of the LP determines whether or not each MAKEFISH activity meets objectives for terminal harvest and spawning escapement for each stock. This uses the data produced by the deterministic simulation model (described in Appendix A) on the number of adults harvested in the subbasin and the number escaping to spawn.

$$
\begin{aligned}
& \text { SPAWGOAL }_{\mathrm{i}, \mathrm{j}}=\forall_{\mathrm{m}, \mathrm{n}} \sum_{\mathrm{h}} \text { MAKEFISH }_{\mathrm{i}, \mathrm{j}, \mathrm{m}, \mathrm{n}, \mathrm{b}} \cdot \mathrm{b}_{\mathrm{i}, \mathrm{m}, \mathrm{m}, \mathrm{n}, \mathrm{h}} \\
& \text { HARVGOAL }_{\mathrm{i}, \mathrm{j}}=\forall_{\mathrm{m}, \mathrm{n}} \sum_{\mathrm{h}} \text { MAKEFISH }_{\mathrm{i}, \mathrm{j}, \mathrm{m}, \mathrm{n}, \mathrm{h}} \cdot \mathrm{a}_{\mathrm{i}, \mathrm{j}, \mathrm{m}, \mathrm{n}, \mathrm{b}}
\end{aligned}
$$

where:

HARVGOAL $\mathrm{i}_{\mathrm{i} j}=1$ if a non-zero harvest goal has been established for stock $\mathrm{i}, \mathrm{j} ; 0$ otherwise;

SPAWGOAL $_{\mathrm{i}, \mathrm{j}}=1$ if a non-zero spawning escapement goal has been established for 
stock $\mathrm{i}, \mathrm{j} ; 0$ otherwise;

$a_{i, j, m, n, h}=1$ if MAKEFISH $_{i, j, m, n, h}$ meets or exceeds the harvest objective for stock $\mathrm{i}, \mathrm{j} ; 0$ otherwise (based on output from the DLCM)

$\mathrm{b}_{\mathrm{i}, \mathrm{j}, \mathrm{m}, \mathrm{n}, \mathrm{h}}=1$ if MAKEFISH $_{\mathrm{i}, \mathrm{j}, \mathrm{m}, \mathrm{n}, \mathrm{h}}$ meets or exceeds the spawning escapement objective for stock $i, j ; 0$ otherwise (based on output from the DLCM)

MAKEFISH $_{i, j, m, n, h}$ as previously defined.

Equations (9) and (10) are where the rubber finally meets the road, in that these let the LP know which MAKEFISH alternatives actually meet the goals for each stock. If a particular MAKEFISH $_{i, j, m, n, h}$ meets or exceeds the stock's terminal harvest goal (based on calculations in the Deterministic Life Cycle Model) its $a_{i, j, m, n, h}$ is set to 1 , otherwise the $a_{i, j}, m, n, h$ is set to zero (and similarly for the $b_{i, j, m, n, h}$ and spawning escapement). In this way, the LP determines whether or not each MAKEFISH $\mathrm{i}_{\mathrm{i}, \mathrm{j}, \mathrm{m}, \mathrm{n}, \mathrm{h}}$ is a potential part of a feasible solution (i.e., one which meets the goals for all stocks). Once the LP has found the feasible subset of

MAKEFISH $_{i, j}, m, n, h$ 's, it then checks to see which combination of passage and propagation

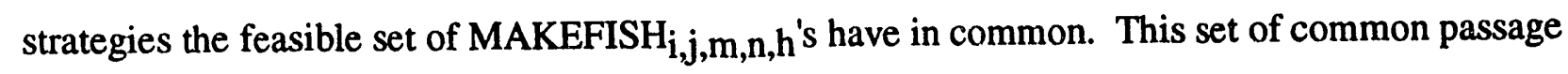
and propagation alternatives is then checked to see which passage/propagation combination has the lowest cost, producing the system-wide least-cost strategy for a given set of adult production goals.

\section{HEURISTIC OPTIMIZATION EXAMPLE}

In this section we combine the heuristic example and the optimization equations developed earlier in this appendix. The result is an LP tableau which contains all of the equations required to solve the LP for the small heuristic example.

The starting point for this is Table B.4, which shows the results for 32 runs of the Deterministic Simulation Model. This contains all of the biological information required to build 
an actual LP for the heuristic model. The only other information needed is the cost of the passage and propagation strategies, shown in Table B.10.

The LP tableau is shown in Table B.11. We show how each element in the tableau is constructed. For convenience in exposition, we follow roughly the same order as in the preceding section.

In this discussion, we focus on how one can translate the heuristic example into a form that the linear programming model can solve. Before plunging into the details of the translation, however, some background on how to interpret the admittedly imposing tableau may be useful. In Table B.11, the rows of the Table represent LP equations, while the columns are LP "decision variables" which the LP can operate at a value of either zero or one. Essentially, the equations are conditions which the LP must meet -- harvest objectives to be achieved, et cetera -- and the columns are activities which the LP can undertake in order to meet them. When the LP solves, or selects a system-wide least-cost strategy, it decides which columns or activities will take on a value of one, and which will take on a value of zero, while meeting the constraints shown in the rows of the tableau.. In the tableau, columns $\mathbf{D}$ and $\mathbf{E}$ represent passage strategies, while $\mathbf{F}$ through I represent propagation strategies. Columns $\mathbf{J}$ through $\mathbf{M}$ link strategies to alternatives, while $\mathbf{N}$ through $\mathbf{A S}$ represent passage/propagation/terminal harvest alternatives.

Each equation or row in the tableau can be interpreted as the sum of the columns or activities values in the solution multiplied by the coefficients in the body of the table (since the matrix of coefficients is very sparse, most zero values are left blank in the tableau). For example, row three in the tableau is interpreted as follows:

$$
\begin{aligned}
& \text { PASS_SOS_ROW }=1(\text { since it has a right-hand-side of } 1) . \\
& \text { PASS_SOS_ROW }=(\text { PASS_BASE } * 1)+(\text { IMPRPASS * } 1)
\end{aligned}
$$

Equation (11) means that for the LP to solve the problem, PASS_SOS_ROW must be equal to 1. Equation (12) means that sum of the PASS_BASE and IMPRPASS activities must equal 1, or in 
other words that exactly one of them must be "operated" by the LP. No other activities are involved in row 3 of the tableau, since all other activities have a coefficient of zero in row 3 . With this as background, we now proceed to the details.

Column " $\mathrm{A}$ " shows which equation numbers (from the previous section) each row of the tableau refers to. The row name is in column " $\mathrm{B}$ ", the "right-hand-side" in column "C", and the activity or strategy names in columns "D" through "AS". Row 1 in Table B.11 contains identifying information for the rows and columns. Row 2 contains the objective function, and has non-zero entries only for the activities with non-zero costs -- the passage activities PASS_BASE and IMPRPASS, and the propagation activities PROP_DE_BASE, PROP_DE_IMPROVED, PROP_CL_BASE, and PROP_CL_IMPROVED. The passage strategies are, respectively, the base case, PASS_BASE, (with a cost of zero) and an improvement, IMPRPASS, which costs $\$ 9$ million per year. The propagation strategies apply to two subbasins (Deschutes, or "DE", and the Clearwater, "CL") and are their base cases or improvements in propagation represented by "BASE" or "IMPROVED" in the column names. The objective function is the equation which the model tries to minimize. By convention the right-hand-side of the objective function is denoted by an "N" in the RHS column, meaning that the row is unconstrained. (All other rows have a right-hand-size of either 0 or 1.) The interpretation of row 2 of the tableau is that the objective function is:

$$
\begin{aligned}
\text { OBJROW }= & (\text { PASS_BASE * })+(\text { IMPRPASS * })+ \\
& (\text { PROP_DE_BASE } * 0)+(\text { PROP_DE_IMPROVED *0.3 })+ \\
& (\text { PROP_CL_BASE *0)+(PROP_CL_IMPROVED * 0.41 })
\end{aligned}
$$

The LP will minimize the value of this function, subject to the constraints described below. In effect, the model will chose which strategies (columns in the tableau) to set to one, and which to set to zero, so as to meet the constraints and minimize the value of the objective function.

Recall from equations (2) and (5) that the LP can use only one system-wide passage 
strategy and one propagation strategy for each subbasin. This is shown in row 3 of Table B.11 for the passages strategies, and rows 16-17 for the propagation strategies. For passage, the sum of PASS_BASE and PASS_IMP is constrained to be equal to 1 (from row 3's RHS value) so only one of the passage strategies (either the base case or the improvement strategy) will operate. The same applies for the propagation strategies for each subbasin, with row 16 constraining the Deschutes propagation strategies, and row 17 constraining the Clearwater, to be equal to one.

Equations (3) and (4) ensure consistency between the basin-wide passage strategy and the passage strategy used at the subbasin and stock levels. This is translated into the model tableau in rows 4-7 for equation (3), and rows 8-15 for equation (4). For example, row 4 specifies that the values for PASS_BASE (column "D") and SUBPASS_DE_BASE (column "J") must equal each other:

$$
\begin{aligned}
& \text { DE_PASS_BASE }=0 \text { (since the RHS of row } 4=0 \text { ), and } \\
& \text { DE_PASS_BASE }=\text { PASS_BASE } * 1+\text { SUBPASS_DE_BASE } *-1 .
\end{aligned}
$$

This ensures that if the LP operates the base-case passage strategy, PASS_BASE, it must also operate SUBPASS_DE_BASE, thus meeting the requirement imposed by equation (3). Conversely, the model cannot operate SUBPASS_DE_BASE without also operating PASS_BASE. Similarly, rows 8 and 9 in the tableau assure that if SUBPASS_DE_BASE is operated by the LP, both Deschutes spring chinook (DE_SPC_BASEPASS_ROW) and Deschutes summer steelhead (DE_SSH_BASEPASS_ROW) will use the base-case passage strategy, and therefore meet to requirement of equation (4).

A similar set of relationships holds for the propagation activities. Equation (6) requires that each individual stock within a subbasin uses the same propagation strategy. This is made operational in rows $18-25$ of the tableau. In row 18 , for example, the constraint DE_SPC_BASEPROP_ROW assures that both spring chinook and steelhead within the Deschutes will use base-case propagation if and only if the PROP_DE_BASE activity (column 
"F" in the tableau) is operating with a value of 1 .

Equations (7) through (9) all involve the "MAKEFISH" variables, and are shown in columns N-AS of the tableau. These variables perform four tasks simultaneously:

1. Ensure consistency between the system-wide passage strategy and the passage/propagation/terminal harvest alte .native.

2. Ensure consistency between thie subbasin-level propagation strategy and the passage/propagation/termina! harvest alternative.

3. Meet the stork-level terminal harvest goal, if possible.

4. Meet the stock-leve' spawning escapement goal, if possible.

Decoding the names of the variables is fairly straightforward, and follow the naming convention established for the MAKEFISH variables in the preceding section. The first eight characters are always "MAKEFISH", as was the case in the equations in the earlier discussion. The next two letters are an abbreviation for the name of the subbasin ("DE" for Deschutes, "CL" for Clearwater). The next three letiers are ali atbreviation for the species ("SPC" for spring chinook. "SSH" for summer steelhead). This is followed by a designation for the passage strategy ("BASEPASS" or "IMPRPASS" for base-case or Improved passage, respectively), anu? propagation strategy ("BASEYROP" or "IMPRCP", for base case and Improved propagation, respectively). Finally, a designation for terminal harvest rate completes the activity name ("TH20" or "TH40"). Taking column "Q" from the tableau as an example, the activity name is "MAKEFISH_DE_SFC_BASEPASS_IMPRTP_TH40". This means that it is a fish production alternative from the Deschutes subbasin for spring chinook. It uses base-case passage, Improved propagation, and a terminal harvest rate of 40 percent.

Obviously, the alternative in column $\mathrm{Q}$ of the tableau should onily be abie to operate, or take on a non-zero value, if the base-case passage strategy and the improved-habitat Deschutes propagation alternative both take on a value of 1 . These conditions are met via two of the nonzero coefficients in column Q. First, placing a -1 in row 8, "DE_SPC_BASEPASS_ROW", we ensure that "MAKEFISH_DE_SPC_BASEPASS_IMPROP_TH40" can operate if and only if 
column J, "SUBPASS_DE_BASE", also takes on a value of 1 , since "DE_SPC_BASEPASS_ROW" must be equal to zero, its right-hand-side (RHS) value. (Recall from model equation (3) that column $\mathrm{J}$, in turn, can be equal to 1 if and only if column $\mathrm{D}$, "PASS_BASE", is also equal to 1.) This of course links column Q back to the LP's "choice" of a passage strategy. In a similar fashion, the -1 in column Q, row 20, "DE_SFC_IMPROP_ROW", requires that the passage improvement strategy, column G, "PROP_DE_IMPROVED", operate before column Q can take on a non-zero value, since "DE_SPC_IMPROP_ROW" must be equal to zero.

Equations (9) and (10) address whether or not an alternative meets the terminal harvest and subbasin escapement goals for a stock. We see from tables B.3 and B.4 that the passage/propagation/terminal harvest alternative represented by column $\mathrm{Q}$ meets both the terminal harvest and spawning escapement goals for Deschutes spring chinook. This is represented in the tableau by the coefficient " 1 " in row 26 (for Deschutes spring chinook terminal harvest goal) and the coefficient " 1 " in row 30 (for Deschutes spring chinook spawning escapement goal). Whether these coefficients are zero or one is determined by running the DLCM. Obviously, many alternatives will fail to meet one or both goals. For example, in column $\mathrm{N}$ (Deschutes base case passage and propagation, 20 percent terminal harvest rate) both rows 26 and 30 have coefficients of zero, so the alternative met neither goal. All of the MAKEFISH alternatives in columns N--AS are constructed using the same logic as in the example. As noted previously, there is one MAKEFISH column in the tableau for each passage/propagation/terminal harvest alternative for each subbasin and stock.

\section{POTENTIAL EXTENSIONS}

\section{Other Objectives}

In Chapter 5, we discuss the use of the optimization model to investigate strategies for doubling the runsize of each stock. We did this by simply substituting constraints on runsize for 
those on terminal harvest and spawning escapement, and running the DLCM to produce information on total runsize for each stock. Other stock-specific objectives, including constraints on ocean harvest, in-river harvest, or even smolt production, could easily be added to the model or substituted for the objectives already analyzed.

\section{Variability and Uncertainty}

As currently constructed, the cost-effectiveness models do not directly address natural variability in the fish production measures employed. This is a direct outgrowth of the fact that the DLCM is deterministic. There are two reasons we chose a deterministic model to simulate the fish life cycle. The first is that the planners' goals for harvest and escapement are stated in terms of averages over a long time period, as is the NPPC's runsize-doubling goal. The second is that the DLCM must analyze approximately 80,000 passage/propagation/terminal harvest alternatives for the above-Bonneville cost-effectiveness modeling. The DLCM requires about fifteen minutes (900 seconds) to analyze the alternatives, or approximately 0.01 seconds per alternative.

As noted in Appendix A, the DLCM is a deterministic simplification of the Stochastic Life Cycle Model, or SLCM. The SLCM mimics natural variability of salmon populations by treating model parameters as random draws from probability distributions. The SLCM requires approximately five minutes to analyze an alternative, which translates into roughly nine months of computer time to analyze the 80,000 alternatives used to date. This, obviously, explains why we developed the DLCM for the above-Bonneville project. While in principle one could use the SLCM as the biological simulation model and formulate objectives in terms of probability distribution moments (e.g., the 10th percentile of spawning escapement should not fall below $x$ ) practical problems preclude extending this to all of the stocks and alternatives analyzed with the DLCM.

Fortunately, the problem is not as severe as it might seem. Data for many stocks is insufficient to calibrate them properly for the SLCM; only about one-quarter of the nearly 80 
stocks in the above-Bonneville analysis have sufficiently long time-series of adult returns to calibrate the variance terms in the stochastic model. We expect that it will be feasible to run the SLCM for the management alternatives which apply to these stocks, and substitute moments of probability distributions for the averages used to calculate the $a_{i, j, m, n, h}$ 's and $b_{i, j, m, n, h}$ 's equations (9) and (10).

\section{Dynamics}

Extending the comparative-static framework used in the above-Bonneville analysis to a dynamic analysis has three basic justifications. The first is that numerical objectives for each stock may change over time. For example, planners may desire a terminal harvest of 1000 fish in year 5 , 2500 fish in year 10, and 3000 fish in years 15 and higher. Second, many management actions have substantial lead times between the initial proposal and full biological effectiveness. For example, if the region decides to implement drawdowns in one or more Snake River reservoirs, it will be some years before new smolt and adult passage facilities are in place and operational. In addition, it is thought that many habitat-improvement projects require several years after completion before they are fully effective. Finally, budget constraints, lack of trained personnel, and other practical problems may prohibit completion of every desirable project in a single year, and models should be adapted to reflect this.

We show in equations (13) through (22) how the static framework could be extended to a dynamic analysis 8 . Variables are all defined as before, except that most variables which appeared in equations (1) through (10) have an additional subscript $t$ to denote the planning period (e.g., from 1 to $T$ ) in which the action is implemented. The reader may wish to consult Table B.9 for variable and subscript definitions, as the equations are presented without further explanation.

\footnotetext{
8This presentation ignores several potential complications discussed in the text which follows.
} 


$$
\begin{aligned}
& \text { Minimize } \sum_{\mathrm{l}} \sum_{\mathrm{m}}\left(\mathrm{PASS}_{\mathrm{m}, \mathrm{l}} * \mathrm{CPASS}_{\mathrm{m}}\right)+\sum_{\mathrm{i}} \sum_{\mathrm{i}} \sum_{\mathrm{n}}\left(\mathrm{PROP}_{\mathrm{i}, \mathrm{n}, \mathrm{l}} * \mathrm{CPROP}_{\mathrm{i}, \mathrm{n}}\right) \\
& \forall, \sum_{\mathrm{m}} \mathrm{PASS}_{\mathrm{m}, \mathrm{l}}=1 \\
& \forall \text { SUBPASS }_{\mathrm{i}, \mathrm{m}, \mathrm{l}}=\text { PASS }_{\mathrm{m}, \mathrm{l}} \\
& \forall \text { STOCKPASS }_{\mathrm{i}, \mathrm{j}, \mathrm{m}, \mathrm{t}}=\text { SUBPASS }_{\mathrm{i}, \mathrm{m}, \mathrm{t}} \\
& \forall_{\mathrm{i}, \mathrm{t}} \sum_{\mathrm{n}} \operatorname{PROP}_{\mathrm{i}, \mathrm{n}, \mathrm{t}}=1 \\
& \forall_{j, t} \text { STOCKPROP }_{i, j, n, t}=\text { PROP }_{i, n, t} \\
& \forall_{\mathrm{i}, \mathrm{j}, \mathrm{n}} \sum_{\mathrm{h}} \text { MAKEFISH }_{\mathrm{i}, \mathrm{j}, \mathrm{m}, \mathrm{n}, \mathrm{h}, \mathrm{l}}=\text { STOCKPASS }_{\mathrm{i}, \mathrm{j}, \mathrm{n}, \mathrm{l}} \\
& \forall_{\mathrm{i}, \mathrm{j}, \mathrm{m}} \sum_{\mathrm{h}} \text { MAKEFISH }_{\mathrm{i}, \mathrm{j}, \mathrm{m}, \mathrm{n}, \mathrm{h}, \mathrm{t}}=\text { STOCKPROP }_{\mathrm{i}, \mathrm{j}, \mathrm{m}, \mathrm{l}} \\
& \text { SPAWGOAL }_{\mathrm{i}, \mathrm{j}, \mathrm{t}}=\forall_{\mathrm{m}, \mathrm{n}} \sum_{\mathrm{h}} \operatorname{MAKEFISH}_{\mathrm{i}, \mathrm{j}, \mathrm{m}, \mathrm{n}, \mathrm{h}, \mathrm{t}} \cdot \mathrm{b}_{\mathrm{i}, \mathrm{j}, \mathrm{m}, \mathrm{n}, \mathrm{h}, \mathrm{l}} \\
& \text { HARVGOAL }_{\mathrm{i}, \mathrm{j}, \mathrm{t}}=\forall_{\mathrm{m}, \mathrm{n}} \sum_{\mathrm{h}} \operatorname{MAKEFISH}_{\mathrm{i}, \mathrm{j}, \mathrm{m}, \mathrm{n}, \mathrm{h}, \mathrm{t}} \cdot \mathrm{a}_{\mathrm{i}, \mathrm{j}, \mathrm{m}, \mathrm{n}, \mathrm{h}, \mathrm{t}}
\end{aligned}
$$

Obviously, numerous complications will arise when extending the problem into a dynamic framework. Among the more pressing problems are the need for more detailed economic, biological, and planning data, and the much larger potential size of the problem to be addressed in the cost-effectiveness models. In this appendix, we will touch on the more important problems and suggest how they might be solved. A full explication of the difficulties is left to a later phase of the research. 
At present, when an action is implemented, we do not consider design and construction lead-times, whether or not the action can be temporarily suspended or permanently decommissioned, or whether or not a different action might replace the original at the end of its useful life span. In addition, we do not try to analyze how long the action must be in place before it becomes fully effective, and what its effectiveness might be during the construction phase or at other points before it comes on-line. For a dynamic analysis all these data will need to be generated from empirical experiments or assumed, so that we can trace the economic costs and biological effects of different strategies over time. For exampie, flow-augmentation measures may be designed and implemented relatively quickly if the regional power producers do not need to bring new capacity (e.g., conservation or gas-fired turbines) on line to compensate for lost energy. In contrast, a major new hatchery may take several years to design and construct, and for both projects, several years will pass before additional adult returns are created, since both passage and propagation actions effectively focus on increasing the number of smolts reaching the ocean. The final complication on the economic side is that there may be budget constraints within each planning period; these could be added to the problem formulation fairly easily.

More detailed data on age-specific population abundances will also be required, to trace the effectiveness of harvest measures, and to judge whether or not sufficient spawners will be available to take advantage of improved hatchery and natural propagation opportunities. As noted above, we will require data on how quickly biological parameters change as a result of management actions. For example, at present, we may say that a habitat improvement action will increase rearing capacity from one million to two million smolts. For the dynamic analysis, we will also need to know how soon the capacity will increase, following the action's completion. Data may be available on this for a few stocks and subbasins, but at this point it appears that we will probably be confined to sensitivity testing (i.e., testing how sensitive the results are to different assumptions regarding timing and effectiveness) for most stocks. Also, it is obvious that time-specific information on objectives would be needed as well; e.g., not just how many fish are desired, but how soon planners want the additional fish to be produced. 
The size of the problem may also increase very rapidly, as stocks, actions, and planning periods are added to the analysis. Recall from Chapter 2 that if $n$ actions are analyzed, $2^{n}$ strategies will be generated (in the static case.) If there are $\mathrm{T}$ planning periods, and each action can be implemented independently in each time period, there will be:

$$
2^{n}+2^{n^{2}}+2^{n^{3}}+\ldots+2^{n^{T}}
$$

strategies, which obviously increases very quickly with both actions and planning periods.

While space does not permit a explicating all of the details of the solution to the problem posed by (23), we can outline the more important points. First, we have already noted that substantially more biological data will be required for the dynamic analysis; this will probably preclude analyzing the majority of the stocks considered in the static analysis, and so will reduce the dimensions of the problem considerably. Second, it would probably be prudent to limit the number of planning periods to (say) four or five five-year periods, and so reduce $T$ in equation (23) to no more than four or five. Finally, it seems likely that many of the projected outcomes from strategies in (23) will be infeasible (i.e., will not meet the biological objectives.) This also limits the number of strategies that must be subject to detailed analysis.

In summary, while substantial problems of both data and methodology will need to be overcome, our preliminary look at the problem suggests that these problems can be solved. The potential pay-off for such an undertaking is considerable, in both economic, planning, and research terms. 
TABLE B.1

Definitions of Terms Used to Specify Mitigation Options

\begin{tabular}{ll}
\hline Term & $\begin{array}{l}\text { Definition } \\
\text { Management Action }\end{array}$ \\
$\begin{array}{l}\text { Smallest single management option that will have a unique effect on a biological } \\
\text { parameter; } \text { e.g., add screens at a run-of river dam, or add rearing capacity at a } \\
\text { hatchery }\end{array}$ \\
Passage Strategy & $\begin{array}{l}\text { Combination of passage actions; will affect all stocks in the system } \\
\text { simultaneously; can only use one passage strategy for the entire system. }\end{array}$ \\
Propagation Strategy & $\begin{array}{l}\text { Combination of propagation actions; will affect all stocks in a given subbasin } \\
\text { simultaneously. Exactly one propagation strategy per subbasin. }\end{array}$ \\
Propagation/Terminal & $\begin{array}{l}\text { Combination of a system-wide passage strategy, subbasin-specific propagation } \\
\text { strategy, and stock- specific terminal harvest rate, for a single stock. The } \\
\text { alternative defines all the information necessary to calculate the adults produced } \\
\text { for a given stock. Generated by the deterministic simulation model. }\end{array}$ \\
System-Wide Strategy & $\begin{array}{l}\text { Combination of propagation/terminal harvest/passage alternatives for all stocks } \\
\text { in the model. All stocks use the same passage strategy and all stocks within a } \\
\text { given subbasin use the same propagation strategy, although different stocks in } \\
\text { the same subbasin may have different terminal harvest rates. }\end{array}$ \\
System-Wide Least-Cost & $\begin{array}{l}\text { The system-wide strategy which meets a set of biological objectives at the lowest } \\
\text { possible cost of subbasin-specific propagation strategies and one passage } \\
\text { strategy. Generated by the linear programming model, using alternatives } \\
\text { generated by the deterministic simulation model. }\end{array}$ \\
\hline
\end{tabular}


TABLE B.2

Example Propagation Strategies, Passage Strategies, and Terminal Harvest Alternatives

\begin{tabular}{|c|c|c|c|c|c|}
\hline Subbasin & $\begin{array}{l}\text { Propagation } \\
\text { Strategies }\end{array}$ & $\begin{array}{l}\text { Passage } \\
\text { Strategies }\end{array}$ & $\begin{array}{l}\text { Summer Steelhead } \\
\text { Terminal Harvest } \\
\text { Rates }\end{array}$ & $\begin{array}{l}\text { Spring Chinook } \\
\text { Terminal Harvest } \\
\text { Rates }\end{array}$ & $\begin{array}{l}\text { Propagation-Terminal } \\
\text { Harvest-Passage } \\
\text { Alternatives }\end{array}$ \\
\hline Clearwater & $\begin{array}{l}\text { Base Case, } \\
\text { Habitat } \\
\text { Improvement }\end{array}$ & $\begin{array}{l}\text { Base Case, } \\
\text { Passage } \\
\text { Improvement }\end{array}$ & $20 \%, 40 \%$ & $20 \%, 40 \%$ & 16 \\
\hline Deschutes & $\begin{array}{l}\text { Base Case, } \\
\text { Habitat } \\
\text { Improvement }\end{array}$ & $\begin{array}{l}\text { Base Case, } \\
\text { Passage } \\
\text { Improvement }\end{array}$ & $20 \%, 40 \%$ & $20 \%, 40 \%$ & 16 \\
\hline
\end{tabular}


TABLE H.3

Results from the Deterministic Life Cycle Model

\begin{tabular}{|c|c|c|c|c|c|c|c|c|c|c|}
\hline Subbasin & $\begin{array}{l}\text { Passage } \\
\text { Strategy }\end{array}$ & $\begin{array}{l}\text { Prop. } \\
\text { Strategy }\end{array}$ & $\begin{array}{l}\text { SPC }^{\circ} \\
\text { Harvest } \\
\text { Goal }\end{array}$ & $\begin{array}{l}\text { SPC" } \\
\text { Harvest }\end{array}$ & $\begin{array}{l}\text { SPC }^{*} \\
\text { Spawn } \\
\text { Goal }\end{array}$ & $\begin{array}{l}\mathrm{SPC}^{*} \\
\text { Spawn }\end{array}$ & $\begin{array}{l}\text { SSH } \\
\text { Harvest } \\
\text { Goal }\end{array}$ & $\begin{array}{l}\text { SSH }^{\circ} \\
\text { Harvest }\end{array}$ & $\begin{array}{l}\text { SSH }^{\circ} \\
\text { Spawn } \\
\text { Goal }\end{array}$ & $\begin{array}{l}\text { SSH }^{\circ} \\
\text { Spawn }\end{array}$ \\
\hline Clearwater & Base Case & Improved & 50,000 & 16,471 & 3,000 & 4,805 & 74,000 & 42,668 & 12,000 & 13,724 \\
\hline Clearwater & Base Case & Improved & 50,000 & 45,179 & 3,000 & 3,234 & 74,000 & 83,209 & 12,000 & 12,062 \\
\hline Clearwater & Base Case & Base Case & 50,000 & 7,936 & 3,000 & 2,292 & 74,000 & 42,557 & 12,000 & 13,401 \\
\hline Clearwater & Base Case & Base Case & 50,000 & 20,856 & 3,000 & 1,491 & 74,000 & 82,990 & 12,000 & 9,837 \\
\hline Clearwater & Improved & Improved & 50,000 & 18,362 & 3,000 & 5,466 & 74,000 & 47,438 & 12,000 & 15,344 \\
\hline Clearwater & Improved & Improved & 50,000 & 50,059 & 3,000 & 3,662 & 74,000 & 92,515 & 12,000 & 11,274 \\
\hline Clearwater & Improved & Base Case & 50,000 & 8,866 & 3,000 & 2,643 & 74,000 & 47,314 & 12,000 & 14,979 \\
\hline Clearwater & Improved & Base Case & 50,000 & 23,129 & 3,000 & 1,702 & 74,000 & 92,270 & 12,000 & 11,017 \\
\hline Deschutes & Base Case & Improved & 4,000 & 5,444 & 1,950 & 3,152 & 25,000 & 28,864 & 6,000 & 12,912 \\
\hline Deschutes & Base Case & Improved & 4,000 & 6,776 & 1,950 & 2,265 & 25,000 & 31,629 & 6,000 & 7,786 \\
\hline Deschutes & Base Case & Base Case & 4,000 & 3,750 & 1,950 & 1,939 & 25,000 & 27,642 & 6,000 & 6,347 \\
\hline Deschutes & Base Case & Base Case & 4,000 & 4,689 & 1,950 & 1,338 & 25,000 & 29,232 & 6,000 & 4,439 \\
\hline Deschutes & Improved & Improved & 4,000 & 5,968 & 1,950 & 3,385 & 25,000 & 30,962 & 6,000 & 11,780 \\
\hline Deschutes & Improved & Improved & 4,000 & 7,407 & 1,950 & 2,439 & 25,000 & 33,971 & 6,000 & 8,439 \\
\hline Deschutes & Improved & Base Case & 4,000 & 4,115 & 1,950 & 2,096 & 25,000 & 29,649 & 6,000 & 6,880 \\
\hline Deschutes & Improved & Base Case & 4,000 & 5,146 & 1,950 & 1,457 & 25,000 & 31,394 & 6,000 & 4,838 \\
\hline
\end{tabular}

- SPC and SSH represent Spring Chinook and Summer Steelhead, respectively 
TABLE B.4

Feasibility of Alternatives by Stock

\begin{tabular}{|c|c|c|c|c|c|c|}
\hline Passage Strategy & Subbasin & Species $^{+}$ & Propagation Surategy & $\begin{array}{l}\text { Terminal } \\
\text { Harvest Rate }\end{array}$ & $\begin{array}{l}\text { Meets } \\
\text { Terminal } \\
\text { Harvest Goal? }\end{array}$ & $\begin{array}{l}\text { Meets Spawning } \\
\text { Escapement Goal? }\end{array}$ \\
\hline Base Case & $\mathrm{CL}$ & SPC & Base Case & 20 & NO & NO \\
\hline Base Case & $\mathrm{CL}$ & SPC & Base Case & 40 & NO & NO \\
\hline Base Case & $\mathrm{CL}$ & SPC & Habitat Improvement & 20 & NO & YES \\
\hline Base Case & $\mathrm{CL}$ & SPC & Habitat Improvement & 40 & NO & YES \\
\hline Base Case & $\mathrm{CL}$ & SSH & Jase Case & 20 & NO & YES \\
\hline Base Case & $\mathrm{CL}$ & SSH & Base Case & 40 & YES & NO \\
\hline Base Case & $\mathrm{CL}$ & SSH & Habitat Improvement & 20 & NO & YES \\
\hline Base Case & $\mathrm{CL}$ & SSH & Habitat Improvement & 40 & YES & YES \\
\hline Base Case & $\mathrm{DE}$ & SPC & Base Case & 20 & NO & NO \\
\hline Base Case & $\mathrm{DE}$ & SPC & Base Case & 40 & YES & NO \\
\hline Base Case & $\mathrm{DE}$ & SPC & Habitat Improvement & 20 & YES & YES \\
\hline Base Case & $\mathrm{DE}$ & SPC & Habitat Improvement & 40 & YES & YES \\
\hline Base Case & $\mathrm{DE}$ & SSH & Base Case & 20 & YES & YES \\
\hline Base Case & $\mathrm{DE}$ & SSH & Base Case & 40 & YES & NO \\
\hline Base Case & $\mathrm{DE}$ & SSH & Habitat Improvement & 20 & YES & YES \\
\hline Base Case & $\mathrm{DE}$ & SSH & Habitat Improvement & 40 & YES & YES \\
\hline Improved & CL & SPC & Base Case & 20 & NO & NO \\
\hline Improved & $\mathrm{CL}$ & SPC & Base Case & 40 & NO & NO \\
\hline Improved & $\mathrm{CL}$ & SPC & Habitat Improvement & 20 & NO & YES \\
\hline Improved & $\mathrm{CL}$ & SPC & Habitat Improvement & 40 & YES & YES \\
\hline Improved & $\mathrm{CL}$ & SSH & Base Case & 20 & NO & YES \\
\hline Improved & $\mathrm{CL}$ & SSH & Base Case & 40 & YES & YES \\
\hline Improved & $\mathrm{CL}$ & SSH & Habitat Improvemeni & 20 & NO & YES \\
\hline Improved & $\mathrm{CL}$ & SSH & Habitat Improvement & 40 & YES & YES \\
\hline Improved & $\mathrm{DE}$ & SPC & Base Case & 20 & YES & YES \\
\hline Improved & $\mathrm{DE}$ & SPC & Base Case & 40 & YES & NO \\
\hline Improved & $\mathrm{DE}$ & SPC & Habitat Improvement & 20 & YES & YES \\
\hline Improved & $\mathrm{DE}$ & SPC & Habital Improvement & 40 & YES & YES \\
\hline Improved & $\mathrm{DE}$ & SSH & Base Case & 20 & YES & YES \\
\hline Improved & $\mathrm{DE}$ & SSH & Base Case & 40 & YES & NO \\
\hline Improved & DE & SSH & Habitat Improvement & 20 & YES & YES \\
\hline Improved & DE & SSH & Habitat Improvement & 40 & YES & YES \\
\hline
\end{tabular}

- $\quad \mathrm{CL}$ and DE represent the Clearwater and Deschutes basins, respectively

- SPC and SSH represent Spring Chinook and Summer Steelhead, respectively 
TABLE B.5

Feasible Alternatives Only

\begin{tabular}{lcccccc}
\hline Passage Strategy & Subbasin & Species & Propagation Strategy & $\begin{array}{l}\text { Terminal } \\
\text { Harvest Rate }\end{array}$ & $\begin{array}{l}\text { Meets } \\
\text { Terminal } \\
\text { Harvest Goal? }\end{array}$ & $\begin{array}{l}\text { Meets Spawning } \\
\text { Escapement Goal? }\end{array}$ \\
Base Case & CL & SSH & Habitat Improvement & 40 & YES & YES \\
Base Case & DE & SPC & Habitat Improvement & 20 & YES & YES \\
Base Case & DE & SPC & Habitat Improvement & 40 & YES & YES \\
Base Case & DE & SSH & Base Case & 20 & YES & YES \\
Base Case & DE & SSH & Habitat Improvenent & 20 & YES & YES \\
Base Case & DE & SSH & Habitat Improvement & 40 & YES & YES \\
Improved & CL & SPC & Habitat Improvement & 40 & YES & YES \\
Improved & CL & SSH & Base Case & 40 & YES & YES \\
Improved & CL & SSH & Habitat Improvement & 40 & YES & YES \\
Improved & DE & SPC & Base Case & 20 & YES & YES \\
Improved & DE & SPC & Habitat Improvement & 20 & YES & YES \\
Improved & DE & SPC & Habitat Improvement & 40 & YES & YES \\
Improved & DE & SSH & Base Case & 20 & YES & YES \\
Improved & DE & SSH & Habitat Improvemert & 20 & YES & YES \\
Improved & DE & SSH & Habitat Improvement & 40 & YES & YES \\
\hline
\end{tabular}

- $\mathrm{CL}$ and DE represent the Clearwater and Deschutes basins, respectively

- SPC and SSH represent Spring Chinook and Summer Steelhead, respectively 
TABLE B.6

System-Wide Feasible Alternatives Only

\begin{tabular}{lcclccc}
\hline Passage Strategy & Subbasin* & Species & Propagation Strategy & $\begin{array}{l}\text { Terminal } \\
\text { Harvest Rate }\end{array}$ & $\begin{array}{l}\text { Meets } \\
\text { Terminal } \\
\text { Harvest Goal? }\end{array}$ & $\begin{array}{l}\text { Meets Spawning } \\
\text { Escapement Goal ? }\end{array}$ \\
Improved & CL & SPC & Habitat Improvement & 40 & YES & YES \\
Improved & CL & SSH & Habitat Improvement & 40 & YES & YES \\
Improved & DE & SPC & Base Case & 20 & YES & YES \\
Improved & DE & SPC & Habitat Improvement & 20 & YES & YES \\
Improved & DE & SPC & Habitat Improvement & 40 & YES & YES \\
Improved & DE & SSH & Base Case & 20 & YES & YES \\
Improved & DE & SSH & Habitat Improvement & 20 & YES & YES \\
Improved & DE & SSH & Habitat Improvement & 40 & YES & YES \\
\hline
\end{tabular}

- $\quad C L$ and DE represent the Clearwater and Deschutes basins, respectively

- SPC and SSH represent Spring Chinook and Summer Steelhead, respectively 
TABLE B.7

System-Wide Cost-Effectiveness Strategy

\begin{tabular}{llllllc}
\hline Passage Strategy & Subbasin & Species & Propagation Strategy & $\begin{array}{l}\text { Tcrminal } \\
\text { Harvest Rate }\end{array}$ & $\begin{array}{l}\text { Meets } \\
\text { Terminal } \\
\text { Harvest Goal? }\end{array}$ & $\begin{array}{l}\text { Meets Spawning } \\
\text { Escapement Goal ? }\end{array}$ \\
Improved & CL & SPC & Habitat Improvement & 40 & YES & YES \\
Improved & CL & SSH & Habitat Improvement & 40 & YES & YES \\
Improved & DE & SPC & Base Case & 20 & YES & YES \\
Improved & DE & SSH & Base Case & 20 & YES & YES \\
\hline
\end{tabular}

- $\quad C L$ and DE represent the Clearwater and Deschutes basins, respectively

- SPC and SSH represent Spring Chinook and Summer Steclhead, respectively 
TABLE B.8

\section{Optinization Model Terminology}

\section{Term}

Objective Function

Constraint

Mass-Balance Constraint

Activity

RHS

Coefficient

Tableau
Definition

Function that the optimization tries to minimize, within bounds established by a set of constraints.

An equation or expression used to establish limits on what the optimization can do.

Used to ensure internal consistency in the optimization, so that all stocks in the system use the same downstream passage strategy, or all stocks in the same subbasin use the same propagation strategy.

A variable whose value is set by the optimization model as in selecting the least cost strategy (e.g., whether or not to use a particular passage strategy, or at what rate to harvest a particular stock. Also known as a decision variable.

Abbreviation for "Right Hand Side." Determines how much of each activity must be undertaken. In the current problem, always set to zero or one.

Used to define the relationship between activities and constraints. Always set to -1 , 0 , or +1 in the current problem.

Computerized representation of the objective function, activities, constraints, coefficients, and RHS values. 
TABLE B.9

Optimization Model Variable and Subscript Definitions

\begin{tabular}{|c|c|c|}
\hline Varlable & Type* & Definition \\
\hline PASS $_{\mathbf{m}}$ & Activity & Propagation strategy \\
\hline PROP $_{i, n}$ & Activity & Passage strategy \\
\hline $\mathrm{CPASS}_{\mathbf{m}}$ & $\begin{array}{l}\text { Objective Function } \\
\text { Coefficient }\end{array}$ & Cost of passage strategy, annualized dollars \\
\hline $\mathrm{CPROP}_{\mathrm{i}, \mathrm{n}}$ & $\begin{array}{l}\text { Objective Function } \\
\text { Coefficient }\end{array}$ & Cost of propagation strategy, annualized dollars \\
\hline SUBPASS $_{\mathrm{i}, \mathrm{m}}$ & Activity & Subbasin-specific passage capacity \\
\hline STOCKPASS $_{\mathrm{i}, \mathrm{j}, \mathrm{m}}$ & Activity & Stock-specific passage capacity \\
\hline STOCKPROP $_{i, j, n}$ & Activity & Stock-specific propagation capacity \\
\hline MAKEFISH $_{i, j, m, n, b}$ & Activity & Stock-specific fish production activity \\
\hline HARVGOAL $_{\mathbf{i}, j}$ & Constraint & $\begin{array}{l}\text { Stock-specific harvest goal ( } 1 \text { if subbasin planners } \\
\text { established a harvest goal for the stock, } 0 \text { otherwise) }\end{array}$ \\
\hline SPAWGOAL $_{\mathbf{i}, \mathbf{j}}$ & Constraint & $\begin{array}{l}\text { Stock-specific spawning escapement goal ( } 1 \text { if subbasin } \\
\text { planners established a harvest goal for the stock, } 0 \\
\text { otherwise) }\end{array}$ \\
\hline $\mathrm{i}=1, \ldots, \mathrm{I}$ & Subscript & Subbasins \\
\hline $\mathrm{j}=1, \ldots, \mathrm{J}$ & Subscript & $\begin{array}{l}\text { Stocks (note that J will vary with the number of stocks } \\
\text { in cach subbasin) }\end{array}$ \\
\hline $\mathrm{m}=1, \ldots, \mathrm{M}$ & Subscript & Passage Strategies \\
\hline $\mathrm{n}=1, \ldots, \mathrm{N}$ & Subscript & $\begin{array}{l}\text { Propagation Strategies (note that } N \text { will vary with the } \\
\text { number of propagation strategies in each subbasin) }\end{array}$ \\
\hline $\mathrm{h}=0,20, \ldots, 80$ & Subscript & $\begin{array}{l}\text { Terminal harvest rates for each stock, in } 20 \text { percent } \\
\text { increments. }\end{array}$ \\
\hline
\end{tabular}

- The different types of variables are defined in Table B.8 
TABLE $\mathrm{B} .10$

Costs of Strategies for Heuristic Example

Strategy

Deschutes Propagation Improvement

Base Case Passage

Passage Improvements

Clearwater Base Case Propagation

Clearwater Propagation Improvement

Deschutes Base Case Propagation
Annual Cost (\$ millions)

0.30

0

9

0

0.41 


\begin{tabular}{|c|c|c|c|c|c|c|c|c|c|c|c|}
\hline & 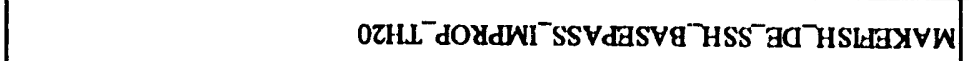 & & & & & & & & 7 & & \\
\hline & 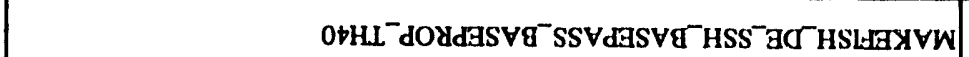 & & & & & & & & 7 & & \\
\hline & 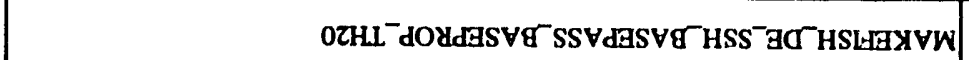 & & & & & & & & $T$ & & \\
\hline & 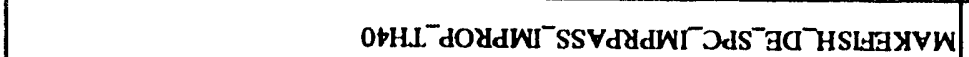 & & & & & & & & & 7 & \\
\hline & 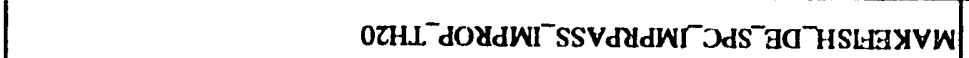 & & & & & & & & & 7 & \\
\hline & 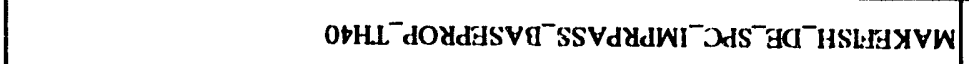 & & & & & & & & & 7 & \\
\hline & 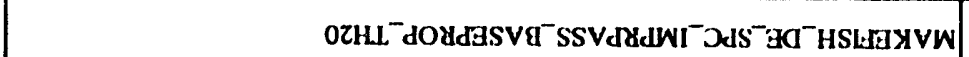 & & & & & & & & & 7 & \\
\hline & 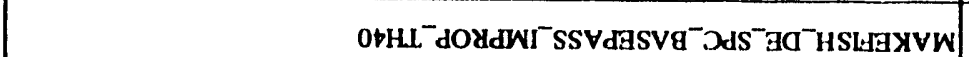 & & & & & & & 7 & & & \\
\hline & 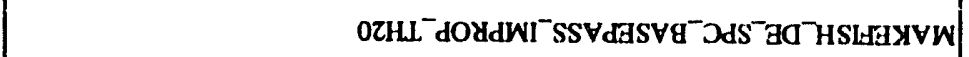 & & & & & & & 7 & & & \\
\hline & 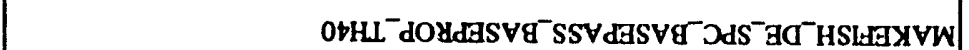 & & & & & & & 7 & & & \\
\hline & 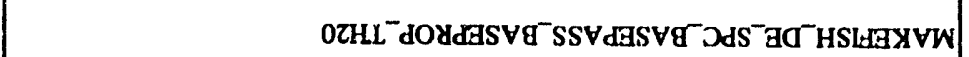 & & & & & & & 7 & & & \\
\hline 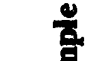 & 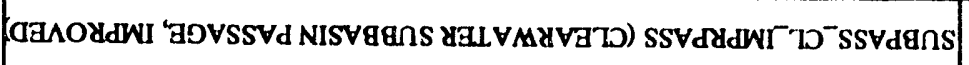 & & & & & & 7 & & & & \\
\hline 菌 & 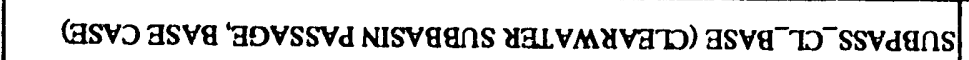 & & & & & $T$ & & & & & \\
\hline 宽 & 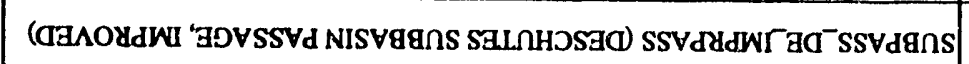 & & & & 7 & & & & & - & - \\
\hline 苋 & 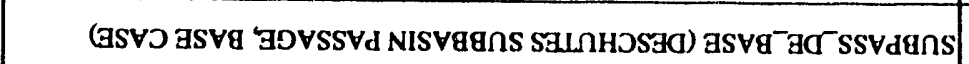 & & & 7 & & & & -7 & -7 & & \\
\hline 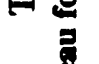 & 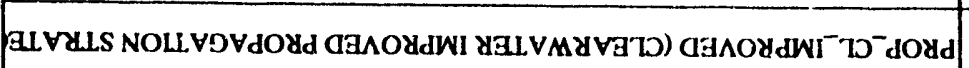 & F⿱ & & & & & & & & & \\
\hline$\frac{\partial}{\omega}$ & 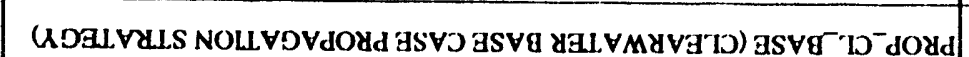 & 8 & & & & & & & & & \\
\hline & 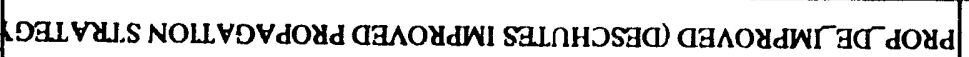 & 旁 & & & & & & & & & \\
\hline & 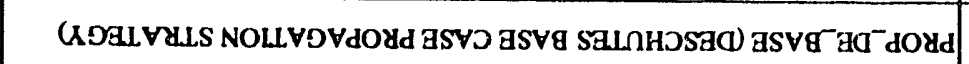 & 8. & & & & & & & & & \\
\hline & 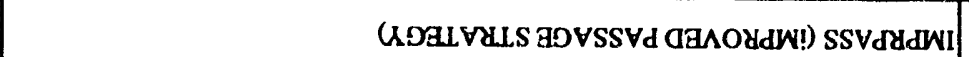 & 8 & - & & - & & $\rightarrow$ & & & & \\
\hline & (NDALVELS GDVSSVd GSVD-aSVG) GSVG'SSVd & 8 & - & - & & - & & & & & \\
\hline & วP!S PuEY-148?!y & $\mathbf{z}$ & - & 0 & 0 & 0 & ○ & 0 & 0 & 0 & $\circ$ \\
\hline & 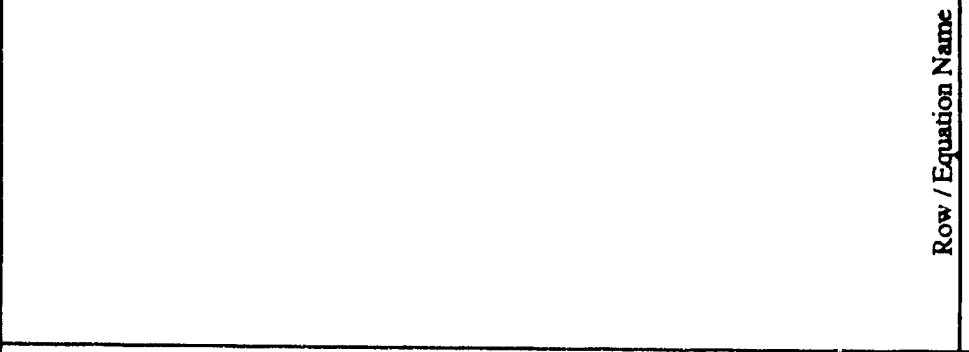 & 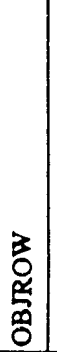 & 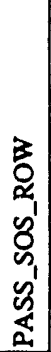 & 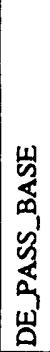 & 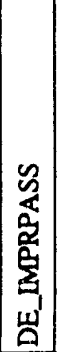 & 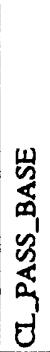 & 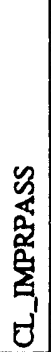 & 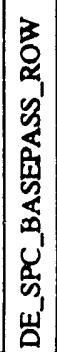 & 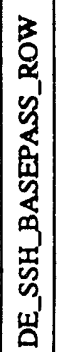 & 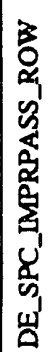 & 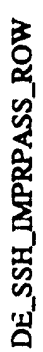 \\
\hline & soquen $n_{N}$ uo!nenbg d7 & - & $n$ & $m$ & $m$ & $m$ & $m$ & + & + & $\rightarrow$ & + \\
\hline
\end{tabular}




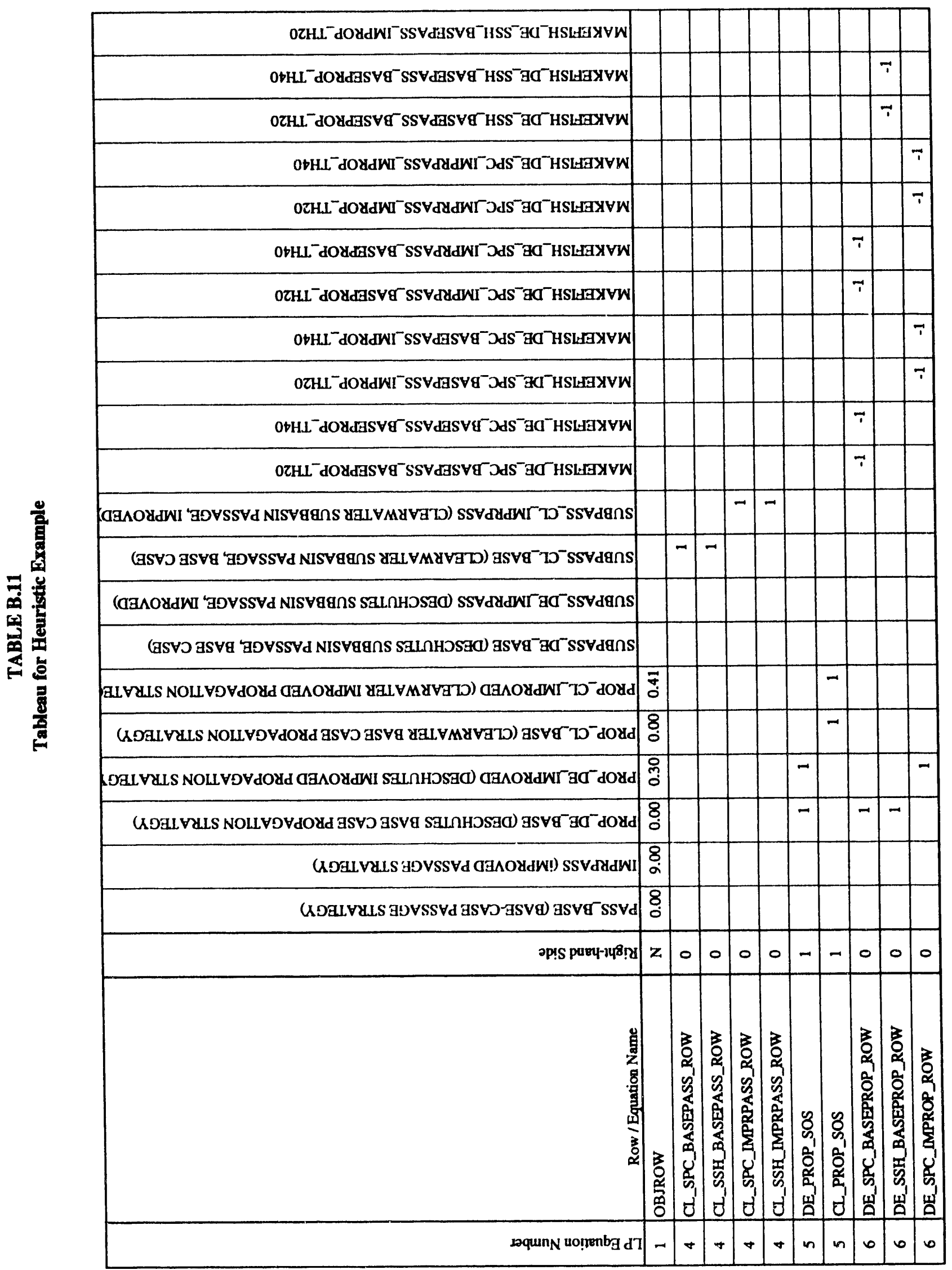




\begin{tabular}{|c|c|c|c|c|c|c|c|c|c|c|c|}
\hline & 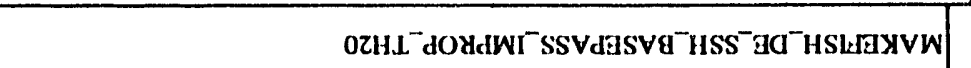 & & 7 & & & & & & - & & \\
\hline & 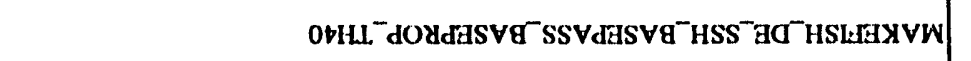 & & & & & & & & -1 & & \\
\hline & 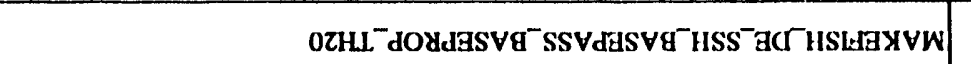 & & & & & & & & - & & \\
\hline & 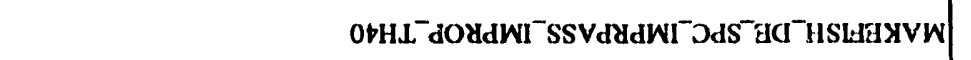 & & & & & & & -1 & & & \\
\hline & 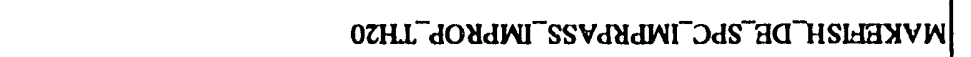 & & & & & & & 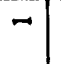 & & & \\
\hline & 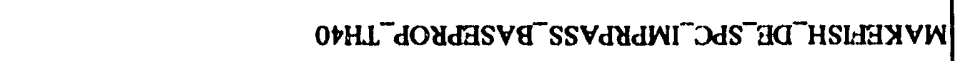 & & & & & & & - & & & \\
\hline & 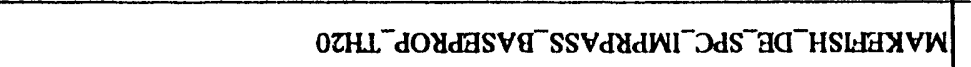 & & & & & & & -7 & & & \\
\hline & 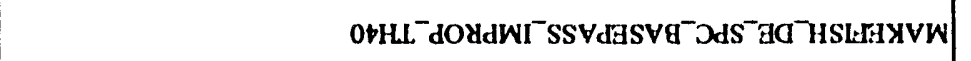 & & & & & & & -7 & & & \\
\hline & 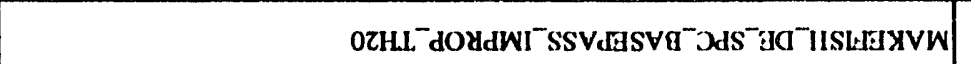 & & & & & & & - & & & \\
\hline & 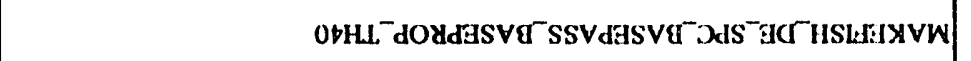 & & & & & & & -1 & & & \\
\hline & 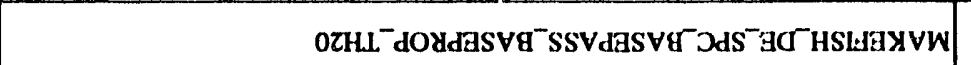 & & & & & & & 0 & & & \\
\hline & 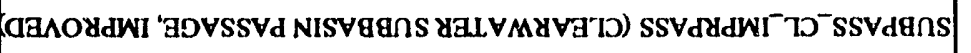 & & & & & & & & & & \\
\hline g & 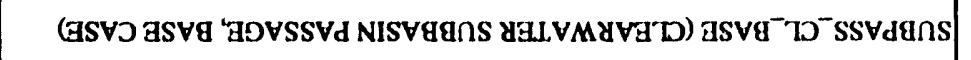 & & & & & & & & & & \\
\hline & 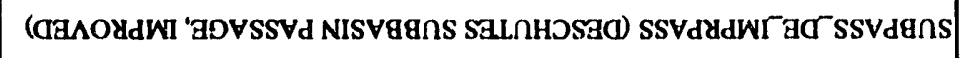 & & & & & & & & & & \\
\hline 里 & 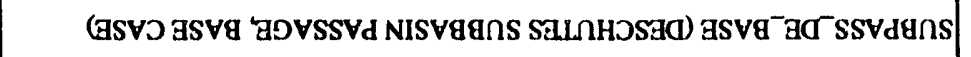 & & & & & & & & & & \\
\hline 电 & 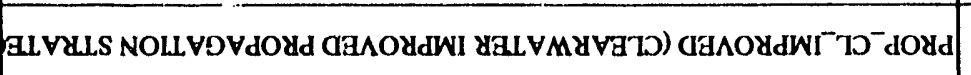 & $\overline{0}$ & & & & -1 & - & & & & \\
\hline 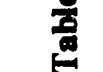 & 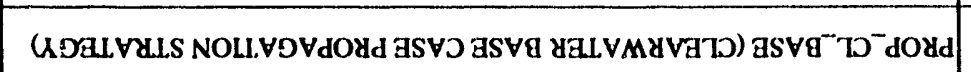 & 8 & & - & - & & & & & & \\
\hline & 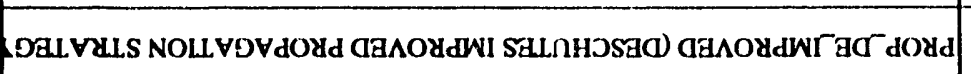 & 并 & - & & & & & & & & \\
\hline & 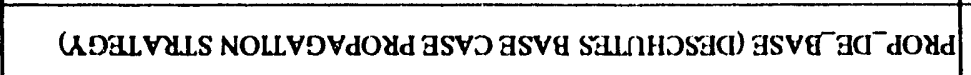 & 8 & & & & & & & & & \\
\hline & 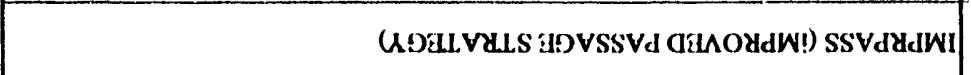 & 8 & & & & & & & & & \\
\hline & 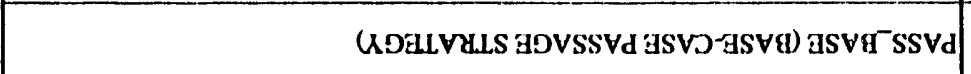 & 8 & & & & & & & & & \\
\hline & op!S puey-348?!y & $z$ & 0 & $\circ$ & $\circ$ & $\circ$ & 0 & - & - & - & - \\
\hline & 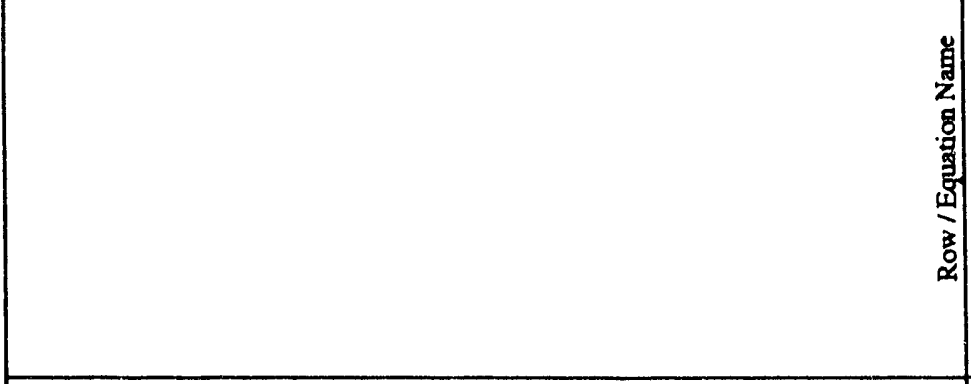 & \begin{tabular}{|c|} 
\\
\\
3 \\
0 \\
0 \\
0 \\
0 \\
0 \\
0
\end{tabular} & 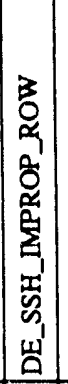 & 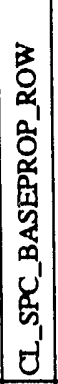 & 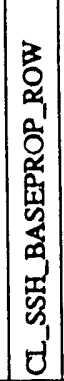 & 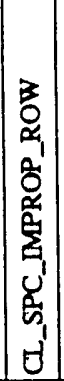 & 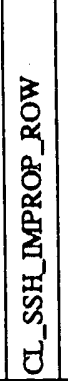 & 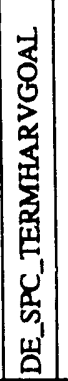 & 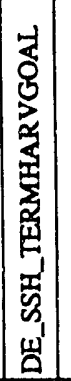 & 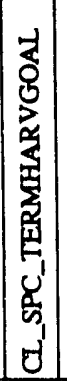 & 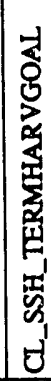 \\
\hline & soqunn $N$ uo!̣enbrd d $\mathrm{d}$ & - & 0 & 0 & 0 & 0 & 0 & $a$ & $a$ & $a$ & $a$ \\
\hline
\end{tabular}




\begin{tabular}{|c|c|c|c|c|c|c|}
\hline & 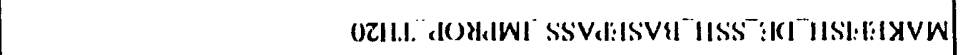 & & & -1 & & \\
\hline & 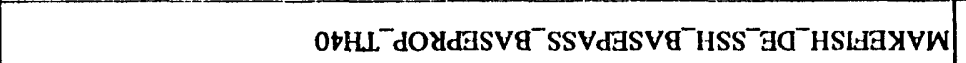 & & & 0 & & \\
\hline & 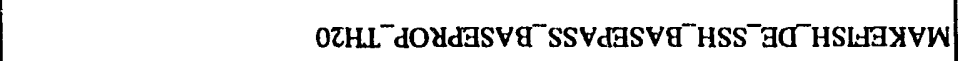 & & & $\rightarrow$ & & \\
\hline & 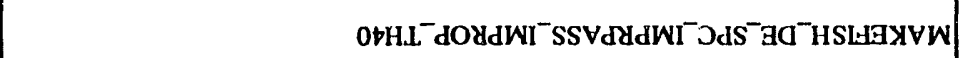 & & $\pi$ & & & \\
\hline & 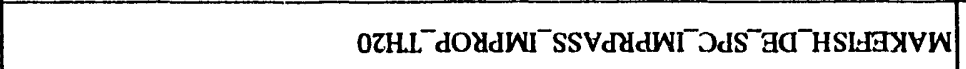 & & - & & & \\
\hline & 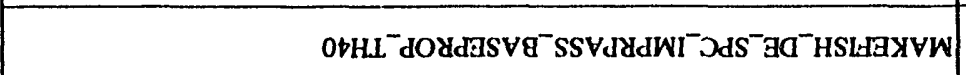 & & 0 & & & \\
\hline & 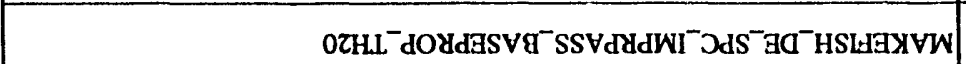 & & - & & & \\
\hline & 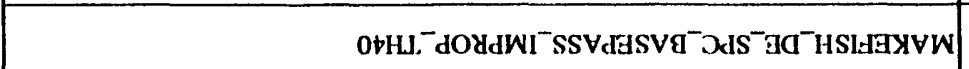 & & -1 & & & \\
\hline & 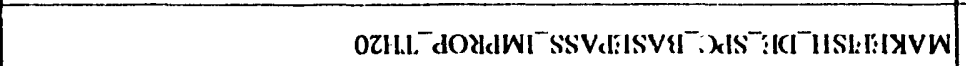 & & - & & & \\
\hline & 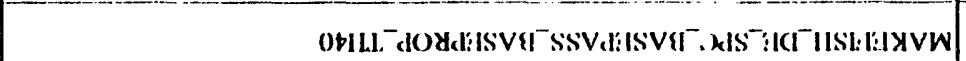 & & 0 & & & \\
\hline & 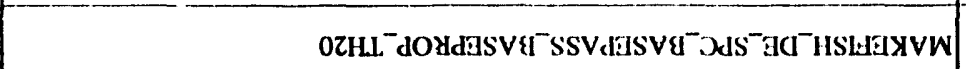 & & 0 & & & \\
\hline 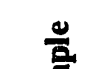 & 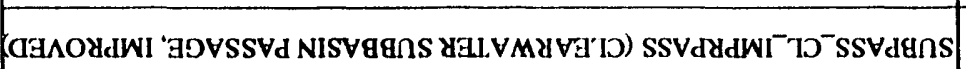 & & & & & \\
\hline 武 & 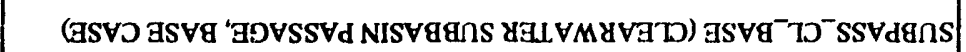 & & & & & \\
\hline 要 & 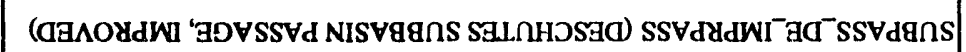 & & & & & \\
\hline 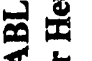 & 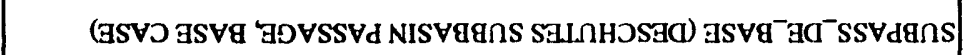 & & & & & \\
\hline 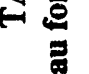 & 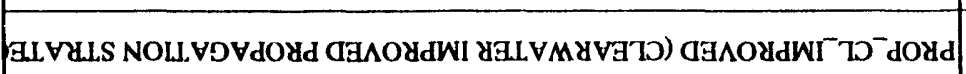 & $\vec{\nabla}$ & & & & \\
\hline 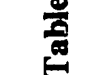 & 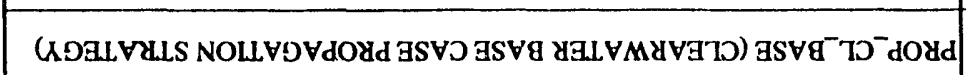 & 8 & & & & \\
\hline & 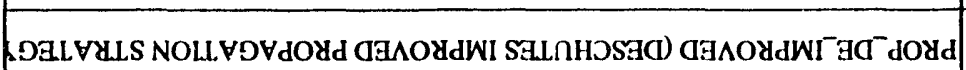 & $\begin{array}{l}0 \\
\text { jej } \\
0\end{array}$ & & & & \\
\hline & 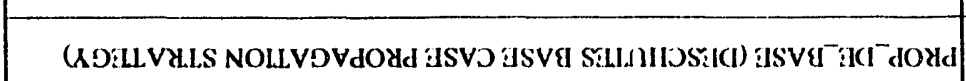 & \begin{tabular}{|l|l|} 
\\
\\
\end{tabular} & & & & \\
\hline & 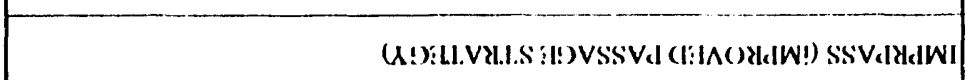 & 8 & & & & \\
\hline & (UI):LLVILIS:IIJVSSVA :ISVI)-ISVU :ISVYTSSVA & $\stackrel{8}{8}$ & & & & \\
\hline & 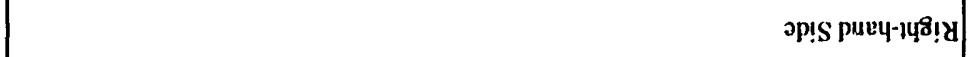 & z & - & - & - & - \\
\hline & 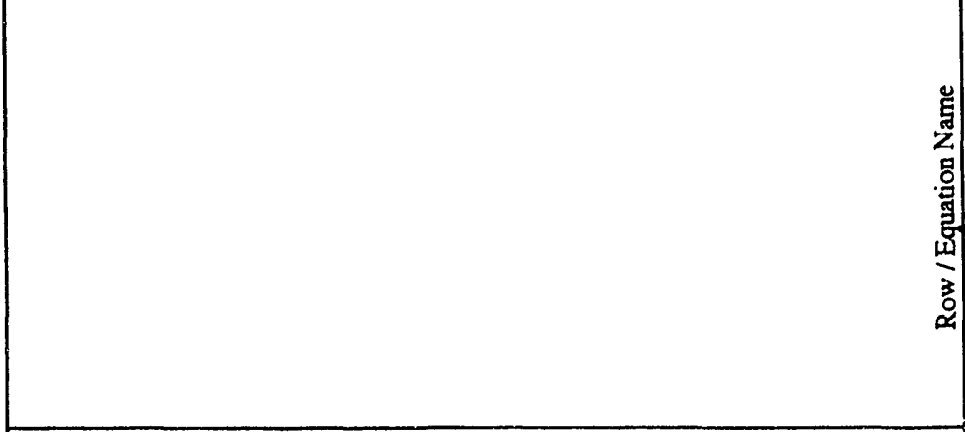 & 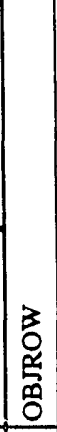 & 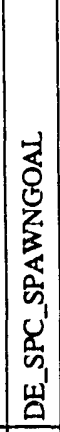 & 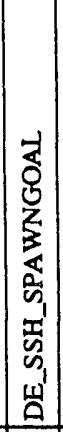 & 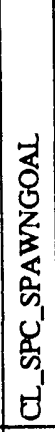 & 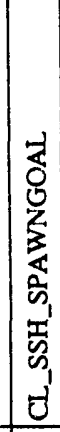 \\
\hline & Jaqun $_{N}$ uo!̣ıenbal d'l & - & 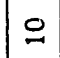 & $\therefore$ & 응 & 음 \\
\hline
\end{tabular}




\begin{tabular}{|c|c|c|c|c|c|c|c|c|c|c|c|}
\hline & 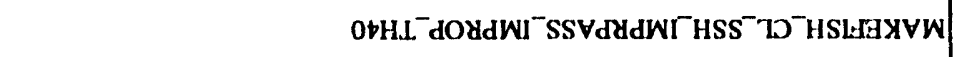 & & & & & & & & & & \\
\hline & 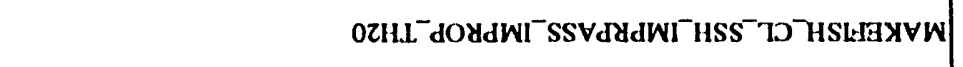 & & & & & & & & & & \\
\hline & 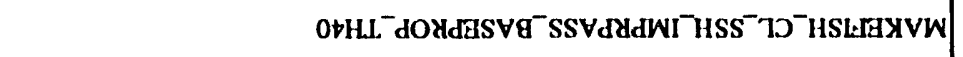 & & & & & & & & & & \\
\hline & 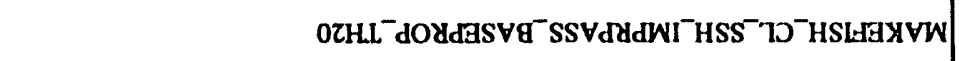 & & & & & & & & & & \\
\hline & 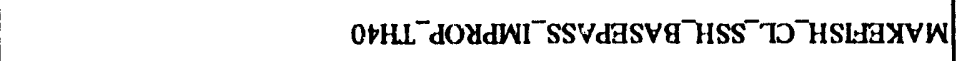 & & & & & & & & & & \\
\hline & $\mathrm{OZHL}^{-}$dOYdWI'SSVdaSVG HSS & & & & & & & & & & \\
\hline & 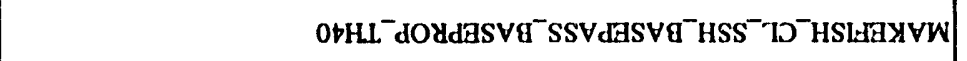 & & & & & & & & & & \\
\hline & 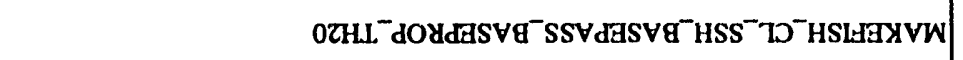 & & & & & & & & & & \\
\hline & 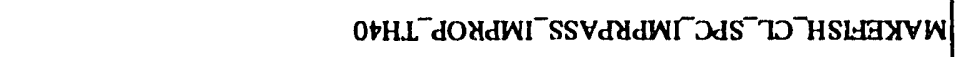 & & & & & & & & & & \\
\hline & 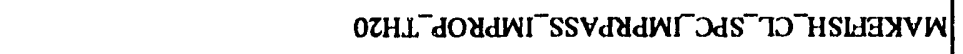 & & & & & & & & & & \\
\hline$\frac{\infty}{\sigma}$ & 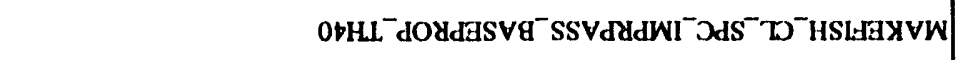 & & & & & & & & & & \\
\hline 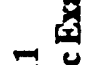 & 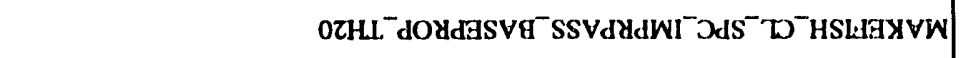 & & & & & & & & & & \\
\hline & 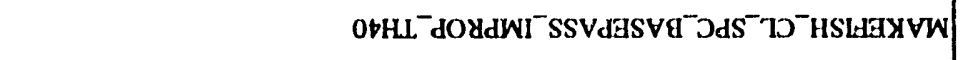 & & & & & & & & & & \\
\hline 齐 & 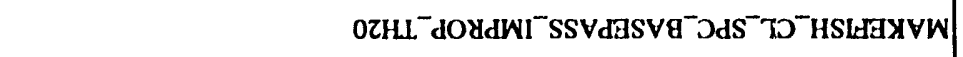 & & & & & & & & & & \\
\hline $\bar{g}$ & 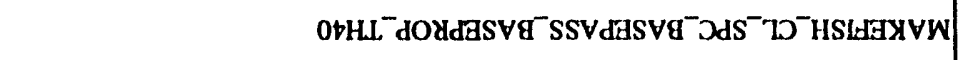 & & & & & & & & & & \\
\hline 常 & 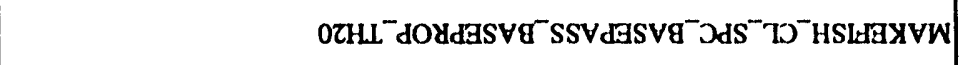 & & & & & & & & & & \\
\hline & OtHI' dOYdWrSSVd\&dWr HSS" & & & & & & & & & & $T$ \\
\hline & 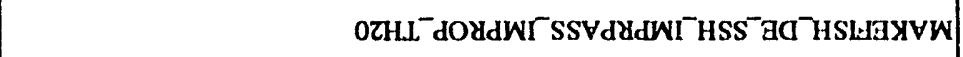 & & & & & & & & & & $T$ \\
\hline & 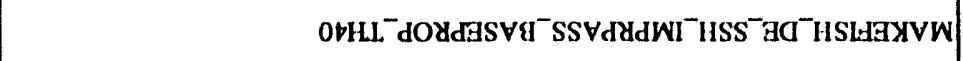 & & & & & & & & & & $\vec{T}$ \\
\hline & 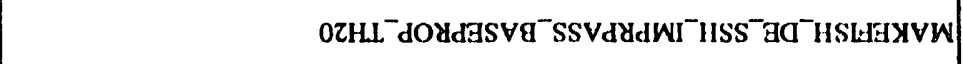 & & & & & & & & & & $T$ \\
\hline & 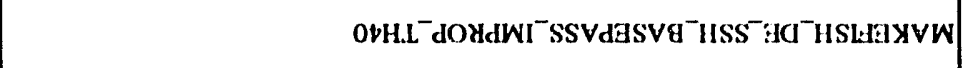 & & & & & & & & $T$ & & \\
\hline & 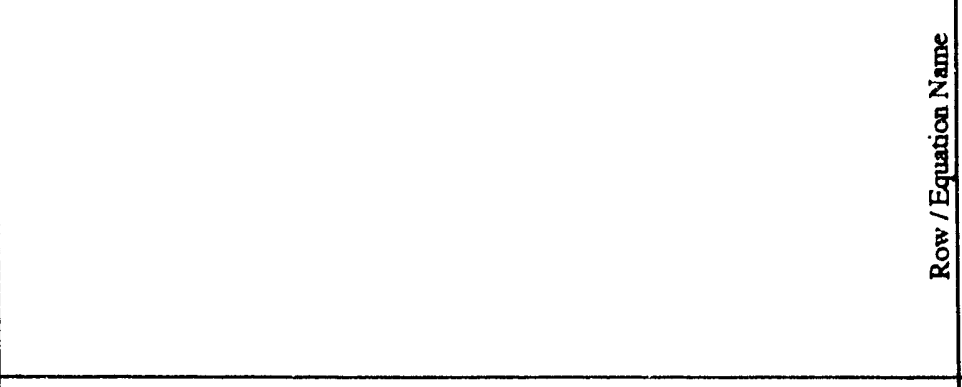 & 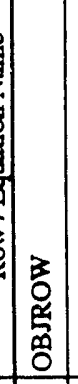 & 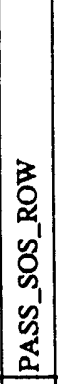 & 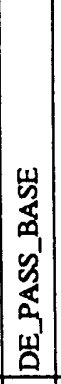 & 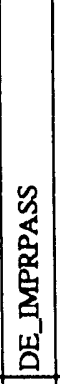 & 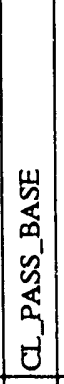 & 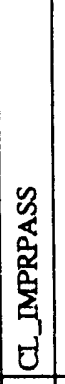 & 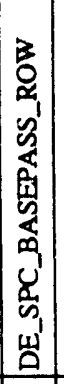 & 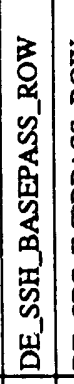 & 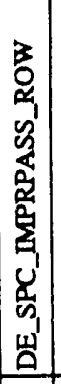 & 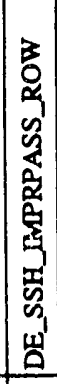 \\
\hline & LaquiniN uotrenbs d7] & $\rightarrow$ & $a$ & $m$ & $m$ & $m$ & $m$ & + & + & + & + \\
\hline
\end{tabular}




\begin{tabular}{|c|c|c|c|c|c|c|c|c|c|c|c|}
\hline & 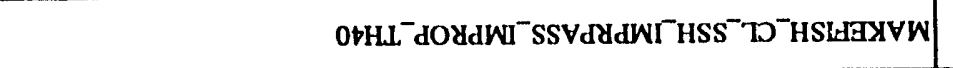 & & & & & $T$ & & & & & \\
\hline & 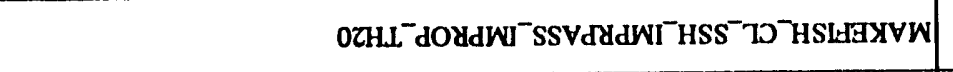 & & & & & $T$ & & & & & \\
\hline & 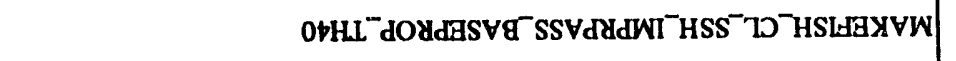 & & & & & $\vec{\imath}$ & & & & & \\
\hline & OZHL $^{-}$dOYdESVG SSVdYdWI HSS ${ }^{-1} D^{-}$HSLAGXYW & & & & & $\vec{T}$ & & & & & \\
\hline & 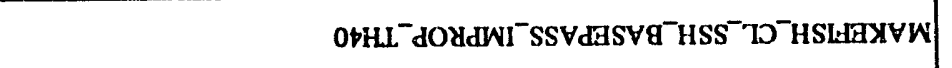 & & & $T$ & & & & & & & \\
\hline & 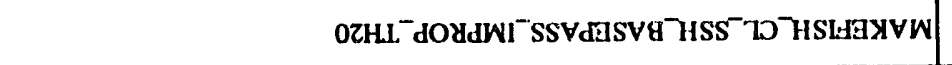 & & & $T$ & & & & & & & \\
\hline & 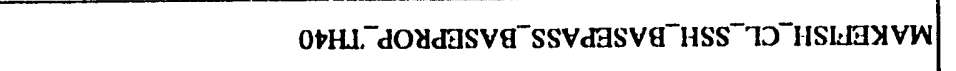 & & & 7 & & & & & & & \\
\hline & 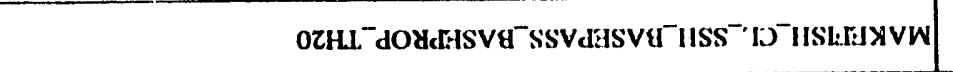 & & & $T$ & & & & & & & \\
\hline & 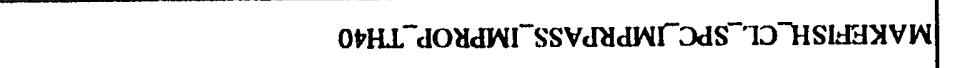 & & & & $T$ & & & & & & \\
\hline & 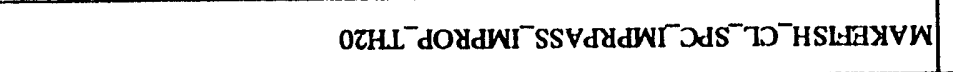 & & & & $T$ & & & & & & \\
\hline 营 & 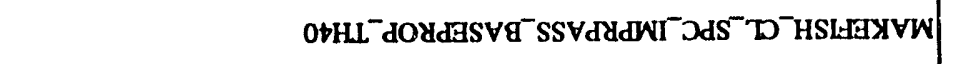 & & & & $T$ & & & & & & \\
\hline 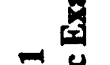 & 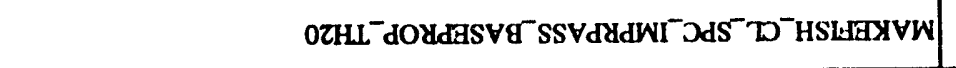 & & & & $T$ & & & & & & \\
\hline & 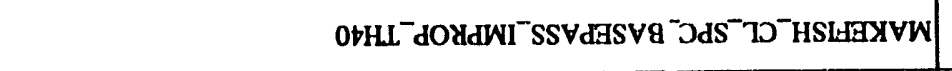 & & 7 & & & & & & & & \\
\hline 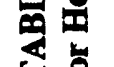 & 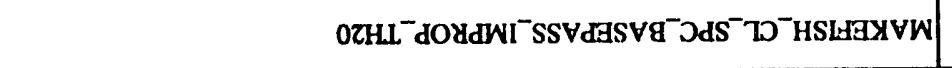 & & $T$ & & & & & & & & \\
\hline $\bar{\Xi}$ & 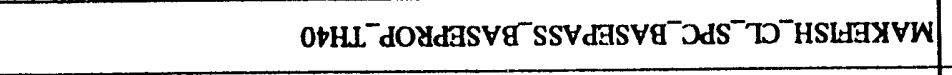 & & $T$ & & & & & & & & \\
\hline 苗 & 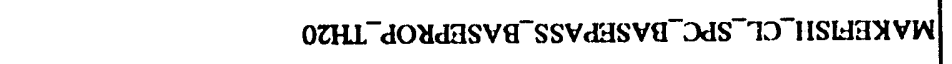 & & 7 & & & & & & & & \\
\hline & 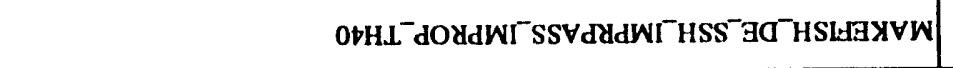 & & & & & & & & & & \\
\hline & 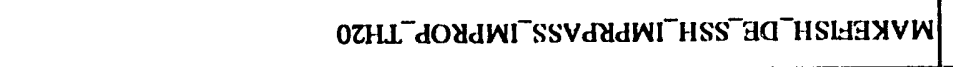 & & & & & & & & & & \\
\hline & 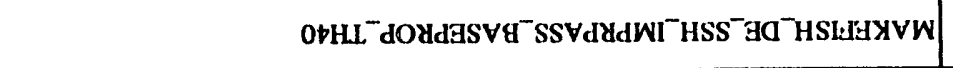 & & & & & & & & & $\vec{T}$ & \\
\hline & 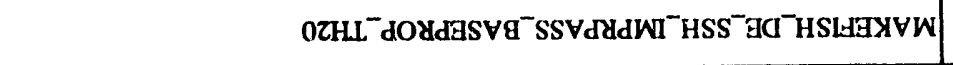 & & & & & & & & & $\vec{T}$ & \\
\hline & 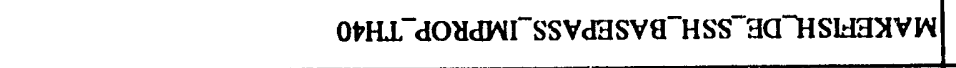 & & & & & & & & & & \\
\hline & 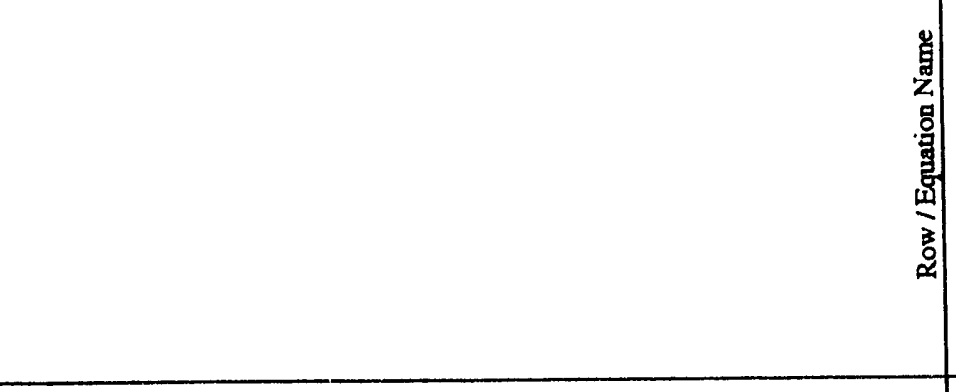 & 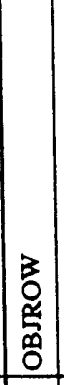 & 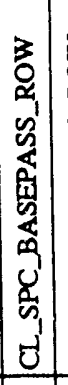 & 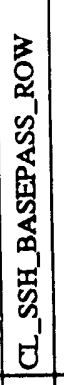 & 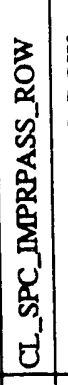 & 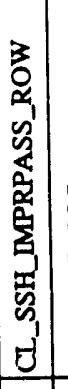 & 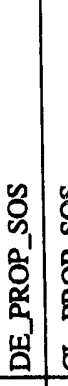 & $\begin{array}{l}n \\
0 \\
0 \\
0 \\
0 \\
\vdots \\
\vdots \\
j \\
0\end{array}$ & 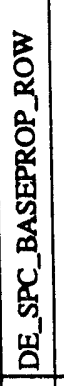 & 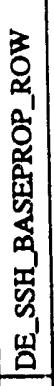 & 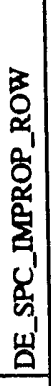 \\
\hline & soutun $N$ wo!lenbal d d7 & - & + & + & + & + & $n$ & $n$ & ○ & 0 & $\infty$ \\
\hline
\end{tabular}




\begin{tabular}{|c|c|c|c|c|c|c|c|c|c|c|}
\hline & 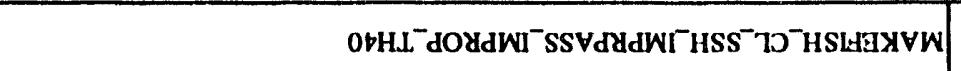 & & & & & & $\vec{T}$ & & & -1 \\
\hline & 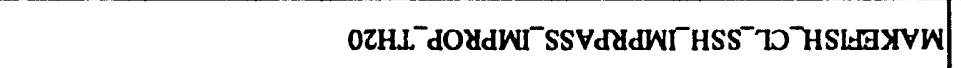 & & & & & & $\bar{T}$ & & & 0 \\
\hline & 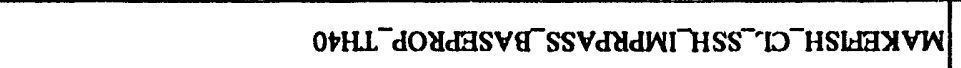 & & & & 7 & & & & & -1 \\
\hline & 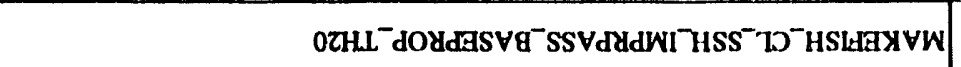 & & & & $T$ & & & & & 0 \\
\hline & ObHL'- dOYdWI'SSVdGSVG'HSS' & & & & & & 7 & & & -7 \\
\hline & 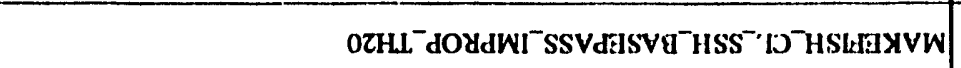 & & & & & & $T$ & & & 0 \\
\hline & 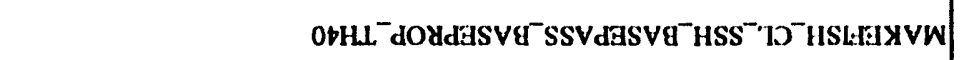 & & & & $T$ & & & & & -7 \\
\hline & 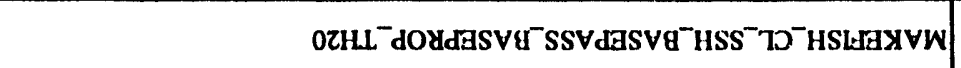 & & & & 7 & & & & & 0 \\
\hline & 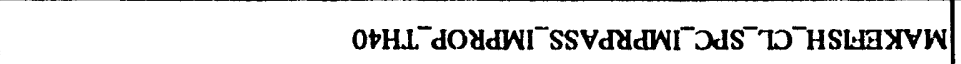 & & & & & $\vec{T}$ & & & -7 & \\
\hline & 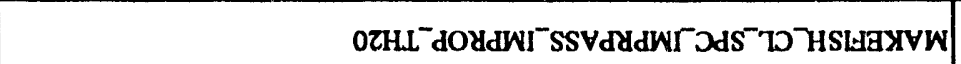 & & & & & 7 & & & 0 & \\
\hline 总 & 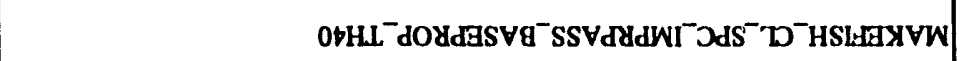 & & & $T$ & & & & & 0 & \\
\hline & 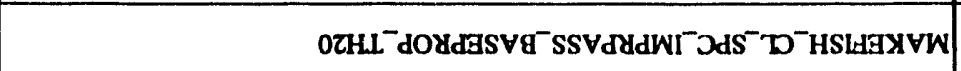 & & & 7 & & & & & 10 & \\
\hline 湜 & 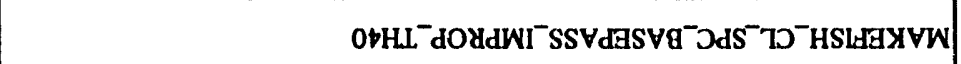 & & & & & $T$ & & & 10 & \\
\hline 菅 & 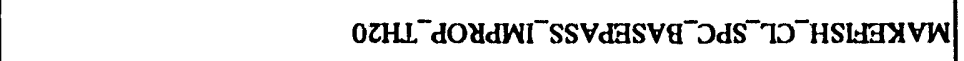 & & & & & $T$ & & & 0 & \\
\hline 趸 & 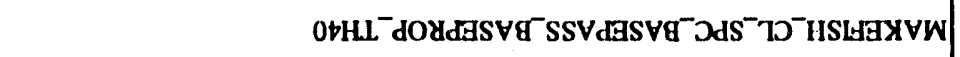 & & & $T$ & & & & & 0 & \\
\hline$\stackrel{\text { बै }}{\Leftrightarrow}$ & 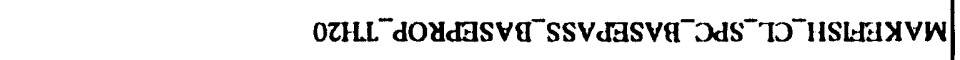 & & & $T$ & & & & & 0 & \\
\hline & 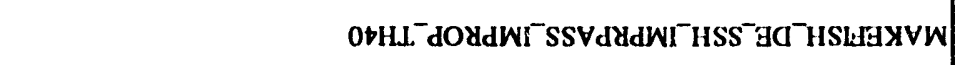 & & $T$ & & & & & - & & \\
\hline & 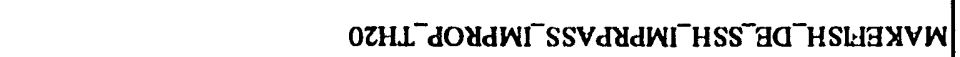 & & 7 & & & & & - & & \\
\hline & 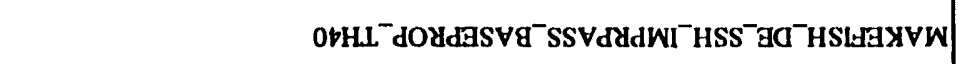 & & & & & & & - & & \\
\hline & 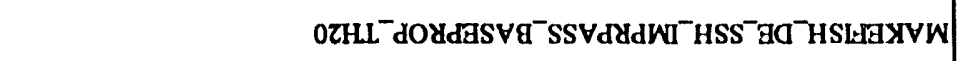 & & & & & & & - & & \\
\hline & 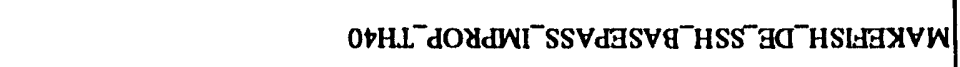 & & $T$ & & & & & - & & \\
\hline & 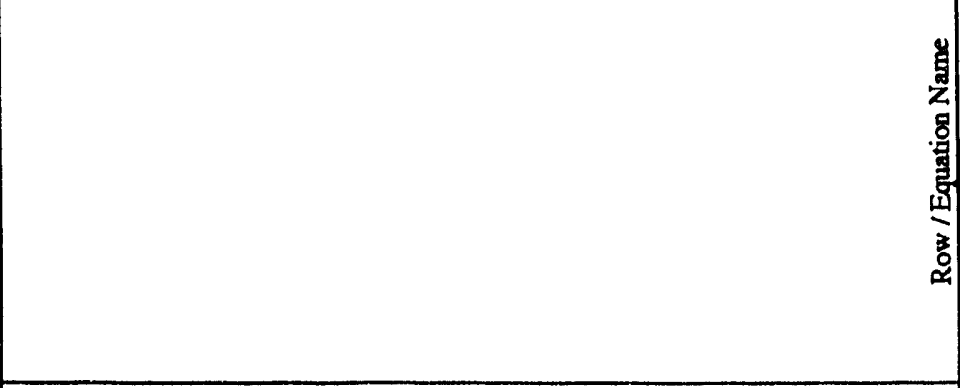 & $\mid$ & 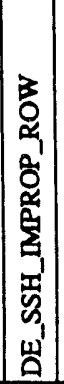 & 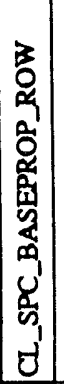 & 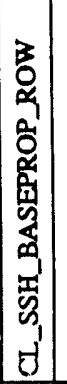 & 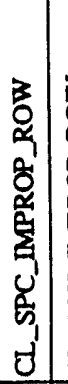 & 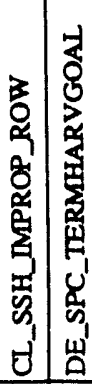 & 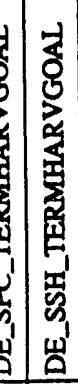 & 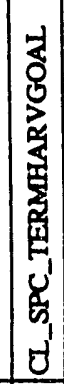 & 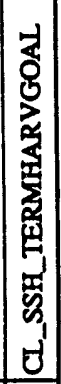 \\
\hline & soquin $N$ uoụtenbr dT & - & - & 0 & o & ○ & 0 - & $a$ & $a$ & $a$ \\
\hline
\end{tabular}




\begin{tabular}{|c|c|c|c|c|c|c|}
\hline & 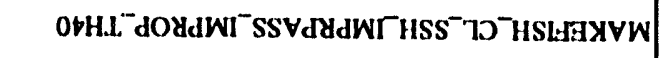 & & & & & 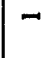 \\
\hline & 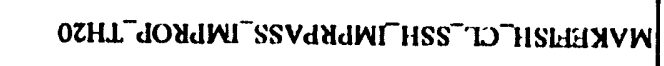 & & & & & - \\
\hline & 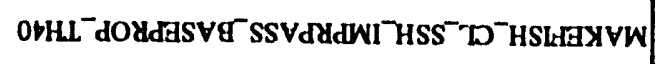 & & & & & - \\
\hline & 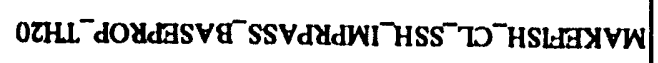 & & & & & 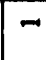 \\
\hline & 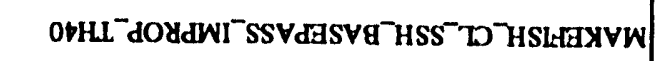 & & & & & - \\
\hline & 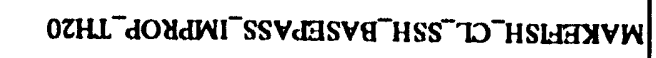 & & & & & - \\
\hline & 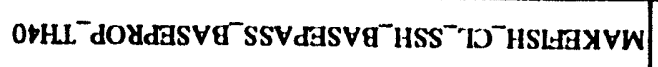 & & & & & 0 \\
\hline & 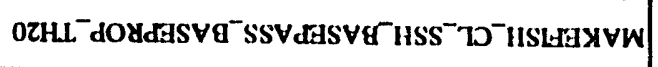 & & & & & $\rightarrow$ \\
\hline & 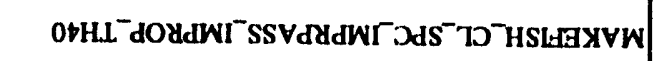 & & & & - & \\
\hline & 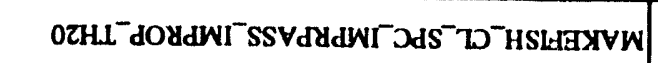 & & & & $\rightarrow$ & \\
\hline 总 & 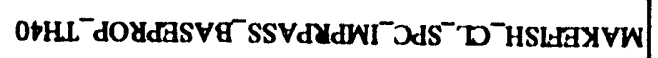 & & & & 0 & \\
\hline-1 & 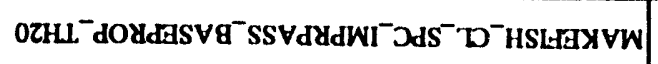 & & & & 0 & \\
\hline (x) & 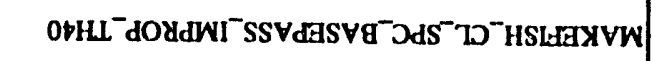 & & & & - & \\
\hline 2 & 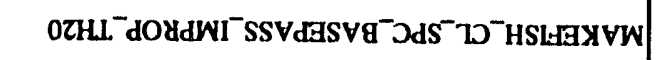 & & & & $\rightarrow$ & \\
\hline 8 & 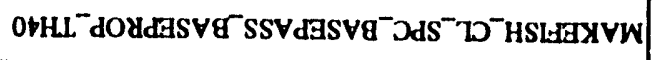 & & & & 0 & \\
\hline$\Leftrightarrow$ & 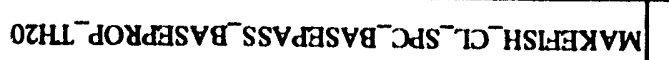 & & & & 0 & \\
\hline & 0tHL'- dO\&dWI'SSVd\&dWI'HSS"ađ"HSLEXVW & & & - & & \\
\hline & 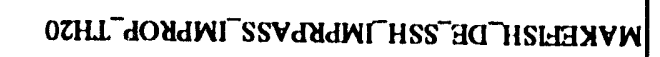 & & & $\varpi$ & & \\
\hline & 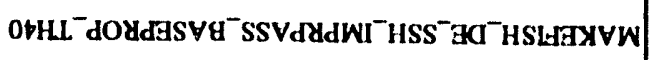 & & & 0 & & \\
\hline & 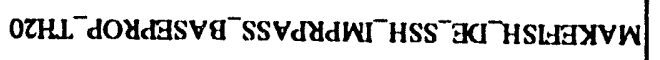 & & & - & & \\
\hline & 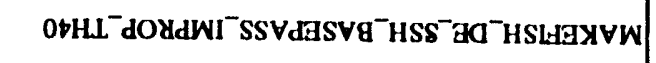 & & & $\rightarrow$ & & \\
\hline & 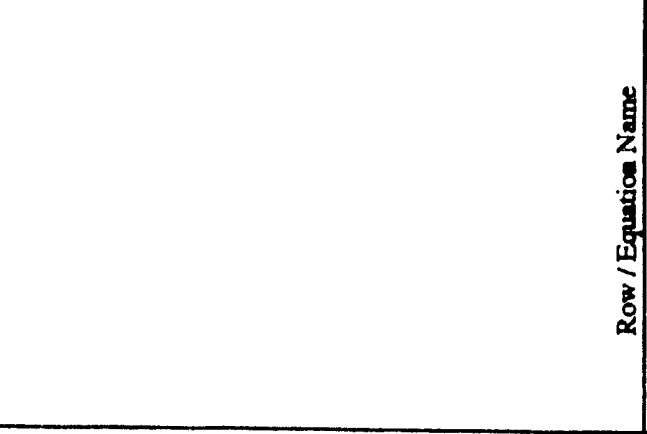 & 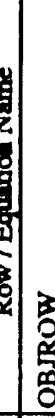 & 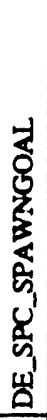 & 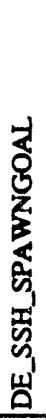 & 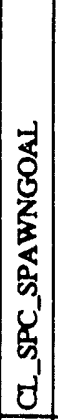 & 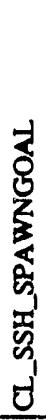 \\
\hline & squunN woịtenbra dT & - & 인 & 욱 & 음 & 으 \\
\hline
\end{tabular}


TABLE C.1

Base-Case Propagation Parameters

\begin{tabular}{|c|c|c|c|c|c|c|c|c|}
\hline \multirow[t]{2}{*}{ PARAMETER } & \multicolumn{2}{|c|}{ GRANDE RONDE } & \multicolumn{2}{|c|}{ GRANDE RONDE } & \multicolumn{2}{|c|}{ GRAINDE RONDE } & \multicolumn{2}{|c|}{ CLEARWATER } \\
\hline & $\begin{array}{l}\text { Spring } \\
\text { Chinook } \\
\text { Natural } \\
\text { Value }\end{array}$ & $\begin{array}{l}\text { Spring } \\
\text { Chinook } \\
\text { Natural } \\
\text { Source* }\end{array}$ & $\begin{array}{l}\text { Spring } \\
\text { Chinook } \\
\text { Hatchery } \\
\text { Value }\end{array}$ & $\begin{array}{l}\text { Spring } \\
\text { Chinook } \\
\text { Hatchery } \\
\text { Source* }\end{array}$ & $\begin{array}{l}\text { Summer } \\
\text { Stcelhead } \\
\text { Natural } \\
\text { Value }\end{array}$ & $\begin{array}{l}\text { Summer } \\
\text { Steelhead } \\
\text { Natural } \\
\text { Source* }\end{array}$ & $\begin{array}{l}\text { Spring } \\
\text { Chinook } \\
\text { Natural } \\
\text { Value }\end{array}$ & $\begin{array}{l}\text { Spring } \\
\text { Chinook } \\
\text { Natural } \\
\text { Source* }\end{array}$ \\
\hline ffem & 0.608 & $\mathbf{A}$ & 0.475 & A & 0.63 & A & 0.49 & A \\
\hline prspsv & 0.65 & $\mathbf{A}$ & 0.9 & A & 0.8 & A & 0.6 & $\mathbf{A}$ \\
\hline egfem & 3,577 . & A & 4,023 & A & 5,000 & A & 4,221 & $\mathbf{A}$ \\
\hline hatrem & 183. & $\mathrm{Cl}$ & 386. & $\mathrm{Cl}$ & 702. & $\mathrm{Cl}$ & 992. & $\mathrm{C} 1$ \\
\hline hatsmolt & 294,358 & $\mathrm{C}$ & 619,630 & $\mathrm{C}$ & $1,555,204$ & $\mathrm{C}$ & $1,464,375$ & C \\
\hline hintsv & 0.75 & B & 0.75 & B & 0.6 & B & 0.75 & B3 \\
\hline bhincp & 0.13 & $A 1$ & 0.838 & $\mathrm{~A} 1$ & 0.239942 & $A 1$ & 0.163967 & A1 \\
\hline bhcap & 433,000 & A & -- & & 460,000 & $\mathrm{~A}$ & $5,886,114$ & A \\
\hline smtage 1 & 1. & A & 1. & A & 0.6 & A & 1. & A \\
\hline smtage 2 & -- & A & -. & A & 0.4 & A & -- & A \\
\hline smtage3 & -- & A & -- & A & -. & A & -- & A \\
\hline inbsmsv & 0.5 & A & 0.8 & B & 0.5 & A & 0.5 & $\mathbf{A}$ \\
\hline adtrecv & 0.0825 & F & 0.01088 & $\mathbf{F}$ & 0.1292 & F & 0.01425 & $\mathbf{F}$ \\
\hline sadtrecv & 0.0085 & F & -.- & $\mathbf{F}$ & 0.01696 & F & 0.0083 & F \\
\hline ocn 1har & 0.001 & D & 0.001 & D & -- & D & 0.001 & D \\
\hline ocnlruh & 0.011 & D & 0.011 & D & - & D & 0.011 & D \\
\hline ocnlsuv & 0.875 & D & 0.875 & D & 0.54542 & D & 0.875 & D \\
\hline ocn2har & 0.004 & D & 0.004 & D & -- & D & 0.004 & D \\
\hline ocn2rvh & 0.11 & D & 0.11 & D & -. & D & 0.11 & D \\
\hline ocn2suv & 0.301 & D & 0.301 & D & 0.19132 & D & 0.301 & D \\
\hline ocn3har & -- & D & -- & D & -- & D & -- & D \\
\hline ocn3rvh & 0.389 & D & 0.389 & D & -- & D & 0.389 & D \\
\hline ocn3suv & 0.009 & D & 0.009 & D & 0.30567 & D & 0.009 & D \\
\hline ocn4har & -- & D & -- & D & -- & D & -- & D \\
\hline ocn4rvh & 0.8 & D & 0.8 & D & -- & D & 0.8 & D \\
\hline ocn1sbe & 0.113 & D & 0.113 & D & 0.45458 & $\mathrm{D}$ & 0.113 & D \\
\hline ocn2sbe & 0.585 & D & 0.585 & D & 0.80868 & D & 0.585 & D \\
\hline ocn3sbe & 0.602 & D & 0.602 & D & 0.69433 & $\mathrm{D}$ & 0.602 & D \\
\hline ocn 4 sbe & 0.2 & D & 0.2 & D & 1. & $D$ & 0.2 & D \\
\hline termhar & 0.03 & A & 0.03 & A & -. & A & 0.04 & A \\
\hline suptermh & 0.03 & $A$ & .- & A & 0.1 & A & 0.04 & A \\
\hline msurv & 0.30131 & $\mathrm{E}$ & 0.24105 & $\mathrm{E}$ & 0.39314 & $\mathrm{E}$ & 0.56409 & $\mathrm{E}$ \\
\hline passcr & 0.248485 & $\mathrm{E}$ & 0.248485 & $\mathrm{E}$ & 0.233072 & $\mathrm{E}$ & 0.092341 & $\mathrm{E}$ \\
\hline jackspı & -- & A & -- & A & 1. & A & -- & A \\
\hline
\end{tabular}


TABLE C.1

Base-Case Propagation Parameters

\begin{tabular}{|c|c|c|c|c|c|c|c|c|}
\hline \multirow[t]{2}{*}{ PARAMETER } & \multicolumn{2}{|c|}{ CLEARWATER } & \multicolumn{2}{|c|}{ CLEARWATER } & \multicolumn{2}{|c|}{ CLEARWATER } & \multicolumn{2}{|c|}{ LOWER SALMON } \\
\hline & $\begin{array}{l}\text { Spring } \\
\text { Chinook } \\
\text { Hatchery } \\
\text { Value }\end{array}$ & $\begin{array}{l}\text { Spring } \\
\text { Chinook } \\
\text { Hatchery } \\
\text { Source* }\end{array}$ & $\begin{array}{l}\text { Summer } \\
\text { Steelhead } \\
\text { Natural } \\
\text { Value }\end{array}$ & $\begin{array}{c}\text { Summer } \\
\text { Steelhead } \\
\text { Natural } \\
\text { Source* }\end{array}$ & $\begin{array}{l}\text { Summer } \\
\text { Steelhead } \\
\text { Hatchery } \\
\text { Value }\end{array}$ & $\begin{array}{l}\text { Summer } \\
\text { Steelhead } \\
\text { Hatchery } \\
\text { Source* }\end{array}$ & $\begin{array}{l}\text { Spring } \\
\text { Chinook } \\
\text { Natural } \\
\text { Value }\end{array}$ & $\begin{array}{l}\text { Spring } \\
\text { Chinook } \\
\text { Natural } \\
\text { Source* }\end{array}$ \\
\hline ffem & 0.6 & J & 0.592352 & A & 0.6 & J & 0.547 & $\mathbf{A}$ \\
\hline prspsv & 0.8 & A & 0.8 & A & 0.952 & B & 0.6 & $\mathbf{A}$ \\
\hline egfem & 4,100 . & $\mathbf{J}$ & 6,000 . & A & 6,000 . & J & 3,912 . & A \\
\hline hatrem & 1,112 & $\mathrm{Cl}$ & 536. & $\mathrm{Cl}$ & 764. & $\mathrm{C} 1$ & 0. & \\
\hline hatsmolt & $1,642,444$ & C & $1,122,846$ & $\mathrm{C}$ & $1,540,704$ & C & 0. & \\
\hline hintsv & 0.75 & B3 & 0.6 & B3 & 0.6 & B3 & 0.5 & B \\
\hline bhincp & . & & 0.239942 & Al & . & & 0.163967 & A1 \\
\hline bhcap & -- & & $1,600,000$ & A & -- & & 530,317 & A \\
\hline smtage 1 & -- & & 0.2 & A & -- & & 1. & $\mathbf{A}$ \\
\hline smtage2 & -- & & 0.72 & A & -. & & -- & A \\
\hline smtage3 & -- & & 0.08 & A & -- & & -- & $\mathbf{A}$ \\
\hline inbsmsv & -. & & 0.5 & A & -- & & 0.5 & A \\
\hline adtrecv & 0.00459 & F & 0.0495 & $\mathbf{F}$ & 0.1687 & F & 0.0405 & F \\
\hline sadtrecv & -- & $\mathbf{F}$ & 0.03135 & $\mathrm{~F}$ & -- & F & NS & $\mathbf{F}$ \\
\hline ocnlhar & 0.001 & D & -. & B2 & 0.01 & D & 0.001 & D \\
\hline ocnlrvb & 0.011 & D & -- & B2 & 0.02 & D & 0.011 & D \\
\hline ocn1suv & 0.875 & D & 1. & B2 & 0.96 & D & 0.875 & D \\
\hline ocn2har & 0.004 & D & -- & B2 & 0.01 & D & 0.004 & D \\
\hline$o c n 2 r v h$ & 0.11 & D & $-\cdot$ & B2 & 0.52 & D & 0.11 & $D$ \\
\hline ocn2suv & 0.301 & D & 1. & B2 & 0.2 & D & 0.301 & D \\
\hline ocn3har & -- & D & -- & B2 & -- & D & -- & D \\
\hline ocn3rvh & 0.389 & D & $-\cdot$ & B2 & 0.64 & D & 0.389 & D \\
\hline ocn3suv & 0.009 & D & 1. & B2 & 0.03 & D & 0.009 & D \\
\hline ocn4har & -- & D & -- & B2 & -- & D & $-\cdot$ & D \\
\hline ocn4rvh & 0.8 & D & $\cdots$ & B2 & 0.61 & D & 0.8 & D \\
\hline ocn1sbe & 0.113 & D & -- & B2 & 0.01 & D & 0.113 & D \\
\hline ocn2sbe & 0.585 & D & 0. & B2 & 0.27 & D & 0.585 & D \\
\hline ocn3sbe & 0.602 & D & 0. & B2 & 0.33 & D & 0.602 & D \\
\hline ocn 4sbe & 0.2 & D & -- & B2 & 0.39 & D & 0.2 & D \\
\hline termhar & 0.04 & $\mathbf{A}$ & -- & A & 0.6 & A & -- & $\mathbf{A}$ \\
\hline suptermh & -- & A & 0.6 & A & -- & $\mathbf{A}$ & -- & A \\
\hline msurv & 0.45128 & $\mathrm{E}$ & 0.47353 & $\mathrm{E}$ & 0.37883 & $\mathrm{E}$ & 0.34693 & $\mathrm{E}$ \\
\hline passcv & 0.092341 & $\mathrm{E}$ & 0.211943 & $\mathrm{E}$ & 0.211943 & $\mathrm{E}$ & 0.119771 & $\mathrm{E}$ \\
\hline jackspn & -. & A & 1. & A & -. & A & -- & A \\
\hline
\end{tabular}


TABLE C.1

Base-Case Propagation Parameters

PARAMETER LOWER SALMON LOWER SALMON LOWER SALMON LITTLE SALMON

\begin{tabular}{|c|c|c|c|c|c|c|c|c|}
\hline & $\begin{array}{l}\text { Spring } \\
\text { Chinook } \\
\text { Hatchery } \\
\text { Value }\end{array}$ & $\begin{array}{l}\text { Spring } \\
\text { Chinook } \\
\text { Hatchery } \\
\text { Source* }\end{array}$ & $\begin{array}{l}\text { Summer } \\
\text { Steelhead } \\
\text { Natural } \\
\text { Value }\end{array}$ & $\begin{array}{l}\text { Suminer } \\
\text { Steelhead } \\
\text { Natural } \\
\text { Source* }\end{array}$ & $\begin{array}{l}\text { Summer } \\
\text { Steelhead } \\
\text { Hatchery } \\
\text { Value }\end{array}$ & $\begin{array}{l}\text { Summer } \\
\text { Steelhead } \\
\text { Hatchery } \\
\text { Source* }\end{array}$ & $\begin{array}{l}\text { Spring } \\
\text { Chinook } \\
\text { Natural } \\
\text { Value }\end{array}$ & $\begin{array}{l}\text { Spring } \\
\text { Chinook } \\
\text { Natural } \\
\text { Source* }\end{array}$ \\
\hline flem & 0.503101 & A & 0.67 & A & 0.52825 & A & 0.50416 & A \\
\hline prspsv & 0.819 & A & 0.8 & A & 0.9 & A & 0.6 & A \\
\hline egfem & 3,831 . & $\mathbf{A}$ & 3,200 . & A & 6,468 & A & 3,832 . & A \\
\hline hatrem & 0. & & 307. & $\mathrm{Cl}$ & 6. & $\mathrm{Cl}$ & 217. & $\mathrm{Cl}$ \\
\hline hatsmolt & 0. & & 629,541 & $\mathrm{C}$ & 0. & & 250,000 & C \\
\hline hintsv & 0.5 & B & 0.65 & B & 0.65 & B & 0.5 & B \\
\hline bhincp & 0.58 & A1 & 0.239942 & A1 & 0.61 & Al & 0.163967 & Al \\
\hline bhcap & -- & & 94,949 . & A & -- & & 291,103 & A \\
\hline smtage 1 & $\cdot-$ & & 0.2 & A & -- & & 1. & A \\
\hline smtage2 & -- & & 0.72 & $\mathbf{A}$ & -- & & -- & $\mathbf{A}$ \\
\hline smtage 3 & -- & & 0.08 & A & -- & & -- & A \\
\hline inbsmsv & -- & & 0.4 & A & -- & & 0.5 & A \\
\hline adtrecv & 0.06 & F1 & 0.134 & F & 0.0907 & F1 & 0.0088 & $\mathbf{F}$ \\
\hline sadtrecv & -- & F & 0.02365 & F & -- & $\mathbf{F}$ & 0.0255 & $\mathbf{F}$ \\
\hline ocn1har & 0.001 & D & -- & B2 & 0.01 & D & 0.001 & D \\
\hline ocn1ruh & 0.011 & D & -- & B2 & 0.02 & D & 0.011 & D \\
\hline ocn1suv & 0.875 & D & 1. & B2 & 0.96 & D & 0.875 & D \\
\hline ocn2har & 0.004 & D & -- & B2 & 0.01 & D & 0.004 & D \\
\hline ocm2rvh & 0.11 & D & -- & B2 & 0.52 & D & 0.11 & D \\
\hline ocn2suv & 0.301 & D & 1. & B2 & 0.2 & D & 0.301 & D \\
\hline ocn3har & -- & D & -- & B2 & -- & D & -- & D \\
\hline ocn3rvh & 0.389 & D & -- & B2 & 0.64 & D & 0.389 & D \\
\hline ocn3suv & 0.009 & D & - & B2 & 0.03 & D & 0.009 & D \\
\hline ocn4har & -. & D & -- & B2 & -- & D & -- & D \\
\hline ocn4rvh & 0.8 & D & -- & B2 & 0.61 & D & 0.8 & D \\
\hline ocnlsbe & 0.113 & D & - & B2 & 0.01 & D & 0.113 & D \\
\hline acn2sbe & 0.585 & D & 0. & B2 & 0.27 & D & 0.585 & D \\
\hline ocn3sbe & 0.602 & D & -- & B2 & 0.33 & D & 0.602 & D \\
\hline ocn4sbe & 0.2 & D & -- & B2 & 0.39 & D & 0.2 & D \\
\hline termhar & -- & A & -- & A & -- & A & -- & A \\
\hline suptermh & -- & A & -- & A & -- & A & -- & A \\
\hline msurv & 0.27754 & E & 0.46972 & $\mathrm{E}$ & 0.37578 & E & 0.34693 & $\mathrm{E}$ \\
\hline passcv & 0.119771 & $\mathrm{E}$ & 0.203222 & E & 0.203222 & E & 0.119771 & E \\
\hline jackspn & -- & A & 1. & A & - & A & -- & A \\
\hline
\end{tabular}


TABLE C.1

Base-Case Propagation Parameters

PARAMETER LITTE SALMON LITTLE SALMON MID MAIN SALMON MID MAIN SALMON

$\begin{array}{llllllll}\text { Spring } & \text { Spring } & \text { Summer } & \text { Summer } & \text { Spring } & \text { Spring } & \text { Spring } & \text { Spring } \\ \text { Chinook } & \text { Chinook } & \text { Steelhead } & \text { Steelhead } & \text { Chinook } & \text { Chinook } & \text { Chincick } & \text { Chinook } \\ \text { Hatchery } & \text { Hatchery } & \text { Natural } & \text { Natural Natural } & \text { Natural } & \text { Hatchery } & \text { Hatchery } \\ \text { Value } & \text { Source* }^{*} & \text { Value } & \text { Source* } & \text { Value } & \text { Source* } & \text { Value } & \text { Source* }\end{array}$

\begin{tabular}{|c|c|c|c|c|c|c|c|}
\hline ffem & 0.50587 & A & 0.571007 & A & 0.547 & A & 0.616944 \\
\hline prspsy & 0.819 & $A$ & 0.8 & A & 0.6 & A & 0.819 \\
\hline egfem & 3,912 . & A & 5,162 . & A & 4,500 . & $A$ & 3,427 . \\
\hline hatnem & 2,195 & $\mathrm{Cl}$ & 393. & $\mathrm{Cl}$ & 0. & & 0. \\
\hline hatsmolt & $2,520,400$ & $\mathrm{C}$ & 699,317 & C & 0. & & 0. \\
\hline hintsv & 0.5 & B & 0.65 & B & 0.5 & B & 0.5 \\
\hline bhincp & 0.58 & Al & 0.239942 & Al & 0.16397 & $\mathrm{~A} 1$ & 0.58 \\
\hline blicap & -- & & 118,759 & A & 505,456 & A & -- \\
\hline smtage1 & - & & 0.2 & A & 1. & $A$ & -- \\
\hline smtage 2 & -- & & 0.72 & A & -- & A & -- \\
\hline smiage 3 & -- & & 0.08 & A & -- & A & - \\
\hline inbsmsv & -- & & 0.5 & A & 0.5 & A & -- \\
\hline adtrect & 0.0607 & F1 & 0.137 & $F$ & 0.0378 & $\mathrm{~F}$ & 0.06 \\
\hline sadtiecr & - & $\mathbf{F}$ & 0.02364 & F & NS & $\mathrm{F}$ & -- \\
\hline ocnl har & 0.001 & D & -- & B2 & 0.001 & $\mathrm{D}$ & 0.001 \\
\hline ocnlruh & 0.011 & D & - & B2 & 0.011 & $\mathrm{D}$ & 0.011 \\
\hline ocnlsuv & 0.875 & D & 1. & B2 & 0.875 & D & 0.875 \\
\hline ocn2har & 0.004 & D & -- & B2 & 0.004 & D & 0.004 \\
\hline ocn2rvb & 0.11 & $\mathrm{D}$ & -. & B2 & 0.11 & D & 0.11 \\
\hline ocn2sur & 0.301 & $\mathrm{D}$ & 1. & B2 & 0.301 & D & 0.301 \\
\hline ocn3har & -- & $D$ & -. & B2 & -- & D & -- \\
\hline ocn3rvh & 0.389 & D & .. & B2 & 0.389 & $\mathrm{D}$ & 0.389 \\
\hline ocn3suv & 0.009 & D & -- & B2 & 0.009 & $\mathrm{D}$ & 0.009 \\
\hline ocn 4 har & -- & D & -- & B2 & -- & D & -- \\
\hline ocn $4 \mathrm{rvb}$ & 0.8 & D & -. & B2 & 0.8 & D & 0.8 \\
\hline ocnlsbe & 0.113 & $\mathrm{D}$ & -. & B2 & 0.113 & D & 0.113 \\
\hline ocn2sbe & 0.585 & D & 0. & B2 & 0.585 & D & 0.585 \\
\hline cion3sbe & 0.602 & D & -. & B2 & 0.602 & D & 0.602 \\
\hline oc 4 sbe & 0.2 & $\mathrm{D}$ & -. & B2 & 0.2 & D & 0.2 \\
\hline termhar & -- & A & -. & A & -- & A & -- \\
\hline suptermh & -- & A & 0.6 & A & -- & $A$ & -- \\
\hline msurv & 0.2432 & $\mathrm{E}$ & 0.46972 & $\mathrm{E}$ & 0.34693 & $E$ & 0.27754 \\
\hline passcr & 0.239738 & $\mathrm{E}$ & 0.203222 & $\mathrm{E}$ & 0.119771 & $\mathrm{E}$ & 0.119771 \\
\hline jackspn & - & A & 1. & A & -- & A & -- \\
\hline
\end{tabular}


TABLE C.1

Base-Case Propagation Parameters

\begin{tabular}{|c|c|c|c|c|c|c|c|c|}
\hline & $\begin{array}{l}\text { Summer } \\
\text { Steelhead } \\
\text { Natural } \\
\text { Value }\end{array}$ & $\begin{array}{l}\text { Summer } \\
\text { Stcelhead } \\
\text { Natural } \\
\text { Source* }\end{array}$ & $\begin{array}{l}\text { Summer } \\
\text { Steelhead } \\
\text { Hatchery } \\
\text { Value }\end{array}$ & $\begin{array}{l}\text { Summer } \\
\text { Steelhead } \\
\text { Hatchery } \\
\text { Source* }\end{array}$ & $\begin{array}{l}\text { Spring } \\
\text { Chinook } \\
\text { Natural } \\
\text { Value }\end{array}$ & $\begin{array}{l}\text { Spring } \\
\text { Chinook } \\
\text { Natural } \\
\text { Source* }\end{array}$ & $\begin{array}{l}\text { Spring } \\
\text { Chinook } \\
\text { Natural } \\
\text { Value }\end{array}$ & $\begin{array}{l}\text { Spring } \\
\text { Chinook } \\
\text { Natural } \\
\text { Source* }\end{array}$ \\
\hline ffem & 0.67 & A & 0.560785 & $\mathbf{A}$ & 0.547 & A & 0.5 & A \\
\hline prspsv & 0.8 & $\mathbf{A}$ & 0.9 & A & 0.6 & A & 0.6 & $\mathbf{A}$ \\
\hline egfem & 3,200 . & $\mathbf{A}$ & 7,228 . & A & 5,313 & A & 4,787 & A \\
\hline $\begin{array}{l}\text { hatrem } \\
\text { hatsmolt }\end{array}$ & 5. & $\mathrm{Cl}$ & 6. & $\mathrm{C} 1$ & 0. & & 0. & \\
\hline hatsmolt & 0. & & 0. & & 0. & & 0. & \\
\hline hintsv & 0.65 & B & 0.65 & B & 0.5 & B & 0.5 & B \\
\hline bhincp & 0.239942 & A.1 & . & & 0.163967 & A1 & 0.163967 & A1 \\
\hline bhcap & 186,722 & A & -- & & $3,786,756$ & A & 715,499 & A \\
\hline smtagel & 0.2 & A & -- & & 1. & A & 1. & A \\
\hline smtage2 & 0.72 & $\mathbf{A}$ & -- & & -- & A & -- & A \\
\hline smtage 3 & 0.08 & A & -- & & -- & A & -- & A \\
\hline inbsmsv & 0.4 & A & -- & & 0.5 & A & 0.5 & A \\
\hline adtrecv & 0.154 & F & 0.0907 & F1 & 0.03256 & F & 0.0386 & F \\
\hline sadtrecv & NS & $F$ & -- & $\mathbf{F}$ & 0.0185 & $\mathbf{F}$ & 0.0185 & $\mathbf{F}$ \\
\hline ocn1har & -. & B2 & 0.01 & D & 0.001 & D & 0.001 & D \\
\hline ocn1ruh & -- & B2 & 0.02 & D & 0.011 & D & 0.011 & D \\
\hline ocn1suv & 1. & B2 & 0.96 & D & 0.875 & D & 0.875 & D \\
\hline ocn2har & -. & B2 & 0.01 & D & 0.004 & D & 0.004 & D \\
\hline ocn $2 \mathrm{rvh}$ & -- & B2 & 0.52 & D & 0.11 & D & 0.11 & D \\
\hline ocn2suv & 1. & B2 & 0.2 & D & 0.301 & D & 0.301 & D \\
\hline ocn3har & -. & B2 & - & D & -. & D & -. & D \\
\hline ocn3rvh & - & B2 & 0.64 & D & 0.389 & D & 0.389 & D \\
\hline ocn3suv & -- & B2 & 0.03 & D & 0.009 & D & 0.009 & D \\
\hline ocn4har & -- & B2 & -- & D & -- & D & -. & D \\
\hline ocn4rvh & -- & B2 & 0.61 & D & 0.8 & D & 0.8 & D \\
\hline ocn1sbe & -. & B2 & 0.01 & D & 0.113 & D & 0.113 & D \\
\hline ocn2sbe & 0. & B2 & 0.27 & D & 0.585 & D & 0.585 & D \\
\hline ocn3sbe & -- & B2 & 0.33 & D & 0.602 & D & 0.602 & D \\
\hline ocn4sbe & -. & B2 & 0.39 & D & 0.2 & D & 0.2 & D \\
\hline termhar & -- & A & -- & $A$ & -- & A & -- & A \\
\hline suptermh &.- & A & -- & A & -- & $\mathbf{A}$ & -- & A \\
\hline msurv & 0.46972 & $\mathrm{E}$ & 0.37578 & $\mathrm{E}$ & 0.34693 & E & 0.34693 & $\mathrm{E}$ \\
\hline passcr & 0.203222 & E & 0.203222 & $\mathrm{E}$ & 0.119771 & $\mathrm{E}$ & 0.119771 & $\mathrm{E}$ \\
\hline jackspn & 1. & A & -- & A & -- & A & -- & A \\
\hline
\end{tabular}


TABLE C.1

\section{Base-Case Propagation Parameters}

\begin{tabular}{|c|c|c|c|c|c|c|c|c|}
\hline \multirow[t]{2}{*}{ PARAMETER } & \multicolumn{2}{|l|}{ LEMHI } & \multicolumn{2}{|c|}{ UPPER SALMON } & \multicolumn{2}{|c|}{ UPPER SALMON } & \multicolumn{2}{|c|}{ UPPER SALMON } \\
\hline & $\begin{array}{l}\text { Summer } \\
\text { Steelhead } \\
\text { Natural } \\
\text { Value }\end{array}$ & $\begin{array}{l}\text { Summer } \\
\text { Steelbead } \\
\text { Natural } \\
\text { Source* }\end{array}$ & $\begin{array}{l}\text { Spring } \\
\text { Chinook } \\
\text { Natural } \\
\text { Value }\end{array}$ & $\begin{array}{l}\text { Spring } \\
\text { Chinook } \\
\text { Natural } \\
\text { Source* }\end{array}$ & $\begin{array}{l}\text { Spring } \\
\text { Chinook } \\
\text { Hatchery } \\
\text { Value }\end{array}$ & $\begin{array}{l}\text { Spring } \\
\text { Chinook } \\
\text { Hatchery } \\
\text { Source* }\end{array}$ & $\begin{array}{l}\text { Suminer } \\
\text { Chinook } \\
\text { Natural } \\
\text { Value }\end{array}$ & $\begin{array}{l}\text { Summer } \\
\text { Chinook } \\
\text { Natural } \\
\text { Source* }\end{array}$ \\
\hline ffem & 0.5 & A & 0.473 & A & 0.45 & A & 0.553 & A \\
\hline prspsv & 0.8 & $A$ & 0.6 & A & 0.819 & $A$ & 0.7 & A \\
\hline egfem & 4,374 & A & 5,292 . & $\mathbf{A}$ & 5,106 & A & 5,000 & $\mathbf{A}$ \\
\hline hatrem & 5. & $\mathrm{Cl}$ & 457. & $\mathrm{Cl}$ & 1,213 & $\mathrm{Cl}$ & 0. & \\
\hline hatsmolt & 0. & & 715,400 & $\mathrm{C}$ & $1,895,600$ & $\mathrm{C}$ & 0. & \\
\hline hintsv & 0.05 & B & 0.5 & B & 0.5 & B & 0.5 & B \\
\hline bhincp & 0.239942 & Al & 0.163967 & $\mathrm{Al}$ & 0.68 & $A 1$ & 0.163967 & A1 \\
\hline bhcap & $97,998$. & $\mathbf{A}$ & $1,586,454$ & $\mathrm{~A}$ & -- & & 976,459 & A \\
\hline smtage 1 & 0.2 & $\mathbf{A}$ & 1. & A & -- & & 1. & A \\
\hline smtage2 & 0.72 & A & -- & A & -- & & -- & A \\
\hline smtage 3 & 0.08 & $\mathbf{A}$ & -- & A & -- & & -- & A \\
\hline inbsmsv & 0.4 & $A$ & 0.5 & A & -- & & 0.5 & A \\
\hline adtrecr & 0.154 & $\mathbf{F}$ & 0.0129 & F & 0.0594 & F1 & 0.034 & $\mathbf{F}$ \\
\hline sadtrecv & 0.0328 & $\mathrm{~F}$ & 0.0255 & $\mathrm{~F}$ & -- & $\mathbf{F}$ & NS & $\mathbf{F}$ \\
\hline ocn1 har & -- & B2 & 0.001 & D & 0.001 & D & 0.002 & D \\
\hline ocnlrvh & -. & B2 & 0.011 & D & 0.011 & D & 0.029 & D \\
\hline ocnlsuv & 1. & B2 & 0.875 & $\mathrm{D}$ & 0.875 & $\mathrm{D}$ & 0.678 & D \\
\hline ocn2har & -- & B2 & 0.004 & D & 0.004 & $\mathrm{D}$ & 0.005 & D \\
\hline ocn2rvb & -- & B2 & 0.11 & D & 0.11 & D & 0.15 & D \\
\hline ocn2suv & 1. & $\mathrm{~B} 2$ & 0.301 & D & 0.301 & D & 0.2285 & D \\
\hline ocn3har & -. & B2 & -. & D & -- & $\mathrm{D}$ & 0.009 & D \\
\hline ocn3rvh & -- & B2 & 0.389 & D & 0.389 & D & 0.046 & $\mathrm{D}$ \\
\hline ocn3suv & -- & B2 & 0.009 & D & 0.009 & D & 0.002 & D \\
\hline ocn4har & -- & B2 & -. & D & -- & D & -- & D \\
\hline ocn4rvh & -- & B2 & 0.8 & $\mathrm{D}$ & 0.8 & D & -- & D \\
\hline ocn1sbe & -- & B2 & 0.113 & $\mathrm{D}$ & 0.113 & $\mathrm{D}$ & 0.29 & D \\
\hline ocn2sbe & 0. & B2 & 0.585 & D & 0.585 & D & 0.6165 & D \\
\hline ocn3sbe & -- & $\mathrm{B} 2$ & 0.602 & D & 0.602 & D & 0.943 & D \\
\hline ocn4sbe & -- & B2 & 0.2 & $\mathrm{D}$ & 0.2 & D & 1. & D \\
\hline termhar & -- & $A$ & -. & A & -- & A & -. & $A$ \\
\hline suptenmh & -. & A & -. & A & -- & $A$ & .. & A \\
\hline insurv & 0.46972 & $\mathrm{E}$ & 0.34693 & $\mathrm{E}$ & 0.24845 & $\mathrm{E}$ & 0.3405 & $\mathrm{E}$ \\
\hline passcr & 0.203222 & $\mathrm{E}$ & 0.119771 & $\mathrm{E}$ & 0.238995 & $\mathrm{E}$ & 0.151298 & $\mathrm{E}$ \\
\hline jackspn & 1. & $A$ & .. & A & -. & A & .. & A \\
\hline
\end{tabular}


TABLE C.1

Base-Case Propagation Parameters

\begin{tabular}{|c|c|c|c|c|c|c|c|c|}
\hline \multirow[t]{2}{*}{ PARAMETER } & \multicolumn{2}{|c|}{ UPPER SALMON } & \multicolumn{2}{|c|}{ UPPER SALMON } & \multicolumn{2}{|c|}{ UPPER SALMON } & \multicolumn{2}{|c|}{ S. FORK SALMON } \\
\hline & $\begin{array}{l}\text { Summer } \\
\text { Chinook } \\
\text { Hatchery } \\
\text { Value }\end{array}$ & $\begin{array}{l}\text { Summer } \\
\text { Chinook } \\
\text { Hatchery } \\
\text { Source* }\end{array}$ & $\begin{array}{l}\text { Summer } \\
\text { Steelhead } \\
\text { Natural } \\
\text { Value }\end{array}$ & $\begin{array}{l}\text { Summer } \\
\text { Steelhead } \\
\text { Natural } \\
\text { Source* }\end{array}$ & $\begin{array}{l}\text { Summer } \\
\text { Steelhead } \\
\text { Hatchery } \\
\text { Value }\end{array}$ & $\begin{array}{l}\text { Summer } \\
\text { Steelhead } \\
\text { Hatchery } \\
\text { Source* }\end{array}$ & $\begin{array}{l}\text { Summer } \\
\text { Chinook } \\
\text { Natural } \\
\text { Value }\end{array}$ & $\begin{array}{l}\text { Summer } \\
\text { Chinook } \\
\text { Natural } \\
\text { Source* }\end{array}$ \\
\hline ffem & 0.616944 & A & 0.497 & $\mathbf{A}$ & 0.570714 & $\mathbf{A}$ & 0.506 & $\mathbf{A}$ \\
\hline prspsv & 0.893 & A & 0.8 & A & 0.9 & $\mathbf{A}$ & 0.7 & $\mathbf{A}$ \\
\hline egfem & 3,427 . & A & 4,987 . & A & 5,159 . & $\mathbf{A}$ & 3,590 & $\mathbf{A}$ \\
\hline hatrem & 0. & & 1,333 & $\mathrm{C} 1$ & 173. & $\mathrm{Cl}$ & 0. & \\
\hline hatsmolt & 0. & & $2,386,652$. & $\mathrm{C}$ & 301,156 & C & 0. & \\
\hline hintsv & 0.5 & B & 0.65 & B & 0.65 & B & 0.5 & B \\
\hline bhincp & 0.76 & A1 & 0.239942 & A1 & 0.61 & A1 & 0.163967 & A1 \\
\hline bhcap & - & & 665,466 & A & -- & & $2,092,013$. & $\mathbf{A}$ \\
\hline smtage 1 & -- & & 0.2 & $\mathbf{A}$ & - & & 1. & $\mathbf{A}$ \\
\hline smtage2 & -- & & 0.72 & $\mathbf{A}$ & -- & & -- & $\mathbf{A}$ \\
\hline smtage3 & -- & & 0.08 & $\mathbf{A}$ & -- & & -- & $\mathbf{A}$ \\
\hline inbsmsv & -- & & 0.4 & A & -- & & 0.5 & A \\
\hline adtrecv & 0.0604 & $\mathrm{~F} 1$ & 0.1324 & $\mathbf{F}$ & 0.0907 & F1 & 0.05107 & $\mathbf{F}$ \\
\hline sadtrecv & - & $\mathrm{F}$ & 0.02457 & $\mathbf{F}$ & -- & $\mathbf{F}$ & NS & $\mathbf{F}$ \\
\hline ocn1har & 0.002 & D & -- & B2 & 0.01 & D & 0.002 & D \\
\hline ocn1rvh & 0.029 & D & -- & B2 & 0.02 & D & 0.029 & D \\
\hline ocn1suv & 0.678 & D & 1. & B2 & 0.96 & D & 0.678 & D \\
\hline ocn2har & 0.005 & D & -- & B2 & 0.01 & D & 0.005 & D \\
\hline ocn2rvh & 0.15 & D & -- & B2 & 0.52 & D & 0.15 & D \\
\hline ocn2suv & 0.2285 & D & 1. & B2 & 0.2 & D & 0.2285 & D \\
\hline ocn3har & 0.009 & D & -- & B2 & - & D & 0.009 & D \\
\hline ocn3rvb & 0.046 & D & -- & B2 & 0.64 & D & 0.046 & D \\
\hline ocn3suv & 0.002 & D & -- & B2 & 0.03 & D & 0.002 & D \\
\hline ocn4har & -- & D & -- & B2 & -- & D & -- & D \\
\hline ocn4rvh & -- & D & -. & B2 & 0.61 & D & -- & D \\
\hline ocnlsbe & 0.29 & D & -- & B2 & 0.01 & D & 0.29 & D \\
\hline ocn2sbe & 0.6165 & D & 0. & B2 & 0.27 & D & 0.6165 & D \\
\hline ocn3sbe & 0.943 & D & -- & B2 & 0.33 & D & 0.943 & D \\
\hline ocn4sbe & 1. & D & -- & B2 & 0.39 & D & 1. & D \\
\hline termhar & -- & A & -- & A & -- & A & -- & A \\
\hline suptermh & -. & A & -. & A & - & A & -. & A \\
\hline msurv & 0.2724 & $\mathrm{E}$ & 0.45188 & $E$ & 0.37578 & $\mathrm{E}$ & 0.3405 & $\mathrm{E}$ \\
\hline passcv & 0.151298 & E & 0.203222 & $\mathrm{E}$ & 0.203222 & $\mathrm{E}$ & 0.151298 & $\mathbf{E}$ \\
\hline jackspn & -- & A & 1. & A & -- & A & -. & A \\
\hline
\end{tabular}


TABLE C.1

Base-Case Propagation Parameters

\begin{tabular}{|c|c|c|c|c|c|c|c|c|}
\hline \multirow[t]{2}{*}{ PARAMETER } & \multicolumn{2}{|c|}{ S. FORK SALMON } & \multicolumn{2}{|c|}{ S. FORK SALMON } & \multicolumn{2}{|c|}{ S. FORK SALMON } & \multicolumn{2}{|c|}{ PANTHER CREEK } \\
\hline & $\begin{array}{l}\text { Summer } \\
\text { Chinook } \\
\text { Hatchery } \\
\text { Value }\end{array}$ & $\begin{array}{l}\text { Summer } \\
\text { Chinook } \\
\text { Hatchery } \\
\text { Source* }\end{array}$ & $\begin{array}{l}\text { Summer } \\
\text { Stcelhead } \\
\text { Natural } \\
\text { Value }\end{array}$ & $\begin{array}{l}\text { Summer } \\
\text { Steelhead } \\
\text { Natural } \\
\text { Source* }\end{array}$ & $\begin{array}{l}\text { Summer } \\
\text { Steelhead } \\
\text { Hatchery } \\
\text { Value }\end{array}$ & $\begin{array}{l}\text { Summer } \\
\text { Steelhead } \\
\text { Hatchery } \\
\text { Source* }\end{array}$ & $\begin{array}{l}\text { Summer } \\
\text { Chinook } \\
\text { Natural } \\
\text { Value }\end{array}$ & $\begin{array}{l}\text { Summer } \\
\text { Chinook } \\
\text { Natural } \\
\text { Source* }\end{array}$ \\
\hline ffem & 0.33848 & A & 0.488 & A & 0.560785 & A & 0.41492 & $\mathbf{A}$ \\
\hline prspsv & 0.893 & A & 0.8 & $\mathbf{A}$ & 0.9 & A & 0.7 & A \\
\hline egfem & 4,382 & $\mathbf{A}$ & 5,600 & A & 7,228 . & A & 5,527 & A \\
\hline hatrem & 994. & C1 & 5. & $\mathrm{C} 1$ & 6. & $\mathrm{Cl}$ & 0. & \\
\hline hatsmolt & $1,032,500$ & C & 0. & & 0. & & 0. & \\
\hline hintsv & 0.5 & B & 0.65 & B & 0.65 & B & 0.5 & B \\
\hline bhincp & 0.7 & A1 & 0.239942 & A1 & 0.54 & A1 & 0.163967 & Al \\
\hline bhcap & -- & & 445,209 & A & -- & & 42,769 & $\mathbf{A}$ \\
\hline smtage 1 & -- & & 0.2 & $\mathbf{A}$ & -- & & 1. & A \\
\hline smtage2 & -- & & 0.72 & A & -- & & -. & A \\
\hline smtage 3 & -. & & 0.08 & A & -. & & -- & A \\
\hline inbsmsv & -- & & 0.4 & A & -. & & 0.5 & A \\
\hline adtrecv & 0.0602 & F1 & 0.05 & $\mathbf{F}$ & 0.0907 & F1 & 0.0403 & F \\
\hline sadtrecv & -- & $\mathrm{F}$ & NS & F & -- & $\mathrm{F}$ & 0.0173 & $\mathrm{~F}$ \\
\hline ocnlhar & 0.002 & D & - & B2 & 0.01 & D & 0.002 & D \\
\hline ocnlrvb & 0.029 & D & - & B2 & 0.02 & D & 0.029 & D \\
\hline ocn1suv & 0.678 & $\mathrm{D}$ & 1. & B2 & 0.96 & $\mathrm{D}$ & 0.678 & D \\
\hline ocn2har & 0.005 & D & - & B2 & 0.01 & $\mathrm{D}$ & 0.005 & $\mathrm{D}$ \\
\hline ocn2rvh & 0.15 & D & -- & B2 & 0.52 & D & 0.15 & D \\
\hline ocn2suv & 0.2285 & D & 1. & B2 & 0.2 & D & 0.2285 & D \\
\hline ocn3har & 0.009 & D & -- & B2 & -- & D & 0.009 & D \\
\hline ocn3rvh & 0.046 & $\mathrm{D}$ & -- & B2 & 0.64 & D & 0.046 & D \\
\hline ocn3suv & 0.002 & $\mathrm{D}$ & -- & B2 & 0.03 & D & 0.002 & D \\
\hline ocn4har & -- & D & -- & B2 & -. & D & - & D \\
\hline ocn4rvh & -- & D & -- & B2 & 0.61 & D & $\ldots$ & D \\
\hline ocn1sbe & 0.29 & $\mathrm{D}$ & -- & B2 & 0.01 & $\mathrm{D}$ & 0.29 & D \\
\hline ocn2sbe & 0.6165 & D & 0. & B2 & 0.27 & D & 0.6165 & D \\
\hline ocn3sbe & 0.943 & D & -. & B2 & 0.33 & D & 0.943 & D \\
\hline ocn4sbe & 1. & D & -- & $\mathrm{B} 2$ & 0.39 & $\mathrm{D}$ & 1. & D \\
\hline termhar & -- & A & -- & A & -- & A & -- & A \\
\hline suptermb & -- & A & -- & A & -- & A & -- & A \\
\hline msurv & 0.2452 & $\mathrm{E}$ & 0.46972 & $\mathrm{E}$ & 0.37578 & $\mathrm{E}$ & 0.3405 & $\mathrm{E}$ \\
\hline passcv & 0.242227 & $\mathrm{E}$ & 0.203222 & $\mathrm{E}$ & 0.203222 & $\mathrm{E}$ & 0.151298 & $\mathrm{E}$ \\
\hline jackspn & -. & A & 1. & A & -- & $\mathrm{A}$ & -. & $\mathrm{A}$ \\
\hline
\end{tabular}


TABLE C.1

Base-Case Propagation Parameters

\begin{tabular}{|c|c|c|c|c|c|c|c|c|}
\hline \multirow[t]{2}{*}{ PARAMETER } & \multicolumn{2}{|c|}{ PANTHER CREEK } & \multicolumn{2}{|c|}{ PANTHER CREEK } & \multicolumn{2}{|c|}{ PAHSIMEROI } & \multicolumn{2}{|c|}{ PAHSIMEROI } \\
\hline & $\begin{array}{l}\text { Summer } \\
\text { Steelhead } \\
\text { Natural } \\
\text { Value }\end{array}$ & $\begin{array}{l}\text { Summer } \\
\text { Steelhead } \\
\text { Natural } \\
\text { Source* }\end{array}$ & $\begin{array}{l}\text { Summer } \\
\text { Steelhead } \\
\text { Hatchery } \\
\text { Value }\end{array}$ & $\begin{array}{l}\text { Summer } \\
\text { Steelhead } \\
\text { Hatchery } \\
\text { Source* }\end{array}$ & $\begin{array}{l}\text { Summer } \\
\text { Chinook } \\
\text { Natural } \\
\text { Value }\end{array}$ & $\begin{array}{l}\text { Summer } \\
\text { Chinook } \\
\text { Natural } \\
\text { Source* }\end{array}$ & $\begin{array}{l}\text { Summer } \\
\text { Chinook } \\
\text { Hatchery } \\
\text { Value }\end{array}$ & $\begin{array}{l}\text { Summer } \\
\text { Chinook } \\
\text { Hatchery } \\
\text { Source* }\end{array}$ \\
\hline $\begin{array}{l}\text { ffem } \\
\text { prspsv }\end{array}$ & 0.570333 & A & 0.570781 & A & 0.553 & A & 0.36715 & A \\
\hline $\begin{array}{l}\text { prspsv } \\
\text { egfem }\end{array}$ & 0.8 & A & 0.9 & $\mathbf{A}$ & 0.7 & A & 0.893 & A \\
\hline $\begin{array}{l}\text { egfem } \\
\text { hatrem }\end{array}$ & 5,155 & A & 5,160 & A & 5,255 & $\mathbf{A}$ & 5,448 . & $\mathrm{A}$ \\
\hline $\begin{array}{l}\text { hatrem } \\
\text { hatsmolt }\end{array}$ & $\begin{array}{l}5 . \\
0 .\end{array}$ & $\mathrm{C} 1$ & $\begin{array}{l}6 . \\
0 .\end{array}$ & $\mathrm{Cl}$ & 0. & & 695. & $\mathrm{Cl}$ \\
\hline hintsv & 0.65 & B & $\begin{array}{l}0 . \\
0.65\end{array}$ & & $\begin{array}{l}0 . \\
0.5\end{array}$ & & $\begin{array}{l}1,058,000 . \\
0.5\end{array}$ & $\begin{array}{l}\mathbf{C} \\
\mathbf{B}\end{array}$ \\
\hline bhincp & 0.239942 & A1 & $\begin{array}{l}0.65 \\
0.65\end{array}$ & $\begin{array}{c}\text { B } \\
\text { A1 }\end{array}$ & 0.163967 & $\begin{array}{l}\text { B } \\
\text { A1 }\end{array}$ & $\begin{array}{l}0.5 \\
0.76\end{array}$ & $\begin{array}{l}\text { B } \\
\text { A1 }\end{array}$ \\
\hline bhcap & 8,201 . & $\mathbf{A}$ & $\begin{array}{l}0.65 \\
-\end{array}$ & Al & 257,620 & A & 0.10 & A1 \\
\hline smtage1 & 0.2 & $\mathbf{A}$ & -- & & 1. & $\mathbf{A}$ & - & \\
\hline smtage2 & 0.72 & $\mathbf{A}$ & -- & & -- & $\mathbf{A}$ & - & \\
\hline smtage 3 & 0.08 & A & -- & & -- & A & - & \\
\hline inbsmsv & 0.5 & A & -- & & 0.5 & $\mathbf{A}$ & - & \\
\hline adtrecv & 0.15 & F & 0.0907 & F1 & 0.0314 & $\mathbf{F}$ & 0.0606 & F1 \\
\hline sadtrecv & NS & $\mathbf{F}$ & -- & $\mathbf{F}$ & NS & F & -- & $\begin{array}{c}\mathrm{F} 1 \\
\mathrm{~F}\end{array}$ \\
\hline ocn1har & -- & B2 & 0.01 & D & 0.002 & D & 0.002 & $\begin{array}{l}\mathbf{F} \\
\mathbf{D}\end{array}$ \\
\hline ocn1rvh & -- & B2 & 0.02 & $\mathrm{D}$ & 0.029 & D & 0.029 & \\
\hline ocn1suv & 1. & B2 & 0.96 & D & 0.678 & D & 0.678 & $\begin{array}{l}\text { D } \\
\text { D }\end{array}$ \\
\hline ocn2har & -. & B2 & 0.01 & D & 0.005 & D & 0.005 & $\begin{array}{l}\text { D } \\
\text { D }\end{array}$ \\
\hline ocn2rvh & -- & B2 & 0.52 & D & 0.15 & D & 0.15 & $\begin{array}{l}\text { D } \\
\text { D }\end{array}$ \\
\hline ocn2suv & 1. & B2 & 0.2 & D & 0.2285 & D & 0.2285 & $\begin{array}{l}\text { D } \\
\text { D }\end{array}$ \\
\hline ocn3har & -- & B2 & - & D & 0.009 & D & 0.009 & $\begin{array}{l}\text { D } \\
\text { D }\end{array}$ \\
\hline ocn3rvh & -. & B2 & 0.64 & D & 0.046 & D & 0.046 & $\begin{array}{l}\text { D } \\
\text { D }\end{array}$ \\
\hline ocn3suv & -- & B2 & 0.03 & D & 0.002 & D & 0.002 & $\begin{array}{l}\mathrm{D} \\
\mathrm{D}\end{array}$ \\
\hline ocn4har & -- & B2 & -- & D & -- & D & -. & $\begin{array}{l}\text { D } \\
\text { D }\end{array}$ \\
\hline ocn4rvh & -- & B2 & 0.61 & $\mathrm{D}$ & -- & D & - & $\begin{array}{l}\text { D } \\
\text { D }\end{array}$ \\
\hline ocn1sbe & -- & B2 & 0.01 & D & 0.29 & D & 0.29 & $\begin{array}{l}\mathrm{D} \\
\mathrm{D}\end{array}$ \\
\hline ocn2sbe & 0. & B2 & 0.27 & D & 0.6165 & D & 0.6165 & $\begin{array}{l}\mathrm{D} \\
\mathrm{D}\end{array}$ \\
\hline ocn3sbe & -. & B2 & 0.33 & D & 0.943 & D & 0.943 & $\begin{array}{l}\text { D } \\
\text { D }\end{array}$ \\
\hline ocn 4 sbe & .- & B2 & 0.39 & D & 1. & D & $\begin{array}{l}0.74 J \\
1 .\end{array}$ & $\begin{array}{l}\mathrm{D} \\
\mathrm{D}\end{array}$ \\
\hline termhar & -. & A & -- & $\mathrm{A}$ & - & A & 1. & $\begin{array}{l}\text { D } \\
\text { A }\end{array}$ \\
\hline suptermh & -- & A & -- & A & $\ldots$ & A & - & $\begin{array}{l}\text { A } \\
\text { A }\end{array}$ \\
\hline msurv & 0.46972 & $\mathrm{E}$ & 0.37578 & $\mathrm{E}$ & 0.3405 & $\mathrm{E}$ & 0.2437 & $\begin{array}{l}\text { A } \\
\text { E }\end{array}$ \\
\hline passcy & 0.203222 & $\mathbf{E}$ & 0.203222 & $\mathrm{E}$ & 0.151298 & E & 0.244146 & $\begin{array}{l}\mathrm{E} \\
\mathrm{E}\end{array}$ \\
\hline jackspn & 1. & A & -- & A & -- & A & -- & $\begin{array}{l}\mathbf{E} \\
\mathbf{A}\end{array}$ \\
\hline & & & & & & & & A \\
\hline
\end{tabular}


TABLE C.1

Base-Case Propagation Parameters

\begin{tabular}{|c|c|c|c|c|c|c|c|c|}
\hline \multirow[t]{2}{*}{ PARAMETER } & \multicolumn{2}{|c|}{ PAHSIMEROI } & \multicolumn{2}{|c|}{ PAHSIMEROI } & \multicolumn{2}{|c|}{ TUCANNON } & \multicolumn{2}{|c|}{ TUCANNON } \\
\hline & $\begin{array}{l}\text { Summer } \\
\text { Steelhead } \\
\text { Natural } \\
\text { Value }\end{array}$ & $\begin{array}{l}\text { Summer } \\
\text { Steelhead } \\
\text { Natural } \\
\text { Source* }\end{array}$ & $\begin{array}{l}\text { Summer } \\
\text { Steelhead } \\
\text { Hatchery } \\
\text { Value }\end{array}$ & $\begin{array}{l}\text { Summer } \\
\text { Steelhead } \\
\text { Hatchery } \\
\text { Source* }\end{array}$ & $\begin{array}{l}\text { Spring } \\
\text { Chinook } \\
\text { Natural } \\
\text { Value }\end{array}$ & $\begin{array}{l}\text { Spring } \\
\text { Chinook } \\
\text { Natural } \\
\text { Source* }\end{array}$ & $\begin{array}{l}\text { Summer } \\
\text { Steelhead } \\
\text { Natural } \\
\text { Value }\end{array}$ & $\begin{array}{l}\text { Summer } \\
\text { Steelhead } \\
\text { Natural } \\
\text { Source* }\end{array}$ \\
\hline ffem & 0.596 & $\mathbf{A}$ & 0.570656 & A & 0.5225 & A & 0.77 & B \\
\hline prspsv & 0.8 & A & 0.9 & A & 0.6 & B & 0.8 & A \\
\hline egfem & 4,374 & A & 5,158 & A & 4,050 & $\mathrm{~A}$ & 5,347 & B \\
\hline hatrem & 284. & $\mathrm{C} 1$ & 6. & $\mathrm{Cl}$ & 72. & $\mathrm{Cl}$ & 2. & $\mathrm{Cl}$ \\
\hline hatsmolt & 501,600 & $\mathrm{C}$ & 0. & & 145,146 & $\mathrm{C}$ & 0. & \\
\hline hintsv & 0.65 & B & 0.65 & B & 0.75 & B & 0.71 & B \\
\hline bhincp & 0.239942 & Al & 0.61 & $\mathrm{~A} 1$ & 0.16 & $\mathrm{~A} 2$ & 0.0322 & $\mathrm{~A} 1$ \\
\hline bhcap & 29,930 & A & -- & & 180,000 & A & 49,100 . & A \\
\hline smtage1 & 0.2 & $\mathbf{A}$ & -- & & 1. & A2 & 0.1 & $\mathbf{A}$ \\
\hline smtage2 & 0.72 & A & -- & & $\ldots$ & $\mathrm{A} 2$ & 0.9 & A \\
\hline sintage 3 & 0.08 & $\mathrm{~A}$ & -- & & -- & $\mathrm{A} 2$ & -. & A \\
\hline inbsmsv & 0.4 & A & -- & & 0.5 & $\mathrm{~A} 2$ & 0.5 & $\mathrm{~A} 2$ \\
\hline adtrecv & 0.131 & $\mathrm{~F}$ & 0.0907 & $\mathrm{~F} 1$ & 0.078 & $\mathrm{~F}$ & 0.253 & $\mathrm{~F}$ \\
\hline sadtrecv & NS & $\mathbf{F}$ & -- & $\mathrm{F}$ & 0.0575 & $\mathrm{~F}$ & 0.28 & $\mathrm{~F}$ \\
\hline ocnl har & -- & B2 & 0.01 & D & 0.001 & D & -- & B2 \\
\hline ocn1rvh & -- & B2 & 0.02 & D & 0.011 & D & -- & B2 \\
\hline ocn1suv & 1. & B2 & 0.96 & D & 0.875 & D & 1. & B2 \\
\hline ocn 2 har & -- & B2 & 0.01 & D & 0.004 & D & - & B2 \\
\hline ocn2rvh & -- & B2 & 0.52 & D & 0.11 & D & -- & B2 \\
\hline ocn2suv & 1. & $\mathrm{~B} 2$ & 0.2 & $\mathrm{D}$ & 0.301 & $\mathrm{D}$ & 1. & $\mathrm{~B} 2$ \\
\hline ocn3har & -- & B2 & -- & D & -- & D & -- & B2 \\
\hline ocn3rvh & -- & B2 & 0.64 & D & 0.389 & D & -- & B2 \\
\hline ocn3suv & -- & B2 & 0.03 & D & 0.009 & D & 1. & B2 \\
\hline ocn4har & -- & $\mathrm{B} 2$ &.- & $\mathrm{D}$ & -- & $\mathrm{D}$ & - & B2 \\
\hline ocn4rvh & -- & B2 & 0.61 & D & 0.8 & D & -- & B2 \\
\hline ocnlsbe & -- & $\mathrm{B} 2$ & 0.01 & D & 0.113 & D & - & B2 \\
\hline ocn2sbe & 0. & B2 & 0.27 & D & 0.585 & D & 0. & B2 \\
\hline ocn3sbe & -- & B2 & 0.33 & $\mathrm{D}$ & 0.602 & D & 0. & B2 \\
\hline ocn4sbe & -- & B2 & 0.39 & $\mathrm{D}$ & 0.2 & $\mathrm{D}$ &.- & $\mathrm{B} 2$ \\
\hline termhar & -- & A & -- & $A$ & -. & A & -. & A \\
\hline suptermh & -- & $A$ & -- & A & -- & A & 0.8 & $A$ \\
\hline msurv & 0.46972 & $\mathrm{E}$ & 0.37578 & $\mathrm{E}$ & 0.25805 & $\mathrm{E}$ & 0.35703 & $\mathrm{E}$ \\
\hline passcr & 0.203222 & $\mathrm{E}$ & 0.203222 & $\mathrm{E}$ & 0.213465 & $\mathrm{E}$ & 0.157409 & $\mathrm{E}$ \\
\hline jackspn & 1. & $\mathrm{~A}$ & -- & $\mathrm{A}$ & -- & A & & A \\
\hline
\end{tabular}


TABLE C.1

Base-Case Propagation Parameters

\begin{tabular}{|c|c|c|c|c|c|c|c|c|}
\hline \multirow[t]{2}{*}{ PARAMETER } & \multicolumn{2}{|c|}{ TUCANNON } & \multicolumn{2}{|l|}{ IMNAHA } & \multicolumn{2}{|c|}{ DESCHUTES } & \multicolumn{2}{|c|}{ DESCHUTES } \\
\hline & $\begin{array}{l}\text { Summer } \\
\text { Steelhead } \\
\text { Hatchery } \\
\text { Value }\end{array}$ & $\begin{array}{l}\text { Summer } \\
\text { Steelhead } \\
\text { Hatchery } \\
\text { Source* }\end{array}$ & $\begin{array}{l}\text { Spring } \\
\text { Chinook } \\
\text { Natural } \\
\text { Value }\end{array}$ & $\begin{array}{l}\text { Spring } \\
\text { Chinook } \\
\text { Natural } \\
\text { Source* }\end{array}$ & $\begin{array}{l}\text { Spring } \\
\text { Chinook } \\
\text { Natural } \\
\text { Value }\end{array}$ & $\begin{array}{l}\text { Spring } \\
\text { Chinook } \\
\text { Natural } \\
\text { Source* }\end{array}$ & $\begin{array}{l}\text { Spring } \\
\text { Chinook } \\
\text { Hatchery } \\
\text { Value }\end{array}$ & $\begin{array}{l}\text { Spring } \\
\text { Chinook } \\
\text { Hatchery } \\
\text { Source* }\end{array}$ \\
\hline ffem & 0.77 & A & 0.414 & A & 0.62 & $\mathbf{A}$ & 0.616944 & B \\
\hline prspsv & 0.9 & B & 0.65 & A & 0.56 & B & 0.85 & B \\
\hline egfem & 4,262 . & A & 4,805 & $\mathbf{A}$ & 3,300 . & $\mathbf{A}$ & 3,427 . & B \\
\hline hatrem & 46. & $\mathrm{C} 1$ & 327. & $\mathrm{C} 1$ & 0. & & 553. & C1 \\
\hline hatsmolt & 119,264 & $\mathrm{C}$ & 444,462 & C & 0. & & 968,603 & C \\
\hline hintsv & 0.71 & B & 0.8 & B & 0.5 & B & 0.5 & B \\
\hline bhincp & . & & 0.13 & Al & 0.15 & B & . & \\
\hline bhcap & -- & & 245,260 & A & 140,125 & A & -- & \\
\hline smtage1 & -- & & 1. & A & 1. & $\mathbf{A}$ & -- & \\
\hline smtage2 & -- & & -- & A & - & A & -- & \\
\hline smtage3 & -. & & -- & A & -- & A & - & \\
\hline inbsmsv & -- & & 0.5 & A & 0.5 & A2 & -. & \\
\hline adtrecv & 0.0557 & F & 0.119 & F & 0.266 & $\mathbf{F}$ & 0.0215 & $\mathbf{F}$ \\
\hline sadtrecv & -- & $\mathrm{F}$ & 0.0074 & F & NS & F & -. & $\mathrm{F}$ \\
\hline ocn1har & 0.01 & D & 0.001 & D & 0.0018 & D & 0.0018 & D \\
\hline ocn1rvh & 0.02 & D & 0.011 & D & 0.09883 & D & 0.09883 & D \\
\hline ocn1suv & 0.96 & D & 0.875 & D & 0.77242 & D & 0.77242 & D \\
\hline ocn2har & 0.01 & D & 0.004 & D & 0.00466 & D & 0.00466 & D \\
\hline ocn 2 rvh & 0.52 & D & 0.11 & D & 0.37788 & D & 0.37788 & D \\
\hline ocn2suv & 0.2 & D & 0.301 & D & 0.11589 & $\mathrm{D}$ & 0.11589 & D \\
\hline ocn3har & -. & D & -- & D & 0.00787 & $\mathrm{D}$ & 0.00787 & D \\
\hline ocn3rvh & 0.64 & D & 0.389 & D & 0.4287 & D & 0.4287 & D \\
\hline ocn3suv & 0.03 & D & 0.009 & D & 0.04637 & D & 0.04637 & D \\
\hline ocn4har & -- & D & -- & D & 0.07547 & D & 0.07547 & D \\
\hline ocn4rvh & 0.61 & D & 0.8 & D & 0.49057 & D & 0.49057 & D \\
\hline ocnlsbe & 0.01 & D & 0.113 & D & 0.12695 & D & 0.12695 & D \\
\hline ocn2sbe & 0.27 & D & 0.585 & D & 0.50157 & D & 0.50157 & D \\
\hline ocn3sbe & 0.33 & D & 0.602 & D & 0.51706 & D & 0.51706 & D \\
\hline ocn4sbe & 0.39 & D & 0.2 & D & 0.43396 & D & 0.43396 & D \\
\hline termhar & 0.8 & A & - & A & 0.29 & $\mathrm{~A}$ & 0.31 & A \\
\hline suptermh & -- & A & -. & A & 0.29 & A & -- & A \\
\hline msurv & 0.28859 & $\mathrm{E}$ & 0.21672 & $\mathrm{E}$ & 0.6308 & $\mathrm{E}$ & 0.4975 & $\mathrm{E}$ \\
\hline passcv & 0.155999 & $\mathrm{E}$ & 0.034943 & $\mathrm{E}$ & 0.092341 & $\mathrm{E}$ & 0.104338 & $\mathrm{E}$ \\
\hline jackspn & -. & $\mathrm{A}$ & -. & $\mathrm{A}$ & -. & $\mathrm{A}$ & -. & A \\
\hline
\end{tabular}


TABLE C.1

Base-Case Propagation Parameters

\begin{tabular}{|c|c|c|c|c|c|c|c|c|}
\hline \multirow[t]{2}{*}{ PARAMETER } & \multicolumn{2}{|c|}{ DESCHUTES } & \multicolumn{2}{|c|}{ DESCHUTES } & \multicolumn{2}{|c|}{ DESCHUTES } & \multicolumn{2}{|c|}{ WALLA WALLA } \\
\hline & $\begin{array}{l}\text { Fall } \\
\text { Chinook } \\
\text { Natural } \\
\text { Value }\end{array}$ & $\begin{array}{l}\text { Fall } \\
\text { Chinook } \\
\text { Natural } \\
\text { Source* }\end{array}$ & $\begin{array}{l}\text { Summer } \\
\text { Steelhead } \\
\text { Natural } \\
\text { Value }\end{array}$ & $\begin{array}{l}\text { Summer } \\
\text { Steelhead } \\
\text { Natural } \\
\text { Source* }\end{array}$ & $\begin{array}{l}\text { Summer } \\
\text { Steelhead } \\
\text { Hatchery } \\
\text { Value }\end{array}$ & $\begin{array}{l}\text { Summer } \\
\text { Steelhead } \\
\text { Hatchery } \\
\text { Source* }\end{array}$ & $\begin{array}{l}\text { Spring } \\
\text { Chinook } \\
\text { Natural } \\
\text { Value }\end{array}$ & $\begin{array}{l}\text { Spring } \\
\text { Chinook } \\
\text { Natural } \\
\text { Source* }\end{array}$ \\
\hline ffem & 0.422285 & B & 0.672 & A & 0.615 & $\mathbf{A}$ & 0.657802 & B \\
\hline prspsv & 0.95 & B & 0.863 & B & 0.8 & $\mathrm{~B}$ & 0.5 & B \\
\hline egfem & 4,922 & B & 5,341 & A & $4,860$. & A & 4,733 & B \\
\hline hatrem & 0. & & 0. & & 73. & $\mathrm{C} 1$ & 0. & \\
\hline hatsmolt & 0. & & 0. & & 161,608 & C & 0. & \\
\hline hintsv & 0.1 & B & 0.5 & B & 0.5 & B & 0.5 & B3 \\
\hline bhincp & 0.3113 & B & 0.032 & B & . & & 0.16 & B \\
\hline bhcap & $2,418,387$. & A & 147,659 . & A &.- & & 63,650 . & $\mathbf{A}$ \\
\hline smtage 1 & 0.04 & A & 0.29 & $J$ & -- & & 1. & $\mathrm{~A} 2$ \\
\hline smtage2 & -- & A & 0.55 & J & -- & & -- & $\mathrm{A} 2$ \\
\hline smtage 3 & -- & A & 0.16 & J & -- & & -- & $\mathrm{A} 2$ \\
\hline inbsmsv & 0.5 & $\mathrm{~A} 2$ & 0.793 & B & -- & & 0.5 & $\mathrm{~A} 2$ \\
\hline adtrecv & 0.09762 & $\mathbf{F}$ & 0.1628 & $\mathbf{F}$ & 0.876 & $\mathbf{F}$ & 0.3978 & $\mathbf{F}$ \\
\hline sadtrecv & NS & $\mathrm{F}$ & NS & $\mathrm{F}$ & -- & $\mathbf{F}$ & 0.073 & F \\
\hline ocn1har & 0.03081 & D & -- & B2 & -- & D & 0.0018 & D \\
\hline ocnlrvh & 0.01631 & D & -. & B2 & 0.1519 & D & 0.09883 & $\mathrm{D}$ \\
\hline ocn1suv & 0.94491 & D & 1. & B2 & 0.51899 & D & 0.77242 & D \\
\hline ocn2har & 0.22679 & $\mathrm{D}$ & -- & B2 & 0.0122 & D & 0.00466 & D \\
\hline ocn2rvh & 0.13467 & $\mathrm{D}$ & -. & B2 & 0.34756 & D & 0.37788 & $\mathrm{D}$ \\
\hline ucn2suv & 0.60055 & D & 1. & B2 & -. & D & 0.11589 & $\mathrm{D}$ \\
\hline ocn3har & 0.28733 & D & -- & B2 & -- & D & 0.00787 & D \\
\hline ocn3rvh & 0.36056 & D & -. & B2 & -- & D & 0.4287 & D \\
\hline ocn3suv & 0.26433 & D & -. & B2 & -- & D & 0.04637 & D \\
\hline ocn4har & 0.39795 & $\mathrm{D}$ & -- & B2 & -- & D & 0.07547 & D \\
\hline ocn4rvh & 0.50608 & D & -- & B2 & -- & D & 0.49057 & D \\
\hline ocnlsbe & 0.00797 & D & -- & B2 & 0.32911 & D & 0.12695 & D \\
\hline ocn2sbe & 0.03798 & D & 0. & B2 & 0.64024 & D & 0.50157 & D \\
\hline ocn3sbe & 0.08777 & D & 0. & B2 & -- & $\mathrm{D}$ & 0.51706 & D \\
\hline ocn 4 sbe & 0.09597 & D & -- & B2 & -- & D & 0.43396 & D \\
\hline termhar & 0.3 & A & 0.1475 & A & 0.38 & A & -- & A \\
\hline suptermh & 0.3 & A & 0.1475 & A & -- & A & -- & A \\
\hline msurv & 0.47771 & $\mathrm{E}$ & 0.6471 & $\mathrm{E}$ & 0.51295 & $\mathrm{E}$ & 0.24458 & $\mathrm{E}$ \\
\hline passcy & 0.18197 & $\mathrm{E}$ & 0.129311 & $\mathrm{E}$ & 0.135635 & $\mathrm{E}$ & 0.192582 & $\mathrm{E}$ \\
\hline jackspn & -- & A & 1. & A & -- & A & -- & A \\
\hline
\end{tabular}


TABLE C.1

Base-Case Propagation Parameters

\begin{tabular}{|c|c|c|c|c|c|c|c|c|}
\hline \multirow[t]{2}{*}{ PARAMETER } & \multicolumn{2}{|c|}{ WALLA WALLA } & \multicolumn{2}{|c|}{ UMATILLA } & \multicolumn{2}{|c|}{ UMATILLA } & \multicolumn{2}{|c|}{ UMATILLA } \\
\hline & $\begin{array}{l}\text { Summer } \\
\text { Steelhead } \\
\text { Natural } \\
\text { Value }\end{array}$ & $\begin{array}{l}\text { Sunmer } \\
\text { Steelhead } \\
\text { Natural } \\
\text { Source* }\end{array}$ & $\begin{array}{l}\text { Spring } \\
\text { Chinook } \\
\text { Natural } \\
\text { Value }\end{array}$ & $\begin{array}{l}\text { Spring } \\
\text { Chinook } \\
\text { Natural } \\
\text { Source* }\end{array}$ & $\begin{array}{l}\text { Fall } \\
\text { Chinook } \\
\text { Natural } \\
\text { Value }\end{array}$ & $\begin{array}{l}\text { Fall } \\
\text { Chinook } \\
\text { Nalural } \\
\text { Source* }\end{array}$ & $\begin{array}{l}\text { Summer } \\
\text { Steelhead } \\
\text { Natural } \\
\text { Value }\end{array}$ & $\begin{array}{l}\text { Summer } \\
\text { Steelhead } \\
\text { Natural } \\
\text { Source* }\end{array}$ \\
\hline ffem & 0.8 & A & 0.657802 & B & 0.618565 & B & 0.63 & A \\
\hline prspsv & 0.8 & B & 0.5 & B & 0.5 & B & 0.8 & B \\
\hline egfem & 3,975 . & A & 4,733 & B & 4,608 & B & 5,268 & $\mathbf{A}$ \\
\hline hatrem & 0. & $\mathrm{Cl}$ & 818. & $\mathrm{Cl}$ & 3,404 & $\mathrm{Cl}$ & 129. & $\mathrm{Cl}$ \\
\hline hatsmolt & 278,762 & C. & $1,700,000$. & C/A & $7,000,000$ & $\mathrm{C} / \mathrm{A}$ & 239,193 & C/A \\
\hline hintsv & 0.5 & B3 & 0.46 & $\mathbf{B}$ & 0.66 & B & 0.5 & B3 \\
\hline bhincp & 0.03 & B & 0.15 & B & 0.5 & B & 0.04 & B \\
\hline bhcap & 100,167 & A & 43,500 . & $\mathbf{A}$ & $2,363,700$. & $\mathbf{A}$ & 107,500 & $\mathbf{A}$ \\
\hline smtage 1 & 0.05 & J & 1. & A2 & 0.04 & $\mathrm{~A} 2$ & 0.05 & $\mathbf{J}$ \\
\hline smtage2 & 0.9 & $\mathbf{J}$ & -- & A2 & $-\cdot$ & A2 & 0.9 & J \\
\hline smtage3 & 0.05 & $\mathbf{J}$ & -- & $f .2$ & - & A2 & 0.05 & J \\
\hline inbsmsv & 0.5 & A2 & 0.6 & A.2 & 0.6 & B & 0.5 & A2 \\
\hline adtrecv & 0.4105 & F & 0.115 & F & 0.1128 & F & 0.2485 & $\mathbf{F}$ \\
\hline sadtrecv & 0.048 & $\mathrm{~F}$ & 0.025 & $\mathbf{F}$ & 0.058 & F & 0.023 & $\mathbf{F}$ \\
\hline ocn1har & $-\cdot$ & B2 & -- & D & 0.03081 & D & -- & B2 \\
\hline ocn1rvb & -- & B2 & 0.00138 & D & 0.01631 & D & -- & B2 \\
\hline ocn1suv & 1. & B2 & 0.98646 & D & 0.94491 & D & 1. & B2 \\
\hline ocn2har & -- & B2 & 0.00279 & D & 0.22679 & D & -- & B2 \\
\hline ocn2rvb & -- & B2 & 0.16822 & D & 0.13467 & D & -- & B2 \\
\hline ocn2suv & 1. & B2 & 0.36203 & D & 0.60055 & D & 1. & B2 \\
\hline ocn3har & -- & B2 & 0.00321 & D & 0.28733 & D & $\cdots$ & B2 \\
\hline ocn3rvb & -- & B2 & 0.35411 & D & 0.36056 & D & $\cdots$ & B2 \\
\hline ocn3suv & 1. & B2 & 0.00578 & D & 0.26433 & D & 1. & B2 \\
\hline ocn4har & -- & B2 & -- & D & 0.39795 & D & -- & B2 \\
\hline ocn4rvb & -- & B2 & 0.55556 & D & 0.50608 & D & -- & B2 \\
\hline ocn1sbe & -- & B2 & 0.01216 & D & 0.00797 & D & -- & B2 \\
\hline ocn2sbe & 0. & B2 & 0.46696 & D & 0.03798 & D & 0. & B2 \\
\hline ocn3sbe & 0. & B2 & 0.63689 & D & 0.08777 & D & 0. & B2 \\
\hline ocn4sbe &.- & B2 & 0.4444 & D & 0.09597 & D & -- & B2 \\
\hline termhar & .. & A & -- & A & -- & A & -- & A \\
\hline suptermh & 0.4 & A & 0.56 & A & 0.33 & A & 0.23 & A \\
\hline msurv & 0.5828 & $\mathbf{E}$ & 0.36537 & $\mathrm{E}$ & 0.33874 & $\mathrm{E}$ & 0.4368 & E \\
\hline passcr & 0.036889 & $\mathbf{E}$ & 0.32003 & $E$ & 0.145575 & $\mathrm{E}$ & 0.194627 & E \\
\hline jackspn & 1. & $\mathbf{A}$ & $\cdots$ & A & -- & A & 1. & A \\
\hline
\end{tabular}


TABLE C.1

Base-Case Propagation Parameters

\begin{tabular}{|c|c|c|c|c|c|c|c|c|}
\hline \multirow[t]{2}{*}{ PARAMETER } & \multicolumn{2}{|c|}{ JOHN DAY } & \multicolumn{2}{|c|}{ JOHN DAY } & \multicolumn{4}{|c|}{ L. WHITE SALMON L. WHITE SALMON } \\
\hline & $\begin{array}{l}\text { Spring } \\
\text { Chinook } \\
\text { Natural } \\
\text { Value }\end{array}$ & $\begin{array}{l}\text { Spring } \\
\text { Chincok } \\
\text { Natural } \\
\text { Source* }\end{array}$ & $\begin{array}{l}\text { Summer } \\
\text { Steelhead } \\
\text { Natural } \\
\text { Value }\end{array}$ & $\begin{array}{l}\text { Summer } \\
\text { Stcelhead } \\
\text { Natural } \\
\text { Source* }\end{array}$ & $\begin{array}{l}\text { Spring } \\
\text { Chinook } \\
\text { Natural } \\
\text { Value }\end{array}$ & $\begin{array}{l}\text { Spring } \\
\text { Chincok } \\
\text { Natural } \\
\text { Source* }\end{array}$ & $\begin{array}{l}\text { Spring } \\
\text { Chinook } \\
\text { Hatchery } \\
\text { Value }\end{array}$ & $\begin{array}{l}\text { Spring } \\
\text { Chinook } \\
\text { Hatchery } \\
\text { Source* }\end{array}$ \\
\hline ffem & 0.657802 & B & 0.5 & J & 0.558 .364 & B & 0.55 & $\mathbf{A}$ \\
\hline prspsv & 0.8 & B & 0.95 & B & 0.9 & B & 0.9 & B \\
\hline egfem & $4,733$. & B & $4,784$. & B & $4,300$. & B & $\begin{array}{l}4,300 . \\
701\end{array}$ & A \\
\hline $\begin{array}{l}\text { hatrem } \\
\text { hatsmolt }\end{array}$ & $\begin{array}{l}0 . \\
0 .\end{array}$ & & $\begin{array}{l}0 . \\
0 .\end{array}$ & & $\begin{array}{l}0 . \\
0 .\end{array}$ & & $\begin{array}{l}701 \\
1,459,066\end{array}$ & $\begin{array}{l}\mathrm{Cl} \\
\mathrm{C}\end{array}$ \\
\hline hintsv & 0.5 & B & 0.5 & B3 & 0.5 & B & 0.5 & B \\
\hline bhincp & 0.158 & B & 0.027 & B & 0.123 & B & . & \\
\hline bhcap & 279,000 . & A & 518,581 . & A & 32,350 . & A & 836,116 & $\mathbf{A}$ \\
\hline smtagel & 1. & A & -- & J & 1. & $\mathrm{~A} 2$ & -. & \\
\hline smtage2 &.- & A & 0.617 & J & -- & $\mathrm{A} 2$ & - & \\
\hline smtage 3 & -- & A & 0.383 & J & -- & A2 & -- & \\
\hline inbsmsv & 0.5 & A2 & 0.5 & A2 & 0.5 & A2 & -- & \\
\hline adtrecv & 0.114 & $\mathbf{F}$ & 0.7207 & $\mathbf{F}$ & 0.018 & $\mathbf{F}$ & 0.0059 & $\mathbf{F}$ \\
\hline sadtrecv & NS & F & NS & $\mathrm{F}$ & 0.0504 & F & -. & $\mathbf{F}$ \\
\hline ocnlhar & 0.0018 & D & -- & B2 & -- & D & -- & D \\
\hline ocn1rvh & 0.09883 & D & -- & B2 & 0.00138 & D & 0.00138 & D \\
\hline ocnlsuv & 0.77242 & D & 1. & B2 & 0.98646 & D & 0.98646 & D \\
\hline ocn2har & 0.00466 & D & -- & B2 & 0.00279 & D & 0.00279 & D \\
\hline ocn2rvh & 0.37788 & D & -- & B2 & 0.16822 & D & 0.16822 & D \\
\hline ocn2suv & 0.11589 & D & 1. & B2 & 0.36203 & D & 0.36203 & D \\
\hline ocn3har & 0.00787 & D & .. & B2 & 0.00321 & $\mathrm{D}$ & 0.00321 & D \\
\hline ocn3rvh & 0.4287 & D & -- & B2 & 0.35411 & D & 0.35411 & D \\
\hline ocn3suv & 0.04637 & D & 1. & B2 & 0.00578 & $\mathrm{D}$ & 0.00578 & D \\
\hline ocn4har & 0.07547 & D & -- & B2 & -. & D & -. & D \\
\hline ocn 4 rvh & 0.49057 & D & -. & B2 & 0.55556 & D & 0.55556 & D \\
\hline ocnlsbe & 0.12695 & D & -- & B2 & 0.01216 & D & 0.01216 & D \\
\hline ocn2sbe & 0.50157 & D & 0. & B2 & 0.46696 & D & 0.46696 & D \\
\hline ocn3sbe & 0.51706 & D & 0. & B2 & 0.63689 & D & 0.63689 & D \\
\hline ocn4sbe & 0.43396 & D & -- & B2 & 0.4444 & D & 0.4444 & $\mathrm{D}$ \\
\hline lermhar & 0.01 & $\mathbf{A}$ & 0.15 & A & -- & A & 0.084 & A \\
\hline suptermh & .- & A & -- & A & 0.084 & A & .- & A \\
\hline msurv & 0.56858 & $\mathrm{E}$ & 0.60478 & $\mathrm{E}$ & 0.85081 & $\mathbf{E}$ & 0.68065 & $\mathbf{E}$ \\
\hline passcr & 0.142005 & $\mathrm{E}$ & 0.109043 & $\mathrm{E}$ & 0.046198 & $\mathrm{E}$ & 0.046198 & E \\
\hline jackspn & .. & A & 1. & A & -. & A & -- & A \\
\hline
\end{tabular}


TABLE C.1

Base-Case Propagation Parameters

\begin{tabular}{|c|c|c|c|c|c|c|c|c|}
\hline \multirow[t]{2}{*}{ PARAMETER } & \multicolumn{2}{|c|}{ L. WHITE SALMON } & \multicolumn{2}{|c|}{ L. WHITE SALMON } & \multicolumn{2}{|c|}{ WHITE SALMON } & \multicolumn{2}{|c|}{ WHITE SALMON } \\
\hline & $\begin{array}{l}\text { Fall } \\
\text { Chinook } \\
\text { Natural } \\
\text { Value }\end{array}$ & $\begin{array}{l}\text { Fall } \\
\text { Chinook } \\
\text { Natural } \\
\text { Source* }\end{array}$ & $\begin{array}{l}\text { Fall } \\
\text { Chinook } \\
\text { Hatchery } \\
\text { Value }\end{array}$ & $\begin{array}{l}\text { Fall } \\
\text { Chinook } \\
\text { Hatchery } \\
\text { Source* }\end{array}$ & $\begin{array}{l}\text { Spring } \\
\text { Chinook } \\
\text { Natural } \\
\text { Value }\end{array}$ & $\begin{array}{l}\text { Spring } \\
\text { Chinook } \\
\text { Natural } \\
\text { Source* }\end{array}$ & $\begin{array}{l}\text { Spring } \\
\text { Chinook } \\
\text { Hatchery } \\
\text { Value }\end{array}$ & $\begin{array}{l}\text { Spring } \\
\text { Chinook } \\
\text { Hatchery } \\
\text { Source* }\end{array}$ \\
\hline ffem & 0.451515 & B & 0.447 & $\mathbf{A}$ & 0.558364 & B & 0.55278 & B \\
\hline prspsv & 0.9 & B & 0.9 & B & 0.9 & B & 0.9 & B \\
\hline egfem & 4,503 & B & 4,503 & A & 4,300 & B & 4,300 & $\mathbf{B}$ \\
\hline hatrem & 0. & & 1,398 & C1 & 0. & & 92. & $\mathrm{Cl}$ \\
\hline batsmolt & 0. & & $1,438,372$ & C & 0. & & 175,000 & C \\
\hline hintsv & 0.5 & B & 0.5 & B & 0.5 & B & 0.5 & B \\
\hline bhincp & 0.213 & B & & & 0.158 & B & . & \\
\hline bhcap & 73,652 . & $\mathbf{A}$ & $1,546,819$ & $\mathbf{A}$ & 45,307 . & $\mathbf{A}$ & -- & \\
\hline smtage 1 & 0.1 & A2 & -- & & 1. & $\mathrm{~A} 2$ & -. & \\
\hline smtage2 & -- & A2 & -. & & -. & A2 & -- & \\
\hline smtage 3 & -- & A2 & -- & & - & A2 & -- & \\
\hline inbsmsv & 0.5 & A2 & -- & & 0.5 & $\mathrm{~A} 2$ & -- & \\
\hline adtrecr & 0.042 & $\mathbf{F}$ & 0.0403 & F & 0.0145 & $\mathbf{F}$ & 0.0025 & $\mathbf{F}$ \\
\hline sadtrecv & 0.348 & $\mathbf{F}$ & -- & F & 0.053 & $\mathrm{~F}$ & -- & F \\
\hline ocn1har & 0.03081 & D & 0.03081 & D & -- & D & -- & D \\
\hline ocn1rvh & 0.01631 & D & 0.01631 & D & 0.00138 & D & 0.00138 & D \\
\hline ocn1suv & 0.94491 & D & 0.94491 & D & 0.98646 & D & 0.98646 & D \\
\hline ocn2har & 0.22679 & D & 0.22679 & D & 0.00279 & D & 0.00279 & D \\
\hline ocn2rvb & 0.13467 & D & 0.13467 & D & 0.16822 & D & 0.16822 & D \\
\hline ocn2suv & 0.60055 & D & 0.60055 & D & 0.36203 & D & 0.36203 & D \\
\hline ocn3har & 0.28733 & D & 0.28733 & D & 0.00321 & D & 0.00321 & D \\
\hline ocn3rvh & 0.36056 & D & 0.36056 & D & 0.35411 & D & 0.35411 & D \\
\hline ocn3suv & 0.26433 & D & 0.26433 & $\mathrm{D}$ & 0.00578 & D & 0.00578 & D \\
\hline ocn4har & 0.39795 & D & 0.39795 & D & .- & D & -- & D \\
\hline ocn4rvh & 0.50608 & D & 0.50608 & D & 0.55556 & D & 0.55556 & D \\
\hline ocn1sbe & 0.00797 & D & 0.00797 & D & 0.01216 & D & 0.01216 & D \\
\hline ocn2sbe & 0.03798 & D & 0.03798 & D & 0.46696 & D & 0.46696 & D \\
\hline ocn3sbe & 0.08777 & D & 0.08777 & D & 0.63689 & D & 0.63689 & D \\
\hline ocn4sbe & 0.09597 & D & 0.09597 & D & 0.4444 & D & 0.4444 & D \\
\hline termbar & -- & A & 0.026 & A & -- & A & -- & $\mathbf{A}$ \\
\hline suptermh & 0.026 & A & -- & A & -- & A & -. & A \\
\hline msurv & 0.79913 & $\mathrm{E}$ & 0.6393 & $\mathrm{E}$ & 0.80559 & $\mathrm{E}$ & 0.64448 & E \\
\hline passcr & 0.093426 & $\mathrm{E}$ & 0.093425 & $\mathrm{E}$ & 0.079336 & $\mathrm{E}$ & 0.079336 & $\mathrm{E}$ \\
\hline jackspn & .- & A & $\ldots$ & A & -. & A & -- & A \\
\hline
\end{tabular}


TABLE C. 1

Base-Case Propagation Parameters

\begin{tabular}{|c|c|c|c|c|c|c|c|c|}
\hline \multirow[t]{2}{*}{ PARAMETER } & \multicolumn{2}{|c|}{ WHITE SALMON } & \multicolumn{2}{|c|}{ WHITE SALMON } & \multicolumn{2}{|c|}{ KLICKITAT } & \multicolumn{2}{|c|}{ KLICKITAT } \\
\hline & $\begin{array}{l}\text { Summer } \\
\text { Steelhead } \\
\text { Natural } \\
\text { Value }\end{array}$ & $\begin{array}{l}\text { Summer } \\
\text { Steelhead } \\
\text { Natural } \\
\text { Source* }\end{array}$ & $\begin{array}{l}\text { Summer } \\
\text { Steelhead } \\
\text { Hatchery } \\
\text { Value }\end{array}$ & $\begin{array}{l}\text { Summer } \\
\text { Steelhead } \\
\text { Hatchery } \\
\text { Source* }\end{array}$ & $\begin{array}{l}\text { Spring } \\
\text { Chinook } \\
\text { Natural } \\
\text { Value }\end{array}$ & $\begin{array}{l}\text { Spring } \\
\text { Chinook } \\
\text { Natural } \\
\text { Source* }\end{array}$ & $\begin{array}{l}\text { Spring } \\
\text { Chinook } \\
\text { Hatchery } \\
\text { Value }\end{array}$ & $\begin{array}{l}\text { Spring } \\
\text { Chinook } \\
\text { Hatchery } \\
\text { Source* }\end{array}$ \\
\hline ffem & 0.519 & A & 0.503 & $A$ & 0.533 & B & 0.488738 & A \\
\hline prspsv & 0.9 & B & 0.9 & B & 0.5 & B & 0.8 & B \\
\hline egfem & 4,170 & $\mathbf{A}$ & 4,170 & $A$ & 4,310 . & B & 4,188 & A \\
\hline hatrem & 19. & $\mathrm{Cl}$ & 0. & $\mathrm{Cl}$ & 67. & $\mathrm{Cl}$ & 531. & C1 \\
\hline hatsmolt & 33,044 . & A & 9,828 & C & 99,300 & $\mathrm{C}$ & 783,200 & C \\
\hline hintsv & 0.67 & B & 0.67 & B & 0.46 & B & 0.46 & B \\
\hline bhincp & 0.025 & B & . & & 0.2086 & B & 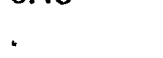 & \\
\hline bhcap & 1,771 & $\mathbf{A}$ & $-\cdot$ & & 620,000 & A & -. & \\
\hline smtage 1 & -- & J & -- & & 1. & A2 & -- & \\
\hline smtage2 & 1. & $\mathbf{J}$ & -- & & -- & A2 & -- & \\
\hline smtage 3 & -- & J &.- & & -- & A2 & - & \\
\hline inbsmsv & 0.5 & A2 & -- & & 0.5 & A2 & -- & \\
\hline adtrect & 0.31 & $\mathbf{F}$ & 0.777 & F & 0.029 & $\mathbf{F}$ & 0.0163 & F \\
\hline sadtrecv & 0.1733 & $F$ & $-\cdot$ & F & 0.0268 & $F$ & -- & F \\
\hline ocn 1 har & -. & B2 & - & D & -- & D & -- & D \\
\hline ocn1ruh & $\cdot \cdot$ & B2 & 0.1519 & D & 0.00138 & D & 0.00138 & D \\
\hline ocnlsuv & 1. & B2 & 0.51899 & D & 0.98646 & D & 0.98646 & D \\
\hline ocn2har &.- & B2 & 0.0122 & D & 0.00279 & D & 0.00279 & D \\
\hline$o c n 2 r v b$ & -. & B2 & 0.34756 & $\mathrm{D}$ & 0.16822 & D & 0.16822 & D \\
\hline ocn2suv & 1. & B2 & -- & $\mathrm{D}$ & 0.36203 & D & 0.36203 & D \\
\hline ocn3har & -- & B2 & -. & D & 0.00321 & D & 0.00321 & D \\
\hline ocn3rvh & -. & B2 & -- & D & 0.35411 & D & 0.35411 & D \\
\hline ocn3suv & 1. & B2 & -- & D & 0.00578 & D & 0.00578 & D \\
\hline ocn4har & -- & B2 & -- & D & -- & D & -. & D \\
\hline ocn4rvh & -. & B2 & -- & D & 0.55556 & D & 0.55550 & D \\
\hline ocn1sbe & -- & B2 & 0.32911 & D & 0.01216 & D & 0.01216 & D \\
\hline ocn2sbe & 0. & B2 & 0.64024 & D & 0.46696 & D & 0.46696 & D \\
\hline ocn3sbe & 0. & B2 & -. & D & 0.63689 & D & 0.63689 & D \\
\hline ocn4sbe & -- & B2 & -- & $\mathrm{D}$ & 0.4444 & D & 0.4444 & D \\
\hline termhar & $-\cdot$ & A & 0.7 & A & 0.4477 & $A$ & 0.4477 & A \\
\hline suptermh & 0.7 & A & $\ldots$ & A & 0.4477 & A & -- & A \\
\hline msurv & 0.85823 & $\mathrm{E}$ & 0.68658 & $\mathrm{E}$ & 0.8022 & $\mathrm{E}$ & 0.596 & $\mathrm{E}$ \\
\hline passcr & 0.042177 & $\mathrm{E}$ & 0.042177 & $\mathrm{E}$ & 0.052146 & $\mathrm{E}$ & 0.10983 & $\mathrm{E}$ \\
\hline jackspn & 1. & A & -. & A & -. & A & .. & A \\
\hline
\end{tabular}


TABLE C.1

Base-Case Propagation Parameters

\begin{tabular}{|c|c|c|c|c|c|c|c|c|}
\hline \multirow[t]{2}{*}{ PARAMETER } & \multicolumn{2}{|c|}{ KLICKITAT } & \multicolumn{2}{|l|}{ HOOD } & \multicolumn{2}{|l|}{ HOOD } & \multicolumn{2}{|l|}{ HOOD } \\
\hline & $\begin{array}{l}\text { Summer } \\
\text { Steelhead } \\
\text { Natural } \\
\text { Value }\end{array}$ & $\begin{array}{l}\text { Summer } \\
\text { Steelhead } \\
\text { Natural } \\
\text { Source* }\end{array}$ & $\begin{array}{l}\text { Spring } \\
\text { Chinook } \\
\text { Natural } \\
\text { Value }\end{array}$ & $\begin{array}{l}\text { Spring } \\
\text { Chinook } \\
\text { Natural } \\
\text { Source* }\end{array}$ & $\begin{array}{l}\text { Fall } \\
\text { Chinook } \\
\text { Natural } \\
\text { Value }\end{array}$ & $\begin{array}{l}\text { Fall } \\
\text { Chinook } \\
\text { Natural } \\
\text { Source* }\end{array}$ & $\begin{array}{l}\text { Summer } \\
\text { Steelhead } \\
\text { Natural } \\
\text { Value }\end{array}$ & $\begin{array}{l}\text { Summer } \\
\text { Steelhead } \\
\text { Natural } \\
\text { Source* }\end{array}$ \\
\hline ffem & 0.55 & A & 0.584348 & B & 0.422273 & B & 0.6 & B \\
\hline prspsv & 0.9 & B & 0.9 & A2 & 0.9 & A2 & 0.9 & A2 \\
\hline egfem & 3,668 . & A & 4,300 & A & 4,500 . & A & 3,500 . & A \\
\hline hatrem & & $\mathrm{C} 1$ & 0. & $\mathrm{Cl}$ & 0. & & 0. & $\mathrm{Cl}$ \\
\hline hatsmolt & 50,038 & C & 197,988 & C & 0. & & 81,795 & C \\
\hline hintsv & 0.7 & B & 0.5 & B & 0.5 & B3 & 0.5 & B \\
\hline bhincp & 0.0403 & B & 0.065 & B & 0.4686 & B & 0.0251 & B \\
\hline bhcap & 95,437 . & A & 24,000 & A & 46,000 & A & 32,000 . & A \\
\hline smtage 1 & -- & A & 1. & A2 & 0.1 & A2 & 0.05 & J1 \\
\hline smtage2 & 0.94 & A & -- & A2 & -- & A2 & 0.9 & $\mathbf{J} 1$ \\
\hline smtage3 & 0.06 & A & -- & A2 & -- & A2 & 0.05 & J1 \\
\hline inbsmsv & 0.5 & A2 & 0.5 & A2 & 0.5 & A2 & 0.5 & A2 \\
\hline adtrecv & 0.404 & F & 0.052 & F & 0.066 & $\mathrm{~F}$ & 0.733 & $\mathbf{F}$ \\
\hline sadtrecv & 0.0344 & F & 0.0131 & $\mathbf{F}$ & NS & F & 0.098 & $\mathbf{F}$ \\
\hline ocn1har & -. & B2 & -- & D & 0.03998 & D & -- & B2 \\
\hline ocn1ruh & -- & B2 & 0.00138 & D & 0.0285 & D & -- & B2 \\
\hline ocnlsuv & 1. & B2 & 0.98646 & D & 0.91268 & D & 1. & B2 \\
\hline ocn2har & $-\cdot$ & B2 & 0.00279 & D & 0.35933 & D & -- & B2 \\
\hline ocn2rvh & -- & B2 & 0.16822 & D & 0.24903 & D & -- & B2 \\
\hline ocn2suv & 1. & B2 & 0.36203 & D & 0.30856 & D & 1. & B2 \\
\hline ocn3har & -- & B2 & 0.00321 & D & 0.29433 & D & -- & B2 \\
\hline ocn3rvh & -- & B2 & 0.35411 & D & 0.44884 & D & -- & B2 \\
\hline ocn3suv & 1. & B2 & 0.00578 & D & 0.13902 & D & 1. & B2 \\
\hline ocn4har & -- & B2 & -- & D & 0.39672 & D & -- & B2 \\
\hline ocn4rvh & -- & B2 & 0.55556 & D & 0.55 & D & -. & B2 \\
\hline ocn1sbe & -- & B2 & 0.01216 & D & 0.01884 & D & -- & B2 \\
\hline ocn2sbe & 0. & B2 & 0.46696 & D & 0.08308 & D & 0. & B2 \\
\hline ocn3sbe & 0. & B2 & 0.63689 & D & 0.11782 & D & 0. & B2 \\
\hline ocn4sbe & -- & B2 & 0.4444 & D & 0.05328 & D & 1. & B2 \\
\hline termhar & -- & A & -. & A & 0.2 & A & -. & A \\
\hline suptermh & 0.25 & A & 0.2 & A & 0.2 & A & 0.7 & $A$ \\
\hline msurv & 0.78993 & E & 0.87375 & $\mathrm{E}$ & 0.75144 & $\mathrm{E}$ & 0.85823 & $\mathrm{E}$ \\
\hline passcv & 0.064845 & E & 0.025657 & $\mathrm{E}$ & 0.065404 & E & 0.042177 & E \\
\hline jackspn & 1. & A & -- & A & -- & A & 1. & A \\
\hline
\end{tabular}


TABLE C.1

Base-Case Propagation Parameters

\begin{tabular}{|c|c|c|c|c|c|c|c|c|}
\hline \multirow[t]{2}{*}{ PARAMETER } & \multicolumn{2}{|l|}{ WIND } & \multicolumn{2}{|l|}{ WIND } & \multicolumn{2}{|l|}{ WIND } & \multicolumn{2}{|l|}{ WIND } \\
\hline & $\begin{array}{l}\text { Spring } \\
\text { Chinook } \\
\text { Natural } \\
\text { Value }\end{array}$ & $\begin{array}{l}\text { Spring } \\
\text { Chinook } \\
\text { Natural } \\
\text { Source* }\end{array}$ & $\begin{array}{l}\text { Spring } \\
\text { Chinook } \\
\text { Hatchery } \\
\text { Value }\end{array}$ & $\begin{array}{l}\text { Spring } \\
\text { Chinook } \\
\text { Hatchery } \\
\text { Source* }\end{array}$ & $\begin{array}{l}\text { Summer } \\
\text { Steelhead } \\
\text { Natural } \\
\text { Value }\end{array}$ & $\begin{array}{l}\text { Summer } \\
\text { Steelhead } \\
\text { Natural } \\
\text { Source* }\end{array}$ & $\begin{array}{l}\text { Summer } \\
\text { Steelhead } \\
\text { Hatchery } \\
\text { Value }\end{array}$ & $\begin{array}{l}\text { Summer } \\
\text { Steelhezd } \\
\text { Hatche y } \\
\text { Source* }\end{array}$ \\
\hline ffem & 0.5585 .39 & B & 0.533 & A & 0.519 & A & 0.503 & A \\
\hline prspsv & 0.9 & B & 0.9 & B & 0.9 & B & 0.9 & B \\
\hline egfem & 4,300 & B & 4,300 & A & $4,138$. & $\mathbf{A}$ & 4,073 & $\mathbf{A}$ \\
\hline hatrem & 0. & & 1,020 & $\mathrm{C} 1$ & 0. & & & $\mathrm{C} 1$ \\
\hline hatsmolt & 0. & & $2,105,281$. & $\mathbf{C}$ & 0. & & 20,125 . & $\mathrm{C}$ \\
\hline hintsv & 0.5 & B & 0.5 & B3 & 0.67 & B & 0.67 & B3 \\
\hline bhincp & 0.1557 & B & . & & 0.0341 & B & . & \\
\hline bhcap & 157,533 & A & -- & & 23,498 . & A & -- & \\
\hline smtagel & 1. & $\mathrm{~A} 2$ & -- & & 0.05 & $\mathrm{~J}$ & $\cdots$ & \\
\hline smtage 2 & -- & A2 & -- & & 0.9 & J & -- & \\
\hline smtage 3 & -- & A2 & -- & & 0.05 & J & -- & \\
\hline inbsmsv & 0.5 & A2 & -- & & 0.5 & A2 & -- & \\
\hline Psittrecv & 0.0165 & $F$ & 0.0074 & F & 0.136 & $\mathrm{~F}$ & 0.1027 & F \\
\hline sadtrecy & 0.0097 & F & -- & F & 0.0162 & $F$ & -- & $F$ \\
\hline ocn1har & - & D & -- & D & .. & B2 & -- & D \\
\hline acnlruh & 0.00138 & $D$ & 0.00138 & $D$ & -- & B2 & 0.1519 & $\mathrm{D}$ \\
\hline ocnlsuv & 0.98646 & D & 0.98646 & D & 1. & B2 & 0.51899 & D \\
\hline ocn2har & 0.00279 & $\mathrm{D}$ & 0.00279 & D & -- & B2 & 0.0122 & D \\
\hline$o c n 2 r v b$ & 0.16822 & $\mathrm{D}$ & 0.16822 & $D$ & -- & B2 & 0.34756 & D \\
\hline ocn2suv & 0.36203 & D & 0.36203 & $\mathrm{D}$ & 1. & B2 & -- & $\mathrm{D}$ \\
\hline ocn3har & 0.00321 & $\mathrm{D}$ & 0.00321 & D & -- & B2 & -- & D \\
\hline ocn3rvh & 0.35411 & $\mathrm{D}$ & U.35411 & D & -- & B2 & -. & D \\
\hline ocn3suv & 0.00578 & $\mathrm{D}$ & 0.00578 & D & 1. & B2 & -. & $\mathrm{D}$ \\
\hline ocn4har & -- & $D$ & -- & D & -- & B2 & -- & $\mathrm{D}$ \\
\hline ocn 4 rvh & 0.55556 & D & 0.55556 & D & -- & B2 & -- & D \\
\hline ocnlsbe & 0.01216 & $\mathrm{D}$ & 0.01216 & D & -- & B2 & 0.32911 & D \\
\hline ocn2sbe & 0.46696 & D & 0.46696 & $\mathrm{D}$ & 0. & $\mathrm{~B} 2$ & 0.64024 & $D$ \\
\hline ocn3sbe & 0.63689 & D & 0.63689 & $\mathrm{D}$ & 0. & B2 & -- & D \\
\hline ocn4sbe & 0.4444 & D & 0.4444 & D & - & B2 & -- & D \\
\hline termbar & 0.2 & A & 0.2 & A & -- & A & 0.7 & $\mathbf{A}$ \\
\hline suptermb & 0.2 & A & ..- & A & 0.7 & A & -- & A \\
\hline msurv & 0.88735 & $\mathrm{E}$ & 0.69853 & $\mathrm{E}$ & 0.88843 & $\mathrm{E}$ & 0.70255 & $\mathrm{E}$ \\
\hline passcr & 0.028467 & $\mathrm{E}$ & 0.044767 & $\bar{E}$ & 0.02904 & $\mathrm{E}$ & 0.040182 & $\mathrm{E}$ \\
\hline jackspn & -- & A & -- & $A$ & 1. & $\bar{A}$ & -. & A \\
\hline
\end{tabular}


TABLE C.1

Base-Case Propagation Parameters

\begin{tabular}{|c|c|c|c|c|c|c|c|c|}
\hline \multirow{2}{*}{ PARAMETER } & \multicolumn{2}{|c|}{ WENATCHEE } & \multicolumn{2}{|c|}{ WENATCHEE } & \multicolumn{2}{|c|}{ WENATCHEE } & \multicolumn{2}{|c|}{ ENTIAT-R. REACH } \\
\hline & $\begin{array}{l}\text { Spring } \\
\text { Chinook } \\
\text { Natural } \\
\text { Value }\end{array}$ & $\begin{array}{l}\text { Spring } \\
\text { Chinook } \\
\text { Natural } \\
\text { Source* }\end{array}$ & $\begin{array}{l}\text { Spring } \\
\text { Chinook } \\
\text { Hatchery } \\
\text { Value }\end{array}$ & $\begin{array}{l}\text { Spring } \\
\text { Chinook } \\
\text { Hatchery } \\
\text { Source* }\end{array}$ & $\begin{array}{l}\text { Summer } \\
\text { Chinook } \\
\text { Natural } \\
\text { Value }\end{array}$ & $\begin{array}{l}\text { Summer } \\
\text { Chinook } \\
\text { Natural } \\
\text { Source* }\end{array}$ & $\begin{array}{l}\text { Spring } \\
\text { Chinook } \\
\text { Natural } \\
\text { Value }\end{array}$ & $\begin{array}{l}\text { Spring } \\
\text { Chinook } \\
\text { Natural } \\
\text { Source* }\end{array}$ \\
\hline ffem & 0.56 & $\mathrm{H}$ & 0.56 & $\mathrm{H}$ & 0.46 & H & 0.586 & A \\
\hline prspsv & 0.75 & B & 0.75 & B & 0.526 & B & 0.72 & B \\
\hline egfem & 4,600 . & $\mathbf{G}$ & 4,600 & G & 5,240 . & G & 4,600 . & $\mathbf{G}$ \\
\hline hatrem & 358. & C1 & 1,199 & C1 & 490. & C1 & 360. & $\mathrm{C} 1$ \\
\hline hatsmolt & 672,000 & $\mathrm{C}$ & $2,250,000$ & C & 864,000 & C & 800,000 & C \\
\hline hintsv & 0.083333 & $\mathbf{G}$ & 0.083333 & G & 0.516926 & $\mathbf{H}$ & 0.038462 & $\mathbf{G}$ \\
\hline bhincp & 0.23 & B & 0.23 & B & 0.5 & B & 0.23 & B \\
\hline bhcap & $1,200,000$ & B & - & B & $2,960,504$. & B & 176,000 & B \\
\hline smtage1 & 1. & $\mathbf{H}$ & 1. & $\mathbf{H}$ & 0.05 & $\mathbf{H}$ & 1. & $\mathbf{H}$ \\
\hline smtage2 & - & $\mathbf{H}$ & -- & $\mathbf{H}$ & -- & $\mathbf{H}$ & -- & $\mathbf{H}$ \\
\hline smtage3 & -- & $\mathrm{H}$ & -- & $\mathbf{H}$ & -- & $\mathbf{H}$ & -- & $\mathbf{H}$ \\
\hline inbsmsv & 0.5 & $\mathbf{G}$ & 0.5 & G & 0.5 & $\mathbf{G}$ & 0.5 & $\mathbf{G}$ \\
\hline adtrecv & 0.0761 & $\mathbf{F}$ & 0.2985 & F & 0.443 & $\mathbf{F}$ & 0.211 & $\mathbf{F}$ \\
\hline sadtrecv & NS & $F$ & -. & $\mathbf{F}$ & NS & $\mathbf{F}$ & 0.123 & $\mathbf{F}$ \\
\hline ocn1har & 0.023 & D & 0.023 & D & 0.059 & D & 0.023 & D \\
\hline ocnlrvh & 0.07 & D & 0.07 & D & 0.024 & D & 0.07 & D \\
\hline ocnlsuv & 0.897 & D & 0.897 & D & 0.873 & D & 0.897 & D \\
\hline ocn2har & 0.041 & D & 0.041 & D & 0.352 & D & 0.041 & D \\
\hline $\operatorname{ocn} 2 \mathrm{rvh}$ & 0.135 & D & 0.135 & D & 0.137 & D & 0.135 & D \\
\hline ocn2suv & 0.454 & D & 0.454 & D & 0.456 & D & 0.454 & D \\
\hline ocn3har & 0.04 & D & 0.04 & D & 0.388 & D & 0.04 & D \\
\hline ocn3rvh & 0.152 & D & 0.152 & D & 0.301 & D & 0.152 & D \\
\hline ocn3suv & -- & D & -- & D & 0.111 & i & -- & D \\
\hline ocn4har & -- & D & -- & D & 0.549 & D & -- & D \\
\hline ocn4rvh & -- & D & -- & D & 0.451 & D & -- & D \\
\hline ocn1sbe & 0.01 & D & 0.01 & D & 0.043 & D & 0.01 & $\mathrm{D}$ \\
\hline ocn2sbe & 0.369 & D & 0.369 & D & 0.055 & D & 0.369 & $\mathrm{D}$ \\
\hline ocn3sbe & 0.808 & D & 0.808 & D & 0.096 & D & 0.808 & D \\
\hline ocn4sbe & -- & D & -- & D & -- & D & -. & D \\
\hline termhar & -- & A & 0.1 & A & -- & A & -- & $\mathbf{A}$ \\
\hline suptermh & .. & $\mathbf{A}$ & 0.1 & A & -- & A & -- & $\mathbf{A}$ \\
\hline msurv & 0.27808 & $\mathrm{E}$ & 0.22246 & $\mathrm{E}$ & 0.07925 & $\mathrm{E}$ & 0.2222 & $\mathbf{E}$ \\
\hline passcr & 0.13316 & $\mathrm{E}$ & 0.13316 & $\mathrm{E}$ & 0.4146 & $\mathrm{E}$ & 0.146 & $\mathrm{E}$ \\
\hline jackspn & -- & A & 1. & A & -- & A & -- & $\mathbf{A}$ \\
\hline
\end{tabular}


TABLE C.1

Base-Case Propagation Parameters

PARAMETER ENTIAT-R. REACH ENTIAT-R.REACH ENTIAT-R. REACH METHOW

\begin{tabular}{|c|c|c|c|c|c|c|c|c|}
\hline & $\begin{array}{l}\text { Sum/Fall } \\
\text { Chinook } \\
\text { Natural } \\
\text { Value }\end{array}$ & $\begin{array}{l}\text { Sum/Fall } \\
\text { Chinook } \\
\text { Natural } \\
\text { Source* }\end{array}$ & $\begin{array}{l}\text { Summer } \\
\text { Chinook } \\
\text { Natural } \\
\text { Value }\end{array}$ & $\begin{array}{l}\text { Summer } \\
\text { Chinook } \\
\text { Natural } \\
\text { Source* }\end{array}$ & $\begin{array}{l}\text { Fall } \\
\text { Chinook } \\
\text { Hatchery } \\
\text { Value }\end{array}$ & $\begin{array}{l}\text { Fall } \\
\text { Chinook } \\
\text { Hatchery } \\
\text { Source* }\end{array}$ & $\begin{array}{l}\text { Spring } \\
\text { Chinook } \\
\text { Natural } \\
\text { Value }\end{array}$ & $\begin{array}{l}\text { Spring } \\
\text { Chinool } \\
\text { Natural } \\
\text { Source* }\end{array}$ \\
\hline ffem & 0.30184 & $\mathrm{H}$ & 1. & & 1. & & 0.7 & A \\
\hline prspsv & 0.7 & B & 1. & & 1. & & 0.7 & B \\
\hline egfem & 5,240 & $\mathbf{G}$ & 1. & & 1. & & 4,337 & A \\
\hline hatrem & 0. & $\mathrm{C} 1$ & 1,064 & $\mathrm{Cl}$ & 0. & $\mathrm{Cl}$ & 491. & $\mathrm{Cl}$ \\
\hline hatsmolt & 0. & & $1,690,000$ & C & 200,000 & C & 800,000 . & C \\
\hline hintsv & 0.400004 & $\mathbf{H}$ & 0.400004 & $\mathrm{H}$ & 0.400004 & $\mathbf{H}$ & 0.1 & G \\
\hline bhincp & . & & . & 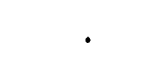 & . & & 0.1707 & $\mathrm{~A}$ \\
\hline bhcap & -- & & -- & - &.- & & 826,539 & A \\
\hline smtage 1 & -- & $\mathrm{H}$ & 0.05 & -- & $\ldots$ & & 1. & H \\
\hline smtage2 & -- & H & - & & & & -- & $\mathbf{H}$ \\
\hline smtage 3 & -- & $\mathrm{H}$ & -. & & & & -- & $\mathbf{H}$ \\
\hline inbsmsv & 1. & $\mathbf{G}$ & 0.5 & -- & 1. & & 0.5 & $\mathbf{G}$ \\
\hline adtrecv & 0.044627 & $\mathrm{~F}$ & 0.225 & $\mathbf{k}$ & 0.044627 & $\mathbf{k}$ & 0.0858 & F \\
\hline sadtrecv & NS & F & NS & & 0.3 & & 0.086 & $\mathbf{F}$ \\
\hline ocnlhar & 0.0588 & D & 0.059 & 1 & 0.058 & 1 & 0.023 & D \\
\hline ocn1rvh & 0.0323 & D & 0.024 & 1 & 0.065 & 1 & 0.07 & D \\
\hline ocn1suv & 0.87 & D & 0.873 & 1 & 0.8 .56 & 1 & 0.897 & D \\
\hline ocn2har & 0.3676 & D & 0.352 & 1 & 0.432 & 1 & 0.041 & D \\
\hline ocn2rvh & 0.1628 & D & 0.137 & 1 & 0.268 & 1 & 0.135 & D \\
\hline ocn2suv & 0.4191 & D & 0.456 & 1 & 0.266 & 1 & 0.454 & D \\
\hline ocn3har & 0.397 & D & 0.388 & 1 & 0.435 & 1 & 0.04 & D \\
\hline ocn3rvh & 0.329 & D & 0.301 & 1 & 0.445 & 1 & 0.152 & D \\
\hline ocn3suv & 0.1016 & D & 0.111 & 1 & 0.063 & 1 & -- & D \\
\hline ocn4har & 0.5167 & D & 0.549 & 1 & 0.384 & 1 & -- & D \\
\hline ocn4rvh & 0.4833 & D & 0.451 & 1 & 0.616 & 1 & -. & D \\
\hline ocn1sbe & 0.0389 & D & 0.043 & 1 & 0.021 & 1 & 0.01 & $\bar{D}$ \\
\hline ocn2sbe & 0.0504 & D & 0.055 & 1 & 0.033 & i & 0.369 & D \\
\hline ocn3sbe & 0.0883 & D & 0.096 & 1 & 0.057 & 1 & 0.808 & D \\
\hline ocn4sbe & -- & D & - & 1 & -- & 1 & -- & $\bar{D}$ \\
\hline termhar & -- & A & -- & A & -- & A & - & A \\
\hline suptermh & -- & A & & A & - & A & -- & A \\
\hline msurv & 0.19317 & $\mathrm{E}$ & 0.09999 & $\mathrm{E}$ & 0.19317 & $\mathrm{E}$ & 0.2152 & E \\
\hline passcr & 0.2342 & $\mathrm{E}$ & 0.2163 & $\mathrm{E}$ & 0.2342 & $\mathrm{E}$ & 0.134 & E \\
\hline jackspn & -- & A & -- & & -- & & .. & A \\
\hline
\end{tabular}


TABLE C.1

Base-Case Propagation Parameters

\begin{tabular}{|c|c|c|c|c|}
\hline \multirow[t]{2}{*}{ PARAMETER } & \multicolumn{2}{|l|}{ METHOW } & \multicolumn{2}{|c|}{ OKANOGAN } \\
\hline & $\begin{array}{l}\text { Summer } \\
\text { Chinook } \\
\text { Natural } \\
\text { Value }\end{array}$ & $\begin{array}{l}\text { Summer } \\
\text { Chinook } \\
\text { Natural } \\
\text { Source* }\end{array}$ & $\begin{array}{l}\text { Summer } \\
\text { Chinook } \\
\text { Natural } \\
\text { Value }\end{array}$ & $\begin{array}{l}\text { Summer } \\
\text { Chinook } \\
\text { Natural } \\
\text { Source* }\end{array}$ \\
\hline ffem & 0.46 & J & 0.46 & H \\
\hline prspsv & 0.333 & B & 0.333 & B \\
\hline egfem & 5,240 . & G & 5,240 . & $\mathbf{G}$ \\
\hline hatrem & 226. & $\mathrm{Cl}$ & 326. & $\mathrm{C} 1$ \\
\hline hatsmolt & 400,000 & $\mathrm{C}$ & 576,000 & C \\
\hline hintsv & 0.387694 & $\mathbf{H}$ & 0.484618 & H \\
\hline bhincp & 0.3162 & B & 0.3162 & B \\
\hline bhcap & $1,470,822$ & B & $1,435,704$ & B \\
\hline smtage 1 & 0.05 & $\mathbf{H}$ & 0.05 & $\mathbf{H}$ \\
\hline smtage2 & -- & $\mathbf{H}$ & -- & $\mathbf{H}$ \\
\hline smtage3 & -- & $\mathbf{H}$ & -- & $\mathbf{H}$ \\
\hline inbsmsv & 0.5 & $\mathbf{G}$ & 0.5 & $\mathbf{G}$ \\
\hline adtrecv & 1.027 & $\mathbf{F}$ & 0.984 & $\mathbf{F}$ \\
\hline sadtrecv & NS & $F$ & NS & $\mathbf{F}$ \\
\hline ocn1har & 0.059 & D & 0.059 & D \\
\hline ocn1rvh & 0.024 & D & 0.024 & D \\
\hline ocnisuv & 0.873 & D & 0.873 & D \\
\hline ocn2har & 0.352 & D & 0.352 & D \\
\hline$o c n 2 r v h$ & 0.137 & $\mathrm{D}$ & 0.137 & D \\
\hline ocn2suv & 0.456 & D & 0.456 & D \\
\hline ocn3har & 0.388 & D & 0.388 & D \\
\hline ocn3rvh & 0.301 & D & 0.301 & $\mathrm{D}$ \\
\hline ocn3suv & 0.111 & D & 0.111 & D \\
\hline ocn 4har & 0.549 & D & 0.549 & D \\
\hline ocn4rvh & 0.451 & D & 0.451 & D \\
\hline ocn1sbe & 0.043 & $\mathrm{D}$ & 0.043 & D \\
\hline ocn2sbe & 0.055 & $\mathrm{D}$ & 0.055 & D \\
\hline ocn3sbe & 0.096 & D & 0.096 & D \\
\hline ocn4sbe & -- & D & -- & D \\
\hline termhar & -- & A & -- & A \\
\hline suptermh & - & A & -- & A \\
\hline msurv & 0.04984 & $\mathrm{E}$ & 0.04984 & $\mathrm{E}$ \\
\hline passcr & 0.478 & $\mathrm{E}$ & 0.478 & $\mathrm{E}$ \\
\hline jackspn & -- & A & -- & A \\
\hline
\end{tabular}


TABLE C.1

Base-Case Propagation Parameters

$\begin{array}{ll}\text { Parameter } & \text { Description } \\ \text { ffem } & \text { fraction female } \\ \text { prspsv } & \text { prespawning survival } \\ \text { egfem } & \text { mean eggs per female } \\ \text { hatrcm } & \text { adult take by hatchery } \\ \text { hatsmolt } & \text { hatchery fry released } \\ \text { hintsv } & \text { post-release survival } \\ \text { bhincp } & \text { Beverton-Holt intercept } \\ \text { bhcap } & \text { Beverton-Holt carrying capacity } \\ \text { smtage1 } & \text { yearling migrants (0-1) } \\ \text { smtage2 } & \text { yearling migrants (1-2) } \\ \text { smtage3 } & \text { yearling migrants (2-3) } \\ \text { inbsmsv } & \text { inbasin overwinter survival } \\ \text { adtrecv } & \text { fraction recovered as adults } \\ \text { sadtrecv } & \text { C.V. of adult recovery } \\ \text { ocn1har } & \text { 1st year ocean harvest } \\ \text { ocn1rvh } & \text { 1st year river harvest } \\ \text { ocn1suv } & \text { fraction recovered in years } 2+ \\ \text { ocn2har } & \text { 2nd year ocean harvest } \\ \text { ocn2rvh } & \text { 2nd year river harvest } \\ \text { ocn2suv } & \text { fraction recovered in years 3+ } \\ \text { ocn3har } & \text { 3rd year occan survival } \\ \text { ocn3rvh } & \text { 3rd year river harvest } \\ \text { ocn3suv } & \text { fraction recovered in year 4 } \\ \text { ocn4har } & \text { 4th year ocean harvest } \\ \text { ocn4rvh } & \text { 4th year river harvest } \\ \text { ocn1sbe } & \text { 1st year subbasin escapement } \\ \text { ocn2sbe } & \text { 2nd year " " } \\ \text { ocn3sbe } & \text { 3rd year " } \\ \text { ocn4sbe } & \text { 4th year " } \\ \text { termhar } & \text { terminal harvest rate for natural fish } \\ \text { suptermh } & \text { terminal harvest rate for supplementation fish } \\ \text { msurv } & \text { mean mainstem survival rate } \\ \text { passcv } & \text { C.V. of mainstem survival } \\ \text { jackspn } & \text { If 0, jacks do not contribute to spawning population } \\ & \end{array}$


TABLE C.1

Base-Case Propagation Parameters

\section{*Sources of Data:}

\begin{tabular}{|c|c|}
\hline A & Subbasin Plans \\
\hline A1 & Caiculated from data in Subbasin Plans \\
\hline $\mathrm{A} 2$ & Based on Subbasin Plans for a different subbasin \\
\hline B & System Planning Model Parameter Files (NPPC) \\
\hline B1 & Parameter calculated from age specific data \\
\hline B2 & $\begin{array}{l}\text { Parameter estimated from age specific return data; } \\
\text { assumes that ocean and inriver harvest is zero }\end{array}$ \\
\hline B3 & Parameter taken from a different stock \\
\hline $\mathrm{C}$ & $\begin{array}{l}\text { Fish Passage Center } 1990 \text { Hatchery Data/ WA State Dept. of } \\
\text { Fisheries } 1990 \text { Hatchery Program data }\end{array}$ \\
\hline $\mathrm{C} 1$ & $\begin{array}{l}\text { Brood needs for hatsmolt calculated based on fraction female, } \\
\text { eggs per female, and egg-smolt survival }\end{array}$ \\
\hline $\mathrm{D}$ & $\begin{array}{l}\text { Estimated from Coded Wire Tag data (Pacific States Marine Fisheries } \\
\text { Commission. Unpublished Document.) }\end{array}$ \\
\hline $\mathrm{E}$ & Estimated from CRiSP output \\
\hline F & Internal Calculation based on estimates of fish abundance. \\
\hline F1 & $\begin{array}{l}\text { Internal Calculation based on hatchery release and } \\
\text { assumed smolt-adult survival. }\end{array}$ \\
\hline G & Mullan 1990 \\
\hline $\mathrm{H}$ & Mullan 1987 \\
\hline I & estimated from run data in Mullan 1987 \\
\hline $\mathbf{J}$ & Howell et al. 1985 \\
\hline $\mathbf{J 1}$ & Based on data from Howell et al. 1985 for a different stock \\
\hline NS & No supplementation in base case or in actions \\
\hline
\end{tabular}


TABLE C.2

Calibration Data

\begin{tabular}{|c|c|c|c|c|c|c|c|c|c|}
\hline SUBBASIN & $\begin{array}{l}\text { Stock } \\
\text { Type }\end{array}$ & $\begin{array}{l}\text { Calib. } \\
\text { Spawn }\end{array}$ & $\begin{array}{ll}\text { alib. } & \text { C } \\
\text { scape } & \text { I }\end{array}$ & $\begin{array}{l}\text { Calib. } \\
\text { Runsize }\end{array}$ & $\begin{array}{l}\text { Calib. } \\
\text { Hattake }\end{array}$ & $\begin{array}{l}\text { Calib. } \\
\text { Hatsmit }\end{array}$ & $\begin{array}{l}\text { Calib. } \\
\text { Sbharv }\end{array}$ & lib. & $\begin{array}{l}\text { Calib. } \\
\text { Adtrecv }\end{array}$ \\
\hline \multicolumn{10}{|l|}{ GRANDE RONDE } \\
\hline Spring Chinook & Nat & 1,080 & 1,736 & 2,215 & 183 & & 45 & 0.03 & 0.0825 \\
\hline Spring Chinook & Supp & 220 & 443 & 565 & 37 & 294,358 & 11 & 0.03 & 0.0085 \\
\hline Steelhead & Nat & 11,027 & 8,857 & 8,857 & 702 & & & 0.00 & 0.1292 \\
\hline Steelhead & Supp & 4,271 & 6,222 & 6,222 & 290 & $1,555,204$ & 593 & 0.10 & 0.0170 \\
\hline \multicolumn{10}{|l|}{ CLEARWATER } \\
\hline Spring Chinook & Nat & 2,747 & 2,534 & 3,233 & 992 & & 86 & 0.04 & 0.0143 \\
\hline Spring Chinook & Supp & 1,687 & 4,031 & 5,142 & 609 & $1,464,375$ & 137 & 0.04 & 0.0083 \\
\hline Steelhead & Nat & 10,262 & 9,195 & 9,195 & 536 & & & 0.00 & 0.0495 \\
\hline Steelhead & Supp & 3,111 & 10,001 & 10,001 & 279 & $1,122,846$ & 5,833 & 0.60 & 0.0314 \\
\hline \multicolumn{10}{|l|}{ LOWER SALMON } \\
\hline Spring Chinook & Nat & 25 & 49 & 62 & & & & 0.00 & 0.0405 \\
\hline Spring Chinook & Supp & & & & & & & 0.00 & NS \\
\hline Steelhead & Nat & 4,309 & 1,148 & 1,148 & 307 & & & 0.00 & 0.1340 \\
\hline Steclhead & Supp & 3,441 & 4,546 & 4,546 & 245 & 629,541 & & 0.00 & 0.0237 \\
\hline \multicolumn{10}{|l|}{ LITTLE SALMON } \\
\hline Spring Chinook & Nat & 387 & 103 & 132 & 217 & & & 0.00 & 0.0088 \\
\hline Spring Chinook & Supp & 345 & 867 & 1,106 & 194 & 250,000 & & 0.00 & 0.0255 \\
\hline Steelhead & Nat & 3,116 & 2,103 & 2,103 & 393 & & & 0.00 & 0.1370 \\
\hline Steelhead & Supp & 1,526 & 5,047 & 5,047 & 306 & 699,317 & 2,862 & 0.60 & 0.0236 \\
\hline \multicolumn{10}{|c|}{ MID MAIN SALMON } \\
\hline Spring Chinook & Nat & 86 & 167 & 213 & & & & 0.00 & 0.0378 \\
\hline Spring Chinook & Supp & & & & & & & 0.00 & NS \\
\hline Steelhead & Nat & 1,797 & 2,251 & 2,251 & 5 & & & 0.00 & 0.1540 \\
\hline Steelhead & Supp & & & & & & & 0.00 & NS \\
\hline \multicolumn{10}{|c|}{ MID FORK SALMON } \\
\hline Spring Chinook & Nat & 674 & $1,3: 3$ & 1,675 & & & & 0.00 & 0.0326 \\
\hline Spring Chinook & Supp & & & & & & & 0.00 & 0.0185 \\
\hline \multicolumn{10}{|l|}{ LEMHI } \\
\hline Spring Chinook & Nat & 112 & 219 & 279 & & & & 0.00 & 0.0386 \\
\hline Spring Chinook & Supp & & & & & & & 0.00 & 0.0185 \\
\hline Steelhead & Nat & 944 & 1,186 & 1,186 & 5 & & & 0.00 & 0.1540 \\
\hline Steelhead & Supp & & & & & & & 0.00 & 0.0328 \\
\hline \multicolumn{10}{|l|}{ UPPER SALMON } \\
\hline Spring Chinook & Nat & 1,424 & 749 & 956 & 457 & & & 0.00 & 0.0129 \\
\hline Spring Chinook & Supp & 1,093 & 2,480 & 3,164 & 351 & 715,400 & & 0.00 & 0.0255 \\
\hline Summer Chinook & Nat & 95 & 206 & 241 & & & & 0.00 & 0.0340 \\
\hline Summer Chinook & Supp & & & & & & & 0.00 & NS \\
\hline Steelhead & Nat & 18,734 & 7,526 & 7,526 & 1,333 & & & 0.00 & 0.1324 \\
\hline Steelhead & Supp & 13,037 & 17,224 & 17,224 & 928 & $2,386,652$ & & 0.00 & 0.0246 \\
\hline \multicolumn{10}{|l|}{ S. FORK SALMON } \\
\hline Summer Chinook & Nat & 238 & 516 & 603 & & & & 0.00 & 0.0511 \\
\hline Summer Chinook & Supp & & & & & & & 0.00 & NS \\
\hline Steelhead & Nat & 990 & 1,242 & 1,242 & 5 & & & 0.00 & 0.0500 \\
\hline Steelhead & Supp & & & & & & & 0.00 & NS \\
\hline
\end{tabular}


TABLE C.2

Calibration Data

\begin{tabular}{|c|c|c|c|c|c|c|c|c|c|}
\hline SUBBASIN & $\begin{array}{l}\text { Stock } \\
\text { Type }\end{array}$ & $\begin{array}{ll}\text { Calib. } & \text { Ca } \\
\text { Spawn } & \text { Es }\end{array}$ & $\begin{array}{ll}\text { lib. } & C \\
\text { cape } & R\end{array}$ & $\begin{array}{ll}\text { Calib. } & \text { C } \\
\text { Runsize } & \text { H }\end{array}$ & $\begin{array}{l}\text { Calib. } \\
\text { Hattake } \mathrm{F}\end{array}$ & $\begin{array}{l}\text { Calib. } \\
\text { Hatsmlt }\end{array}$ & $\begin{array}{l}\text { Calib. } \\
\text { Sbharv }\end{array}$ & $\begin{array}{l}\text { Calib. } \\
\text { Hrvrate }\end{array}$ & $\begin{array}{l}\text { Calib. } \\
\text { Adtrecv }\end{array}$ \\
\hline \multicolumn{10}{|l|}{ PANTHER CREEK } \\
\hline $\begin{array}{l}\text { Summer Chinook } \\
\text { Summer Chinook }\end{array}$ & Supp & & 0 & & & & & 0.00 & 0.0173 \\
\hline Steelhead & Nat & 118 & 153 & 153 & 5 & & & 0.00 & 0.1500 \\
\hline \multirow{2}{*}{\multicolumn{10}{|c|}{$\begin{array}{l}\text { Steelhead } \\
\text { PAHSIMEROI } \\
\text { Summer Chinook }\end{array}$}} \\
\hline & & & & & & & & & \\
\hline $\begin{array}{l}\text { Summer Chinook } \\
\text { Summer Chinook }\end{array}$ & $\begin{array}{l}\text { Nat } \\
\text { Supp }\end{array}$ & 13 & 28 & 33 & & & & $\begin{array}{l}0.00 \\
0.00\end{array}$ & $\begin{array}{r}0.0314 \\
\text { NS }\end{array}$ \\
\hline Steelhead & Nat & 2,960 & 363 & 363 & 284 & & & 0.00 & 0.1310 \\
\hline \multirow{2}{*}{\multicolumn{10}{|c|}{$\begin{array}{l}\text { Steelhead } \\
\text { TUCANNON }\end{array}$}} \\
\hline & & & & & & & & & \\
\hline Spring Chinook & Nat & 202 & 391 & 500 & & & & 0.00 & 0.0780 \\
\hline $\begin{array}{l}\text { Spring Chinook } \\
\text { Steelhead }\end{array}$ & Supp & & & & & & & 0.00 & 0.0575 \\
\hline $\begin{array}{l}\text { Steelhead } \\
\text { Steelhead }\end{array}$ & Nat & 603 & 755 & 755 & 2 & & & 0.00 & 0.2530 \\
\hline $\begin{array}{l}\text { Steelhead } \\
\text { IMNAHA }\end{array}$ & Supp & & \multirow{2}{*}{\multicolumn{7}{|c|}{$\begin{array}{l}\text { Steelhead } \\
\text { IMNAHA }\end{array}$}} \\
\hline Spring Chinook & Nat & 482 & & & & & & & \\
\hline Spring Chinook & Supp & 52 & $\begin{array}{l}839 \\
102\end{array}$ & $\begin{array}{r}1,071 \\
128\end{array}$ & $\begin{array}{r}13 \\
8\end{array}$ & 100,000 & & 0.00 & $\begin{array}{l}0.1190 \\
0.0074\end{array}$ \\
\hline \multicolumn{10}{|l|}{$\begin{array}{l}\text { Spring Chinook } \\
\text { DESCHUTES }\end{array}$} \\
\hline Spring Chinook & $\begin{array}{l}\text { Nat } \\
\text { Sunn }\end{array}$ & 1,555 & 5,050 & 9,026 & 61 & & 1,464 & 0.29 & 0.2660 \\
\hline $\begin{array}{l}\text { Spring Chinook } \\
\text { Fall Chinook }\end{array}$ & $\begin{array}{l}\text { Supp } \\
\text { Nat }\end{array}$ & & & & & & & 0.00 & NS \\
\hline $\begin{array}{l}\text { Fall Chinook } \\
\text { Fall Chinook }\end{array}$ & $\begin{array}{l}\text { Nat } \\
\text { Supp }\end{array}$ & 3,619 & 5,875 & 54,348 & & & 1,763 & 0.30 & 0.0976 \\
\hline $\begin{array}{l}\text { Fall Chinook } \\
\text { Steelhead }\end{array}$ & $\begin{array}{l}\text { Supp } \\
\text { Nat }\end{array}$ & & & & & & & 0.00 & $\begin{array}{r}\text { NS } \\
01628\end{array}$ \\
\hline & $\begin{array}{l}\text { Nat } \\
\text { Supp }\end{array}$ & 6,210 & 8,441 & 8,441 & 8 & & 1,245 & $\begin{array}{l}0.15 \\
0.00\end{array}$ & $\begin{array}{r}0.1628 \\
\text { NS }\end{array}$ \\
\hline \multicolumn{10}{|l|}{$\begin{array}{l}\text { Steelhead } \\
\text { WALLA WALLA }\end{array}$} \\
\hline Spring Chinook & Nat & 546 & 1,412 & 2,510 & & & & 0.00 & 0.3978 \\
\hline Spring Chinook & Supp & & & & & & & 0.00 & 0.0730 \\
\hline $\begin{array}{l}\text { Steelhead } \\
\text { Steelhead }\end{array}$ & Nat & 3,862 & 4,828 & 4,828 & & & & 0.00 & 0.4105 \\
\hline \multirow{2}{*}{\multicolumn{10}{|c|}{$\begin{array}{l}\text { Steelhead } \\
\text { UMATILLA }\end{array}$}} \\
\hline & & & & & & & & & \\
\hline $\begin{array}{l}\text { Spring Cninook } \\
\text { Spring Chinook }\end{array}$ & Supp & & & 644 & & & & $\begin{array}{l}0.00 \\
0.00\end{array}$ & $\begin{array}{l}0.1150 \\
0.0255\end{array}$ \\
\hline Fall Chinook & Nat & 2,772 & 5,986 & 55,381 & & & & 0.00 & $\begin{array}{l}0.0255 \\
0.1128\end{array}$ \\
\hline Fall Chinook & Supp & & & & & & & 0.00 & $\begin{array}{l}0.1128 \\
0.0580\end{array}$ \\
\hline Steelhead & Nat & 1,857 & 2,082 & 2,082 & 32 & & & 0.00 & $\begin{array}{l}0.0580 \\
0.2485\end{array}$ \\
\hline Steelhead & Supp & 214 & 301 & 301 & 4 & 60,000 & 30 & 0.10 & $\begin{array}{l}0.2485 \\
0.0230\end{array}$ \\
\hline \multicolumn{10}{|l|}{$\begin{array}{l}\text { Steelhead } \\
\text { JOHN DAY }\end{array}$} \\
\hline Spring Chinook & Nat & 2,552 & 4,161 & 7,398 & & & 42 & 0.01 & 0.1140 \\
\hline Spring Chinook & Supp & & & & & & & 0.00 & NS \\
\hline Steelhead & Nat & 28,862 & 35,743 & 35,743 & & & 5,361 & 0.15 & ; 0.7207 \\
\hline $\begin{array}{l}\text { Steelhead } \\
\text { L. WHITE SALMON }\end{array}$ & Supp & & & & & & & 0.00 & NS \\
\hline \multicolumn{9}{|c|}{ L. WHITE SALMON } & \\
\hline Spring Chinook & Supp & 44 & 50 & 71 & & & & $\begin{array}{l}0.00 \\
0.00\end{array}$ & $\begin{array}{ll}0 & 0.0180 \\
0 & 0.0504\end{array}$ \\
\hline Fall Chinook & Nat & 42 & 50 & 461 & & & & 0.00 & $\begin{array}{ll}0 & 0.0420\end{array}$ \\
\hline Fall Chinook & Supp & & & & & & & 0.00 & $0 \quad 0.3480$ \\
\hline
\end{tabular}




\section{TABLE C.2}

\section{Calibration Data}

\begin{tabular}{|c|c|c|c|c|c|c|c|c|c|}
\hline SUBBASIN & $\begin{array}{l}\text { Stock } \\
\text { Type }\end{array}$ & $\begin{array}{l}\text { Calib. } \\
\text { Spawn }\end{array}$ & $\begin{array}{l}\text { Calib. } \\
\text { Escape }\end{array}$ & $\begin{array}{l}\text { Calib. } \\
\text { Runsize }\end{array}$ & $\begin{array}{l}\text { Calib. } \\
\text { Hattake }\end{array}$ & $\begin{array}{l}\text { Calib. } \\
\text { Hatsmit }\end{array}$ & $\begin{array}{l}\text { Calib. } \\
\text { Sbharv }\end{array}$ & $\begin{array}{l}\text { Calib. } \\
\text { Hrvrate }\end{array}$ & $\begin{array}{l}\text { Calib. } \\
\text { Adtrecr }\end{array}$ \\
\hline \multicolumn{10}{|l|}{ WHITE SALMON } \\
\hline Spring Chinook & Nat & 45 & 50 & 72 & & & & 0.00 & 0.0145 \\
\hline Spring Chinook & Supp & & & & & & & 0.00 & 0.0530 \\
\hline Steelhead & Nat & 447 & 110 & 110 & 8 & & & 0.00 & 0.3100 \\
\hline Steelhead & Supp & 349 & 1,300 & 1,300 & 7 & 13,044 & 905 & 0.70 & 0.1733 \\
\hline \multicolumn{10}{|l|}{ KLICKITAT } \\
\hline Spring Chinook & Nat & 91 & 334 & 478 & & & 150 & 0.45 & 0.0290 \\
\hline Spring Chinook & Supp & & & & & & & 0.00 & 0.0268 \\
\hline Steelhead & Nat & 2,993 & 5,305 & 5,305 & & & 2,902 & 0.55 & 0.4040 \\
\hline Steelhead & Supp & 830 & 2,035 & 2,035 & & 107,000 & 1,113 & 0.55 & 0.0344 \\
\hline \multicolumn{10}{|l|}{ HOOD } \\
\hline Spring Chinook & Nat & 123 & 174 & 249 & & & 35 & 0.20 & 0.0520 \\
\hline Spring Chinook & Supp & & & & & & & 0.00 & 0.0131 \\
\hline Fall Chinook & Nat & 122 & 198 & 1,521 & & & 40 & 0.20 & 0.0660 \\
\hline Fall Chinook & Supp & & & & & & & 0.00 & NS \\
\hline Steelhead & Nat & 1,997 & 3,956 & 3,956 & & & 2,769 & 0.70 & 0.7330 \\
\hline Steelhead & Supp & 929 & 3,440 & 3,440 & & 81,795 & 2,408 & 0.70 & 0.0980 \\
\hline \multicolumn{10}{|l|}{ WIND } \\
\hline Spring Chincok & Nat & 151 & 213 & 304 & & & 43 & 0.20 & 0.0165 \\
\hline Spring Chinook & Supp & & & & & & & 0.00 & 0.0097 \\
\hline Stcelhead & Nat & 334 & 371 & 371 & & & & 0.00 & 0.1360 \\
\hline Steelhead & Supp & & & & & & & 0.00 & 0.0162 \\
\hline \multicolumn{10}{|l|}{ ENTIAT } \\
\hline Spring Chinook & Nat & 1,847 & 2,400 & 3,576 & 360 & & & 0.00 & 0.2110 \\
\hline Spring Chinook & Supp & 352 & 565 & 842 & 69 & 800,000 & & 0.00 & 0.1230 \\
\hline \multicolumn{10}{|l|}{ METHOW } \\
\hline Spring Chinook & Nat & 2,503 & 3,127 & 4,661 & 491 & & & 0.00 & 0.0858 \\
\hline Spring Chinook & Supp & 603 & 993 & 1,481 & 118 & 800,000 & & 0.00 & 0.0860 \\
\hline Summer Chinook & Nat & 1,188 & 4,798 & 27,954 & & & & 0.00 & 1.0270 \\
\hline Summer Chinook & Supp & & & & & & & 0.00 & 1.0270 \\
\hline \multicolumn{10}{|l|}{ OKANOGON } \\
\hline Summer Chinook & Nat & 1,033 & 4,172 & 24,308 & & & & 0.00 & 0.9840 \\
\hline Summer Chinook & Supp & & & & & & & 0.00 & 0.9840 \\
\hline \multicolumn{10}{|l|}{ WENATCHEE } \\
\hline Spring Chinook & Nat & 4,268 & 5,777 & 8,611 & & & & 0.00 & 0.0761 \\
\hline Spring Chinook & Supp & & & & & & & 0.00 & 0.0761 \\
\hline Summer Chinook & Nat & 4,346 & 11,111 & 64,742 & & & & 0.00 & 0.4430 \\
\hline Summer Chinook & Supp & & & & & & & 0.00 & 0.4430 \\
\hline
\end{tabular}

The sum of natural and supplementation fish spawning in streams equals natural apawners.

The sum of natural and supplementation fish taken for broodstock equals HATTAKE.

Hatchery take is calculated as the number of fish needed to provide broodstock for plant, i.e., Hatchery take $=$ Hatchery plant / (fraction female * eggs per female * egg-smolt survival).

A hatchery plant is considered "hatchery production" if (1) the release is on site, or (2) It appears that the intention of management is for the released fish to return to the hatchery racks

A hatchery plant is considered supplementation if (1) release is off site, such as from an acclimation pond, or (2) it appears that management's intent is for the released fish to return to natural spawning grounds NS: No supplementation in base case or in actions 
TABLE C.3

Base Case Data

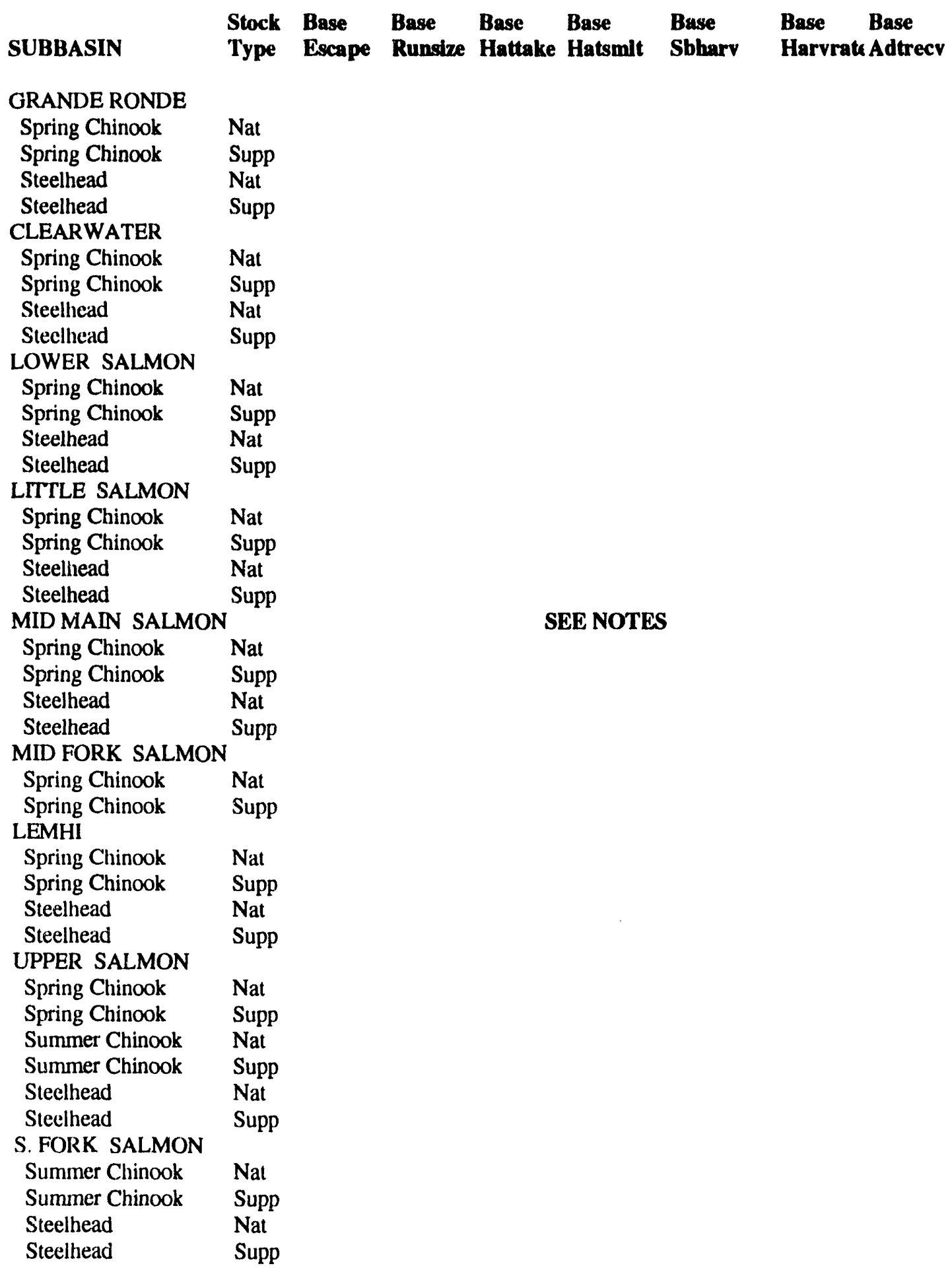


TABI E C.3

Base Case Data

\begin{tabular}{|c|c|c|c|c|c|c|c|c|}
\hline \multirow{2}{*}{$\begin{array}{l}\text { SUBBASIN } \\
\text { PANTHER CREEK }\end{array}$} & \multirow[t]{2}{*}{$\begin{array}{l}\text { Stock } \\
\text { Type }\end{array}$} & \multirow[t]{2}{*}{$\begin{array}{l}\text { Base } \\
\text { Escape }\end{array}$} & $\begin{array}{l}\text { Base } \\
\text { Runsize }\end{array}$ & $\begin{array}{l}\text { Base } \\
\text { Hattake }\end{array}$ & $\begin{array}{l}\text { Base } \\
\text { Hatsmit }\end{array}$ & \multirow[t]{2}{*}{$\begin{array}{l}\text { Base } \\
\text { Sbharv }\end{array}$} & \multicolumn{2}{|c|}{$\begin{array}{l}\text { Base Base } \\
\text { Harvratt Adtrecv }\end{array}$} \\
\hline & & & & & & & & \\
\hline Summer Chinook & Nat & & & & & & & \\
\hline Summer Chinook & Supp & & & & & & & \\
\hline Steclhead & Natt & & & & & & & \\
\hline Steelhead & Supp & & & & & & & \\
\hline \multicolumn{9}{|l|}{ PAHSIMEROI } \\
\hline Summer Chinook & Nat & & & & & & & \\
\hline Summer Chinook & Supp & & & & & & & \\
\hline Steelhead & Nat & & & & & & & \\
\hline Steelhead & Supp & & & & & & & \\
\hline \multicolumn{9}{|l|}{ TUCANNON } \\
\hline Spring Chinook & Nat & 1,106 & 959 & 1,223 & 72 & & 0.00 & 0.0000 \\
\hline Spring Chinook & Supp & 629 & 1,266 & 1,615 & 41 & 145,146 & 0.00 & 0.0000 \\
\hline Steelhead & Nat & & & & & & & \\
\hline Steelhead & Supp & & & & & & & \\
\hline \multicolumn{9}{|l|}{ IMNAHA } \\
\hline Spring Chinook & Nat & 606 & 970 & 1,237 & 327 & & 0.00 & 0.0000 \\
\hline Spring Chinook & Supp & 191 & 447 & 570 & 103 & 444,462 & 0.00 & 0.0000 \\
\hline \multicolumn{9}{|l|}{ DESCHUTES } \\
\hline Spring Chinook & Nat & & & & & & & \\
\hline Spring Chinook & Supp & & & & & & & \\
\hline Fall Chinook & Nat & & & & & & & \\
\hline Fall Chinook & Supp & & & & & & & \\
\hline Steclhead & Nat & & & & & & & \\
\hline Steelhead & Supp & & & & & & & \\
\hline \multicolumn{9}{|l|}{ WALLA WALLA } \\
\hline Spring Chinook & Nat & & & & & & & \\
\hline Spring Chinook & Supp & & & & & & & \\
\hline Steelhead & $\mathrm{Nat}$ & 6,059 & 5,234 & 5,234 & & & 0.00 & 0.0000 \\
\hline Steelhead & Supp & 1,872 & 3,899 & 3,899 & & 278,762 & 21560.00 & 0.4000 \\
\hline \multicolumn{9}{|l|}{ UMATILLA } \\
\hline Spring Chinook & Nat & 1,889 & 733 & 1,045 & 818 & & 0.00 & 0.0000 \\
\hline Spring Chinook & Supp & 1,425 & 5,109 & 7,286 & 715 & $1,700,000$ & 2460.00 & 0.5600 \\
\hline Fall Chinook* & Nat & 8,179 & 7,986 & 73,888 & 3,404 & & 0.00 & 0.0000 \\
\hline Fall Chinook & Supp & 3,693 & 9,810 & 90,769 & 1,876 & $7,000,000$ & 02618.00 & 0.3300 \\
\hline Steelhead & $\mathrm{Nat}$ & 2,441 & 2,245 & 2,245 & 129 & & 0.00 & 0.0000 \\
\hline Steelhead & Supp & 712 & 1,202 & 1,202 & 45 & 239,193 & $3 \quad 266.00$ & 0.2300 \\
\hline \multicolumn{9}{|l|}{ JOHN DAY } \\
\hline Spring Chinook & Nat & & & & & & & \\
\hline Spring Chinook & Supp & & & & & & & \\
\hline Steelhead & Nat & & & & & & & \\
\hline Steelhead & Supp & & & & & & & \\
\hline \multicolumn{9}{|l|}{ L. WHITE SALMON } \\
\hline Spring Chinook & Nat & & & & & & & \\
\hline Spring Chinook & Supp & & & & & & & \\
\hline Fall Chinook & Nat & & & & & & & \\
\hline Fall Chinook & Supp & & & & & & & \\
\hline
\end{tabular}


TABLE C.3

Base Case Data

\begin{tabular}{|c|c|c|c|c|c|c|c|c|}
\hline SUBBASIN & $\begin{array}{l}\text { Stock } \\
\text { Type }\end{array}$ & $\begin{array}{l}\text { Base } \\
\text { Escape }\end{array}$ & $\begin{array}{l}\text { Base } \\
\text { Runsize }\end{array}$ & $\begin{array}{l}\text { Base } \\
\text { Hattake }\end{array}$ & $\begin{array}{l}\text { Base } \\
\text { Hatsmit }\end{array}$ & $\begin{array}{l}\text { Base } \\
\text { Sbharv }\end{array}$ & $\begin{array}{l}\text { Base } \\
\text { Harvrate }\end{array}$ & $\begin{array}{l}\text { Base } \\
\text { Adtrecy }\end{array}$ \\
\hline \multicolumn{9}{|l|}{ WHITE SALMON } \\
\hline $\begin{array}{l}\text { Spring Chinook } \\
\text { Spring Chinook }\end{array}$ & $\begin{array}{l}\text { Nat } \\
\text { Supp }\end{array}$ & & & & & & & \\
\hline Steelhead & $\mathrm{Nat}$ & 986 & 114 & 114 & 19 & & 0.00 & 0.0000 \\
\hline Steelhead & Supp & 884 & 3,293 & 3,293 & 18 & 33,044 & 2292.00 & 0.7000 \\
\hline \multicolumn{9}{|l|}{ KLICKITAT } \\
\hline Spring Chinook & Nat & 602 & 1,605 & 2,289 & 67 & & 701.00 & 0.4500 \\
\hline Spring Chinook & Supp & 181 & 689 & 982 & 20 & 99,300 & 301.00 & 0.4500 \\
\hline Steelhead & Nat & 6,237 & 6,216 & 6,216 & & & 0.00 & 0.0000 \\
\hline Stcelhead & Supp & 642 & 952 & 952 & & 50,038 & 238.00 & 0.2500 \\
\hline \multicolumn{9}{|l|}{ HOOD } \\
\hline Spring Chinook & Nat & 850 & 326 & 465 & & & 0.00 & 0.0000 \\
\hline Spring Chinook & Supp & 562 & 794 & 1,133 & & 197,988 & 159.00 & 0.2000 \\
\hline Fall Chinook & Nat & & & & & & & \\
\hline Fall Chinook & Supp & & & & & & & \\
\hline Steelhead & Nat & 5,075 & 4,607 & 4,607 & & & 0.00 & 0.0000 \\
\hline Steelhead & Supp & 929 & 3,440 & 3,440 & & 81,795 & 2408.00 & 0.7000 \\
\hline \multicolumn{9}{|l|}{ WIND } \\
\hline Spring Chinook & Nat & & & & & & & \\
\hline Spring Chinook & Supp & & & & & & & \\
\hline Steelhead & Nat & & & & & & & \\
\hline Steelhead & Supp & & & & & & & \\
\hline \multicolumn{9}{|l|}{ ENTIAT } \\
\hline Spring Chinook & Nat & & & & & & & \\
\hline Spring Chinook & Supp & & & & & & & \\
\hline \multicolumn{9}{|l|}{ METHOW } \\
\hline Spring Chinook & Nat & & & & & & & \\
\hline Spring Chinook & Supp & & & & & & & \\
\hline Summer Chinook & Nat & 1,777 & 6,040 & 35,189 & 226 & & 0.00 & 0.0000 \\
\hline Summer Chinook & Supp & 327 & 1,362 & 7,938 & 42 & 400,000 & 0.00 & 0.0000 \\
\hline \multicolumn{9}{|l|}{ OKANOGON } \\
\hline Summer Chinook & Nat & 2,006 & 6,076 & 35,402 & 326 & & 0.00 & 0.0000 \\
\hline Summer Chinook & Supp & 559 & 2,350 & 13,689 & 91 & 576,000 & 0.00 & 0.0000 \\
\hline \multicolumn{9}{|l|}{ WENATCHEE } \\
\hline Spring Chinook & Nat & 4,729 & 5,965 & 8,890 & 358 & & 0.00 & 0.0000 \\
\hline Spring Chinook & Supp & 556 & 795 & 1,185 & 42 & 672,000 & 0.00 & 0.0000 \\
\hline Summer Chinook & Nat & 5,587 & 12,081 & 70,388 & 490 & & 0.00 & 0.0000 \\
\hline Summer Chinook & Supp & 1,018 & 2,691 & 15,679 & 109 & 864,000 & 0.00 & 0.0000 \\
\hline
\end{tabular}

Base case data are not entered if the values are the same as in the Calibration case in Table C.2

* Prespawning survival different than in calibration case for Umatilla Fall Chinook

The sum of natural and supplementation fish spawning in streams equals natural apawners.

The sum of natural and supplementation fish taken for broodstock equals HATTAKE.

Hatchery take equals the number of fish needed to provide broodstock for planting (Hatchery take = Hatchery plant / (fraction female * eggs per female * egg-smolt survival); parameters are specific for hatchery stock.

A hatchery plant is considered "hatchery production" if (1) the release is on site, or (2) It appears that the intention of management is for the released fish to return to the hatchery racks

A hatchery plant is considered "supplementation" if (1) The release is off site, such as from an acclimation pond, or (2) It appears that the intention of management is for the released fish to return to natural spawning grounds

NS: No supplementation in base case or actions 
TABLE D.1

Effects of Propagation Actions

\begin{tabular}{|c|c|c|c|c|c|c|}
\hline Subbasin & Description of action & $\begin{array}{l}\text { Subbasin } \\
\text { Plans } \\
\text { Action \# }\end{array}$ & $\begin{array}{l}\text { post-rel } \\
\text { surv }\end{array}$ & $\begin{array}{l}\text { pre-sp } \\
\text { surv }\end{array}$ & $\begin{array}{l}\text { basin } \\
\text { surv }\end{array}$ & $\begin{array}{l}\text { egg-sm } \\
\text { surv }\end{array}$ \\
\hline \multicolumn{2}{|l|}{ GRANDE RONDE } & 1.2 & 1.275 & 1.000 & 1.000 & 1.000 \\
\hline Spring Chinook & improve habitat & 1.3 & 1.000 & 0.994 & 0.994 & 1.016 \\
\hline Spring Chinook & supplementation** & 2.4 & 1.000 & 1.000 & 1.000 & 1.000 \\
\hline Summer Steelhead & improve hatchery effectiveness & 1.2 & 1.500 & 1.000 & 1.000 & 1.000 \\
\hline Summer Steelhead & improve habitat & 1.3 & 1.000 & 1.000 & 0.995 & 1.266 \\
\hline Summer Steelhead & supplementation** & 2.4 & 1.000 & 1.000 & 1.000 & 1.000 \\
\hline \multicolumn{7}{|l|}{ CLEARWATER } \\
\hline $\begin{array}{l}\text { Spring Chinook } \\
\text { Spring Chinook }\end{array}$ & hatchery production** & $1.1,1.2$ & 1.000 & 1.000 & 1.000 & 1.000 \\
\hline $\begin{array}{l}\text { Spring Chinook } \\
\text { Spring Chinook }\end{array}$ & supplementation** & 1.6 & 1.000 & 1.000 & 1.000 & 1.000 \\
\hline $\begin{array}{l}\text { Spring } \mathrm{Ch} \\
\text { Spring } \mathrm{Cl}\end{array}$ & halchery production** & $1.12,3.29$ & 1.000 & 1.000 & 1.000 & 1.000 \\
\hline $\begin{array}{l}\text { Spring Chinook } \\
\text { Spring Chinook }\end{array}$ & supplementation** & 1.16 & 1.000 & 1.000 & 1.000 & 1.000 \\
\hline $\begin{array}{l}\text { Spring Chinook } \\
\text { Spring Chinook }\end{array}$ & improve habitat (also steelhead 1.1) & $2.22,3.28$ & 1.000 & 1.000 & 1.000 & 1.000 \\
\hline $\begin{array}{l}\text { Spring Chinook } \\
\text { Spring Chinook }\end{array}$ & improve habitat; acquire land & $3.26,3.27$ & 1.000 & 1.000 & 1.000 & 1.000 \\
\hline $\begin{array}{l}\text { Spring Chinook } \\
\text { Spring Chinook }\end{array}$ & remove barriers & 4.34 & 1.000 & 1.000 & 1.000 & 1.000 \\
\hline $\begin{array}{l}\text { Spring Chino } \\
\text { Summer Stee }\end{array}$ & plementation** & 5.35 & 1.000 & 1.000 & 1.000 & 1.000 \\
\hline $\begin{array}{l}\text { Summer Steelhead } \\
\text { Summer Steelhead }\end{array}$ & improve habitat & $1.1,2.22$ & 1.000 & 1.000 & 1.000 & 1.000 \\
\hline $\begin{array}{l}\text { Summer Steelhead } \\
\text { Summer Steelhead }\end{array}$ & improve habital; acquire land & 2.20 & 1.000 & 1.000 & 1.000 & 1.000 \\
\hline $\begin{array}{l}\text { Summer Steelhead } \\
\text { Summer Steelhead }\end{array}$ & remove barriers & $2.24,3.28$ & 1.000 & 1.000 & 1.000 & 1.000 \\
\hline \multicolumn{2}{|l|}{$\begin{array}{l}\text { Summer Steelnead } \\
\text { LOWER SALMON }\end{array}$} & 2.30 & 1.642 & 1.000 & 1.000 & 1.000 \\
\hline Spring Chinook & hatchery prod & 3.7 & 1.000 & 1.000 & 1.000 & \\
\hline Summer Steelhead & hatchery production** & 3.5 & 1.000 & 1.000 & 1.000 & $\begin{array}{l}1.000 \\
1.000\end{array}$ \\
\hline \multicolumn{7}{|l|}{$\begin{array}{l}\text { Summer Steelhead } \\
\text { LITTLE SALMON }\end{array}$} \\
\hline Spring Chinook & enhance habitat; remove barriers & $3.7,3.8$ & 1.000 & 1.000 & 1.000 & 1.000 \\
\hline Spring Chinook & entation** & 3.9 & 1.000 & 1.000 & 1.000 & 1.000 \\
\hline Summer Steelhead & improve habitat; remove barriers & 3.7 .3 .8 & 1.000 & 1.000 & 1.000 & 1.000 \\
\hline Summer Steelhead & supplementation** & 3.9 & 1.000 & 1.000 & 1.000 & 1.000 \\
\hline \multicolumn{7}{|c|}{$\begin{array}{l}\text { Summer Steelnead } \\
\text { MID MAIN SALMON }\end{array}$} \\
\hline Spring Chinook & hatchery production** & 2.2 & 1.000 & 1.000 & 1.000 & 1.000 \\
\hline Summer Steelhead & hatchery production** & 2.2 & 1.000 & 1.000 & 1.000 & 1.000 \\
\hline \multicolumn{7}{|c|}{ MID FORK SALMON } \\
\hline Spring Chinook & atation** & 2.7 & 1.000 & 1.000 & 1.000 & 1.000 \\
\hline Spring Chinook & supplementation** & 3.9 & 1.000 & 1.000 & 1.000 & 1.000 \\
\hline \multicolumn{7}{|l|}{$\begin{array}{l}\text { Spring Chinook } \\
\text { LEMHI }\end{array}$} \\
\hline Spring Chinook & ** & 3.4 & 1.000 & 1.000 & 1.000 & 1.000 \\
\hline Summer Steelhead & supplementation** & 3.4 & 1.000 & 1.000 & 1.000 & 1.000 \\
\hline \multicolumn{7}{|l|}{ UPPER SALMON } \\
\hline Spring Chinook & improve habitat & 2.9 & 1.000 & 1.000 & 1.000 & 1.000 \\
\hline Spring Chinook & supplementation** & $3.11,3.12$ & 1.000 & 1.000 & 1.000 & 1.000 \\
\hline Summer Chinook & hatchery production** & 3.8 & 1.000 & 1.000 & 1.000 & 1.000 \\
\hline Summer Steelhead & improve habitat & 2.8 & 1.000 & 1.000 & 1.000 & 1.000 \\
\hline Sumrner Steelhead & hatchery production** & 3.10 & 1.000 & 1.000 & 1.000 & 1.000 \\
\hline \multicolumn{7}{|l|}{ S. FORK SALMON } \\
\hline Summer Chinook & ir & 1.1 & 1.000 & 1.000 & 1.000 & 1.333 \\
\hline Immer Chinook & hatchery production** & 3.7 & 1.000 & 1.000 & 1.000 & 1.000 \\
\hline Summer Steelhead & improve habitat & 1.1 & 1.000 & 1.000 & 1.000 & 1.267 \\
\hline Summer Steclhead & hatchery production** & 3.4 & 1.000 & 1.000 & 1.000 & 1.000 \\
\hline
\end{tabular}


TABLE D.1

Effects of Propagation Actions

Subbasin

GRANDE RONDE

Spring Chinook

Spring Chinook

Spring Chinook

Summer Steelhead

Summer Steelhead

Summer Steelhead

CLEARWATER

Spring Chinook

Spring Chinook

Spring Chinook

Spring Chinook

Spring Chinook

Spring C'hinook

Spring Chinook

Spring Chinook

Summer Steelhead

Summer Steelhead

Summer Steelhead

Summer Steelhead

LOWER SALMON

Spring Chinook

Summer Steelhead

LITTLE SALMON

Spring Chinook

Spring Chinook

Summer Steelhead

Summer Steelhead

MID MAIN SALMON

Spring Chinook

Summer Steelhead

MID FORK SALMON

Spring Chinook

Spring Chinook

LEMHI

Spring Chinook

Summer Steelhead

UPPER SALMON

Spring Chinook

Spring Chinook

Summer Chinook

Summer Steelhead

Summer Steelhead

S. FORK SALMON

Summer Chinook

Summer Chinook

Summer Steelhead

Summer Steelhead

\section{Description of action}

improve hatchery effectiveness

improve habitat

supplementation**

improve hatchery effectiveness

improve habitat

supplementation**

hatchery production**

supplementation**

hatchery production**

supplementation**

improve habitat (also steelhead 1.1)

improve habitat; acquire land

remove barriers

supplementation**

improve habitat

improve habitat; acquire land

remove barriers

improve hatchery effectiveness

hatchery production**

hatchery production**

enhance habitat; remove barriers

supplementation**

improve habitat; remove barriers

supplementation**

hatchery production**

hatchery production**

supplementation**

supplementation**

supplementation**

supplementation**

improve habitat

supplementation**

hatchery production**

improve habitat

hatchery production**

improve habitat

hatchery production**

improve habitat

hatchery production** $\begin{array}{lllll}\text { smolt hatch } & \text { hatch } & \text { gen } & \text { gen } \\ \text { cap } & \text { take } & \text { plant } & \text { sens } & \text { risk }\end{array}$

1.000

1.133

1.000

1.000

1.219

1.000

1.000

1.000

1.000

1.000

1.012

1.033

1.045

1.000

1.004

1.009

1.047

1.000

1.000

1.000

1.124

1.000

1.045

1.000

1.000

1.000

1.000

1.000

1.000

1.000

1.005

1.000

1.000

1.005

1.000

1.117

1.000

1.042

1.000

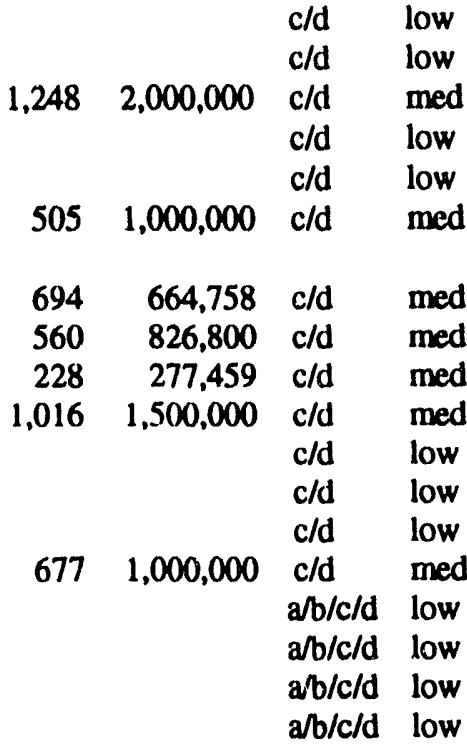

$8941,000,000 \mathrm{a} b$ high

$6231,300,000 \mathrm{a} / \mathrm{b} / \mathrm{c} / \mathrm{d}$ med

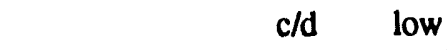

$8711,000,000 \mathrm{c} / \mathrm{d}$ med

$444 \quad 800,000$ c/d low

$8151,000,000 \mathrm{a} / \mathrm{b} \quad$ high

$4041,000,000 \mathrm{a} / \mathrm{b}$ high

$347500,000 \mathrm{a} / \mathrm{b} \quad$ high

$347500,000 \mathrm{a} / \mathrm{b}$ high

$8151,000,000 \mathrm{a} / \mathrm{b}$ high

$4701,000,000 \mathrm{c} / \mathrm{d}$ med

c/d low

$1,7922,800,000 \mathrm{c} / \mathrm{d}$ med

$6221,000,000 \mathrm{a} / \mathrm{b}$ high

$\begin{array}{llll}1,391 & 2,500,000 & \mathrm{c} / \mathrm{d} & \mathrm{d}\end{array}$

$\mathrm{c} / \mathrm{d}$ low

$9631,000,000 \mathrm{c} / \mathrm{d}$ med

$\begin{array}{llll}228 & 500,000 & \mathrm{a} / \mathrm{b} & \text { low } \\ \mathrm{a} / \mathrm{b} & \text { high }\end{array}$ 
TABLE D.1

Effects of Propagation Actions

\begin{tabular}{|c|c|c|c|c|c|c|}
\hline Subbasin & Description of action & $\begin{array}{l}\text { Subbasin } \\
\text { Plans } \\
\text { Action \# }\end{array}$ & $\begin{array}{l}\text { post-rel } \\
\text { surv }\end{array}$ & $\begin{array}{l}\text { pre-sp } \\
\text { surv }\end{array}$ & $\begin{array}{l}\text { basin } \\
\text { surv }\end{array}$ & $\begin{array}{l}\text { egg-sm } \\
\text { surv }\end{array}$ \\
\hline \multicolumn{2}{|l|}{ PANTHER CREEK } & 2.3 & 1.000 & 1.000 & 1.000 & 1.000 \\
\hline $\begin{array}{l}\text { Surmmer Chinook } \\
\text { Summer Chinook }\end{array}$ & trap and haul program & 3.4 & 1.000 & 0.968 & 1.000 & 1.841 \\
\hline Summer Cilinook & design/implement restoration & 4.5 & 1.000 & 1.000 & 1.000 & 2.080 \\
\hline Summer Steelhead & hatchery product $: 7^{* *}$ & 2.3 & 1.000 & 1.000 & 1.000 & 1.000 \\
\hline Summer Steelhead & trap and haul program & 3.5 & 1.000 & 0.985 & 1.000 & 1.408 \\
\hline $\begin{array}{l}\text { Summer Steelhead } \\
\text { PAHSIMEROI }\end{array}$ & design/implement restoration & 4.6 & 1.000 & 1.000 & 1.000 & 1.520 \\
\hline \multicolumn{7}{|l|}{$\begin{array}{l}\text { Summer Steelhead } \\
\text { PAHSIMEROI }\end{array}$} \\
\hline $\begin{array}{l}\text { Summer Chinook } \\
\text { Summer Steelbe id }\end{array}$ & hatchery production** & 3.6 & 1.000 & 1.000 & 1.000 & 1.000 \\
\hline $\begin{array}{l}\text { Summer Steelbe dd } \\
\text { TUCANNON }\end{array}$ & tatchery production** & 3.6 & 1.000 & 1.000 & 1.000 & 1.000 \\
\hline Spring Chinook & improve habitat & 1.1 & 1.000 & 1.000 & 1.000 & 1.350 \\
\hline Spring Chinook & improve passage at Starbuck & 1.2 & 1.000 & 1.250 & 1.000 & 1.000 \\
\hline Sumoer Steelhead & improve habitat & $1.2,1.3,1.4$ & 1.000 & 1.000 & 1.000 & 1.150 \\
\hline Summer Steelhead & improve habitat & $2.5,2.6$ & 1.000 & 1.000 & 1.000 & 1.610 \\
\hline Summer Steelhead & trap natural broodstock & 3.7 & 1.056 & 1.000 & 1.000 & 1.000 \\
\hline \multicolumn{7}{|l|}{$\begin{array}{l}\text { Summer Steelhead } \\
\text { IMNAHA }\end{array}$} \\
\hline Spring Chinook & $\mathrm{on}^{* *}$ & 3.2 & 1.000 & 1.000 & 1.000 & 1.000 \\
\hline Spring Chinook & supplementation & 3.2 & 1.000 & 1.000 & 1.000 & 1.000 \\
\hline \multicolumn{7}{|l|}{$\begin{array}{l}\text { Spring Chinook } \\
\text { DESCHUTES }\end{array}$} \\
\hline Srring Chinook & improve habitat & $1.1,1.2$ & 1.000 & 1.250 & 1.003 & 1.380 \\
\hline Spring Chinook & provide passage at $W$. River ralis & 2.3 & 1.000 & 1.000 & 0.984 & 0.990 \\
\hline Spring Chinook & hatchery production** & 1.4 & 1.000 & 1.000 & 1.000 & 1.000 \\
\hline Fall Chinook & prove habitat-pant 1 & 4 & 1.000 & 1.000 & 1.000 & \\
\hline Fall Chinook & prove habitat-part 2 & $2.2,1.4$ & 1.000 & 1.000 & 1.000 & $\begin{array}{l}1.017 \\
1.307\end{array}$ \\
\hline Fall Chinook & prove habitat--part 3 & $3.3,1.4$ & 1.000 & 1.000 & 1.000 & $\begin{array}{l}1.301 \\
1.474\end{array}$ \\
\hline Summer Steelhead & improve habitat & 1.41 .5 & 1.000 & 1.032 & 1.078 & 1.125 \\
\hline Surnmer Steelhead & provide passage at W. River Falis & 3.6 & 1.000 & 1.001 & 0.998 & 0.972 \\
\hline Summer Steelhead & improve habitat & $2.2,2.3$ & 1.000 & 1.008 & 1.014 & 1.000 \\
\hline Summer Steelhead & hatchery productiou** & 5.7 & 1.000 & 1.000 & 1.000 & 1.000 \\
\hline \multicolumn{7}{|l|}{$\begin{array}{l}\text { Summer Steelhead } \\
\text { WALLA WALLA }\end{array}$} \\
\hline Spring Chinook & supplementation**; improve passage & $\begin{array}{l}\text { I.A } \\
\text { LB }\end{array}$ & $\begin{array}{l}1.000 \\
1.000\end{array}$ & 1.000 & 1.000 & $\begin{array}{l}1.000 \\
1.312\end{array}$ \\
\hline Spring Chinook & pplementation **; improve habitat & I.B & & 1.000 & 1.000 & $\begin{array}{l}1.312 \\
1.000\end{array}$ \\
\hline Spring Chinook & pplementation** & IIIB & 1.000 & 1.200 & & 1.000 \\
\hline Spring Chinook & upplementation ${ }^{* *}$; enhance flow & II.B & 1.000 & & 1.053 & 1.000 \\
\hline Spring Chinook & supplementation * & III.C & 1.000 & 1.000 & 1.000 & $\therefore .000$ \\
\hline Summer Steelhead & improve adult and juvenile passage & I.A & 1.000 & 1.125 & 1.188 & 1.000 \\
\hline Summer Steelhead & improve habitat & I.B & 1.000 & 1.000 & 1.000 & 1.333 \\
\hline Summer Steelhead & enhance flows & II.B & 1.000 & 1.000 & 1.053 & 1.000 \\
\hline Summer Steelhead & supplementation $* *$ & III.C & 1.000 & 1.000 & 1.000 & 1.000 \\
\hline
\end{tabular}


TABLE D.1

Effects of Propagation Actions

Subbasin

PANTHER CREEK

Summer Chinook

Summer Chinook

Summer Chinook

Summer Steelhead

Summer Steelhead

Summer Steelhead

PAHSIMEROI

Summer Chinook

Summer Steelhead

TUCANNON

Spring Chinook

Spring Chinook

Summer Steelhead

Summer Steelhead

Summer Steelhead

IMNAHA

Spring Chinook

Spring Chinook

DESCHUTES

Spring Chinook

Spring Chinook

Spring Chinook

Spring Chinook

Spring Chinook

Fall Chinook

Fall Chinook

Fall Chinook

Summer Steelhead

Summer Steelhead

Summer Steelhead

Summer Steelhead

WALLA WALLA

Spring Chinook

Spring Chinook

Spring Chinook

Spring Chinook

Spring Chinook

Summer Steelhead

Summer Steelhead

Summer Steelhead

Summer Steelhead
Description of action

supplementation**

trap and haul program

design/implement restoration

hatchery production**

trap and haul program

design/implement restoration

hatchery production**

hatchery production**

improve habitat

improve passage at Starbuck

improve habitat

improve habitat

trap natural broodstock

supplementation**

supplementation**

improve habitat

provide passage at W. River Falls

hatchery production**

hatchery production**

improve habitat--part 1

improve habitat--part 2

improve habitat--part 3

improve habitat

provide passage at W. River Falls

improve habitat

hatchery production**

smolt
cap

hatch

hatch gen

sens

gen

risk

supplementation**; improve passage

supplementation**; improve habitat

supplementation**

supplementation ${ }^{* *}$; enhance flow

supplementation**

improve adult and juvenile passage

improve habitat

enhance flows

supplementation**
1.000

4.525

11.025

1.000

4.752

12.976

1.000

1.000

1.000

1.000

1.000

1.000

1.000

1.000

1.000

1.181

1.392

1.000

1.000

$350,000 \mathrm{c} / \mathrm{d}$

$317 \quad 500,000 \quad \mathrm{c} / \mathrm{d}$

1.028

1.206

1.559

1.385

1.153

1.143

1.000

1.000

1.682

$\begin{array}{rrrr}622 & 1,000,000 & \text { a/b } & \text { high } \\ & & \\ & & \text { ab } & \text { low } \\ \text { a/b } & \text { low } \\ 365 & 700,000 & \text { a/b } & \text { high } \\ & \text { a/b } & \begin{array}{l}\text { low } \\ \text { a/b }\end{array} & \text { low } \\ & & & \\ & & & \\ 657 & 1,000,000 & \text { c/d } & \text { med } \\ 389 & 700,000 & \text { c/d } & \text { med }\end{array}$

$\mathrm{a} / \mathrm{b} \quad$ low

$\mathrm{a} / \mathrm{b}$ low

c/d low

c/d low

c/d low

$506688,000 \mathrm{c} / \mathrm{d}$ med

716972,000 c/d med

1.000

1.000

1.000

1.443

1.021

1.000

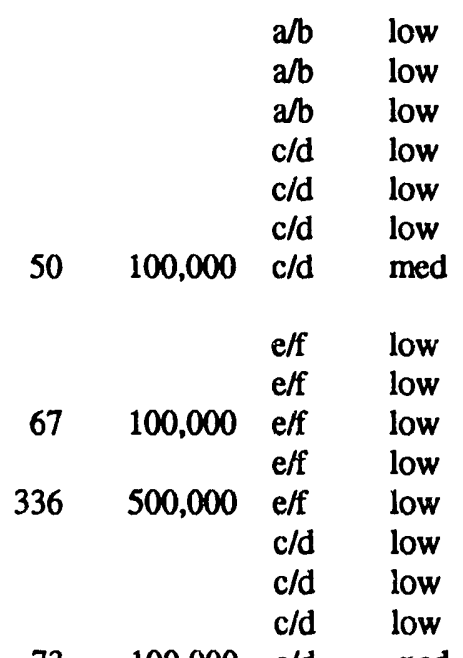

$73100,000 \mathrm{c} / \mathrm{d}$ rised


TABLE D.1

Effects of Propagation Actions

\begin{tabular}{|c|c|c|c|c|c|c|}
\hline Subbasin & Description of action & $\begin{array}{l}\text { Subbasin } \\
\text { Plans } \\
\text { Action \# }\end{array}$ & $\begin{array}{l}\text { post-rel } \\
\text { surv }\end{array}$ & $\begin{array}{l}\text { pre-sp } \\
\text { surv }\end{array}$ & $\begin{array}{l}\text { basin } \\
\text { surv }\end{array}$ & $\begin{array}{l}\text { egg-sm } \\
\text { surv }\end{array}$ \\
\hline \multicolumn{7}{|l|}{ UMATILLA } \\
\hline Spring Chinook & improve adult and juvenile passage & I.A & 1.000 & 1.500 & 1.203 & 1.000 \\
\hline Spring Chinook & improve habitat & I.B & 1.000 & 1.000 & 1.000 & 1.400 \\
\hline Spring Chinook & enhance flow & II.A & 1.000 & 1.200 & 1.053 & 1.000 \\
\hline Spring Chinook & supplementation** & III.B & 1.000 & 1.000 & 1.000 & 1.000 \\
\hline Spring Chinook & provide headwater storage & II.B & 1.000 & 1.056 & 1.000 & 1.143 \\
\hline Fall Chinook & improve adult and juvenile passage & I.A & 1.000 & 1.500 & 1.900 & 1.000 \\
\hline Fall Chinook & improve habitat & I.B & 1.000 & 1.000 & 1.000 & 1.027 \\
\hline Fall Chinook & enhance flow & II.A & 1.000 & 1.200 & 1.053 & 1.000 \\
\hline Fall Chinook & provide headwater storage & II:B & 1.000 & 1.056 & 1.000 & 1.000 \\
\hline \multicolumn{7}{|l|}{ Fall Chinook } \\
\hline Summer Steelhead & improve adult and juvenile passage & I.A & 1.000 & 1.125 & 1.203 & 1.000 \\
\hline Summer Steelhead & improve habitat & I.B & 1.000 & 1.000 & 1.000 & 0.926 \\
\hline Summer Steelhead & enhance flow & II.A & 1.000 & 1.056 & 1.053 & 1.000 \\
\hline $\begin{array}{l}\text { Summer Steelhead } \\
\text { JOHN DAY }\end{array}$ & provide headwater storage & Ш.В & 1.000 & 1.000 & 1.000 & 1.000 \\
\hline Spring Chinook & improve habitat & $1.1,1.2,2.3$ & 1.000 & 1.068 & 1.000 & 1.259 \\
\hline Spring Chinook & screen diversions & 1.5 & 1.000 & 1.000 & 1.000 & 1.095 \\
\hline \multicolumn{7}{|l|}{ Spring Chinook } \\
\hline Summer Steelhead & habitat & 1.1 & 1.000 & 1.000 & 1.000 & 1.407 \\
\hline $\begin{array}{l}\text { Summer Steelhead } \\
\text { L. WHITE SALMON }\end{array}$ & provide adult passage & 2.2 & 1.000 & 1.000 & 1.000 & 1.030 \\
\hline Spring Chinook & supplementation** & 1.1 & 1.000 & 1.000 & 1.000 & 1.000 \\
\hline Spring Chinook & tion** & 2.2 & 1.000 & 1.000 & 1.000 & 1.000 \\
\hline Fall Chinook & i** & 1.1 & 1.000 & 1.000 & 1.000 & 1.000 \\
\hline Fall Chinook & hatchery production** & 2.2 & 1.000 & 1.000 & 1.000 & 1.000 \\
\hline \multicolumn{7}{|l|}{ WHITE SALMION } \\
\hline Spring Chinook & Condit dam & 1.1, & .000 & 1.000 & 1.000 & 1.000 \\
\hline Spring Chinook & screen diversions & $1.2,1.1,1.3$ & 1.000 & 1.000 & 1.000 & 1.266 \\
\hline Spring Chinook & Condit and RM16.3 & $2.4,1.1,1.3$ & 1.000 & 1.000 & 1.000 & 1.000 \\
\hline Spring Chinook & reen diversions; remove barriers & $1.1,2,3 ; 2.4,4$ & 1.000 & 1.000 & 1.000 & 1.266 \\
\hline Spring Chinook & supplementation** & 3.6 & 1.000 & 1.000 & 1.000 & 1.000 \\
\hline Spring Chinook & hatchery production** & 4.7 & 1.000 & 1.000 & 1.000 & 1.000 \\
\hline Summer Steelhead & enhance habitat & 1.1 & 1.000 & 1.000 & 1.000 & 1.100 \\
\hline Summer Steelhead & entation** & 2.3 & 1.060 & 1.000 & 1.000 & 1.000 \\
\hline $\begin{array}{l}\text { Summer Steelhead } \\
\text { KLICKITAT }\end{array}$ & hatchery production** using net pens & \multicolumn{4}{|c|}{ KLICKITAT } & 1.000 \\
\hline Spring Chinook & sarrier at Castile Falls & 2.3 & 1.000 & 1.000 & $1.00 c$ & 1.000 \\
\hline Spring Chinook & reciesign ladder at Klickitat Hatchery & 2.4 & 1.000 & 1.600 & 1.000 & 1.091 \\
\hline Spring Chinook & improve habitat & $3.5,3.6$ & 1.000 & 1.000 & 1.000 & 1.143 \\
\hline Spring Chinook & pplementation** & 1.2 & 1.543 & 1.000 & 1.000 & 1.000 \\
\hline teelhead & hila & $3.4,3.5$ & 1.000 & 1.000 & 1.000 & 1.241 \\
\hline Summer Stcelhead & remove barrier at Castile Falls & 2.3 & 1.000 & 1.000 & 1.000 & 1.000 \\
\hline Summer Steelhead & remove barrier at $\mathrm{W}$. Fork Falls & 2.3 & 1.000 & 1.000 & 1.000 & $i .000$ \\
\hline Summer Steelhead & remove barrier at L. Klickitat Falls & 2.3 & 1.000 & 1.000 & 1.000 & 1.000 \\
\hline
\end{tabular}


TABLE D.1

Effects of Propagation Actions

Subbasin

UMATILLA

Spring Chinook

Spring Chinook

Spring Chinook

Spring Chinook

Spring Chinook

Fall Chinook

Fall Chinook

Fall Chinook

Fall Chinook

Fall Chinook

Summer Steelhead

Summer Steelhead

Summer Steelhead

Summer Steelhead

JOHN DAY

Spring Chinook

Spring Chinook

Spring Chinook

Summer Steelhead

Summer Steelhead

L. WHITE SALMON

Spring Chinook

Spring Chinook

Fall Chinook

Fall Chinook

WHITE SALMON

Spring Chinook

Spring Chinook

Spring Chinook

Spring Chinook

Spring Chinook

Spring Chinook

Summer Steelhead

Summer Steelhead

Summer Steeihead

KLICKITAT

Spring Chinook

Spring Chinook

Spring Chinook

Spring Chinook

Summer Steelhead

Summer Steelhead

Summer Steelhead

Summer Steelhead
Description of action

improve adult and juvenile passage

1.000

improve habitat

1.977

enhance flow

supplementation**

1.000

1.000

provide headwater storage

1.215

improve adult and juvenile passage $\quad 1.000$

improve habitat $\quad 1.091$

enhance flow

1.000

provide headwater storage

1.000

improve adult and juvenile passage $\quad 1.000$

improve habitat $\quad 1.577$

enhance flow

1.000

1.112

provide headwater storage

1.207

improve habitat

1.000

improve habitat

1.265

provide adult passage

1.165

supplementation**

hatchery production**

supplementation**

hatchery production**

remove barrier at Condit dam

1.000

1.000

1.000

1.000

remove barrier; screen diversions

3.258

remove barriers at Condit and RM16.3 6.318

screen diversions; remove barriers $\quad 6.318$

supplementation**

hatchery production**

enhance habitat

supplementation**

1.000

1.000

1.000

1.000

hatchery production** using net pens

1.000

remove barrier at Castile Falls

1.582

redesign ladder at Klickitat Hatchery

improve habitat

1.000

1.000

1.000

1.000

improve habitat

1.149

remove barrier at Castile Falls

1.027

remove barrier at L. Klickitat Falls $\quad 1.009$ $\begin{array}{llll}\text { hatch } & \text { hatch } & \text { gen } & \text { gen } \\ \text { take } & \text { plant } & \text { sens } & \text { risk }\end{array}$

$\begin{array}{rll} & \mathrm{c} / \mathrm{d} & \text { low } \\ \mathrm{c} / \mathrm{d} & \text { low } \\ \mathrm{c} / \mathrm{d} & \text { low } \\ 600,000 & \mathrm{c} / \mathrm{d} & \text { med } \\ \mathrm{c} / \mathrm{d} & \text { low } \\ \mathrm{c} / \mathrm{d} & \text { low } \\ \mathrm{c} / \mathrm{d} & \text { low } \\ \mathrm{c} / \mathrm{d} & \text { low } \\ \mathrm{c} / \mathrm{d} & \text { low } \\ & \\ \mathrm{c} / \mathrm{d} & \text { low } \\ \mathrm{c} / \mathrm{d} & \text { low } \\ \mathrm{c} / \mathrm{d} & \text { low } \\ \mathrm{c} / \mathrm{d} & \text { low } \\ & \\ \mathrm{a} / \mathrm{b} & \text { low } \\ \mathrm{a} / \mathrm{b} & \text { low } \\ & \\ \mathrm{a} / \mathrm{b} & \text { low } \\ \mathrm{a} / \mathrm{b} & \text { low }\end{array}$

58

317

130,000 e/f

660,000 e/f

150,000 e/f

$3,600,000$ e/f

3,500

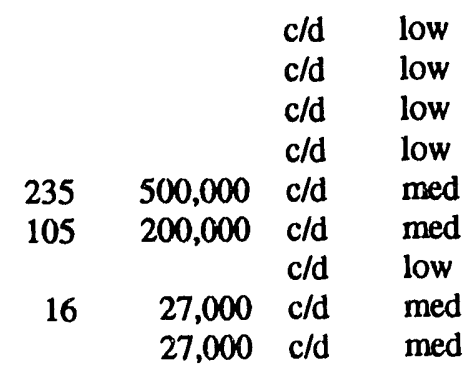

\begin{tabular}{|c|c|c|}
\hline & & $\mathrm{c} / \mathrm{r}$ \\
\hline & & $c_{i}$ \\
\hline & & $\mathrm{c} / \mathrm{d}$ \\
\hline 1,628 & $2,400,000$ & $\mathrm{c} / \mathrm{d}$ \\
\hline & & $\mathrm{c} / \mathrm{d}$ \\
\hline & & $\mathrm{c} / \mathrm{d}$ \\
\hline & & $\mathrm{c} / \mathrm{d}$ \\
\hline & & $\mathrm{c} / \mathrm{d}$ \\
\hline
\end{tabular}


TABLE D.1

Effects of Propagation Actions

\begin{tabular}{|c|c|c|c|c|c|c|}
\hline Subbasin & Description of action & $\begin{array}{l}\text { Subbasin } \\
\text { Plans } \\
\text { Action \# }\end{array}$ & $\begin{array}{l}\text { post-rel } \\
\text { surv }\end{array}$ & $\begin{array}{l}\text { pre-sp } \\
\text { surv }\end{array}$ & $\begin{array}{l}\text { basin } \\
\text { surv }\end{array}$ & $\begin{array}{l}\text { egg-sm } \\
\text { surv }\end{array}$ \\
\hline \multicolumn{7}{|l|}{ HOOD } \\
\hline Spring Chinook & supplement with non-native stock & 1.1 & 1.000 & 1.000 & 1.000 & 1.000 \\
\hline Spring Chinook & supplement with native stock & 2.2 & 1.000 & 1.000 & 1.000 & 1.000 \\
\hline Fall Chinook & install bypass; screen diversions & 1.3 & 1.000 & 1.000 & 1.049 & 1.067 \\
\hline Summer Steelhead & install bypass; screen diversions & 1.5 & 1.000 & 1.000 & 1.022 & 1.020 \\
\hline Summer Steelhead & supplement with non-native stock & 1.1 & 1.000 & 1.000 & 1.000 & 1.000 \\
\hline Summer Steelhead & remove barriers & 2.6 & 1.000 & 1.003 & 1.000 & 1.000 \\
\hline Summer Steelhead & improve habitat & 3.7 & 1.000 & 1.000 & 1.000 & 1.000 \\
\hline WIND & supplement with native stock & 4.2 & 1.000 & 1.000 & 1.000 & 1.000 \\
\hline Spring Chinook & improve habitat & 1.1 & 1.000 & 1.000 & 1.000 & 1.100 \\
\hline Spring Chinook & redesign Trout Creek Dam & 1.2 & 1.000 & 1.022 & 1.022 & 1.000 \\
\hline Spring Chinook & augmentation facility; WRN well & $2.3,2.4$ & 1.000 & 1.000 & 1.000 & 1.000 \\
\hline Spring Chinook & supplementation** & $3.6,3.7,3.8$ & 1.500 & 1.000 & 1.000 & 1.000 \\
\hline Spring Chinook & hatchery production** & 4.9 & 1.000 & 1.000 & 1.000 & 1.000 \\
\hline Spring Chinook & improve habitat & 2.5 & 1.000 & 1.000 & 1.000 & 1.004 \\
\hline Summer Steelhead & improve habitat & 1.1 & 1.000 & 1.000 & 1.000 & 1.100 \\
\hline Summer Steelhead & redesign Trout Creek Dam & 1.2 & 1.000 & 1.022 & 1.022 & 1.000 \\
\hline Summer Steelhead & augmentation facility; WRN well & $2.3,2.4$ & 1.000 & 1.000 & 1.000 & 1.000 \\
\hline Summer Steelhead & supplementation** & $3.6,3.7,3.8$ & 1.119 & 1.000 & 1.000 & 1.000 \\
\hline Summer Steelhead & improve habitat & 2.5 & 1.000 & 1.000 & 1.000 & 1.005 \\
\hline $\begin{array}{l}\text { Summer Steelhead } \\
\text { ENTIAT }\end{array}$ & hatchery production** & $4.9,4.10$ & 1.060 & 1.000 & 1.000 & 1.000 \\
\hline Spring Chinook & screen diversions & 1.1 & 1.000 & 1.000 & 1.130 & 1.000 \\
\hline Spring Chinook & decrease poaching & 1.2 & 1.000 & 1.100 & 1.000 & 1.000 \\
\hline Spring Chinook & passage at Box Canyon & 2.3 & 1.000 & 1.000 & 1.000 & 1.000 \\
\hline Spring Chinook & spawning channel & 2.4 & 1.000 & 1.000 & 1.000 & 1.000 \\
\hline Spring Chinook & supplementation** & 3.5 & 1.000 & 1.000 & 1.000 & 1.000 \\
\hline \multicolumn{7}{|l|}{ METHOW } \\
\hline Spring Chinook & improve habitat & 1.1 & 1.000 & 1.000 & 1.000 & 1.100 \\
\hline Spring Chinook & screen diversions & 1.2 & 1.000 & 1.000 & 1.120 & 1.000 \\
\hline Spring Chinook & water acquisition & 2.3 & 1.000 & 1.000 & 1.000 & 1.000 \\
\hline Spring Chinook & groundwater channels & 2.4 & 1.000 & 1.000 & 1.000 & 1.200 \\
\hline Spring Chinook & supplementation ${ }^{* *}$ & 4.7 & 1.000 & 1.000 & 1.000 & 1.000 \\
\hline Spring Chinook & hatchery improvements & 4.8 & 1.100 & 1.000 & 1.000 & 1.000 \\
\hline Summer Chinook & improve habitat & 1.1 & 1.000 & 1.000 & 1.000 & 1.100 \\
\hline Summer Chinook & screen diversions & 1.2 & 1.000 & 1.000 & 1.120 & 1.000 \\
\hline \multicolumn{7}{|l|}{ OKANOGAN } \\
\hline Summer Chinook & improve habitat & 1.1 & 1.000 & 1.000 & 1.000 & 1.100 \\
\hline Summer Chinook & screen diversions & 1.2 & 1.000 & 1.000 & 1.120 & 1.000 \\
\hline Summer Chinook & water acquisition & 2.3 & 1.000 & 1.000 & 1.000 & 1.000 \\
\hline Summer Chinook & adult passage at Enloe dam & 3.6 & 1.000 & 1.000 & 1.000 & 1.000 \\
\hline \multicolumn{7}{|l|}{ WENATCHEE } \\
\hline Spring Chinook & upstream passage at Dryden dam & 1.1 & 1.000 & 1.020 & 1.000 & 1.000 \\
\hline Spring Chinook & screen diversions & 1.2 & 1.000 & 1.000 & 1.050 & 1.000 \\
\hline Spring Chinook & decrease poaching & 1.3 & 1.000 & 1.030 & 1.000 & 1.000 \\
\hline Spring Chinook & inprove habitat & 2.4 & 1.000 & 1.020 & 1.000 & 1.130 \\
\hline Spring Chinook & improve habitat & 4.5 & 1.000 & 1.000 & 1.000 & 1.000 \\
\hline Spring Chinook & hatchery improvements & 5.7 & 1.400 & 1.000 & 1.000 & 1.000 \\
\hline Summer Chinook & upstream passage at Dryden dam & 1.1 & 1.000 & 1.130 & 1.000 & 1.000 \\
\hline Summer Chinook & screen diversions & 1.2 & 1.000 & 1.000 & 1.200 & 1.000 \\
\hline
\end{tabular}


TABLE D.1

Effects of Propagation Actions

Subbasin

HOOD

Spring Chinook

Spring Chinook

Fall Chinook

Summer Steelhead

Summer Steelhead

Summer Steelhead

Summer Steelhead

WIND

Spring Chinook

Spring Chinook

Spring Chinook

Spring Chinook

Spring Chinook

Spring Chinook

Summer Steelhead

Summer Steelhead

Summer Steelhead

Surnmer Steelhead

Summer Steelhead

Summer Steelhead

ENTIAT

Spring Chinook

Spring Chinook

Spring Chinook

Spring Chinook

Spring Chinook

METHOW

Spring Chinook

Spring Chinook

Spring Chinook

Spring Chinook

Spring Chinook

Spring Chinook

Summer Chinook

Summer Chinook

OKANOGAN

Summer Chinook

Summer Chinook

Summer Chinook

Summer Chinook

WENATCHEE

Spring Chinook

Spring Chinook

Spring Chinook

Spring Chinook

Spring Chinook

Spring Chinook

Summer Chinook

Summer Chinook
Description of action

supplement with non-native stock

supplement with native stock

install bypass; screen diversions

install bypass; screen diversions

supplement with non-native stock

remove barriers

improve habitat

supplement with native stock

improve habitat

redesign Trout Creek Dam

augmentation facility; WRN well

supplementation**

hatchery production**

improve habitat

improve habitat

redesign Trout Creek Dam

augmentation facility; WRN well

supplementation**

improve habitat

hatchery production**

screen diversions

decrease poaching

passage at Box Canyon

spawning channel

supplementation**

improve habitat

screen diversions

water acquisition

groundwater channels

supplementation**

hatchery improvements

improve habitat

screen diversions

improve habitat

screen diversions

water acquisition

adult passage at Enloe dam

upstream passage at Dryden dam

screen diversions

decrease poaching

improve habitat

improve habitat

hatchery improvements

upstream passage at Dryden dam

screen diversions

$\begin{array}{lllll}\text { smolt } & \text { hatch } & \text { hatch } & \text { gen } & \text { gen } \\ \text { cap } & \text { take } & \text { plant } & \text { sens } & \text { risk }\end{array}$

1.000

1.000

1.000

1.000

1.000

1.000

1.024

1.000

1.000

1.000

1.092

1.000

1.000

1.000

1.000

1.000

1.100

1.000

1.000

1.000

1.000

1.000

1.010

1.130

1.000

1.000

1.000

1.050

1.060

1.000

1.000

1.000

1.000

1.000

1.000

1.200

2.040

1.000

1.000

1.000

1.000

1.090

1.000

1.000

1.000

\begin{tabular}{|c|c|c|c|}
\hline \multirow{6}{*}{158} & 275,000 & $a / b$ & high \\
\hline & 275,000 & ah & high \\
\hline & & $a / b$ & low \\
\hline & & $\mathrm{c} / \mathrm{d}$ & low \\
\hline & 90,000 & $\mathrm{c} / \mathrm{d}$ & med \\
\hline & & $\mathrm{c} / \mathrm{d}$ & low \\
\hline \multirow{5}{*}{56} & & $\mathrm{c} / \mathrm{d}$ & low \\
\hline & 90,000 & $\mathrm{c} / \mathrm{d}$ & med \\
\hline & & c/d & low \\
\hline & & $\mathrm{c} / \mathrm{d}$ & low \\
\hline & & $\mathrm{c} / \mathrm{d}$ & low \\
\hline 484 & $1,000,000$ & $\mathrm{c} / \mathrm{d}$ & med \\
\hline \multirow[t]{4}{*}{872} & $1,800,000$ & $\mathrm{c} / \mathrm{d}$ & med \\
\hline & & $\mathrm{c} / \mathrm{d}$ & low \\
\hline & & $\mathrm{c} / \mathrm{d}$ & low \\
\hline & & $\mathrm{c} / \mathrm{d}$ & \\
\hline \multirow{3}{*}{21} & 40000 & cld & \\
\hline & $+4,0 u$ & $\mathrm{c} / \mathrm{d}$ & \\
\hline & 75,000 & $\mathrm{c} / \mathrm{d}$ & med \\
\hline
\end{tabular}

$\rightarrow d d$ low

c/d low

c/d low

c/d low

$90200,000 \mathrm{c} / \mathrm{d}$ med

c/d low

c/d low

c/d low

c/d low

193

$413,813 \mathrm{c} / \mathrm{d}$

c/d

c/d

c/d

c/d

c/d

c/d

c/d

c/d

c/d

$\mathrm{c} / \mathrm{d}$

$\mathrm{c} / \mathrm{d}$

c/d

$\mathrm{c} / \mathrm{d}$

$a / b$

$a / b$

med

low

low

low

low

low

low

low

low

low

low

low

low

low

low

low 
TABLE D.2

Costs of Propagation Actions

\begin{tabular}{|c|c|c|c|c|c|}
\hline Subbasin & Description of action* & $\begin{array}{l}\text { Subbasin } \\
\text { Plans } \\
\text { Action \# }\end{array}$ & $\begin{array}{l}\text { Capital } \\
\text { Cost }\end{array}$ & $\begin{array}{l}\text { \& } M \\
\text { Cost }\end{array}$ & $\begin{array}{l}\text { Annualizex } \\
\text { Cost** }\end{array}$ \\
\hline \multicolumn{2}{|l|}{ GRANDE RONDE } & 1.2 & 0 & 250,000 & 250,000 \\
\hline Spring Chinook & improve habitat & 1.3 & $2,853,600$ & 88,000 & 198,907 \\
\hline Spring Chinook & supplementation $* * *$ & 2.4 & $3,066,667$ & 333,333 & 452,521 \\
\hline Summer Steelhead & improve hatchery effectiveness & 1.2 & 0 & 250,000 & 250,000 \\
\hline Summer Steelhead & improve habitat & 1.3 & $16,186,800$ & 500,000 & $1,129,108$ \\
\hline Summer Steelhead & supplementation $* * *$ & 2.4 & $4,600,000$ & 500,000 & 678,781 \\
\hline \multicolumn{6}{|l|}{ CLEARWATER } \\
\hline Spring Chinook & hatchery production*** & $1.1,1.2$ & 313,056 & 34,028 & 46,195 \\
\hline Spring Chinook & supplementation $* * *$ & 1.6 & 633,880 & 68,900 & 93,536 \\
\hline Spring Chinook & hatchery production*** & $1.12,3.29$ & 265,139 & 28,819 & 39,124 \\
\hline Spring Chinook & supplementation $* * *$ & 1.16 & $1,916,667$ & 208,333 & 282,826 \\
\hline Spring Chinook & improve habitat (also steelhead 1.1) & $2.22,3.28$ & 145,000 & 15,500 & 21,135 \\
\hline Spring Chinook & improve habitat; acquire land & $3.26,3.27$ & $3,357,000$ & 23,000 & 153,471 \\
\hline Spring Chinook & remove barriers & 4.34 & 137,500 & 0 & 5,344 \\
\hline Spring Chinook & supplementation*** & 5.35 & $1,380,000$ & 150,000 & 203,634 \\
\hline Summer Steelhead & improve habitat & $1.1,2.22$ & 145,000 & 15,500 & 21,135 \\
\hline Summer Steelhead & improve habitat; acquire land & 2.20 & $3,357,000$ & 23,000 & 153,471 \\
\hline Summer Steelhead & remove barriers & $2.24,3.28$ & 137,500 & 0 & 5,344 \\
\hline Summer Steelhead & improve hatchery effectiveness & 2.30 & 0 & 250,000 & 250,000 \\
\hline \multicolumn{6}{|l|}{$\begin{array}{l}\text { Summer Steelhead } \\
\text { LOWER SALMON }\end{array}$} \\
\hline Spring Chinook & hatchery production*** & 3.7 & $1,277,778$ & 138,889 & 188,550 \\
\hline Summer Steelhead & hatchery production $* * *$ & 3.5 & $5,980,000$ & 650,000 & 882,416 \\
\hline \multicolumn{6}{|l|}{ LITTLE SALMON } \\
\hline Spring Chinook & enhance habitat; remove barriers & $3.7,3.8$ & $1,585,926$ & 14,212 & 75,850 \\
\hline Spring Chinook & supplementation ${ }^{* * *}$ & 3.9 & $1,277,778$ & 138,889 & 188,550 \\
\hline Summer Steelhead & improve habitat; remove barriers & $3.7,3.8$ & $1,585,926$ & 14,212 & 75,850 \\
\hline Summer Steelhead & supplementation ${ }^{* * *}$ & 3.9 & $3,680,000$ & 400,000 & 543,025 \\
\hline \multicolumn{6}{|c|}{$\begin{array}{l}\text { Summer Steelhead supplementauon } \\
\text { MID MAIN SALMON }\end{array}$} \\
\hline Spring Chinook & hatchery production*** & 2.2 & $1,277,778$ & 138,889 & 188,550 \\
\hline Summer Steelhead & hatchery production $* * *$ & 2.2 & $4,600,000$ & 500,000 & 678,781 \\
\hline \multicolumn{6}{|c|}{$\begin{array}{l}\text { Summer Steelhead hatchery production } \\
\text { MID FORK SALMON }\end{array}$} \\
\hline Spring Chinook & supplementation*** & 2.7 & 638,889 & 69,444 & 94,275 \\
\hline Spring Chinook & supplementation ${ }^{* * *}$ & 3.9 & 638,889 & 69,444 & 94,275 \\
\hline \multicolumn{6}{|l|}{$\begin{array}{l}\text { Spring Chinook } \\
\text { LEMHI }\end{array}$} \\
\hline Spring Chinook & supplementation*** & 3.4 & $1,277,778$ & 138,889 & 188,550 \\
\hline Summer Steelhead & supplementation*** & 3.4 & $4,600,000$ & 500,000 & 678,781 \\
\hline \multicolumn{6}{|l|}{$\begin{array}{l}\text { Summer Steelhead } \\
\text { UPPER SALMON }\end{array}$} \\
\hline Spring Chinook & habitat & 2.9 & 150,374 & 1,900 & 7,744 \\
\hline Spring Chinook & supplemen & $3.11,3.12$ & $3,577,778$ & 388,889 & 527,941 \\
\hline Summer Chinook & hatchery production*** & 3.8 & $1,277,778$ & 138,889 & 188,550 \\
\hline Summe Steelhead & improve habitat & 2.8 & 150,374 & 1,900 & 7,744 \\
\hline Summer Steelhead & hatchery production*** & 3.10 & $11,500,000$ & $1,250,000$ & $1,696,953$ \\
\hline SALMON & & & & & \\
\hline Summer Chinook & improve babitat & 1.1 & $1,017,146$ & 1,330 & 40,862 \\
\hline
\end{tabular}




\section{TABLE D.1 \\ Effects of Propagation Actions}

*Actions are based on "Columbia Basin System Planning Salmon and Steelhead Production Plans (Columbia Basin Fish and Wildlife Authority, 1990).

**A batchery plant is considered "hatchery production" if:

(1) The release is on site,

(2) It appears that the intention of management is for the released fish to return to the hatchery racks. A batchery plant is considered "supplementation" if:

(1) The release is off site, such as from an acclimation pond,

(2) It appears that management's intent is for the released fish to return to natural spawning grounds Parameter definitions:

post-rel surv: post-release survival for hatchery fish

pre-sp surv: pre-spawning survival for adult returns

basin surv: overwintering survival of pre-smolts in the subbasin

egg-sm surv: egg to presmolt survival in the subbasin

smolt cap: smolt capacity of habitst in subbasin

hatch take: number of fish taken for broodstock

hatch plant: number of hatchery fish planted

gen sens: genetic sensitivity of action (see note 4 below)

gen risk: genetic risk of action (see note 4 below)

Notes on Biological Effects:

(1) Biological cffects on survivals and smolt capacity expressed as a multiplier on base parameter values (i.e., $1+$ proportional increase in parameter valuc).

(2) Combinations of actions produce parameter changes that are the product of the individual actions' effects, for parameters post-rel surv, pre-sp surv, basin surv, egg-sm surv, and smolt cap

(3) Combinations of actions produce parameter changes that are the sum of the individual action's effects, for parameters hatch take and hatch plant

(4) Calculation of Genetic Risk

Genetic sensitivity taken from Table 61 (CBFWA, 1991b) and SPM data 1990.

gen risk $=$ low if hatch plant $=0$, or if hatch plant $>0$ and gen sens $=\mathrm{e} / \mathrm{f}$

gen risk $=$ med if hatch plant $>0$ and gen sens $=\mathrm{c} / \mathrm{d}$

gen risk $=$ high if hatch plant $>0$ and gen sens $=a / b$

(5) Hatchery take is calculated as the number of fish needed to provide broodstock for plant, (i.e., Hatchery take $=$ Hatchery plant $/$ (fraction female $*$ eggs per female $*$ egg-smolt survival), where these parameters are specific for the hatchery stock) 
TABLE D.2

Costs of Propagation Actions

\begin{tabular}{|c|c|c|c|c|c|}
\hline Subbasin & Description of action* & $\begin{array}{l}\text { Subbasin } \\
\text { Plans } \\
\text { Action \# }\end{array}$ & $\begin{array}{l}\text { Capital } \\
\text { Cost }\end{array}$ & $\begin{array}{l}O \& M \\
\text { Cost }\end{array}$ & $\begin{array}{l}\text { Annualizec } \\
\text { Cost** }\end{array}$ \\
\hline Summer Chinook & hatchery production*** & 3.7 & $1,277,778$ & 138,889 & 188,550 \\
\hline Summer Steclhead & improve habitat & 1.1 & $1,017,146$ & 1,330 & 40,862 \\
\hline $\begin{array}{l}\text { Summer Steelhcad } \\
\text { PANTHER CREEK }\end{array}$ & hatchery production ${ }^{* * *}$ & 3.4 & $2,300,000$ & 250,000 & 339,391 \\
\hline Summer Chinook & supplementation*** & 2.3 & $1,277,778$ & 138,889 & 188,550 \\
\hline Summer Chinook & trap and haul program & 3.4 & 101,500 & 31,900 & 35,845 \\
\hline Summer Chinook & design/implement restoration & 4.5 & $6,000,000$ & 200,000 & 433,$1 ; 3$ \\
\hline Summer Steelhead & hatchery production*** & 2.3 & $3,220,000$ & 350,000 & 475,147 \\
\hline Summer Steelhead & trap and haul program & 3.5 & 121,500 & 31,900 & 36,622 \\
\hline $\begin{array}{l}\text { Summer Steelhead } \\
\text { PAHSIMEROI }\end{array}$ & design/implement restoration & 4.6 & $6,000,000$ & 200,000 & 433,193 \\
\hline Summer Chinook & hatchery production*** & 3.6 & $1,277,778$ & 138,889 & 188,550 \\
\hline $\begin{array}{l}\text { Summer Steelhead } \\
\text { TUCANNON }\end{array}$ & hatchery production*** & 3.6 & $3,220,000$ & 350,000 & 475,147 \\
\hline $\begin{array}{l}\text { TUCANNON } \\
\text { Spring Chinook }\end{array}$ & improve habitat & 1.1 & 131,300 & 17,160 & 22,263 \\
\hline Spring Chinook & improve passage at Starbuck & 1.2 & 250,000 & 10,000 & 19,716 \\
\hline Summer Steelhead & improve habitat & $1.2,1.3,1.4$ & 131,300 & 17,160 & 22,263 \\
\hline Summer Steelhead & improve habitat & $2.5,2.6$ & 149,051 & 10,855 & 16,648 \\
\hline $\begin{array}{l}\text { Summer Steelhead } \\
\text { IMNAHA }\end{array}$ & trap natural broodstock & 3.7 & 20,000 & 10,000 & 10,777 \\
\hline Spring Chinook & supplementation $* * *$ & 3.2 & $1,582,400$ & 172,000 & 233,501 \\
\hline Spring Chinook & supplementation*** & 3.2 & $2,235,600$ & 243,000 & 329,888 \\
\hline DESCHUTES & & & & & \\
\hline Spring Chinook & improve habitat & $1.1,1.2$ & $1,864,000$ & 30,400 & 102,845 \\
\hline Spring Chinook & provide passage at $W$. River Falls & 2.3 & $2,984,000$ & 62,700 & 178,675 \\
\hline Spring Chinook & atchery production $* * *$ & 1.4 & 805,000 & 87,500 & 118,787 \\
\hline Spring Chinook & hatchery production*** & 1.5 & 0 & 125,000 & 125,000 \\
\hline Spring Chinook & & & & & \\
\hline Fall Chinonk & mprove habitat--part 1 & $1.1,1.4$ & 70,500 & 26,600 & 29,340 \\
\hline Fall Chinook & improve habitat--part 2 & $2.2,1.4$ & 239,500 & 41,800 & 51,108 \\
\hline Fall Chinook & improve habitat--part 3 & $3.3,1.4$ & 408,500 & 57,000 & 72,877 \\
\hline Summer Steelhead & improve habitat & $1.4,1.5$ & $1,864,000$ & 30,400 & 102,845 \\
\hline Summer Steelhead & provide passage at W. River Falls & 3.6 & $2,984,000$ & 62,700 & 178,675 \\
\hline Summer Steelhead & improve habitat & $2.2,2.3$ & $1,202,000$ & 38,000 & 84,716 \\
\hline $\begin{array}{l}\text { Summer Steelhead } \\
\text { WALLA WALLA }\end{array}$ & hatchery production $* * *$ & 5.7 & 460,000 & 50,000 & 67,878 \\
\hline Spring Chinook & supplementation***; improve passage & I.A & $1,475,000$ & 339,000 & 396,327 \\
\hline Spring Chinook & supplementation ${ }^{* * *}$; improve habitat & I.B & $3,910,000$ & 100,300 & 252,264 \\
\hline Spring Chinook & supplementation $* * *$ & III.B & 0 & 35,000 & 35,000 \\
\hline Spring Chinook & supplementation ${ }^{* * *}$; cnhance flow & II.B & $200,600,000$ & 235,000 & $8,031,418$ \\
\hline Spring Chinook & pplementation $* * *$ & III.C & $2,500,000$ & 175,000 & 272,164 \\
\hline Summer Steelhead & improve adult and juvenile passage & I.A & $1,475,000$ & 294,000 & 351,327 \\
\hline Summer Steelhead & improve habitat & I.B & $3,910,000$ & 65,300 & 217,264 \\
\hline Summer Steelhead & enhance flows & II.B & $200,600,000$ & 200,000 & $7,996,418$ \\
\hline Summer Steelhead & supplementation $* * *$ & III.C & 833,333 & 41,667 & 74,055 \\
\hline
\end{tabular}


TABLE D.2

\section{Costs of Propagation Actions}

Subbasin

UMATILLA

Spring Chinook

Spring Chinook

Spring Chinook

Spring Chinook

Spring Chinook

Fall Chinook

Fall Chinook

Fall Chinook

Fall Chinook

Fall Chinook

Summer Steelhead

Summer Steelhead

Summer Steelhuad

Summer Steelhead

JOHN DAY

Spring Chinook

Spring Chinook

Spring Chinook

Summer Steelhead

Summer Steelhead

L. WHITE SALMON

Spring Chinook

Spring Chinook

Fall Chinook

Fall Chinook

WHITE SALMON

Spring Chinook

Spring Chinook

Spring Chinook

Spring Chinook

Spring Chinook

Spring Chinook

Summer Steelhead

Summer Steelhead

Summer Steelhead

KLICKITAT

Spring Chinook

Spring Chinook

Spring Chinook

Spring Chinook

Summer Steelhead

Summer Stcelhead

Summer Steelhead

Summer Steelhead
Description of action*

improve adult and juvenile passage

improve habitat

enhance flow

supplementation***

provide headwater storage

improve adult and juvenile passage

improve habitat

enhance flow

provide headwater storage

improve adult and juvenile passage

improve habitat

enhance flow

provide headwater storage

improve habitat

screen diversions

improve habitat

provide adult passage

supplementation***

hatchery production***

supplementation***

hatchery production***

remove barrier at Condit dam

remove barrier; screen diversions

remove barriers at Condit and RM16.3

screen diversions; remove barriers

supplementation***

hatchery production**:

enhance habitat

supplementation***

hatchery production*** using net pens 3.4

remove barrier at Castile Falls

2.3

redesign ladder at Klickitat Hatchery

improve habitat

supplementation***

improve habitat

remove barrier at Castile. Falls

remove barrier at W. Fork Falls

remove barrier at L. Klickitat Falls

I.A

II.B

1.1

2.2

2.2

1.1

3.6

4.7

1.1

2.3

1.2

$\begin{array}{ll}\text { Subbasin } & \text { Capital } \\ \text { Plans } & \text { Cost } \\ \text { Action \# } & \end{array}$

O \& M

Cost

Annualizec

Action \#

$\begin{array}{lrrr}\text { I.A } & 9,337,000 & 806,500 & 1,169,387 \\ \text { I.B } & 7,230,000 & 138,000 & 418,998 \\ \text { II.A } & 43,050,000 & 750,000 & 2,423,160 \\ \text { III.B } & 3,000,000 & 210,000 & 326,596 \\ \text { II.B } & 78,200,000 & 66,000 & 3,105,282 \\ \text { I.A } & 9,337,000 & 806,500 & 1,169,387 \\ \text { I.B } & 7,230,000 & 138,000 & 418,998 \\ \text { II.A } & 43,050,000 & 750,000 & 2,423,160 \\ \text { II.B } & 78,200,000 & 66,000 & 3,105,282\end{array}$

$9,337,000$

$806,500 \quad 1,169,387$

I.B $\quad 7,230,000$

II.A

$43,050,000$

$138,000 \quad 418,998$

$78,200,000$

$750,000 \quad 2,423,160$

$66,000 \quad 3,105,282$

$\begin{array}{llll}1.1,1.2,2.3 & 13,416,854 & 217,170 & 738,623\end{array}$

$\begin{array}{llll}1.5 & 295,480 & 13,875 & 25,359\end{array}$

$13,416,854$

217,170

738,623

$1,180,000$

15,000

60,861

$1.1 \quad 29,900$

$1,518,000$
8,625
828,000

3,250

4,412

165,000

223,998

938

1,273

90,000

122,181

1.1, $1.3 \quad 7,000,000$

$1.2,1.1,1.3 \quad 7,250,000$

50,000

322,058

75,000

356,775

70,000

380,924

$1.1,2,3 ; 2.4, \quad 8,500,000$

115,000

460,000

120,000

450,357

12,500

16,970

67,878

30,000

324,200

50,000

30,000

33,500

46,100

124,200

13,500

18,327

760,000

8,000

37,538

50,297

1,955

$3.5,3.6$

$3.4,3.5$
$7,074,200$

$5,520,000$

107,420

$7,074,200$

760,000

180,000

160,000

382,362

814,538

382,362

$\begin{array}{rr}8,000 & 37,538 \\ 2,400 & 9,396\end{array}$

2.3

2.3

2,400

8,618 
TABLE D.2

Costs of Propagation Actions

Subbasin
HOOD
Spring Chinook
Spring Chinook
Fall Chinook
Summer Steelhead
Summer Steelhead
Summer Steelhead
Summer Steelhead
WIND
Spring Chinook
Spring Chinook
Spring Chinook
Spring Chinook
Spring Chinook
Spring Chinook
Summer Steelhead
Summer Steelhead
Summer Steelhead
Summer Steelhead
Summer Steelhead
Summer Steelhead
ENTIAT
Spring Chinook
Spring Chinook
Spring Chinook
Spring Chinook
Spring Chinook
METHOW
Spring Chinook
Spring Chinook
Spring Chinook
Spring Chinook
Spring Chinook
Spring Chinook
Summer Chinook
Summer Chinook
OKANOGAN
Summer Chinook
Summer Chinook
Summer Chinook
Summer Chinook

Description of action*

supplement with non-native stock supplement with native stock install bypass; screen diversions

install bypass; screen diversions supplement with non-native stock remove barriers

improve habitat

supplement with native stock

improve habitat

redesign Trout Creek Dam

augmentation facility; WRN well

supplementation***

hatchery production***

improve habitat

improve habitat

redesign Trout Creek Dam

augmentation facility; WRN well

supplementation***

improve habitat

hatchery production***

screen diversions

decrease poaching

passage at Box Canyon

spawning channel

supplementation***

improve habitat

screen diversions

water acquisition

groundwater channels

supplementation***

hatchery improvements

improve habitat

screen diversions

improve habitat

screen diversions

water acquisition

adult passage at Enloe dam

$\begin{array}{llll}\text { Subbasin } & \begin{array}{l}\text { Capital } \\ \text { Cost }\end{array} & \begin{array}{l}\text { O \& M } \\ \text { Cost }\end{array} & \begin{array}{l}\text { Annualizec } \\ \text { Cost** }\end{array} \\ \text { Action \# } & & & \end{array}$

1.1

2.2

690,000

75,000

101,817

1.3

690,000

525,000

525,000

460,000

160,000

625,356

460,000

4.2

1.1

0

350,000

1.2

$2.3,2.4$

$10,300,000$

3.6, 3.7, $3.8 \quad 4,300,000$

4.9

$4,140,000$

2.5

10,000

1.1

1.2

$2.3,2.4$

$3.6,3.7,3.8$

2.5

$4.9,4.10$

0
350,000

$10,300,000$

496,000

10,000

207,000

75,000

48,926

48,926

50,000

101,817

69,330

69,330

67,878

61,186

6,218

50,000

85,491

67,878

30,000

30,000

5,000

18,603

120,000

260,000

450,000

2,000

30,000

5,000

120,000

30,000

2,000

22,500

520,315

427,122

610,903

2,389

30,000

18,603

520,315

49,277

2,389

30,545

1.1

75,000

15,000

19,307

1.2

40,000

$1,500,000$

300,000

46,000

3.5

20,000

30,000

1,266

78,298

55,130

5,000

6,788
1.1

1.2

40,000

$536,4 i 0$

$1,782,500$

300,000

$3,310,504$

2.4

4.7

4.8

1.1

1.2

40,000

536,470

1.1

40,000

536,470

$2,800,000$

160,000

$$
\begin{array}{rr}
0 & 1,266 \\
0 & 30,808 \\
50,000 & 119,278 \\
10,000 & 21,660 \\
206,907 & 335,571 \\
200,000 & 200,000 \\
0 & 1,266 \\
0 & 30,808
\end{array}
$$

2.3

3.6

$\begin{array}{rr}0 & 4,689 \\ 0 & 30,808 \\ 180,000 & 293,570 \\ 0 & 5,063\end{array}$


TABLE D.2

Costs of Propagation Actions

\begin{tabular}{|c|c|}
\hline Subbasin & Description of action* \\
\hline \multicolumn{2}{|l|}{ WENATCHEE } \\
\hline Spring Chinook & upstream passage at Dryden dam \\
\hline Spring Chinook & screen diversions \\
\hline Spring Chinook & decrease poaching \\
\hline Spring Chinook & improve habitat \\
\hline Spring Chinook & improve habitat \\
\hline Spring Chinook & hatchery improvements \\
\hline Summer Chinook & upstream passage at Dryden dam \\
\hline Summer Chinook & screen diversions \\
\hline
\end{tabular}

$\begin{array}{llll}\begin{array}{l}\text { Subbasin } \\ \text { Plans }\end{array} & \begin{array}{l}\text { Capital } \\ \text { Cost }\end{array} & \begin{array}{l}\text { O \& M } \\ \text { Cost }\end{array} & \begin{array}{l}\text { Annualizec } \\ \text { Cost** }\end{array} \\ \text { Action \# } & & & \end{array}$

$\begin{array}{rrrr}1.1 & 1,000,000 & 50,000 & 107,428 \\ 1.2 & 100,000 & 20,000 & 25,743 \\ 1.3 & 50,000 & 50,000 & 51,943 \\ 2.4 & 904,800 & 90,480 & 196,550 \\ 4.5 & 5,000,000 & 50,000 & 244,327 \\ 5.7 & 0 & 200,000 & 200,000 \\ 1.1 & 1,000,000 & 50,000 & 107,428 \\ 1.2 & 100,000 & 20,000 & 25,743\end{array}$

*Actions are based on "Columbia Basin System Planning Salmon and Steelhead Produc 'on Plans (Columbia Basin Fish and Wildlife Authority, 1990).

**Costs are annualized at $3 \%$.

***A hatchery plant is considered "hatchery production" if:

(1) The release is on site,

(2) It appears that the intention of management is for the released fish to return to the hatchery racks.

A hatchery plant is considered "supplementation" if:

(1) The release is off site, such as from an acclimation pond,

(2) It appears that the intention of management is for the released fish to return to natural spawning grounds 
TABLE E.1

Selected Passage Model (CRiSP.0) Parameters

$\begin{array}{ccccc} & \text { project or } & \text { transport travel travel fracmort } \\ \text { specles } & \text { pool } & \text { fge-culib. fge-base } & \text { survival X1 cosff. XO coeff. }\end{array}$
(1)
(2)
(3)
(4)
(5)
(6)

\begin{tabular}{|c|c|c|c|c|c|c|c|}
\hline \multirow[t]{16}{*}{ Yearling (\#) } & Wells & 0.80 & 0.80 & & 0.3169 & 0.7359 & 0.0350 \\
\hline & Rocky Reach & 0.00 & 0.70 & & 0.2970 & 1.0238 & 0.0350 \\
\hline & Rock Island & 0.00 & 0.70 & & 0.5390 & 2.2620 & 0.0350 \\
\hline & Wanapum & 0.00 & 0.70 & & 0.1990 & 0.6040 & 0.0350 \\
\hline & Priest Rapids & 0.00 & 0.72 & & 0.4040 & 0.9160 & 0.0350 \\
\hline & N. Confluence & & & & 0.5000 & 0.5390 & 0.0350 \\
\hline & L. Granite & 0.77 & 0.88 & 0.573 & 0.1310 & 1.1180 & \\
\hline & L. Goose & 0.77 & 0.88 & 0.573 & 0.2060 & 1.7600 & \\
\hline & L. Monumental & 0.02 & 0.73 & & 0.2350 & 2.1700 & \\
\hline & Ice Harbor & 0.51 & 0.78 & & 0.2830 & 1.1190 & \\
\hline & S. Confluence & & & & 0.2400 & 0.5370 & \\
\hline & McNary & 0.75 & 0.90 & 0.534 & 0.0900 & 1.5250 & \\
\hline & John Day & 0.72 & 0.72 & & 0.0500 & 1.0380 & \\
\hline & The Dalles & 0.40 & 0.63 & & 0.2770 & 5.6070 & \\
\hline & Bonneville 1 & 0.76 & 0.76 & & 0.1770 & 6.3940 & \\
\hline & Bonneville 2 & 0.19 & 0.65 & & & & \\
\hline \multirow[t]{16}{*}{ Subyearling (+) } & Wells & 0.70 & 0.70 & & 0.3169 & 0.7359 & 0.0350 \\
\hline & Rocky Reach & 0.00 & 0.50 & & 0.2970 & 1.0238 & 0.0350 \\
\hline & Rock Island & 0.00 & 0.50 & & 0.5390 & 2.2620 & 0.0350 \\
\hline & Wanapum & 0.00 & 0.50 & & 0.1990 & 0.6040 & 0.0350 \\
\hline & Priest Rapids & 0.00 & 0.50 & & 0.4040 & 0.9160 & 0.0350 \\
\hline & N. Confluence & & & & 0.5000 & 0.5390 & 0.0350 \\
\hline & L. Granite & 0.48 & 0.60 & 0.421 & 0.0000 & 5.6200 & 0.0226 \\
\hline & L. Goose & 0.48 & 0.60 & 0.421 & 0.0000 & 5.6200 & 0.0226 \\
\hline & L. Monumental & 0.02 & 0.35 & & 0.0000 & 5.6200 & 0.0226 \\
\hline & Ice Harbor & 0.51 & 0.35 & & 0.0000 & 5.6200 & 0.0226 \\
\hline & S. Confluence & & & & 0.0000 & 5.6200 & 0.0226 \\
\hline & McNary & 0.40 & 0.60 & 0.421 & 0.0000 & 5.6200 & 0.0226 \\
\hline & John Day & 0.30 & 0.30 & & 0.0000 & 5.6200 & 0.0226 \\
\hline & The Dalles & 0.40 & 0.38 & & 0.0000 & 5.6200 & 0.0226 \\
\hline & Bonneville 1 & 0.30 & 0.30 & & 0.0000 & 5.6200 & 0.0226 \\
\hline & Bonneville 2 & 0.24 & 0.24 & & & & \\
\hline \multirow[t]{10}{*}{ Steelhead } & L. Granite & 0.79 & 0.88 & 0.800 & 0.1310 & 1.1180 & \\
\hline & L. Goose & 0.79 & 0.88 & 0.800 & 0.2060 & 1.7600 & \\
\hline & L. Monumental & 0.04 & 0.74 & & 0.2350 & 2.1700 & \\
\hline & Ice Harbor & 0.51 & 0.92 & & 0.2830 & 1.1190 & \\
\hline & S. Confluence & & & & 0.2400 & 0.5370 & \\
\hline & McNary & 0.75 & 0.90 & 0.750 & 0.0900 & 1.5250 & \\
\hline & John Day & 0.86 & 0.86 & & 0.0500 & 1.0380 & \\
\hline & The Dalles & 0.40 & 0.70 & & 0.2770 & 5.6070 & \\
\hline & Bonneville 1 & 0.78 & 0.78 & & 0.1770 & 6.3940 & \\
\hline & Bonneville 2 & 0.35 & 0.50 & & & & \\
\hline
\end{tabular}


TABLE E.1

Selected Passage Model (CRiSP.0) Parameters

$\begin{array}{cccccc} & \text { project or } & \text { mort } & \text { mort } & \text { mort } \\ \text { species } & \text { pool } & \mathbf{X} 2 \text { coeff. } & \mathbf{X} 1 \text { coeff. } & \mathbf{X 0} \text { coeff. cutof } \\ & & (7) & (8) & (9) & (10)\end{array}$

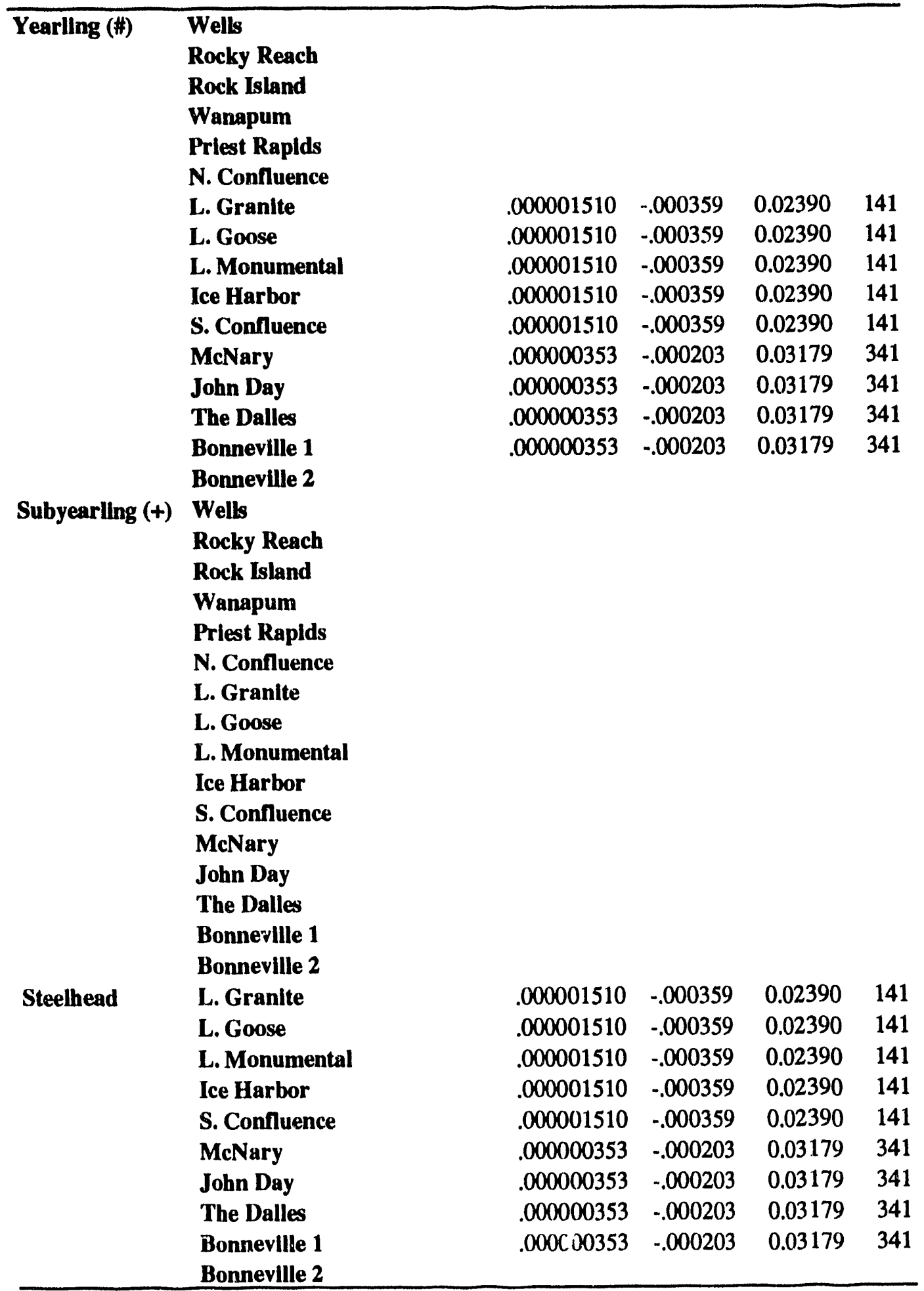


TABLE E.1

Selected Passage Model (CRiSP.0) Parameters

\section{NOTES AND SOURCES OF DATA:}

* see CRiSP.0 documentation for explanation of terms (Hinrichsen, et. al, 1991)

(\#) spring chinook and Snake River summer chinook

(+) fall chinook and Columbia River summer chinook

(1) fish guidance efficiency, calibration case (Sherer and Fisher, 1991)

(2) fish guidance efficiency, all other alternatives (Sherer and Fisher, 1991)

(3) transportation survival (Sherer and Fisher, 1991)

(4) X1 coefficient of travel time relationship, with Snake subyearling at $5 \mathrm{~km} / \mathrm{day}$ (Sherer and Fisher, 1991)

(5) X0 coefficient of travel time relationship, with Snake subyearling at $5 \mathrm{~km} /$ day (Sherer and Fisher, 1991)

(6) fraction mortality per day for constant mortality relationship (Sherer and Fisher, 1991)

(7) X2 coefficient of reservoir mortality relationship (Sherer and Fisher, 1991)

(8) X1 coefficient of reservoir mortality relationship (Sherer and Fisher, 1991)

(9) X0 coefficient of reservoir mortality relationship (Sherer and Fisher, 1991)

10) cutoîi value (kcfs) above which reservoir survival is constant (Sherer and Fisher, 1991) 
TABLE E.2

Entry of Smolts to Mainstem

\begin{tabular}{|c|c|c|c|c|c|c|c|c|c|c|c|c|}
\hline \multirow[b]{2}{*}{ Subbasin } & \multirow[b]{2}{*}{ Stock** } & \multicolumn{11}{|c|}{ Day* } \\
\hline & & Miles*** & 1 & 2 & 3 & 4 & 5 & 6 & 7 & 8 & 9 & 10 \\
\hline \multirow[t]{2}{*}{ Grande Ronde } & $\mathrm{SprCh}$ & 115 & & & & & & 114.7 & & & & \\
\hline & Sthd & 115 & & & & & & & & & & \\
\hline \multirow[t]{2}{*}{ Clearwater } & $\mathrm{Spr} \mathrm{Ch}$ & 115 & 0.7 & 0.7 & 0.7 & 0.7 & 0.7 & 0.7 & 0.7 & 0.7 & 0.7 & 0.7 \\
\hline & Sthd & 115 & & & & & & & & & & \\
\hline \multirow[t]{2}{*}{ Lower Salmon } & $\mathrm{Spr} \mathrm{Ch}$ & 115 & & & & & & & 1.7 & & 5.2 & 1.7 \\
\hline & Sthd & 115 & & & & & & & & & & \\
\hline \multirow[t]{2}{*}{ Little Salmon } & $\mathrm{Spr} \mathrm{Cb}$ & 115 & & & & & & & 1.7 & & 5.2 & 1.7 \\
\hline & Sthd & 115 & & & & & & & & & & \\
\hline \multirow[t]{2}{*}{ Mid Main Salmon } & $\mathrm{Spr} \mathrm{Ch}$ & 115 & & & & & & & 1.7 & & 5.2 & 1.7 \\
\hline & Sthd & 115 & & & & & & & & & & \\
\hline Mid Fork Salmon & Spr Ch & 115 & & & & & & & 1.7 & & 5.2 & 1.7 \\
\hline \multirow[t]{2}{*}{ Lemhi } & $\mathrm{Spr} C h$ & 115 & & & & & & & 1.7 & & 5.2 & 1.7 \\
\hline & Sthd & 115 & & & & & & & & & & \\
\hline \multirow[t]{3}{*}{ Upper Salmon } & $\mathrm{Spr} \mathrm{Ch}$ & 115 & & & & & & & 1.7 & & 5.2 & 1.7 \\
\hline & Sum $\mathrm{Ch}$ & 115 & & & & 2.2 & 0.6 & & 0.6 & 0.6 & 0.6 & \\
\hline & Sthd & 115 & & & & & 70.5 & 70.5 & 70.5 & 70.5 & 70.5 & 70.5 \\
\hline \multirow[t]{2}{*}{ S. Fork Salmon } & Sum $\mathrm{Ch}$ & 115 & & & & 2.2 & 0.6 & & 0.6 & 0.6 & 0.6 & \\
\hline & Sthd & 115 & & & & & & & & & & \\
\hline \multirow[t]{2}{*}{ Panther Creek } & Sum $\mathrm{Ch}$ & 115 & & & & 2.2 & 0.6 & & 0.6 & 0.6 & 0.6 & \\
\hline & Sthd & 115 & & & & & & & & & & \\
\hline \multirow{2}{*}{ Pahsimeroi } & Sum $\mathrm{Ch}$ & 115 & & & & 2.2 & 0.6 & & 0.6 & 0.6 & 0.6 & \\
\hline & Sthd & 115 & & & & & & & & & & \\
\hline \multirow[t]{2}{*}{ Tucannon } & $\mathrm{Spr} \mathrm{Ch}$ & 40 & & & & & & & & & & \\
\hline & Sthd & 40 & & & & & & & & & & \\
\hline Imnaha & $\mathrm{Spr} \mathrm{Ch}$ & 115 & 124.9 & 124.9 & & & & & & & & \\
\hline \multirow[t]{3}{*}{ Deschutes } & $\mathrm{Spr} \mathrm{Ch}$ & 30 & & & & & & & & & & \\
\hline & Fall $\mathrm{Ch}$ & 30 & & & & & & & & & & \\
\hline & Sthd & 30 & & & & & & & & & & \\
\hline \multirow[t]{2}{*}{ Walla Walla } & Spr Ch & 42 & & & & & & & & & & \\
\hline & Sthd & 42 & & & & & & & & & & \\
\hline Umatilla & Spr Ch & 121 & 996 & & & & & & & & & \\
\hline & Fall Ch & 121 & & & & & & & & & & \\
\hline & Sthd & 121 & & & & & & & & & & 4 \\
\hline John Day & $\mathrm{Spr} C h$ & 20 & 50 & & & & & & & & & \\
\hline & Sthd & 20 & & & & & & & & & & \\
\hline L. White Salmon & Spr Ch & 34 & & & & & & & & & & \\
\hline & Fall $\mathrm{Ch}$ & 34 & & & & & & & & & & \\
\hline White Salmon & $\mathrm{Spr} \mathrm{Ch}$ & 42 & & & & & & & & & & \\
\hline & Sthd & 42 & & & & & & & & & & \\
\hline Klickitat & $\mathrm{Spr} \mathrm{Ch}$ & 68 & & & & & & & & & & \\
\hline & Sthd & 68 & & & & & & & . & & & 3 \\
\hline Hood & Spr Ch & 40 & & & & & & & & & & \\
\hline & Fall $\mathrm{Ch}$ & 40 & & & & & & & 5046 & & & \\
\hline & Sthd & 40 & & & & & & & & & & \\
\hline Wind & Spr Ch & 25 & & & & & & & & & & \\
\hline & Sthd & 25 & & & & & & & & & & 2 \\
\hline Entiat & Spr Ch & 27 & 30 & & & & & & & & & \\
\hline Methow & $\mathrm{Spr} \mathrm{Ch}$ & 10 & & & & & & & & & & \\
\hline & Sum $\mathrm{Ch}$ & 10 & & & & & & & & & & \\
\hline Okanogan & Sum $\mathrm{Ch}$ & 10 & & & & & & & & & & \\
\hline Wenatchee & $\mathrm{Spr} C \mathrm{~h}$ & 32 & & & & & & & & & & \\
\hline & Sum $\mathrm{Ch}$ & 32 & & & & & & & & & & \\
\hline
\end{tabular}


TABLE E.2

(continued)

\begin{tabular}{|c|c|c|c|c|c|c|c|c|c|c|c|c|c|}
\hline \multirow[b]{2}{*}{ Subbasin } & \multicolumn{13}{|c|}{ Day* } \\
\hline & Stock** & 11 & 12 & 13 & 14 & 15 & 16 & 17 & 18 & 19 & 20 & 21 & 22 \\
\hline Grande Ronde & $\begin{array}{l}\text { Spr Ch } \\
\text { Sthd }\end{array}$ & & & & & & & & 8.3 & 8.3 & 8.3 & 8.3 & 8.3 \\
\hline Clearwater & Spr Ch & 0.7 & 0.7 & 0.7 & 0.7 & 0.7 & 0.7 & 0.7 & & & & & \\
\hline & Sthd & & & & & & 24.9 & 24.9 & 24.9 & 24.9 & 24.9 & 24.9 & 24.9 \\
\hline Lower Salmon & $\begin{array}{l}\text { Spr Ch } \\
\text { Sthd }\end{array}$ & & & & & 1.7 & 1.7 & 1.7 & 3.5 & 1.7 & & 3.5 & 5.2 \\
\hline Little Salmon & $\begin{array}{l}\text { Spr Ch } \\
\text { Sind }\end{array}$ & & & & & 1.7 & 1.7 & 1.7 & 3.5 & 1.7 & & 3.5 & 5.2 \\
\hline Mid Main Salmon & $\begin{array}{l}\text { Spr Ch } \\
\text { Sind }\end{array}$ & & & & & 1.7 & 1.7 & 1.7 & 3.5 & 1.7 & & 3.5 & 5.2 \\
\hline Mid Fork Salmon & $\mathrm{SprCh}$ & & & & & 1.7 & 1.7 & 1.7 & 3.5 & 1.7 & & 3.5 & 5.2 \\
\hline Lemhi & $\begin{array}{l}\text { Spr Ch } \\
\text { Sthd }\end{array}$ & & & & & 1.7 & 1.7 & 1.7 & 3.5 & 1.7 & & 3.5 & 5.2 \\
\hline Upper Salmon & $\mathrm{Spr} \mathrm{Ch}$ & & & & & 1.7 & 1.7 & 1.7 & 3.5 & 1.7 & & 3.5 & 5.2 \\
\hline & Sum Ch & 0.6 & 2.2 & 1.1 & 1.7 & 1.1 & 3.9 & 3.3 & 1.1 & 2.8 & 8.3 & 8.9 & 7.8 \\
\hline & Sthd & 70.5 & 70.5 & 70.5 & 70.5 & 70.5 & 70.5 & 70.5 & 70.5 & 70.5 & 70.5 & 70.5 & \\
\hline S. Fork Salmon & $\begin{array}{l}\text { Sum Ch } \\
\text { Sthd }\end{array}$ & 0.6 & 2.2 & 1.1 & 1.7 & 1.1 & 3.9 & 3.3 & 1.1 & 2.8 & 8.3 & 8.9 & 7.8 \\
\hline Panther Creek & $\begin{array}{l}\text { Sum Ch } \\
\text { Sthd }\end{array}$ & 0.6 & 2.2 & 1.1 & 1.7 & 1.1 & 3.9 & 3.3 & 1.1 & 2.8 & 8.3 & 8.9 & 7.8 \\
\hline Pahsimeroi & $\begin{array}{l}\text { Sum Ch } \\
\text { Sthd }\end{array}$ & 0.6 & 2.2 & 1.1 & 1.7 & 1.1 & 3.9 & 3.3 & 1.1 & 2.8 & 8.3 & 8.9 & 7.8 \\
\hline Tucannon & $\begin{array}{l}\text { Spr Ch } \\
\text { Sthd }\end{array}$ & & & & & 5 & & & & & 5 & & \\
\hline Imnaha & Spr Ch & & & & & & & & & & & & \\
\hline Deschutes & $\begin{array}{l}\text { Spr Ch } \\
\text { Fall Ch } \\
\text { Sthd }\end{array}$ & & & & & & & & & & & & \\
\hline Walla Walla & $\begin{array}{l}\text { Spr Ch } \\
\text { Suhd }\end{array}$ & 6 & & & & & & & 6 & & 9 & & \\
\hline Umatilla & $\begin{array}{l}\text { Spr Ch } \\
\text { Fall Ch } \\
\text { Sthd }\end{array}$ & 100 & 90 & & & & & & 100 & & 100 & & \\
\hline John Day & $\begin{array}{l}\text { Spr Ch } \\
\text { Sthd }\end{array}$ & & & & & 50 & & & & & & & \\
\hline L. White Salmon & $\begin{array}{l}\text { Spr Ch } \\
\text { Fall } \mathrm{Ch}\end{array}$ & & & & & 517 & & & & & & & \\
\hline White Salmon & $\begin{array}{l}\text { Spr Ch } \\
\text { Sthd }\end{array}$ & 336 & & & & & & & & & & & \\
\hline Klickitat & Spr Ch & & & & & & & & & & & & \\
\hline Hood & $\begin{array}{l}\text { Sthd } \\
\text { Spr Ch } \\
\text { Fall Ch } \\
\text { Sthd }\end{array}$ & & & & & & & & & & 6 & & \\
\hline Wind & Spr Ch & & & & & & & & & & & & \\
\hline Entiat & $\begin{array}{l}\text { Sthd } \\
\text { Spr Ch }\end{array}$ & & & & & & & & & & $\begin{array}{r}2 \\
45\end{array}$ & & \\
\hline Methow & $\begin{array}{l}\text { Spr Ch } \\
\text { Sum Ch }\end{array}$ & & & & & 1 & 2 & 2 & 6 & 11 & 21 & 33 & 47 \\
\hline Okanogan & Sum Ch & & & & & & & & & & & & \\
\hline Wenatchee & $\begin{array}{l}\text { Spr Ch } \\
\text { Sum Ch }\end{array}$ & & & & & 211 & & & & & & & \\
\hline
\end{tabular}


TABLE E.2

(continued)

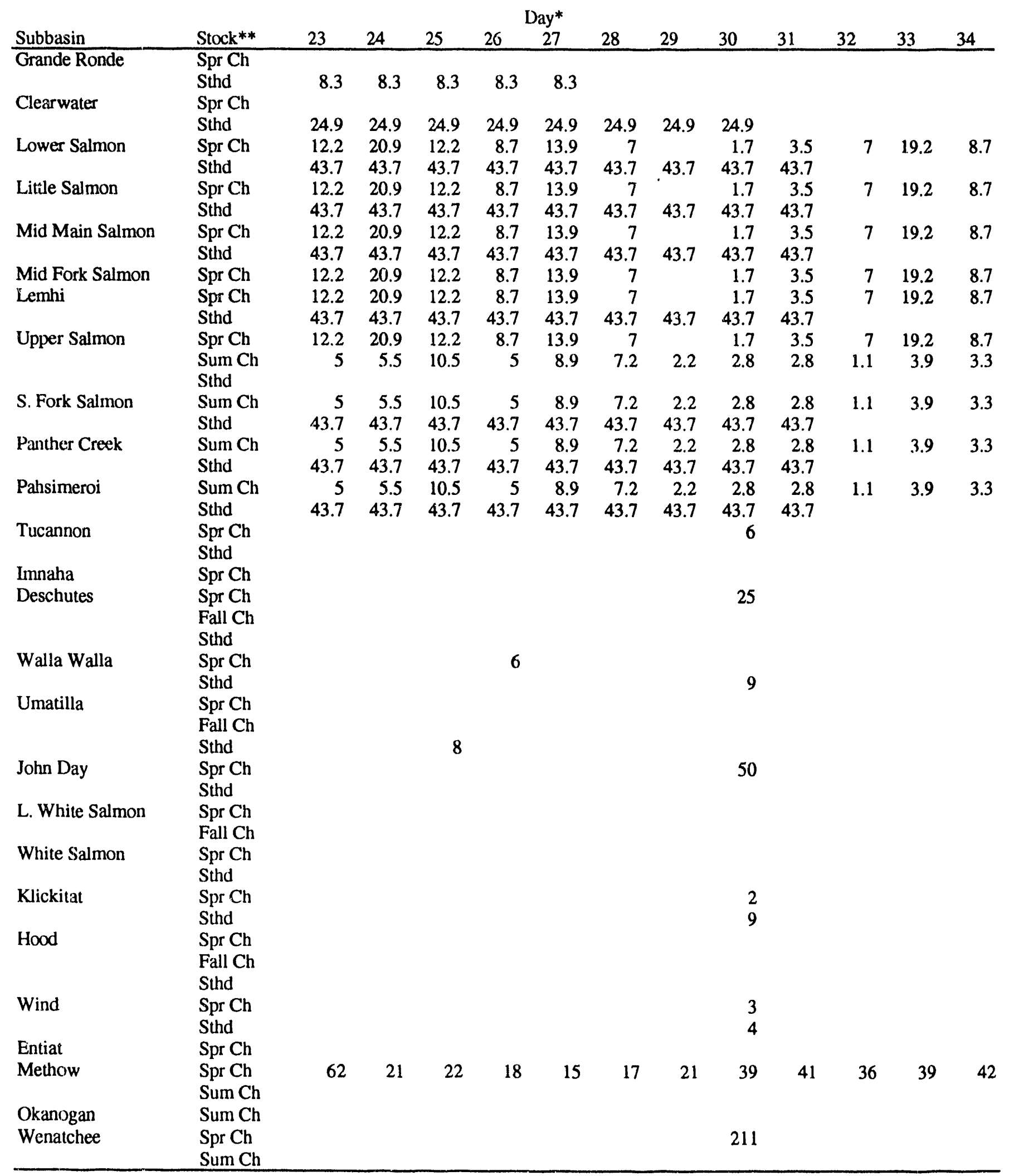


TABLE E.2

(continued)

\begin{tabular}{|c|c|c|c|c|c|c|c|c|c|c|c|c|c|}
\hline \multicolumn{14}{|c|}{ Day* } \\
\hline Subbasin & Stock** & 35 & 36 & 37 & 38 & 39 & 40 & 41 & 42 & 43 & 44 & 45 & 46 \\
\hline Grande Ronde & $\begin{array}{l}\text { Spr Ch } \\
\text { Sthd }\end{array}$ & & & & & & & & & & & & \\
\hline Clearwater & $\begin{array}{l}\text { Spr } \mathrm{Ch} \\
\text { Sthd }\end{array}$ & & & & & & & & & & & & \\
\hline Lower Salmon & $\begin{array}{l}\text { Sthd } \\
\text { Spr Ch } \\
\text { Sthd }\end{array}$ & 17.4 & 8.7 & 13.9 & 8.7 & 15.7 & 26.1 & 15.7 & 26.1 & 22.6 & 22.6 & 19.2 & 5.2 \\
\hline Little Salmon & $\begin{array}{l}\text { Spr Ch } \\
\text { Sthd }\end{array}$ & 17.4 & 8.7 & 13.9 & 8.7 & 15.7 & 26.1 & 15.7 & 26.1 & 22.6 & 22.6 & 19.2 & 5.2 \\
\hline Mid Miain Salmon & $\begin{array}{l}\text { Spr Ch } \\
\text { Sthd }\end{array}$ & 17.4 & 8.7 & 13.9 & 8.7 & 15.7 & 26.1 & 15.7 & 26.1 & 22.6 & 22.6 & 19.2 & 5.2 \\
\hline Mid Fork Salmon & Spr Ch & 17.4 & 8.7 & 13.9 & 8.7 & 15.7 & 26.1 & 15.7 & 26.1 & 22.6 & 22.6 & 19.2 & 5.2 \\
\hline Lemhi & $\begin{array}{l}\text { Spr Ch } \\
\text { Sthd }\end{array}$ & 17.4 & 8.7 & 13.9 & 8.7 & 15.7 & 26.1 & 15.7 & 26.1 & 22.6 & 22.6 & 19.2 & 5.2 \\
\hline Upper Salmon & $\begin{array}{l}\text { Spr } \mathrm{Ch} \\
\text { Sum Ch } \\
\text { Sthd }\end{array}$ & $\begin{array}{r}17.4 \\
2.2\end{array}$ & $\begin{array}{l}8.7 \\
3.9\end{array}$ & $\begin{array}{r}13.9 \\
1.1\end{array}$ & $\begin{array}{l}8.7 \\
3.9\end{array}$ & $\begin{array}{r}15.7 \\
4.4\end{array}$ & $\begin{array}{r}26.1 \\
7.8\end{array}$ & $\begin{array}{r}15.7 \\
7.8\end{array}$ & $\begin{array}{r}26.1 \\
2.2\end{array}$ & $\begin{array}{r}22.6 \\
3.9\end{array}$ & $\begin{array}{r}22.6 \\
3.3\end{array}$ & $\begin{array}{r}19.2 \\
3.3\end{array}$ & $\begin{array}{l}5.2 \\
2.8\end{array}$ \\
\hline S. Fork Salmon & $\begin{array}{l}\text { Sum Ch } \\
\text { Sthd }\end{array}$ & 2.2 & 3.9 & 1.1 & 3.9 & 4.4 & 7.8 & 7.8 & 2.2 & 3.9 & 3.3 & 3.3 & 2.8 \\
\hline Panther Creek & $\begin{array}{l}\text { Sum Ch } \\
\text { Sthd }\end{array}$ & 2.2 & 3.9 & 1.1 & 3.9 & 4.4 & 7.8 & 7.8 & 2.2 & 3.9 & 3.3 & 3.3 & 2.8 \\
\hline Pahsimeroi & $\begin{array}{l}\text { Sum Ch } \\
\text { Sthd }\end{array}$ & 2.2 & 3.9 & 1.1 & 3.9 & 4.4 & 7.8 & 7.8 & 2.2 & 3.9 & 3.3 & 3.3 & 2.8 \\
\hline Tucannon & $\begin{array}{l}\text { Spr Ch } \\
\text { Sthd }\end{array}$ & & & & & & 5 & & & & & 5 & \\
\hline Imnaha & $\mathrm{Spr} \mathrm{Ch}$ & & & & & & & & & & & & \\
\hline Deschutes & $\begin{array}{l}\text { Spr Ch } \\
\text { Fall Ch } \\
\text { Sthd }\end{array}$ & & & & & & & & & & & 25 & \\
\hline Walla Walla & $\begin{array}{l}\text { Spr Ch } \\
\text { Sthd }\end{array}$ & & 6 & & & & 9 & & & & & & 7 \\
\hline Umatilla & $\begin{array}{l}\text { Spr Ch } \\
\text { Fall Ch } \\
\text { Sthd }\end{array}$ & & & & & 552 & 15 & & & & 552 & & \\
\hline John Day & $\begin{array}{l}\text { Spr Ch } \\
\text { Sthd }\end{array}$ & & & & & & & & & & & $\begin{array}{r}50 \\
150\end{array}$ & \\
\hline L. White Salmon & $\begin{array}{l}\text { Spr Ch } \\
\text { Fall } \mathrm{Ch}\end{array}$ & & & & & & & & & & & & \\
\hline White Salmon & $\begin{array}{l}\text { Spr Ch } \\
\text { Sthd }\end{array}$ & & & & & & 12 & & & & & & \\
\hline Klickitat & $\begin{array}{l}\text { Spr Ch } \\
\text { Sthd }\end{array}$ & & & & & & 6 & & & & & 2 & \\
\hline Hood & $\begin{array}{l}\text { Spr Ch } \\
\text { Fall Ch } \\
\text { Sthd }\end{array}$ & & & & & & $\begin{array}{l}32 \\
12\end{array}$ & & & & & & \\
\hline Entiat & $\begin{array}{l}\text { Spr Ch } \\
\text { Sthd } \\
\text { Spr Ch }\end{array}$ & & & & & & $\begin{array}{r}2 \\
55\end{array}$ & & & & & 6 & \\
\hline $\begin{array}{l}\text { Ential } \\
\text { Methow }\end{array}$ & $\begin{array}{l}\text { Spr Ch } \\
\text { Sum Ch }\end{array}$ & 38 & 28 & 25 & 22 & 25 & 25 & 27 & 14 & 27 & 30 & 27 & 16 \\
\hline $\begin{array}{l}\text { Okanogan } \\
\text { Wenatchee }\end{array}$ & $\begin{array}{l}\text { Sum Ch } \\
\text { Spr Ch } \\
\text { Sum Ch }\end{array}$ & & & & & & & & & & & 211 & \\
\hline
\end{tabular}


TABLE E.2

(continued)

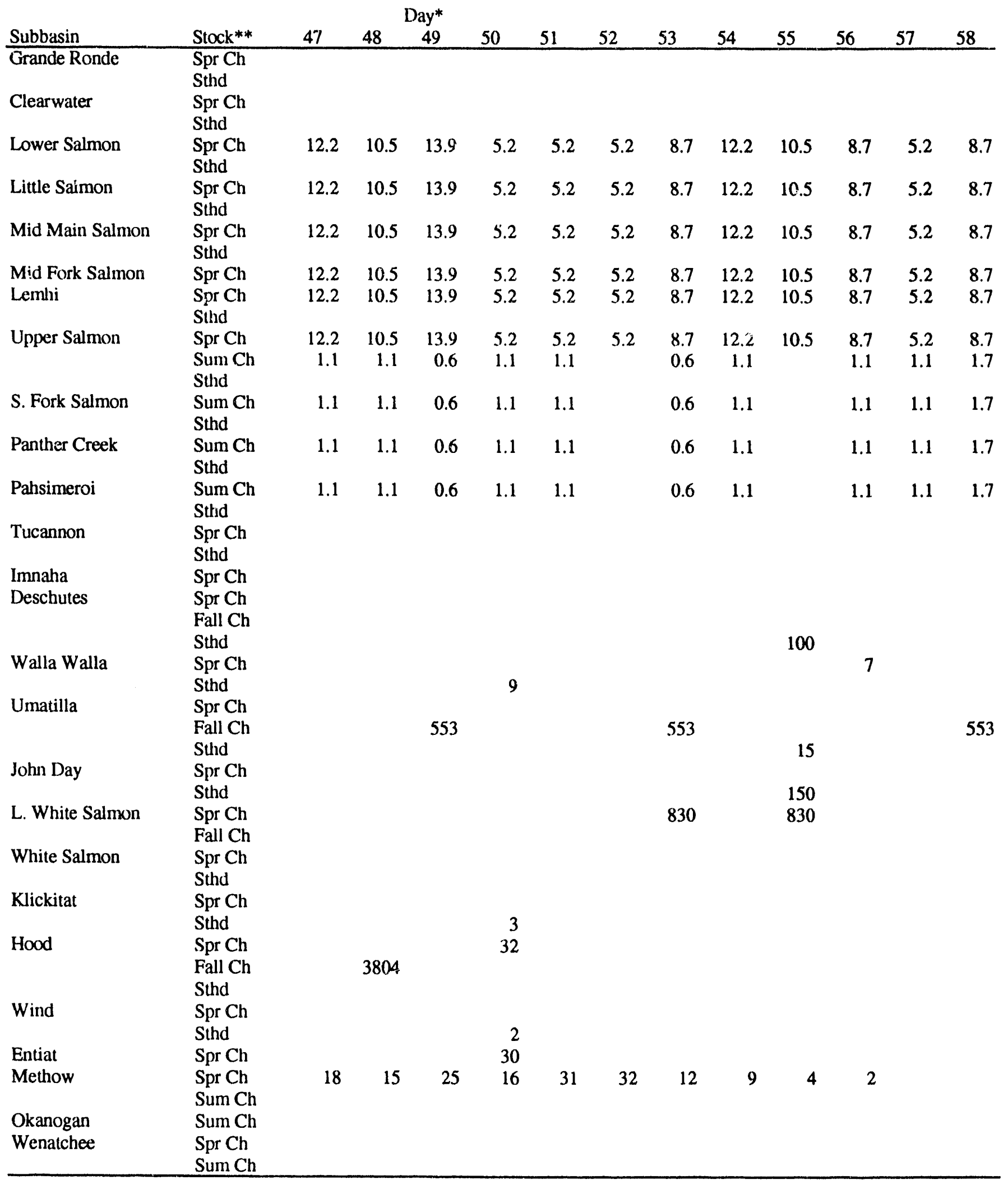


TABLE E.2

(continued)

\begin{tabular}{|c|c|c|c|c|c|c|c|c|c|c|c|c|c|}
\hline \multirow{2}{*}{ Subbasin } & \multicolumn{5}{|c|}{ Day* } & 63 & 64 & 65 & 66 & 67 & 68 & 69 & 70 \\
\hline & $\begin{array}{l}\mathrm{Sllock} \mathrm{K}^{+\pi} \\
\mathrm{Spr} \mathrm{Ch}\end{array}$ & 59 & 60 & 61 & 02 & 03 & 04 & & & & & & \\
\hline Grande Ronde & Sthd & & & & & & & & & & & & \\
\hline \multirow[t]{2}{*}{ Clearwater } & Spr Ch & & & & & & & & & & & & \\
\hline & Sthd & & & & & & & & & 157 & 87 & 226 & 244 \\
\hline Lower Salmon & $\begin{array}{l}\text { Spr Ch } \\
\text { Sthd }\end{array}$ & 10.5 & 13.9 & 15.7 & 10.5 & 5.2 & 7 & 5.2 & 7 & 15.7 & 8.7 & 22.0 & \\
\hline Little Salmon & $\begin{array}{l}\text { Spr Ch } \\
\text { Sthd }\end{array}$ & 10.5 & 13.9 & 15.7 & 10.5 & 5.2 & 7 & 5.2 & 7 & 15.7 & 8.7 & 22.6 & 24.4 \\
\hline Mid Main Salmon & $\begin{array}{l}\text { Spr Ch } \\
\text { Sthd }\end{array}$ & 10.5 & 13.9 & 15.7 & 10.5 & 5.2 & 7 & 5.2 & 7 & 15.7 & 8.7 & 22.6 & 24.4 \\
\hline Mid Fork Salmon & $\mathrm{Spr} \mathrm{Ch}$ & 10.5 & 13.9 & 15.7 & 10.5 & 5.2 & 7 & 5.2 & 7 & 15.7 & 8.7 & 22.6 & 24.4 \\
\hline Lemhi & $\begin{array}{l}\text { Spr Ch } \\
\text { Sthd }\end{array}$ & 10.5 & 13.9 & 15.7 & 10.5 & 5.2 & 7 & 5.2 & 7 & 15.7 & 8.7 & 22.6 & 24.4 \\
\hline \multirow[t]{2}{*}{ Upper Salmon } & $\mathrm{Spr} \mathrm{Ch}$ & 10.5 & 13.9 & 15.7 & 10.5 & 5.2 & 7 & 5.2 & 7 & 15.7 & 8.7 & 22.6 & $\begin{array}{r}24.4 \\
2\end{array}$ \\
\hline & $\begin{array}{l}\text { Sum Ch } \\
\text { Sthd }\end{array}$ & 1.1 & & & 1.1 & & & & & & & & \\
\hline S. Fork Salmon & $\begin{array}{l}\text { Sum Ch } \\
\text { Sthd }\end{array}$ & 1.1 & & & 1.1 & 0.6 & 0.6 & & 1.7 & 1.7 & 0.6 & 2.2 & 2.2 \\
\hline Panther Creek & $\begin{array}{l}\text { Sum Ch } \\
\text { Sthd }\end{array}$ & 1.1 & & & 1.1 & 0.6 & 0.6 & & 1.7 & 1.7 & 0.6 & 2.2 & 2.2 \\
\hline Pahsimeroi & $\begin{array}{l}\text { Sum Ch } \\
\text { Sthd }\end{array}$ & 1.1 & & & 1.1 & 0.6 & 0.6 & & 1.7 & 1.7 & 0.6 & 2.2 & 2.2 \\
\hline Tucannon & $\begin{array}{l}\text { Spr Ch } \\
\text { Sthd }\end{array}$ & & & & & & & & & & & & \\
\hline Imnaha & $\mathrm{Spr} \mathrm{Ch}$ & & & & & & & & & & & & \\
\hline \multirow[t]{2}{*}{ Deschutes } & $\mathrm{Spr} \mathrm{Ch}$ & & 25 & & & & & & & & & & \\
\hline & $\begin{array}{l}\text { Fall Ch } \\
\text { Sthd }\end{array}$ & & 90 & & & & & & & & & & \\
\hline Walla Walla & Spr Ch & & & & & & & & 6 & & & & \\
\hline & Sthd & & & & & & & & & & & & \\
\hline Umatilla & $\mathrm{Spr} \mathrm{Ch}$ & & & & & & & & & & & & \\
\hline & Fall $\mathrm{Ch}$ & & & & 553 & & & & & & & & \\
\hline John Day & Sthd & & & & & & & & & & & & 8 \\
\hline & $\begin{array}{l}\text { Spr Ch } \\
\text { Sthd }\end{array}$ & & & & & & & 150 & & & & & \\
\hline L. White Salmon & $\mathrm{Spr} \mathrm{Ch}$ & & & & & & & & & & & & \\
\hline & Fall $\mathrm{Ch}$ & & & & & & & & & & & & \\
\hline White Salmon & $\mathrm{Spr} \mathrm{Ch}$ & & & & & & & & & & & & \\
\hline & sind & & 12 & & & & & & & & & & \\
\hline Klickitat & $\begin{array}{l}\mathrm{Spr} \mathrm{Ch} \\
\text { Sthd }\end{array}$ & & 7 & & & & & & & & & & \\
\hline Hood & $\mathrm{Spr} \mathrm{Ch}$ & & 32 & & & & & & & & & & 32 \\
\hline & Fall $\mathrm{Ch}$ & & & & & & & & & & & & \\
\hline & Sthd & & 12 & & & & & & & & & & \\
\hline Wind & $\mathrm{Spr} \mathrm{Ch}$ & & 8 & & & & & & & & & & \\
\hline & Sthd & & & & & & & & & & & & \\
\hline Entiat & $\mathrm{Spr} \mathrm{Ch}$ & & & & & & & & & & & & \\
\hline Methow & $\begin{array}{l}\text { Spr Ch } \\
\text { Sum Ch }\end{array}$ & & & & & & & & & & 2 & 2 & 2 \\
\hline Okanogan & Sum $\mathrm{Ch}$ & & & & & & & & & & 2 & 2 & 2 \\
\hline Wenatchee & $\mathrm{Spr} \mathrm{Ch}$ & & & & & & & & & & & & \\
\hline & Sum Ch & & & & & & & 518 & & & & & \\
\hline
\end{tabular}


TABLE E.2

(continued)

\begin{tabular}{|c|c|c|c|c|c|c|c|c|c|c|c|c|c|}
\hline \multirow{3}{*}{$\frac{\text { Subbasin }}{\text { Grande Ronde }}$} & \multicolumn{3}{|c|}{ Day* } & \multirow[b]{2}{*}{73} & \multirow{2}{*}{74} & \multirow[b]{2}{*}{75} & \multirow[b]{2}{*}{76} & \multirow[b]{2}{*}{77} & \multirow[b]{2}{*}{78} & \multirow[b]{2}{*}{79} & \multirow[b]{2}{*}{80} & \multicolumn{2}{|c|}{ Day* } \\
\hline & Stock** & 71 & 72 & & & & & & & & & 81 & 82 \\
\hline & $\begin{array}{l}\text { Spr Ch } \\
\text { Sthd }\end{array}$ & & & & & & & & & & & & \\
\hline Clearwater & $\begin{array}{l}\text { Spr Ch } \\
\text { Sthd }\end{array}$ & & & & & & & & & & & & \\
\hline Lower Salmon & $\begin{array}{l}\text { Spr Ch } \\
\text { Sthd }\end{array}$ & 19.2 & 10.5 & 26.1 & 12.2 & 8.7 & 20.9 & 12.2 & 17.4 & 5.2 & 13.9 & 8.7 & 5.2 \\
\hline Little Salmon & $\begin{array}{l}\text { Spr Ch } \\
\text { Sthd }\end{array}$ & 19.2 & 10.5 & 26.1 & 12.2 & 8.7 & 20.9 & 12.2 & 17.4 & 5.2 & 13.9 & 8.7 & 5.2 \\
\hline Mid Main Salmon & $\begin{array}{l}\text { Spr Ch } \\
\text { Sthd }\end{array}$ & 19.2 & 10.5 & 26.1 & 12.2 & 8.7 & 20.9 & 12.2 & 17.4 & 5.2 & 13.9 & 8.7 & 5.2 \\
\hline Mid Fork Salmon & Spr Ch & 19.2 & 10.5 & 26.1 & 12.2 & 8.7 & 20.9 & 12.2 & 17.4 & 5.2 & 13.9 & 8.7 & 5.2 \\
\hline Lemhi & $\begin{array}{l}\text { Spr Ch } \\
\text { Sthd }\end{array}$ & 19.2 & 10.5 & 26.1 & 12.2 & 8.7 & 20.9 & 12.2 & 17.4 & 5.2 & 13.9 & 8.7 & 5.2 \\
\hline Upper Salmon & $\begin{array}{l}\text { Spr Ch } \\
\text { Sum Ch } \\
\text { Sthd }\end{array}$ & 19.2 & $\begin{array}{r}10.5 \\
1.7\end{array}$ & $\begin{array}{r}26.1 \\
3.3\end{array}$ & $\begin{array}{r}12.2 \\
1.1\end{array}$ & $\begin{array}{l}8.7 \\
1.7\end{array}$ & $\begin{array}{r}20.9 \\
1.7\end{array}$ & 12.2 & $\begin{array}{r}17.4 \\
0.6\end{array}$ & $\begin{array}{l}5.2 \\
1.7\end{array}$ & $\begin{array}{r}13.9 \\
2.8\end{array}$ & $\begin{array}{l}8.7 \\
0.6\end{array}$ & $\begin{array}{l}5.2 \\
1.1\end{array}$ \\
\hline S. Fork Salmon & $\begin{array}{l}\text { Sum Ch } \\
\text { Sthd }\end{array}$ & & 1.7 & 3.3 & 1.1 & 1.7 & 1.7 & & 0.6 & 1.7 & 2.8 & 0.6 & 1.1 \\
\hline Panther Creek & $\begin{array}{l}\text { Sum Ch } \\
\text { Sthd }\end{array}$ & & 1.7 & 3.3 & 1.1 & 1.7 & 1.7 & & 0.6 & 1.7 & 2.8 & 0.6 & 1.1 \\
\hline Pahsimeroi & $\begin{array}{l}\text { Sum Ch } \\
\text { Sthd }\end{array}$ & & 1.7 & 3.3 & 1.1 & 1.7 & 1.7 & & 0.6 & 1.7 & 2.8 & 0.6 & 1.1 \\
\hline Tucannon & $\begin{array}{l}\text { Spr Ch } \\
\text { Sthd }\end{array}$ & & & & & & & & & & & & \\
\hline Imnaha & Spr Ch & & & & & & & & & & & & \\
\hline Deschutes & $\begin{array}{l}\text { Spr Ch } \\
\text { Fall Ch } \\
\text { Sthd }\end{array}$ & & & & & $\begin{array}{r}25 \\
144 \\
100\end{array}$ & & & & & & & \\
\hline Walla Walla & $\begin{array}{l}\text { Spr Ch } \\
\text { Sthd }\end{array}$ & & & & & & 6 & & & & & & \\
\hline Umatilla & $\begin{array}{l}\text { Spr Ch } \\
\text { Fall Ch } \\
\text { Sthd }\end{array}$ & & & & & & & & & & & & \\
\hline Jofin Day & $\begin{array}{l}\text { Spr Ch } \\
\text { Sthd }\end{array}$ & & & & & 150 & & & & & & & \\
\hline L. White Salmon & Spr Ch & & & & & & & & & & & & \\
\hline White Salmon & $\begin{array}{l}\text { Spr Ch } \\
\text { Sthd }\end{array}$ & & & & & & & & & & 12 & 3004 & \\
\hline Klickitat & $\begin{array}{l}\text { Spr Ch } \\
\text { Sthd }\end{array}$ & & & & & 2 & & & & & & & \\
\hline Hood & $\begin{array}{l}\text { Spr Ch } \\
\text { Fall Ch }\end{array}$ & & & & & & & & & & & & \\
\hline Wind & $\begin{array}{l}\text { Sthd } \\
\text { Spr Ch } \\
\text { Sthd }\end{array}$ & & & & & 6 & & & & & 12 & & \\
\hline $\begin{array}{l}\text { Entiat } \\
\text { Methow }\end{array}$ & $\begin{array}{l}\text { Spr Ch } \\
\text { Spr Ch }\end{array}$ & & & & & & & & & & & & \\
\hline $\begin{array}{l}\text { Okanogan } \\
\text { Wenatchee }\end{array}$ & $\begin{array}{l}\text { Sum Ch } \\
\text { Sum Ch } \\
\text { Spr Ch } \\
\text { Sum } C h\end{array}$ & $\begin{array}{l}5 \\
5\end{array}$ & $\begin{array}{l}6 \\
6\end{array}$ & $\begin{array}{l}6 \\
6\end{array}$ & $\begin{array}{l}7 \\
7\end{array}$ & $\begin{array}{l}7 \\
7\end{array}$ & $\begin{array}{l}8 \\
8\end{array}$ & $\begin{array}{l}8 \\
8\end{array}$ & $\begin{array}{l}9 \\
9\end{array}$ & $\begin{array}{l}9 \\
9\end{array}$ & $\begin{array}{l}10 \\
10\end{array}$ & $\begin{array}{l}10 \\
10\end{array}$ & $\begin{array}{l}12 \\
12\end{array}$ \\
\hline
\end{tabular}


TABLE E.2

(continued)

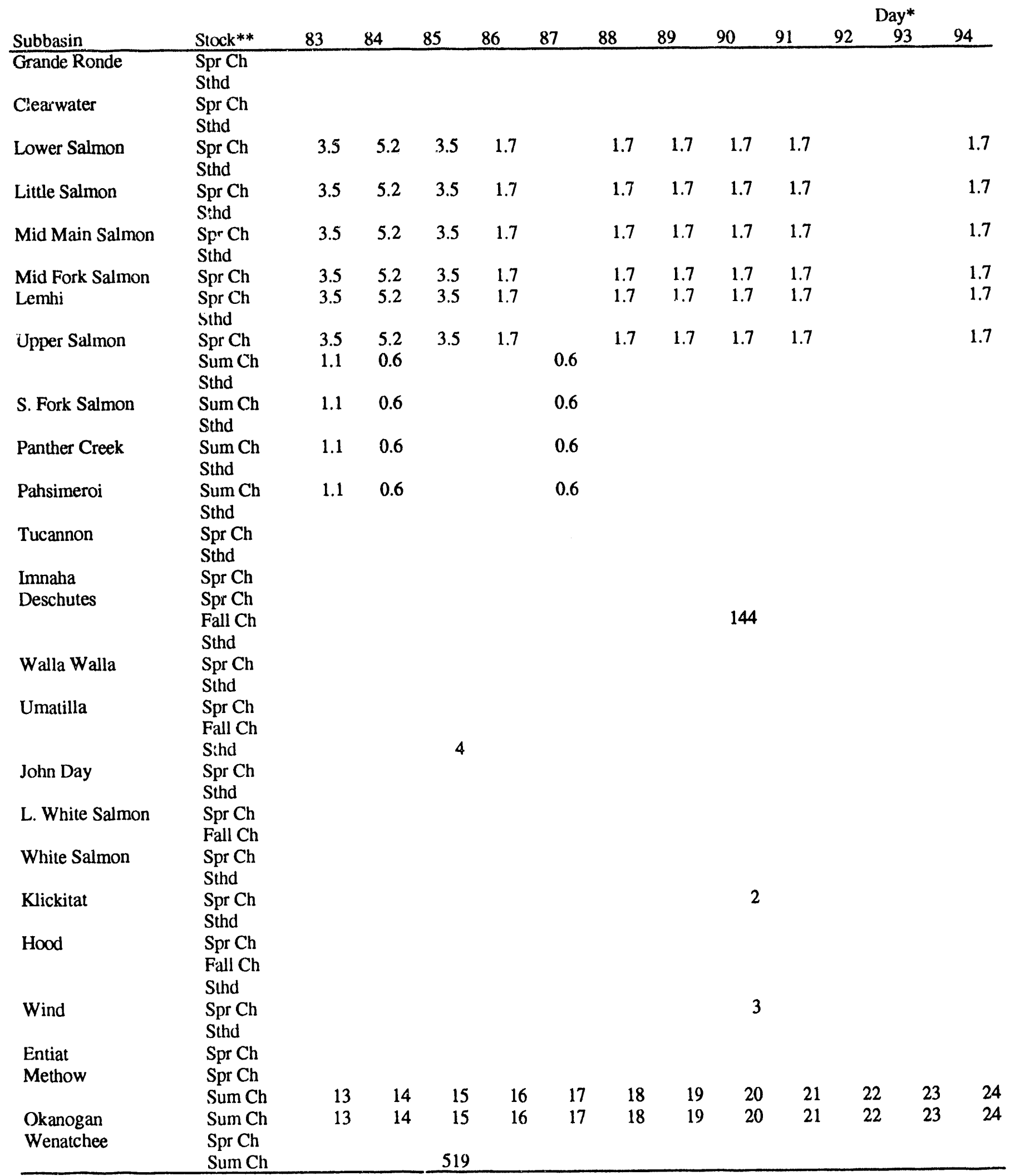


TABL,E E.2

(continued)

\begin{tabular}{|c|c|c|c|c|c|c|c|c|c|c|c|c|c|}
\hline & & & & & & & & & \multicolumn{5}{|c|}{ Day* } \\
\hline$\frac{\text { Subbasin }}{\text { Grande Ronde }}$ & $\begin{array}{l}\text { Stock** } \\
\text { Spr Ch }\end{array}$ & 95 & 96 & 97 & 98 & 99 & 100 & 101 & 102 & 103 & 104 & 105 & 106 \\
\hline & Sthd & & & & & & & & & & & & \\
\hline Clearwater & $\mathrm{Spr} C h$ & & & & & & & & & & & & \\
\hline & Sind & & & & & & & & & & & & \\
\hline Lower Salmon & $\begin{array}{l}\text { Spr Ch } \\
\text { Sthd }\end{array}$ & & 1.7 & & & & 5.2 & & & & & 1.7 & \\
\hline Little Salmon & $\begin{array}{l}\text { Spr Ch } \\
\text { Sthd }\end{array}$ & & 1.7 & & & & 5.2 & & & & & 1.7 & \\
\hline Mid Main Salmen & $\begin{array}{l}\text { Spr Ch } \\
\text { Sthd }\end{array}$ & & 1.7 & & & & 5.2 & & & & & 1.7 & \\
\hline Mid Fork Salmon & $\mathrm{Spr} \mathrm{Ch}$ & & 1.7 & & & & 5.2 & & & & & 1.7 & \\
\hline Lemhi & $\begin{array}{l}\text { Spr Ch } \\
\text { Sthd }\end{array}$ & & 1.7 & & & & 5.2 & & & & & 1.7 & \\
\hline Upper Salmon & $\begin{array}{l}\text { Spr Ch } \\
\text { Sum Ch } \\
\text { Sthd }\end{array}$ & & 1.7 & & & & 5.2 & & & & 0.6 & 1.7 & \\
\hline S. Fork Salmon & $\begin{array}{l}\text { Sum Ch } \\
\text { Sthd }\end{array}$ & & & & & & & & & & 0.6 & & \\
\hline Panther Creek & $\begin{array}{l}\text { Sum Ch } \\
\text { Sthd }\end{array}$ & & & & & & & & & & 0.6 & & \\
\hline Pahsimeroi & $\begin{array}{l}\text { Sum Ch } \\
\text { sthd }\end{array}$ & & & & & & & & & & 0.6 & & \\
\hline Tucannon & $\begin{array}{l}\text { Spr Ch } \\
\text { Sthd }\end{array}$ & & & & & & & & & & & & \\
\hline Imnaha & $\mathrm{Spr} \mathrm{Ch}$ & & & & & & & & & & & & \\
\hline Deschutes & $\begin{array}{l}\text { Spr Ch } \\
\text { Fall Ch } \\
\text { Sthd }\end{array}$ & & & & & & & & & & & & \\
\hline Walla Walla & $\begin{array}{l}\text { Spr Ch } \\
\text { Sthd }\end{array}$ & & & & & & & & & & & & \\
\hline Umatilla & $\begin{array}{l}\text { Spr Ch } \\
\text { Fall Ch } \\
\text { Sthd }\end{array}$ & & & & & & & & & & & & \\
\hline John Day & $\begin{array}{l}\text { Spr Ch } \\
\text { Sthd }\end{array}$ & & & & & & & & & & & & \\
\hline L. White Salmon & $\begin{array}{l}\mathrm{Spr} \mathrm{Ch} \\
\text { Fall } \mathrm{Ch}\end{array}$ & & & & & & & & & & & & \\
\hline White Salmon & $\begin{array}{l}\text { Spr Ch } \\
\text { Sthd }\end{array}$ & & & & & & & & & & & & \\
\hline Klickitat & $\begin{array}{l}\text { Spr Ch } \\
\text { Sthd }\end{array}$ & & & & & & & & & & & & \\
\hline Hood & $\begin{array}{l}\text { Spr Ch } \\
\text { Fall Ch } \\
\text { Sthd }\end{array}$ & & & & & & & & & & & & \\
\hline Wind & $\begin{array}{l}\text { Spr Ch } \\
\text { Sthd }\end{array}$ & & & & & & & & & & & & \\
\hline $\begin{array}{l}\text { Entiat } \\
\text { Methow }\end{array}$ & $\begin{array}{l}\text { Spr Ch } \\
\text { Spr Ch }\end{array}$ & & & & & & & & & & & & \\
\hline & $\begin{array}{l}\text { Sum Ch } \\
\text { Sum Ch }\end{array}$ & $\begin{array}{l}25 \\
25\end{array}$ & $\begin{array}{l}25 \\
25\end{array}$ & $\begin{array}{l}26 \\
26\end{array}$ & $\begin{array}{l}26 \\
26\end{array}$ & $\begin{array}{l}27 \\
27\end{array}$ & $\begin{array}{l}27 \\
27\end{array}$ & $\begin{array}{l}28 \\
28\end{array}$ & $\begin{array}{l}28 \\
28\end{array}$ & $\begin{array}{l}28 \\
28\end{array}$ & $\begin{array}{l}29 \\
29\end{array}$ & $\begin{array}{l}29 \\
29\end{array}$ & $\begin{array}{l}29 \\
29\end{array}$ \\
\hline $\begin{array}{l}\text { Ukanogan } \\
\text { Wenatchee }\end{array}$ & $\begin{array}{l}\text { Spr Ch } \\
\text { Sum Ch }\end{array}$ & & & & & & 519 & & & & & & \\
\hline
\end{tabular}


TABLE E.2

(continued)

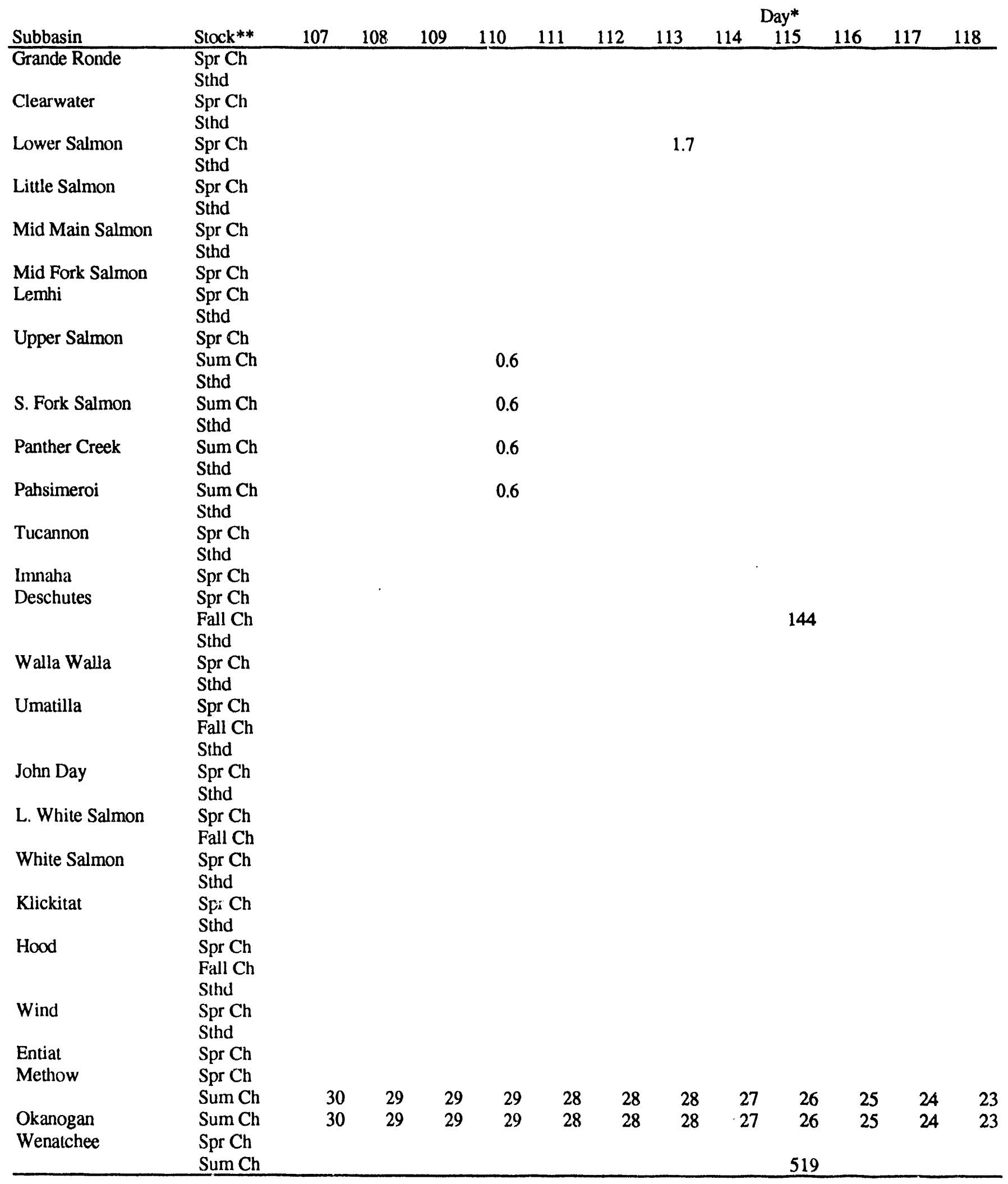


TABLE E.2

(continued)

\begin{tabular}{|c|c|c|c|c|c|c|c|c|c|c|c|c|c|}
\hline \multirow[b]{2}{*}{ Subbasin } & \multirow[b]{2}{*}{ Stock** } & \multirow[b]{2}{*}{119} & \multirow[b]{2}{*}{120} & \multicolumn{10}{|c|}{ Day* } \\
\hline & & & & 121 & 122 & 123 & 124 & 125 & 126 & 127 & 128 & 129 & 130 \\
\hline Grande Ronde & $\begin{array}{l}\text { Spr Ch } \\
\text { Sthd }\end{array}$ & & & & & & & & & & & & \\
\hline Clearwater & $\mathrm{Spr} \mathrm{Ch}$ & & & & & & & & & & & & \\
\hline & Sthd & & & & & & & & & & & & \\
\hline Lower Salmon & Spr Ch & & & & & & & & & & & & \\
\hline & Sthd & & & & & & & & & & & & \\
\hline Little Salmon & $\begin{array}{l}\text { Spr Ch } \\
\text { Sthd }\end{array}$ & & & & & & & & & & & & \\
\hline Mid Main Salmon & $\begin{array}{l}\text { Spr Ch } \\
\text { Sthd }\end{array}$ & & & & & & & & & & & & \\
\hline Mid Fork Salmon & $\mathrm{Spr} \mathrm{Ch}$ & & & & & & & & & & & & \\
\hline Lemhi & $\begin{array}{l}\text { Spr Ch } \\
\text { Sthd }\end{array}$ & & & & & & & & & & & & \\
\hline Upper Salmon & $\begin{array}{l}\text { Spr Ch } \\
\text { Sum Ch } \\
\text { Sthd }\end{array}$ & & & & & & & & & & & & \\
\hline S. Fork Salmon & $\begin{array}{l}\text { Sum Ch } \\
\text { Sthd }\end{array}$ & & & & & & & & & & & & \\
\hline Panther Creek & $\begin{array}{l}\text { Sum Ch } \\
\text { Sthd }\end{array}$ & & & & & & & & & & & & \\
\hline Pahsimeroi & $\begin{array}{l}\text { Sum } \mathrm{Ch} \\
\text { Sthd }\end{array}$ & & & & & & & & & & & & \\
\hline Tucannon & $\begin{array}{l}\text { Spr Ch } \\
\text { Sthd }\end{array}$ & & & & & & & & & & & & \\
\hline Innaha & $\mathrm{Spr} \mathrm{Ch}$ & & & & & & & & & & & & \\
\hline Deschutes & $\mathrm{Spr} \mathrm{Ch}$ & & & & & & & & & & & & \\
\hline & $\begin{array}{l}\text { Fall Ch } \\
\text { Sthd }\end{array}$ & & & & & & & & & & & & 144 \\
\hline Walla Walla & $\mathrm{Spr} \mathrm{Ch}$ & & & & & & & & & & & & \\
\hline & Sthd & & & & & & & & & & & & \\
\hline Umatilla & $\mathrm{Spr} \mathrm{Ch}$ & & & & & & & & & & & & \\
\hline & $\begin{array}{l}\text { Fall Ch } \\
\text { Sthd }\end{array}$ & & & & & & & & . & & & & \\
\hline John Day & Spr Ch & & & & & & & & & & & & \\
\hline & Sthd & & & & & & & & & & & & \\
\hline L. White Salmon & $\begin{array}{l}\text { Spr Ch } \\
\text { Fall Ch }\end{array}$ & & & & & & & & & & & & \\
\hline White Salmon & Spr Ch & & & & & & & & & & & & \\
\hline Klickitat & $\begin{array}{l}\text { Sthd } \\
\text { Spr Ch }\end{array}$ & & & & & & & & & & & & \\
\hline & Sthd & & & & & & & & & & & & \\
\hline Hood & Spr Ch & & & & & & & & & & & & \\
\hline & Fall $\mathrm{Ch}$ & & & & & & & & & & & . & \\
\hline & Sthd & & & & & & & & & & & & \\
\hline Wind & Spr Ch & & & & & & & & & & & & \\
\hline & Sthd & & & & & & & & & & & & \\
\hline Entiat & Spr Ch & & & & & & & & & & & & \\
\hline Methow & Spr Ch & & & & & & & & & & & & \\
\hline & Sum Ch & 22 & 21 & 20 & 19 & 19 & 18 & 17 & 16 & 15 & 14 & 13 & 12 \\
\hline $\begin{array}{l}\text { Okanogan } \\
\text { Wenatchee }\end{array}$ & $\begin{array}{l}\text { Sum Ch } \\
\text { Spr Ch } \\
\text { Sum Ch }\end{array}$ & 22 & 21 & 20 & 19 & 19 & 18 & 17 & 16 & 15 & 14 & 13 & 12 \\
\hline
\end{tabular}


TABLE E.2

(continued)

\begin{tabular}{|c|c|c|c|c|c|c|c|c|c|c|c|c|c|}
\hline \multirow[b]{2}{*}{ Subbasin } & \multirow[b]{2}{*}{ Stock** } & \multirow[b]{2}{*}{131} & \multicolumn{11}{|c|}{ Day* } \\
\hline & & & 132 & 133 & 134 & 135 & 136 & -137 & 138 & 139 & 140 & 141 & 142 \\
\hline Grande Ronde & $\begin{array}{l}\text { Spr Ch } \\
\text { Sthd }\end{array}$ & & & & & & & & & & & & \\
\hline \multirow[t]{2}{*}{ Clearwater } & $\mathrm{Spr} \mathrm{Ch}$ & & & & & & & & & & & & \\
\hline & Sthd & & & & & & & & & & & & \\
\hline \multirow[t]{2}{*}{ Lower Salmon } & $\mathrm{Spr} \mathrm{Ch}$ & & & & & & & & & & & & \\
\hline & Sind & & & & & & & & & & & & \\
\hline \multirow[t]{2}{*}{ Little Salmon } & $\mathrm{Spr} \mathrm{Ch}$ & & & & & & & & & & & & \\
\hline & Sthd & & & & & & & & & & & & \\
\hline \multirow[t]{2}{*}{ Mid Main Salmon } & $\mathrm{Spr} \mathrm{Ch}$ & & & & & & & & & & & & \\
\hline & Sthd & & & & & & & & & & & & \\
\hline Mid Fork Salmon & Spr Ch & & & & & & & & & & & & \\
\hline \multirow[t]{2}{*}{ Lemhi } & $\mathrm{Spr} \mathrm{Ch}$ & & & & & & & & & & & & \\
\hline & Sthd & & & & & & & & & & & & \\
\hline \multirow[t]{3}{*}{ Upper Salmon } & $\mathrm{Spr} \mathrm{Ch}$ & & & & & & & & & & & & \\
\hline & Sum $\mathrm{Ch}$ & & & & & & & & & & & & \\
\hline & Sind & & & & & & & . & & & & & \\
\hline \multirow[t]{2}{*}{ S. Fork Salmon } & Sum $\mathrm{Ch}$ & & & & & & & & & & & & \\
\hline & Sthd & & & & & & & & & & & & \\
\hline \multirow{2}{*}{ Panther Creek } & Sum $C_{2}$ & & & & & & & & & & & & \\
\hline & Sthd & & & & & & & & & & & & \\
\hline \multirow[t]{2}{*}{ Pahsimeroi } & Sum Ch & & & & & & & & & & & & \\
\hline & Sthd & & & & & & & & & & & & \\
\hline \multirow[t]{2}{*}{ Tucannon } & $\mathrm{Spr} C \mathrm{~h}$ & & & & & & & & & & & & \\
\hline & Sthd & & & & & & & & & & & & \\
\hline Imnaha & $\mathrm{Spr} C \mathrm{~h}$ & & & & & & & & & & & & \\
\hline \multirow[t]{3}{*}{ Deschutes } & $\mathrm{Spr} C \mathrm{Ch}$ & & & & & & & & & & & & \\
\hline & Fall $\mathrm{Ch}$ & & & & & & & & & & & & \\
\hline & Sind & & & & & & & & & & & & \\
\hline Walla Walla & $\mathrm{Spr} C h$ & & & & & & & & & & & & \\
\hline & Sthd & & & & & & & & & & & & \\
\hline Umatilla & Spr Ch & & & & & & & & & & & & \\
\hline & Fall $\mathrm{Ch}$ & & & & & & & & & & & & \\
\hline & Sthd & & & & & & & & & & & & \\
\hline John Day & $\mathrm{Spr} \mathrm{Ch}$ & & & & & & & & & & & & \\
\hline & Sthd & & & & & & & & & & & & \\
\hline L. White Salmon & $\mathrm{Spr} C \mathrm{Ch}$ & & & & & & & & & & & & \\
\hline & Fall $\mathrm{Ch}$ & & & & & & & & & & & & \\
\hline White Salmon & $\mathrm{Spr} \mathrm{Ch}$ & & & & & & & & & & & & \\
\hline & Sind & & & & & & & & & & & & \\
\hline Klickitat & $\mathrm{Spr} C h$ & & & & & & & & & & & & \\
\hline & Sthd & & & & & & & & & & & & \\
\hline Hood & $\mathrm{Spr} \mathrm{Ch}$ & & & & & & & & & & & & \\
\hline & Fall Ch & & & & & & & & & & & & \\
\hline & Sthd & & & & & & & & & & & & \\
\hline Wind & Spr Ch & & & & & & & & & & & & \\
\hline Entiat & $\begin{array}{l}\text { Sthd } \\
\text { Spr Ch }\end{array}$ & & & & & & & & & & & & \\
\hline Methow & $\mathrm{Spr} C h$ & & & & & & & & & & & & \\
\hline & Sum Ch & 11 & 10 & 9 & 8 & 7 & 6 & 5 & 4 & 3 & 2 & 1 & \\
\hline Okanogan & Sum $\mathrm{Ch}$ & 11 & 10 & 9 & 8 & 7 & 6 & 5 & 4 & 3 & 2 & 1 & \\
\hline Wenatcha: & Spr Ch & & & & & & & & & & & & \\
\hline & Sum $\mathrm{Ch}$ & & & & & 518 & & & & & & & \\
\hline
\end{tabular}


TABLE E.2

(continued)

\begin{tabular}{|c|c|c|c|c|c|c|c|c|c|c|c|}
\hline \multirow{2}{*}{ Subbasin } & \multirow[b]{2}{*}{ Stock** } & \multicolumn{10}{|c|}{ Day* } \\
\hline & & 143 & 144 & 145 & 146 & 147 & 148 & 149 & 150 & 151 & 152 \\
\hline Grande Ronde & $\begin{array}{l}\text { Spr Ch } \\
\text { Sthd }\end{array}$ & & & & & & & & & & \\
\hline \multirow{2}{*}{ Clearwater } & $\mathrm{Spr} \mathrm{Ch}$ & & & & & & & & & & \\
\hline & Sthd & & & & & & & & & & \\
\hline \multirow[t]{2}{*}{ Lower Salmon } & $\mathrm{Spr} \mathrm{Ch}$ & & & & & & & & & & \\
\hline & Sthd & & & & & & & & & & \\
\hline \multirow[t]{2}{*}{ Little Salmon } & $\mathrm{Spr} \mathrm{Ch}$ & & & & & & & & & & \\
\hline & Sthd & & & & & & & & & & \\
\hline \multirow[t]{2}{*}{ Mid Main Salmon } & $\mathrm{Spr} \mathrm{Ch}$ & & & & & & & & & & \\
\hline & Sthd & & & & & & & & & & \\
\hline Mid Fork Sa!mon & Spr Ch & & & & & & & & & & \\
\hline \multirow[t]{2}{*}{ Lemhi } & $\mathrm{Spr} \mathrm{Ch}$ & & & & & & & & & & \\
\hline & Sthd & & & & & & & & & & \\
\hline \multirow[t]{3}{*}{ Upper Salmon } & $\mathrm{Spr} \mathrm{Ch}_{\mathrm{H}}$ & & & & & & & & & & \\
\hline & Sum $\mathrm{Ch}$ & & & & & & & & & & \\
\hline & Sthd & & & & & & & & & & \\
\hline \multirow{2}{*}{ S. Fork Salmon } & Sum $\mathrm{Ch}$ & & & & & & & & & & \\
\hline & Sthd & & & & & & & & & & \\
\hline \multirow[t]{2}{*}{ Panther Creek } & Sum $\mathrm{Ch}$ & & & & & & & & & & \\
\hline & Sthd & & & & & & & & & & \\
\hline \multirow[t]{2}{*}{ Pahsimeroi } & $\mathrm{Sum} \mathrm{Ch}$ & & & & & & & & & & \\
\hline & Sthd & & & & & & & & & & \\
\hline \multirow[t]{2}{*}{ Tucannon } & $\mathrm{Spr} \mathrm{Ch}$ & & & & & & & & & & \\
\hline & Sthd & & & & & & & & & & \\
\hline \multirow{4}{*}{$\begin{array}{l}\text { Meschutes } \\
\text { Desha }\end{array}$} & $\mathrm{Spr} \mathrm{Ch}$ & & & & & & & & & & \\
\hline & $\mathrm{Spr} \mathrm{Ch}$ & & & & & & & & & & \\
\hline & Fall $\mathrm{Ch}$ & & & 90 & & & & & & & \\
\hline & Sthd & & & & & & & & & & \\
\hline \multirow[t]{2}{*}{ Walla Walla } & $\mathrm{Spr} \mathrm{Ch}$ & & & & & & & & & & \\
\hline & Sthd & & & & & & & & & & \\
\hline \multirow[t]{3}{*}{ Umatilla } & $\mathrm{Spr} \mathrm{Ch}$ & & & & & & & & & & \\
\hline & Fall Ch & & & & & & & & & & \\
\hline & Sthd & & & & & & & & & & \\
\hline John Day & $\mathrm{Spr} \mathrm{Ch}$ & & & & & & & & & & \\
\hline & Sthd & & & & & & & & & & \\
\hline L. White Salmon & $\mathrm{Spr} \mathrm{Ch}$ & & & & & & & & & & \\
\hline & Fall $\mathrm{Ch}$ & & & & & & & & & & \\
\hline White Salmon & Spr Ch & & & & & & & & & & \\
\hline & Sthd & & & & & & & & & & \\
\hline Klickitat & Spr Ch & Notes: & & & & & & & & & \\
\hline & Sthd & & migra & ion is $\mathrm{A}$ & pre1 1 ( & (ay 1) & o Aug & $30(D)$ & y 152) & & \\
\hline Hood & $\mathrm{Spr} \mathrm{Ch}$ & & spring & chinoo: & (Spr & h), sun & mer c & nook ( & $\mathrm{am}$ Ch), & & \\
\hline & Sthd & $* * *$ & point & $100 x(1$ & atcect & steen & ad (Di & in & Hes & & \\
\hline Wind & $\mathrm{Spr} \mathrm{Ch}$ & & above & dosest & ownst & eam d & & & & & \\
\hline & Sthd & Source: & Fish I & sssage & ienter, & 991 (e & lited) & & & & \\
\hline Entiat & $\mathrm{Spr} \mathrm{Ch}$ & & & & & & & & & & \\
\hline Methow & $\mathrm{Spr} C h$ & & & & & & & & & & \\
\hline & Sum $\mathrm{Ch}$ & & & & & & & & & & \\
\hline Okanogan & Sum Ch & & & & & & & & & & \\
\hline Wenatchee & $\mathrm{Spr} \mathrm{Ch}$ & & & & & & & & & & \\
\hline & Sum $\mathrm{Ch}$ & & & & & & & & & & \\
\hline
\end{tabular}




\section{GLOSSARY}

Activity

Adaptive Management

Adult

Alevin

Anadromous

Annualized cost

Beverton-Holt curve

BPA

Brood year

Bypass

C/E

CBFWA

COE
A variable whose value is set by the optimization model as in selecting the least cost strategy (e.g., whether or not to use a particular passage strategy, or at what rate to harvest a particular stock). Also known as a decision variable.

an approach to reducing uncertainty by using management actions as experiments which provide information about the system. Such information is then used for more efficient management.

for salmonids, a fish that is sexually mature.

a newly hatched salmon or trout prior to absorption of the yolk sac.

fish which spawn in fresh water but $\mathrm{s}$ spend a significant portion of their life in the ocean.

cost of a capital investment (e.g., a hatchery or bypass facility) spread out over the useful life of the facility. Includes the interest expense required to finance the investment.

a spawner-recruit relationship characterized by a curve depicting the number of recruits increasing to an asymptotic limit as the number of spawners increase.

Bonneville Power Administration

the year in which a fish begins life.

activities or structures designed to guide smolts around turbines at run-of-river dams

Cost-effectiveness. See Chapter 2.

Columbia Basin Fish and Wildlife Authority. An umbrella organization for state and tribal fisheries management agencies.

U.S Army Corps of Engineers 
Coefficient

Cohort

Collection facilities

Constraint

Council

CRiSP

DLCM

Escapement

Fallback

Fecundity

Fingerling

Fishery

Fry

Heuristic model

Hierarchy

Jack

Juvenile
Used to define the relationship between activities and constraints. Always set to $-1,0$, or +1 in the current problem.

fish offspring of the same brood year.

structures to hold bypassed smolts in preparation for transportation downstream in trucks or barges

An equation or expression used to establish limits on what the optimization can do.

Northwest Power Planning Council

Columbia River Fish Passage Model. Used to evaluate the effects of smolt passage strategies.

Deterministic Life Cycle Moáel. See Chapter 3 and Appendix A.

the number of adults which survive to reach the spawning grounds.

a situation in which fish which have ascended a dam are swept back downstream of the dam.

usually refers to the number of eggs produced per female.

a young or small fish, larger and more developed than a fry.

the complex of interactions among a fish population(s), the people which exploit them, and the environment.

young, recently hatched fish generally capable of feeding only on microorganisms.

a model which serves primarily as an experimental device for exploring modeling techniques.

an arrangement of objects into a graded series based on the relationships among the objects themselves.

a precocious male salmon or steelhead trout, generally fish that have matures at least one year earlier than most members of the same cohort.

fish that are not sexually mature. 
Juvenile production

Life stanza

Mainstem

Management Action

Mass-Balance Constraint

Module

Non-terminal harvest

NPPC

Objective Function

Outplanting

Parr

Passage Strategy

Pre-smolt generally used in this text to refer to the production of smolts.

a distinct period in the salmonid life cycle.

Snake or Columbia rivers, as distinct from subbasins or tributaries.

Smallest single management option that will have a unique effect on a biological parameter; e.g., add screens at a runof river dam, or add rearing capacity at a hatchery.

Used to ensure internal consistency in the optimization, so that all stocks in the system use the same downstream passage strategy, or all stocks in the same subbasin use the same propagation strategy.

a simulation model which can operate independently or in tandem with other modules.

any harvest occurring outside the subbasin (e.g., ocean harvest or mainstem river harvest).

Northwest Power Planning Council

Function that the optimization tries to minimize, within bounds established by a set of constraints.

placing fry or fingerling into areas for rearing to supplement or replace natural reproduction.

juvenile anadromous salmonids which normally reside for a year or more in fresh water and are not capable of tolerating saline water. May refer to steelhead trout, coho, sockeye, or chinook salmon.

Combination of passage actions; will affect all stocks in the system simultaneously; can only use one passage strategy for the entire system.

similar to parr. 


\section{Propagation}

Propagation Strategy

\section{Propagation/Terminal Harvest/Passage Alternative}

\section{Recruit}

\section{Recruitment}

Redd

Resolution

RHS

Ricker curve

Run size

Run year

Run-of-river dam

Runsize

Scope spawning and rearing, in either hatcheries or in natural settings.

Combination of propagation actions; will affect all stocks in a given subbasin simultaneously. Exactly one propagation strategy per subbasin.

Combination of a system-wide passage strategy, subbasinspecific propagation strategy, and stock- specific terminal harvest rate, for a single stock. The alternative defines all the information necessary to calculate the adults produced for a given stock. Generated by the deterministic simulation model.

fish which are newly joined with a population under consideration.

the addition of new members to the aggregate population under consideration.

the spawning nest of salmonids; usually a scooped depression in clean gravel in which eggs are deposited and buried.

the ability to distinguish between two separate objects.

Abbreviation for "Right Hand Side." Determines how much of each activity must be undertaken. In the current problem, always set to zero or one.

a spawner-recruit relationship characterized by a dome shaped curve.

as defined by the Council, the total number of fish returning to the mouth of the Columbia plus ocean harvest.

the year in which a fish returns to spawn as an adult.

dams designed with little or no storage capacity

as used here, the sum of subbasin escapement and nonterminal harvest for a stock.

the relative temporal and spatial extent of the system under consideration. 
Shaker

Smolt

Smoltification

Spawner-recruit curve

Stock

Storage dam

System-Wide Least-Cost Strategy

System-Wide Strategy

Systems analysis

Systems Analysis Model (SAM) a fish which is smaller than the legal size limit for harvest but which is susceptible to the angling gear.

a juvenile salmonid which is physiologically prepared to out migrate from fresh saline waters.

the physiological process which prepares an anadromous fish for life in saline waters.

the relationship between some measure of biomass present in spawning adults and the biomass of recruits derived from the spawning adults.

a population of fish which remain genetically, spatially, or behaviorally separated from other populations and which shares a common life among its members.

used to store water for irrigation and power production

The system-wide strategy which meets a set of biological objectives at the lowest possible cost of subbasin-specific propagation strategies and one passage strategy. Generated by the linear programming model, using alternatives generated by the deterministic simulation model.

Combination of propagation/terminal harvest/passage alternatives for all stocks in the model. All stocks use the same passage strategy and all stocks within a given subbasin use the same propagation strategy, although different stocks in the same subbasin may have different terminal harvest rates.

a body of theory and techniques used to understand complex systems, usually involving advanced mathematical and statistical techniques and the use of computers.

hydropower model used by BPA and others to evaluate the costs and power production implications of hydrosystem and thermal power operations 
Tableau

TBR

Terminal harvest

Water Budget
Computerized representation of the objective function, activities, constraints, coefficients, and RHS values.

Transportation Benefit Ratio, the ratio of transported fish returning to a sampling site to untransported fish returning to the same site.

harvest occurring within a subbasin or just prior to adults returning to spawn at a hatchery

a program to provide addition instream flows during the period of peak outmigration to increase the travel rate of migrating smolts. 


\section{REFERENCES}

Beverton, R. J. H. and S. J. Holt. 1957: "On the Dynamics of Exploited Fish Populations." Fish. Invest. Lond., ser. 2, 19.

Bonneville Power Administration. 1992: Journal, June. DOE/BP-1897.

1991: Issue Alert: What is BPA Doing About the Salmon? November. DOE/BP1730.

Columbia Basin Fish and Wildlife Authority. 1991a: The Biological and Technical Justification for the Flow Propo al of the Columbia Basin Fish and Wildlife Authority. Portland, Oregon: CBFWA.

1991b: Integrated System Plan for Salmon and Steelhead Production in the Columbia River Basin. Portland, Oregon: Northwest Power Planning Council and the Columbia Basin Fish and Wildlife Authority.

1990: Columbia Basin System Planning Salmon and Steelhead Production Plans. (for individual subbasins) Portland, Oregon: Northwest Power Planning Council and the Columbia Basin Fish and Wildlife Authority.

Fish Passage Center. 1991: "Fish Passage Data System Hatchery Releases." July 17, 1991. (Computer Spreadsheet).

Foster, J. Todd. 1992: "BPA Targets Third of Rate Increase for Fish Recovery." Spokesman Review (Spokane, Washington). November 11, 1992.

Giorgi, Albert. 1991: "Biological Issues Pertaining to Smolt Migration and Reservoir Drawdown in the Snake and Columbia Rivers, with Special Reference to Salmon Species Petitioned for Listing Under the Endangered Species Act." Prepared for the U.S. Army Corps of Engineers and Bonneville Power Administration.

Hinrichsen, Richard, et al. 1991: "Columbia River Salmon Passage (CRiSP) Model, Documentation for CRiSP.0." Seattle: Center for Quantitative Science, University of Washington.

Howell, P., et al. 1985: Stock Assessment of Columbia River Anadromous Salmonids: Vols. I and II. DOE/BP-12737-1,2. Portland, Oregon: Bonneville Power Administration, Department of Fish and Wildlife.

Kacyzinski, V.W. and J.F. Palmisano. 1992: A Review of Management and Environmental Factors Responsible for the Decline and Lack of Recovery of Oregon's Wild Anadromous Salmonids. Salem, Oregon: Oregon Forest Industries Council. 
Kindley, Ray. 1991: "Snake River and Lower Columbia River Incremental Flow Benefits Analysis." Discussion Paper Prepared for the Fish and Wildlife Committee, Pacific Northwest Utilities Conference Committee.

Klinge, Rick. Douglas County Public Utility District. Personal Communication. March 27, 1991.

Kneese, Allen V., Danny C. Lee, Charles M. Paulsen, and Walter O. Spofford, Jr. 1988: Design of Studies for Development of Bonneville Power Administration Fish and Wildlife Mitigation Accounting Policy. Phase II Final Report. Portland, Oregon: Bonneville Power Administration and Resources for the Future.

Lee, Danny C. and Jeffrey B. Hyman. 1992: The Stochastic Life-Cycle Model(SLCM): Simulating the Population Dynamics of Anadromous Salmonids. Research Paper INT459. Ogden, Utah: U.S. Department of Agriculture, Forest Service, Intermountain Research Station.

McConnaha, Willis E. 1991a: "A Conceptual Model of Smolt Transportation in the Columbia River." Mimeograph. May 15, 1991.

1991b: "SNKPASS: A Spreadsheet Model of Juvenile Fish Passage in the Columbia River." Documentation Version 1.0. Mimeograph.

Meffe, Gary K. 1992: "Techno-Arrogance and Halfway Technologies: Salmon Hatcheries on the Pacific Coast of North America." Conservation Biology, 6(3). 350-354.

Mullan, J. W. 1990: "Status of Chinook Salmon Stocks in the Mid-Columbia." in D. L. Park, Convenor, Status and Future of Spring Chinook in the Columbia River Basin -Conservation and Enhancement. NOAA Tech. Memo. NMFS FINWC-187. 45-55. 1987: Status and Propagation of Chinook Salmon in the Mid-Columbia River Through 1985. U.S. Fish and Wildlife Service Biological Report 87 (3).

Nason, Dick. Chelan County Public Utility District. Personal Communication. April 1, 1991.

Nehlsen, Willa, Jack E. Williams, and James A. Lichatowich. 1991: "Pacific Salmon at the Crossroads." Fisheries, 16(2). 4-21.

Neter, John, William Wasserman, and Michael Kutner. 1985: Applied Linear Statistical Models. 2nd edition. Homewood, Illinois: Irwin.

Northwest Power Planning Council. 1992: Genetics and Salmon Production. Staff Discussion Paper 92-07. Portland, Oregon: Northwest Power Planning Council. 
1991a: Amendment to the Columbia River Basin Fish and Wildlife Program (Phase

Two). Document 91-31. Portland, Oregon: Northwest Power Planning Council.

1991b: Proposed Amendments with Technical Appendices. Document 91-25.

Portland, Oregon: Northwest Power Planning Council.

1989: System Planning Model Documentation. Portland, Oregon: Northwest Power Planning Council.

1987: 1987 Columbia River Basin Fish and Wildlife Program. Portland, Oregon: Northwest Power Planning Council.

1986: Compilation of Information on Salmon and Steelhead Losses in the Columbia River Basin. Portland, Oregon: Northwest Power Planning Council.

Pacific Northwest Utilities Conference Committee. 1983: The System Analysis Model: Methods and Theory Manual. Portland, Oregon: Pacific Northwest Utilities Conference Committee.

Pratt, K. L. and D. W. Chapman. 1989: Progress Toward the Run Doubling Goal of the Northwest Power Planning Council. Prepared for the Pacific Northwest Utilities Conference Committee. Boise, Idaho: Don Chapman Consultants.

Ricker, W.E. 1954: "Stock and Recruitment." Journal of the Fisheries Research Board of Canada, 11. 559-623.

Sherer, Brett M. and Timothy R. Fisher. 1991: "Input Parameters for the Modeling of Snake River Chinook Salmon with the Columbia River Salmon Passage Model (CRiSP.0)." Portland, Oregon: Bonneville Power Administration.

Skalski, John R. and Albert Giorgi. 1992: "Juvenile Passage Proposal: Estimating Smolt Travel Time and Survival in the Snake and Columbia Rivers." May 18, 1992. Mimeograph.

Soule, Michael. 1987: Viable Populations for Conservation. New York: Cambridge University Press.

Spofford, Walter O., Jr., Danny C. Lee, and Charles M. Paulsen. 1989: "The Use of CostEffectiveness Analysis in Planning for Increases in Sustainable Run Sizes of Anadromous Fish." Background Report for Workshop Series on Strategic Planning for Fish and Wildlife Mitigation, Winter-Spring 1989. Bonneville Power Administration and Resources for the Future.

Swartzman, Gordon, et al. 1990: "Review of Bonneville Power Administration Anadromous Fish Passage Assessment Methods." Mimeograph. 
Tanovan, Bolyvong. 1985: FISHPASS: An Analytical Model of Fish Passage for the ColumbiaSnake River Systems. Portland, Oregon: U.S. Army Corps of Engineers, North Pacific Division. (May).

U.S. Army Corps of Engineers. 1992: 1992 Columbia River Salmon Flow Measures Options Analysis/EIS. Walla Walla, Washington: U.S. Army Corps of Engineers, Bonneville Power Administration, and Bureau of Reclamation.

Woodruff, Ed. U.S. Army Corps of Engineers. Personal Communication. January 6, 1992. 

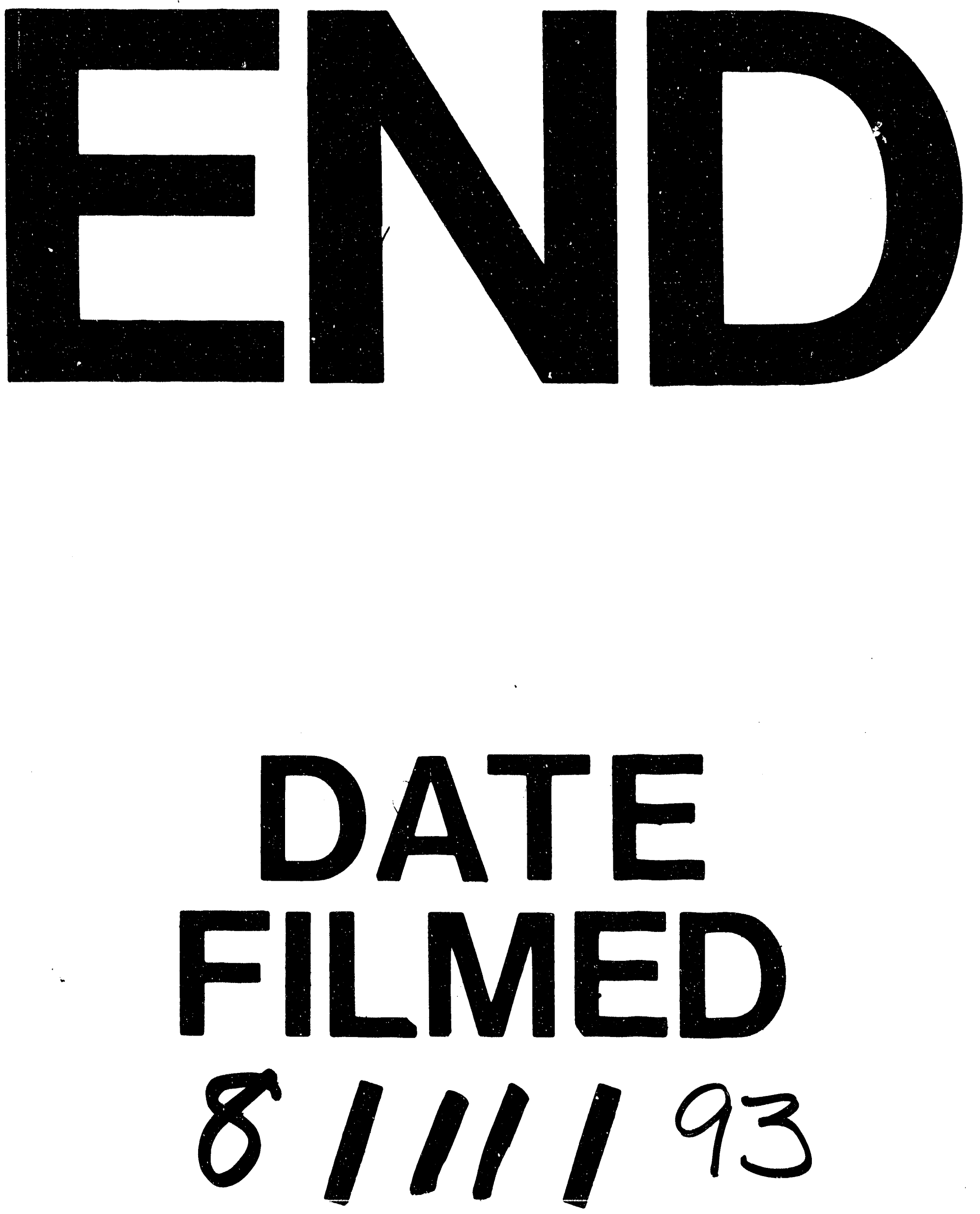
